\title{
Cobalt-Catalyzed Hyperpolarization of Structurally Intact Olefins
}

Safiyah R. Muhammad ${ }^{\dagger}$, Rianna B. Greer ${ }^{\dagger}$, Steven B. Ramirez ${ }^{\dagger}$, Boyd Goodson ${ }^{\ddagger}$, and Alison R. Fout ${ }^{\dagger} *$ + School of Chemical Sciences, University of Illinois at Urbana-Champaign, 600 South Mathews Avenue, Urbana, Illinois 61801, United States

‡ Materials Technology Center, Southern Illinois University Carbondale, Illinois 62901, United States

\section{Supporting Information}

\section{General Considerations}

Sample Preparation and Data Collection $\quad 2$

Signal Enhancement Calculation

NMR Spectrometer

Generation of parahydrogen

SABRE NMR spectra

Styrene and derivatives

$$
4-42
$$

Acrylates and Pentenoates

$43-67$

Isoprene and Terpenes

$68-85$

Nitrogen-based substrates

$86-89$

Field-dependence of ${ }^{\mathbf{1}} \mathbf{H}$ Enhancement

$90-93$

${ }^{13} \mathrm{C}$ Enhancement Values 
General Considerations. All manipulations of air-and moisture-sensitive compounds were carried out in the absence of water and dioxygen in an MBraun inert atmosphere drybox under a dinitrogen atmosphere except where specified otherwise. All glassware was oven dried for a minimum of $8 \mathrm{~h}$ and cooled in an evacuated antechamber prior to use in the drybox. Solvents for sensitive manipulations were dried and deoxygenated on a Glass Contour System (SG Water USA, Nashua, NH) and stored over $4 \AA$ molecular sieves purchased from Strem following a literature procedure prior to use. ${ }^{1}$ Acetone- $d_{6}$, and benzene- $d_{6}$ were purchased from Cambridge Isotope Labs and were degassed and stored over $3 \AA$ molecular sieves prior to use. Celite ${ }^{\circledR} 545$ (J. T. Baker) was dried in a Schlenk flask for $24 \mathrm{~h}$ under dynamic vacuum while heating to at least $150{ }^{\circ} \mathrm{C}$ prior to use in a glovebox. NMR Spectra were recorded at room temperature and $37{ }^{\circ} \mathrm{C}$ on a Varian spectrometer operating at $500 \mathrm{MHz}\left({ }^{1} \mathrm{H}\right.$ NMR) (UI500NB), $600 \mathrm{MHz}\left({ }^{1} \mathrm{H} \mathrm{NMR}\right.$ ) (U600) and $150 \mathrm{MHz}\left({ }^{13} \mathrm{C}\right)(\mathrm{U} 600)$ and referenced to the residual $\mathrm{HD}_{2} \mathrm{COCD}_{3}(\delta$ in parts per million, and $\mathrm{J}$ in $\mathrm{Hz}) .{ }^{2}$ $\left({ }^{\text {Mes }} \mathrm{CCC}\right) \mathrm{Co}-\mathrm{py}^{3}$ was prepared according to literature procedures and commercially available substrates were degassed and dried over $3 \AA$ molecular sieves prior to use.

Sample Preparation. ( $\left.{ }^{\mathrm{Mes}} \mathrm{CCC}\right) \mathrm{Co}-\mathrm{py}(2.0 \mathrm{mg}, 0.00293 \mathrm{mmol})$ was added into a $4 \mathrm{~mL}$ scintillation vial along with substrate $(0.03253 \mathrm{mmol})$, dissolved in $1 / 2 \mathrm{~mL}$ of acetone- $d_{6}$ and transferred to a J. Young NMR tube. The NMR tube was subjected to two freeze-pump-thaw cycles and $p-\mathrm{H}_{2}(1 \mathrm{~atm})$ was added while the sample was frozen in liquid nitrogen on a high-vacuum line. The sample was kept in liquid nitrogen and warmed to ambient temperature in an isopropanol bath before inserting into the spectrometer to warm to $37^{\circ} \mathrm{C}$ for 1 minute. After warming, the samples were removed and shaken immediately for 5 seconds before reinserting the sample into the NMR spectrometer. ${ }^{1} \mathrm{H}$ NMR experiments were run after samples were shaken right outside of the spectrometer, with the field measured at about $50 \mathrm{G}\left(5.0 \times 10^{-3} \mathrm{~T}\right)$, while the ${ }^{13} \mathrm{C}$ NMR experiments were run after shaking at earth's magnetic field, with residual field measured at about $1.8 \mathrm{G}\left(1.8 \times 10^{-4} \mathrm{~T}\right)$, measured with a cellphone gaussmeter (Gauss Meter) ( 20 seconds between initial shaking and collection of first transient). Data collected with mu-Metal was generated by shaking the J. Young sample inside of a large Lakeshore Cryotronics Zero Gauss Chamber (P/N 4065) for 5 seconds near the magnet and then inserting the tube into the spectrometer to collect data.

Signal Enhancement. ${ }^{1} \mathrm{H}$ signal enhancements were calculated with Eq.1 using the absolute integration of resonances of raw spectra with MestReNova's integration tool. Absolute integrations can be found on the integration table.

Eq. 1

$$
E_{\text {int }}=\frac{A_{\text {hyp }}}{A_{\text {therm }}}
$$

All hyperpolarization experiments were run on the same instrument as their thermal experiments with the same acquisition parameters and receiver gain for ${ }^{1} \mathrm{H} .{ }^{19} \mathrm{~F}$ enhancements were not calculated.

${ }^{13} \mathrm{C}$ signal enhancements were calculated using a standard $10 \mathrm{M}$ solution of isoprene in $d_{6}$-acetone for the thermal in Eq. 1. The standard spectrum was averaged over 82 transients with a sufficient delay time in between transients to allow for full relaxation of all nuclei. When comparing to the hyperpolarized spectra, the average absolute integral for a single ${ }^{13} \mathrm{C}$ nuclei in isoprene was used as the $\mathrm{A}_{\text {therm }}$ after calculating what that enhancement would be at 1 transient and $64 \mathrm{mM}$ (shown below):

$$
E_{\text {int }}=\frac{A_{\text {hyp }} * 82 * 10}{A_{\text {therm }} * 0.064}
$$

NMR Spectrometer. All ${ }^{13} \mathrm{C}$ NMR data presented herein were collected on a Varian UNITY INOVA 600 NB High-Resolution NMR Console (Ui600) with a $5 \mathrm{~mm}$ Varian AutoTuneX ${ }^{1} \mathrm{H} / \mathrm{X}$ PFG Z probe, $\mathrm{X}={ }^{31} \mathrm{P}-$ ${ }^{15} \mathrm{~N}$ and ${ }^{1} \mathrm{H}$ NMR data collected on the Ui600 or a Varian UNITY INOVA 500 NB High-Resolution NMR 
Console with a $5 \mathrm{~mm}$ Varian $1 \mathrm{H}\{13 \mathrm{C} / 15 \mathrm{~N}\}$ PFG Z probe. All ${ }^{1} \mathrm{H}$ NMR data were collected in acetone- $d_{6}$ and the residual solvent resonance was referenced to $2.05 \mathrm{ppm}$. All ${ }^{13} \mathrm{C}$ NMR data were collected using acetone- $d_{6}$ and the residual solvent was referenced to $206.26 \mathrm{ppm} .{ }^{1} \mathrm{H}$ NMR spectra were recorded using $45^{\circ}$ pulse angle. ${ }^{13} \mathrm{C}$ NMR spectra were recorded using a standard $90^{\circ}$ pulse. The enhanced ${ }^{13} \mathrm{C}$ NMR signal are anti-phase and are displayed in both magnitude and phased modes. The spectral window of $50 \mathrm{ppm}$ was used in proton and experiments and $245 \mathrm{ppm}$ in the ${ }^{13} \mathrm{C}$ NMR experiments.

Generation of parahydrogen. A parahydrogen converter was used to generate the $p$ - $\mathrm{H}_{2}$ enriched hydrogen gas. This consisted of copper tubing filled with a hydrous ferric oxide catalyst that was cooled to $14 \mathrm{~K}$ using a closed-cycle ${ }^{4} \mathrm{He}$ cryostat. A detailed description of the converter can be found in Tom et al., which was able to consistently convert naturally occurring hydrogen gas (3:1 ortho:para) to $99.99 \%$ p- $\mathrm{H}_{2 .}{ }^{4}$ 
${ }^{1} \mathrm{H}$ NMR Spectrum, $600 \mathrm{MHz}$, acetone- $d_{6}\left(45^{\circ}\right.$ pulse $)$
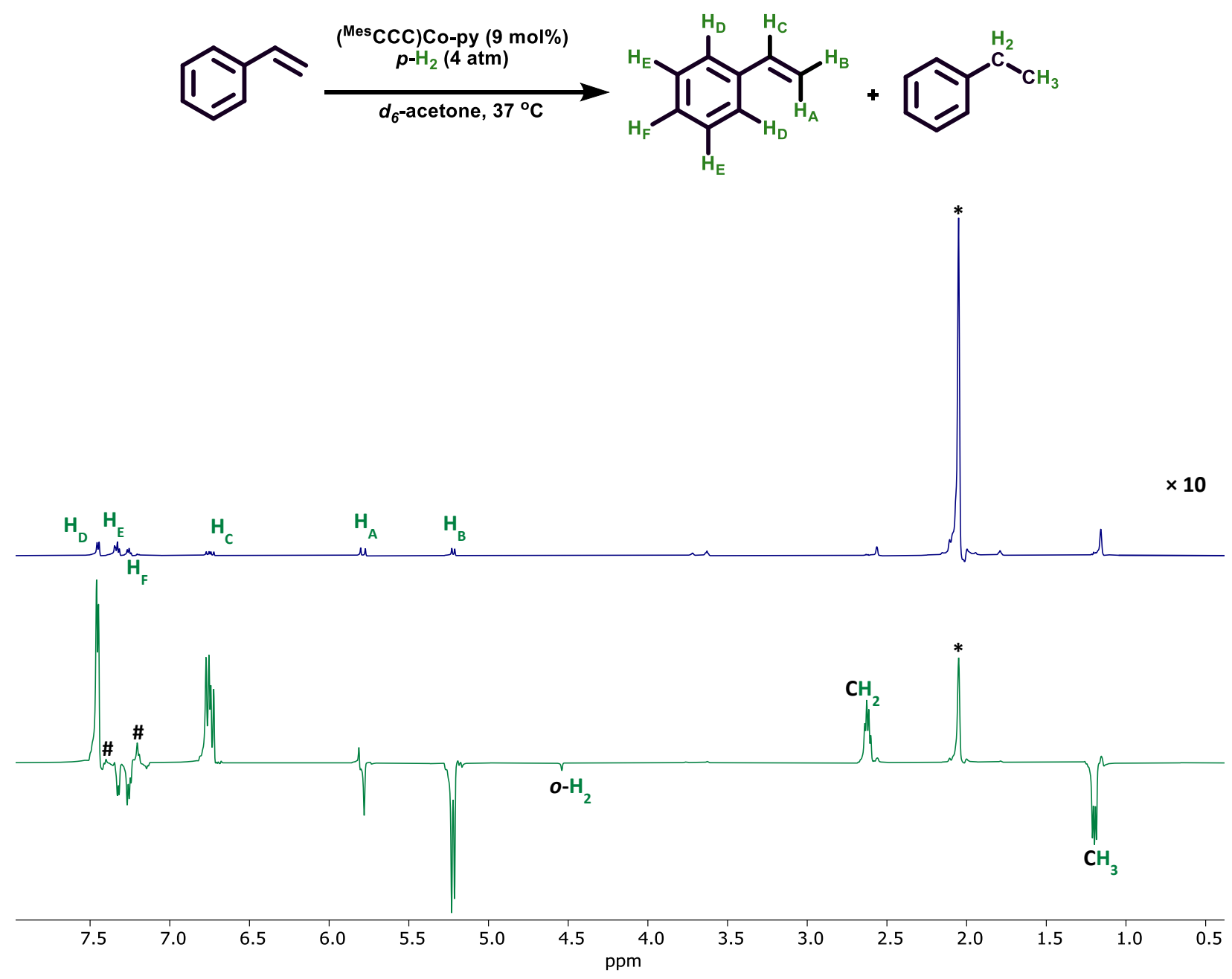

Figure S1. ${ }^{1} \mathrm{H}$ NMR spectra (acetone- $d_{6}(*), 600 \mathrm{MHz}, 37^{\circ} \mathrm{C}$ ) of the reaction of styrene $(65 \mathrm{mM})$ using $\left({ }^{\text {Mes }} \mathrm{CCC}\right)$ Co-py $(9 \mathrm{~mol} \%, 5.9 \mathrm{mM})$ and $p-\mathrm{H}_{2}(4 \mathrm{~atm})$ at the $50 \mathrm{G}$ fringe line of the magnet. Top: spectrum of the sample before $p-\mathrm{H}_{2}$ is introduced through shaking (thermal spectrum) expanded 10-fold compared to hyperpolarized spectrum. Bottom: Single initial transient using a $45^{\circ}$ pulse after shaking, showing the hyperpolarization of styrene resonances (SABRE) and resonances associated with ethyl benzene (ALTADENA, \#). 
${ }^{1} \mathrm{H}$ NMR Spectrum, $600 \mathrm{MHz}$, acetone- $d_{6}\left(45^{\circ}\right.$ pulse $)$
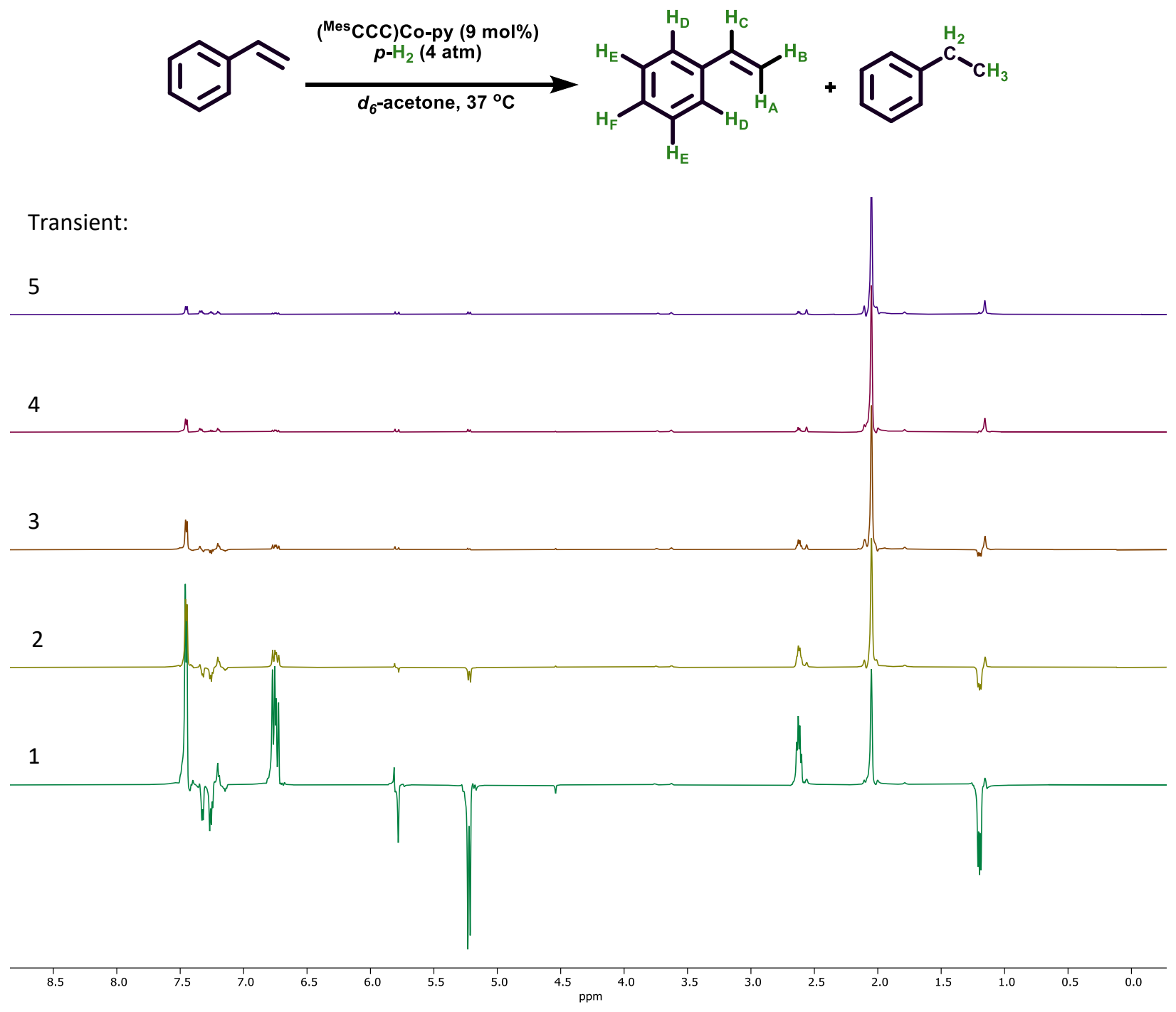

Figure S2. ${ }^{1} \mathrm{H}$ NMR spectra (acetone- $d_{6}(*), 600 \mathrm{MHz}, 37^{\circ} \mathrm{C}$ ) showing the decay of polarization over time of the reaction of styrene $(65 \mathrm{mM})$ using $\left({ }^{\mathrm{Mes}} \mathrm{CCC}\right) \mathrm{Co}-\mathrm{py}(9 \mathrm{~mol} \%, 5.9 \mathrm{mM})$ and $p-\mathrm{H}_{2}(4 \mathrm{~atm})$ at the $50 \mathrm{G}$ fringe line of the magnet. No additional shaking occurred between transients. Bottom (green) spectrum is the first collected transient, followed by an acquisition time of $4.096 \mathrm{~s}$ to collect the next transient (yellow), with no additional delay time in between transients. Subsequent transients were collected in the same fashion. 


\begin{tabular}{|l|c|c|c|}
\hline Proton $(\mathrm{ppm})$ & Thermal Integration & Hyperpolarized Integration & Enhancement (fold) \\
\hline $\mathrm{H}_{\mathrm{A}}(5.22)$ & 44.61 & -1618.04 & -36.3 \\
\hline $\mathrm{H}_{\mathrm{B}}(5.79)$ & 44.24 & -297.22 & -6.7 \\
\hline $\mathrm{H}_{\mathrm{C}}(6.75)$ & 48.97 & 2046 & 41.8 \\
\hline $\mathrm{H}_{\mathrm{D}}(7.45)$ & 61.4 & -517.16 & -8.4 \\
\hline $\mathrm{H}_{\mathrm{E}}(7.33)$ & 117.68 & -378.81 & -3.2 \\
\hline $\mathrm{H}_{\mathrm{F}}(7.25)$ & 98.08 & 2014.81 & 20.5 \\
\hline
\end{tabular}

Table S1. Signal enhancement calculated for the hyperpolarization of the ${ }^{1} \mathrm{H}$ of styrene. The thermal data is derived from the sample before $p-\mathrm{H}_{2}$ is introduced and the hyperpolarized data is derived from the first transient after shaking the sample. 
${ }^{13} \mathrm{C}\left\{{ }^{1} \mathrm{H}\right\}$ NMR Spectrum, $150 \mathrm{MHz}$, acetone- $d_{6}\left(90^{\circ}\right.$ pulse $)$ - Magnitude mode
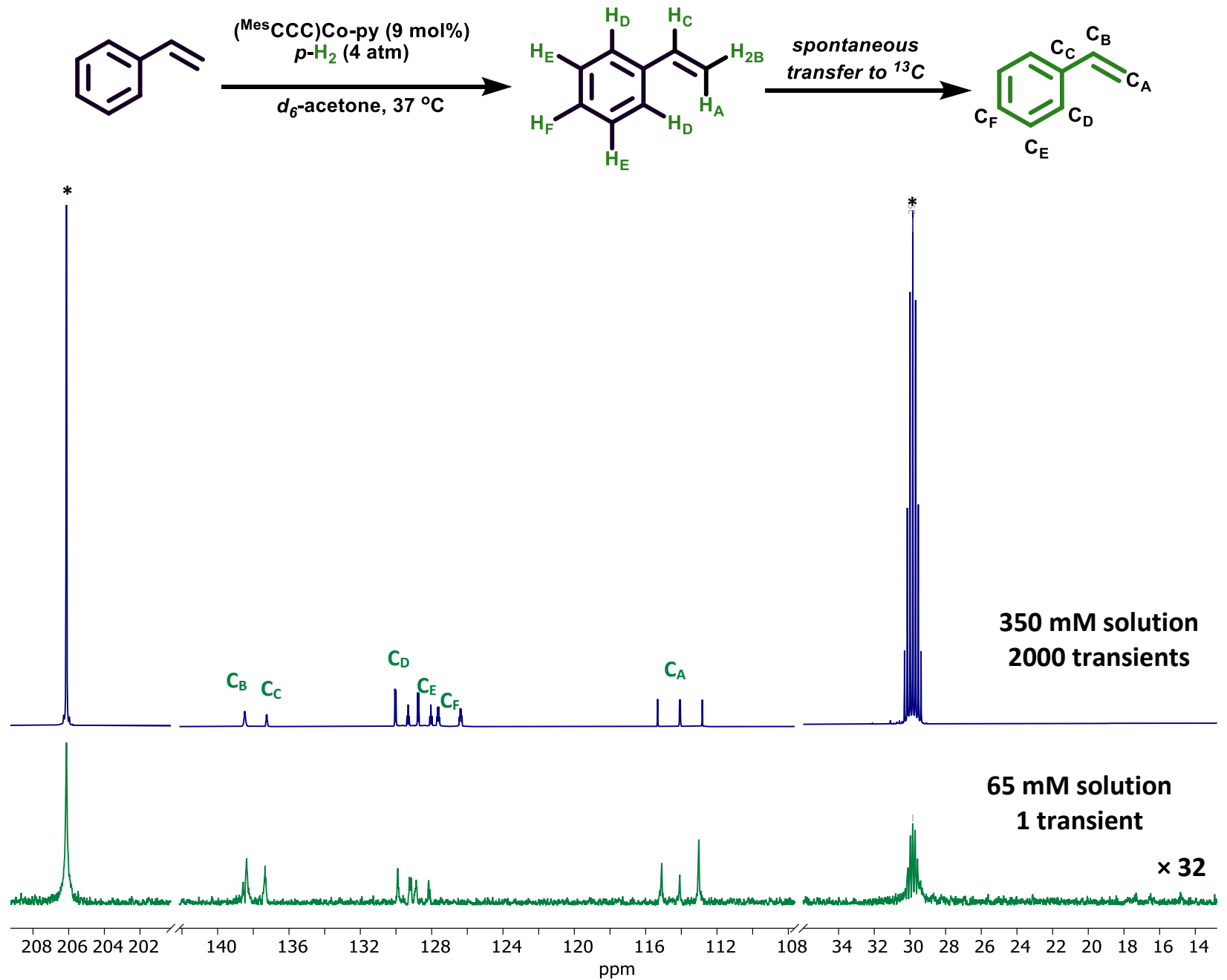

Figure S3. ${ }^{13} \mathrm{C}\left\{{ }^{1} \mathrm{H}\right\}$ NMR spectrum (acetone- $d_{6}(*), 150 \mathrm{MHz}, 37{ }^{\circ} \mathrm{C}$ ), in absolute mode, of the reaction of styrene (65 mM) using ( $\left.{ }^{\text {Mes }} \mathrm{CCC}\right)$ Co-py $(9 \mathrm{~mol} \%, 5.9 \mathrm{mM})$ and $p-\mathrm{H}_{2}(4 \mathrm{~atm})$ at earth's magnetic field with peakless regions removed. Top spectrum is a thermal spectrum of 2000 transients of a $350 \mathrm{mM}$ solution of styrene. The bottom spectrum is the first transient, in absolute mode, after the $4^{\text {th }}$ shake introducing $p$ $\mathrm{H}_{2}$ into the sample at earth's magnetic field, expanded 32-fold compared to the top spectrum. The bottom sample shows the polarization of all ${ }^{13} \mathrm{C}$ nuclei except for $\mathrm{C}_{\mathrm{F}}$. 
${ }^{13} \mathrm{C}\left\{{ }^{1} \mathrm{H}\right\}$ NMR Spectrum, $150 \mathrm{MHz}$, acetone- $d_{6}\left(90^{\circ}\right.$ pulse $)$ - Phased mode
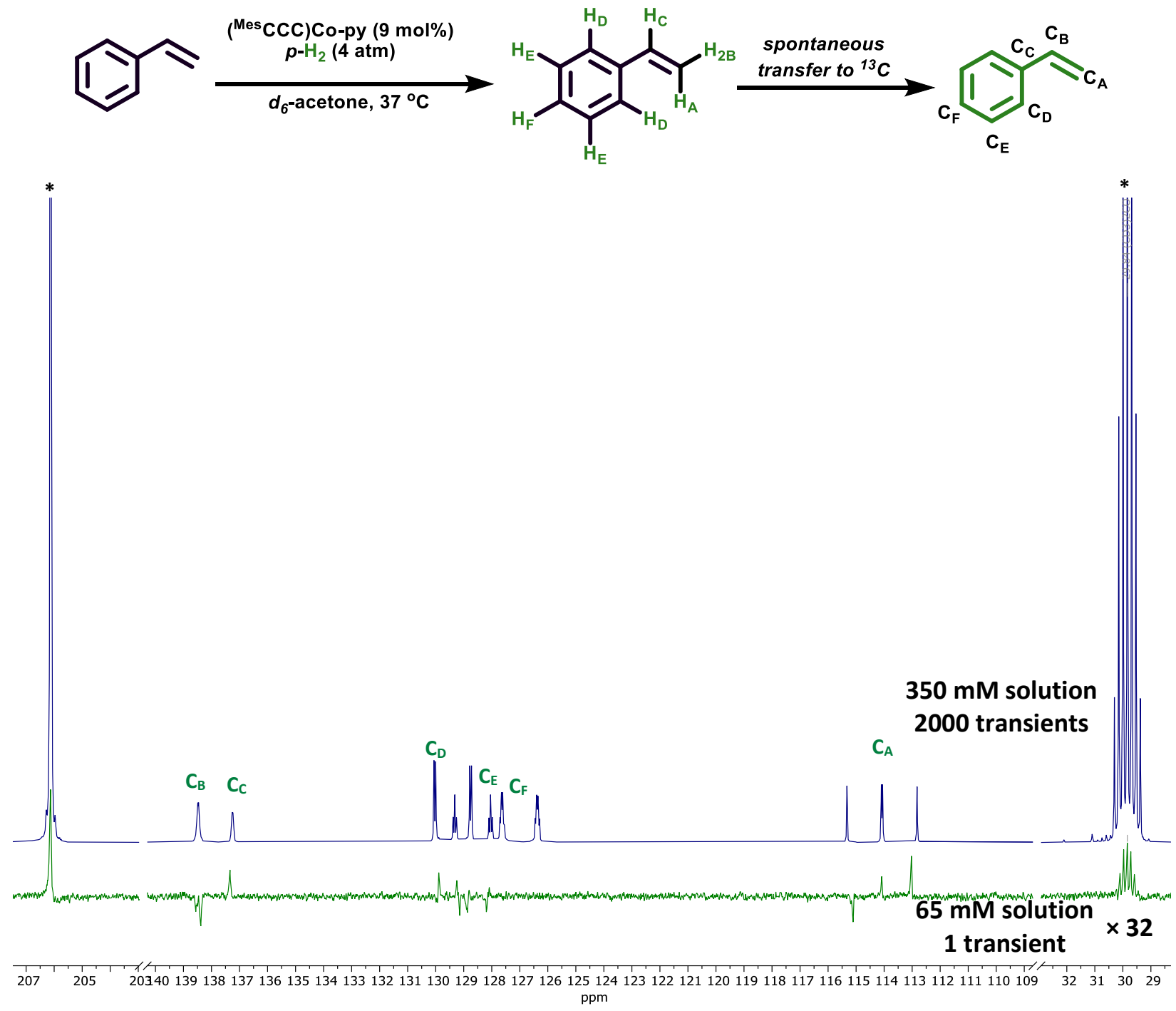

Figure S4. Olefinic region of ${ }^{13} \mathrm{C}\left\{{ }^{1} \mathrm{H}\right\}$ NMR spectrum (acetone- $d_{6}(*), 150 \mathrm{MHz}, 37{ }^{\circ} \mathrm{C}$ ), in phased mode, of the reaction of styrene $(65 \mathrm{mM})$ using $\left({ }^{\text {Mes }} \mathrm{CCC}\right)$ Co-py $(9 \mathrm{~mol} \%, 5.9 \mathrm{mM})$ and $p-\mathrm{H}_{2}(4 \mathrm{~atm})$ at earth's magnetic field. Top spectrum is a thermal spectrum of 2000 transients of a $350 \mathrm{mM}$ solution of styrene. The bottom spectrum is the first transient, in absolute mode, after the $4^{\text {th }}$ shake introducing $p-\mathrm{H}_{2}$ into the sample at earth's magnetic field, expanded 32-fold compared to the top spectrum. The bottom sample shows the polarization of all ${ }^{13} \mathrm{C}$ nuclei except for $\mathrm{C}_{\mathrm{F}}$. 
${ }^{13} \mathrm{C}\left\{{ }^{1} \mathrm{H}\right\}$ NMR Spectrum, $150 \mathrm{MHz}$, acetone- $d_{6}\left(90^{\circ}\right.$ pulse $)$
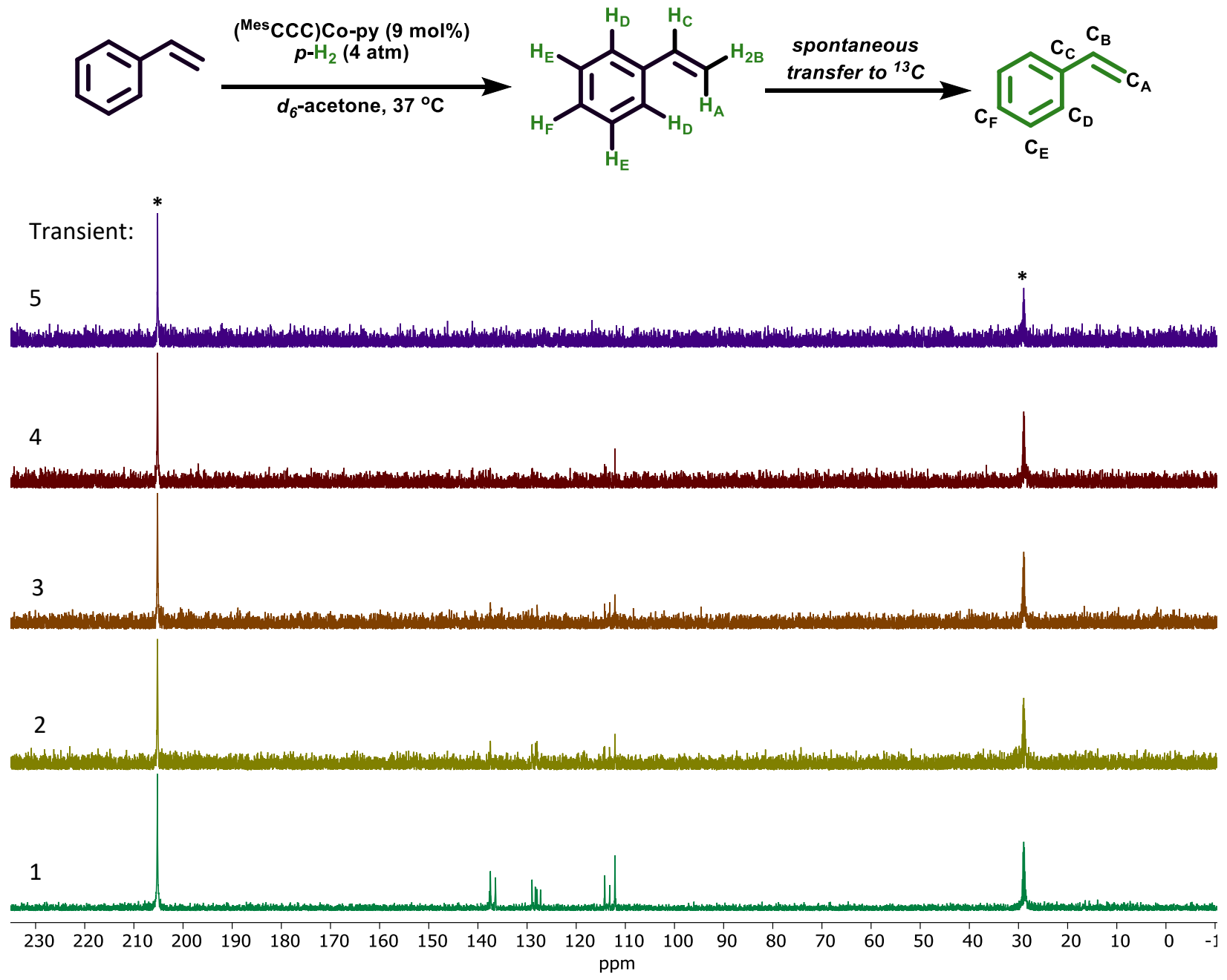

Figure S5. ${ }^{13} \mathrm{C}\left\{{ }^{1} \mathrm{H}\right\}$ NMR spectra (acetone- $d_{6}(*), 150 \mathrm{MHz}, 37{ }^{\circ} \mathrm{C}$ ), in absolute mode, showing the decay of polarization over time of the reaction of styrene $(65 \mathrm{mM})$ using $\left({ }^{\mathrm{Mes}} \mathrm{CCC}\right) \mathrm{Co}-\mathrm{py}(9 \mathrm{~mol} \%, 5.9 \mathrm{mM})$ and $p-\mathrm{H}_{2}(4 \mathrm{~atm})$ at earth's magnetic field. Bottom (green) spectrum is the first collected transient of the $4^{\text {th }}$ shake of $p-\mathrm{H}_{2}$ into the sample, followed by an acquisition time of $1.7695 \mathrm{~s}$ to collect the next transient (yellow), with no delay time in between. Subsequent transients were collected in the same fashion. 
${ }^{13} \mathrm{C}\left\{{ }^{1} \mathrm{H}\right\}$ NMR Spectrum, $150 \mathrm{MHz}$, acetone- $d_{6}\left(90^{\circ}\right.$ pulse $)$

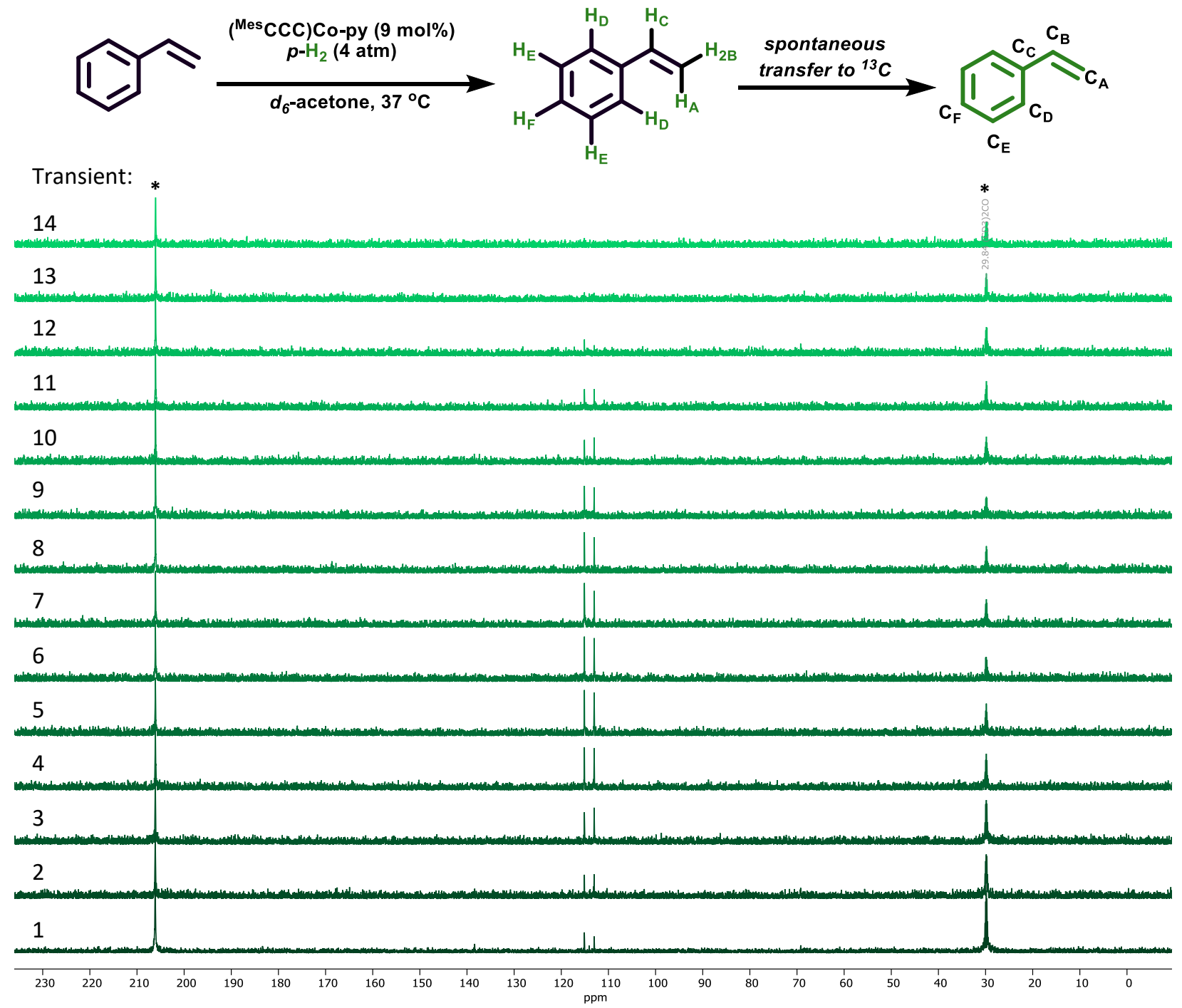

Figure S6. ${ }^{13} \mathrm{C}\left\{{ }^{1} \mathrm{H}\right\}$ NMR spectra (acetone- $d_{6}(*), 150 \mathrm{MHz}, 37{ }^{\circ} \mathrm{C}$ ), in absolute mode, showing the decay of polarization over time of the reaction of styrene $(65 \mathrm{mM})$ using $\left({ }^{\mathrm{Mes}} \mathrm{CCC}\right) \mathrm{Co}-\mathrm{py}(9 \mathrm{~mol} \%, 5.9 \mathrm{mM})$ and $p-\mathrm{H}_{2}(4 \mathrm{~atm})$ at earth's magnetic field. Bottom (green) spectrum is the first collected transient of the $\mathbf{2}^{\text {nd }}$ shake of $p-\mathrm{H}_{2}$ into the sample, followed by an acquisition time of $1.7695 \mathrm{~s}$ to collect the next transient with no delay time in between. No additional shaking occurred between transients. Subsequent transients were collected in the same fashion. 
${ }^{1} \mathrm{H}$ NMR Spectrum, $600 \mathrm{MHz}$, acetone- $d_{6}\left(45^{\circ}\right.$ pulse $)$
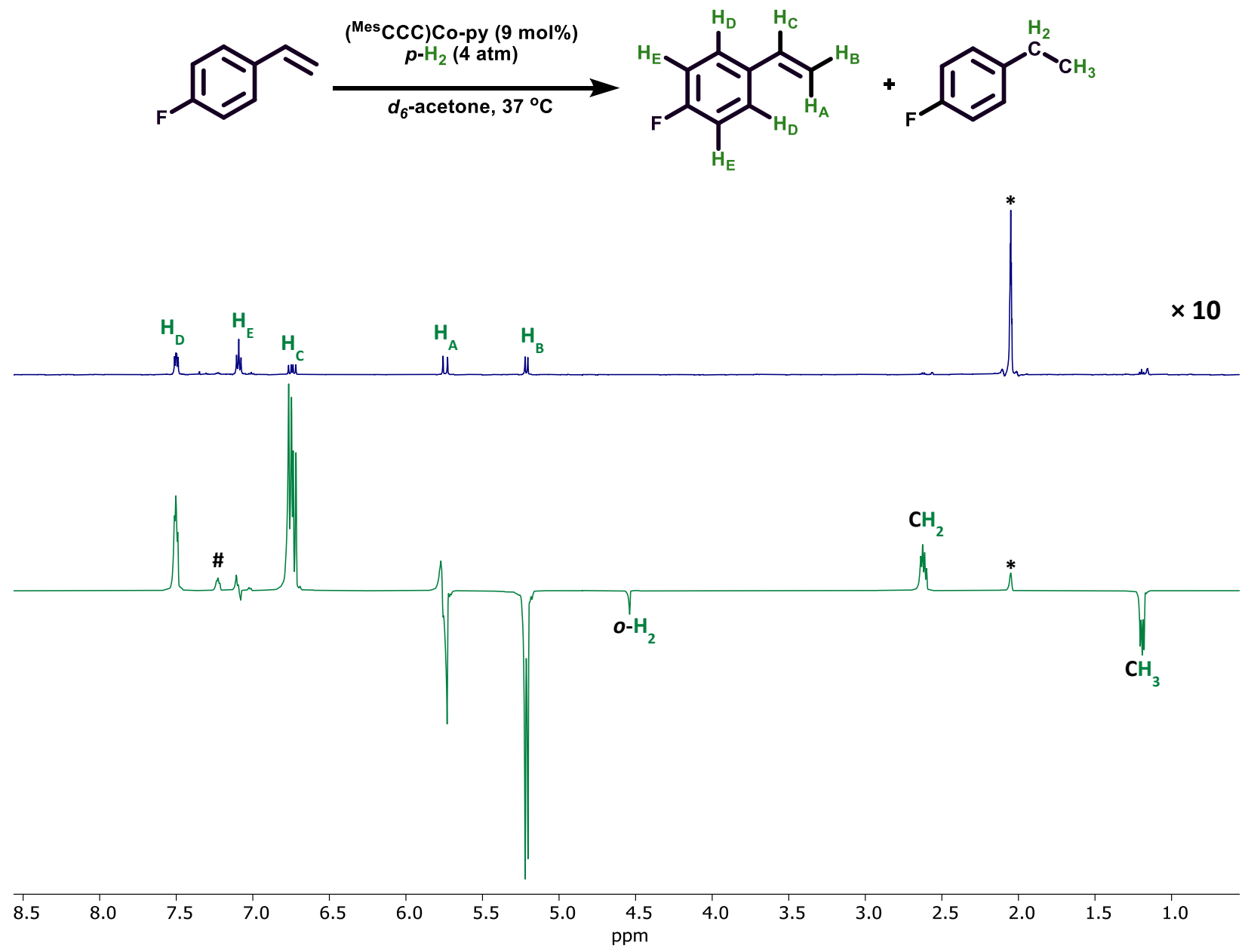

Figure S7. ${ }^{1} \mathrm{H}$ NMR spectra (acetone- $\left.d_{6}(*), 600 \mathrm{MHz}, 37^{\circ} \mathrm{C}\right)$ of the reaction of 4-fluorostyrene $(65 \mathrm{mM})$ using ( $\left.{ }^{\text {Mes }} \mathrm{CCC}\right) \mathrm{Co}-\mathrm{py}(9 \mathrm{~mol} \%, 5.9 \mathrm{mM})$ and $p-\mathrm{H}_{2}(4 \mathrm{~atm})$ at the 50G fringe line of the magnet. Top: spectrum of the sample before $p-\mathrm{H}_{2}$ is introduced through shaking (thermal spectrum) expanded 10-fold compared to hyperpolarized spectrum. Bottom: First transient using a $45^{\circ}$ pulse after the $\mathbf{1}^{\text {st }}$ shake introducing $p-\mathrm{H}_{2}$ to the sample, showing the hyperpolarization of 4-fluorostyrene resonances (SABRE) and resonances associated with ethyl-4-fluorobenzene (ALTADENA, \#). 
${ }^{1} \mathrm{H}$ NMR Spectrum, $600 \mathrm{MHz}$, acetone- $d_{6}\left(45^{\circ}\right.$ pulse $)$

Transient:

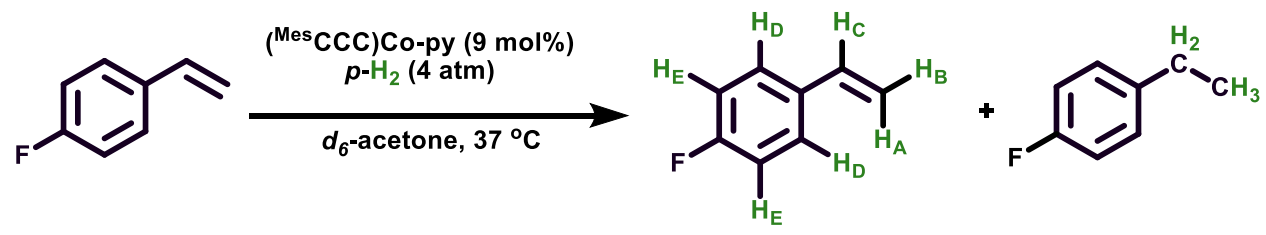

5

4

3

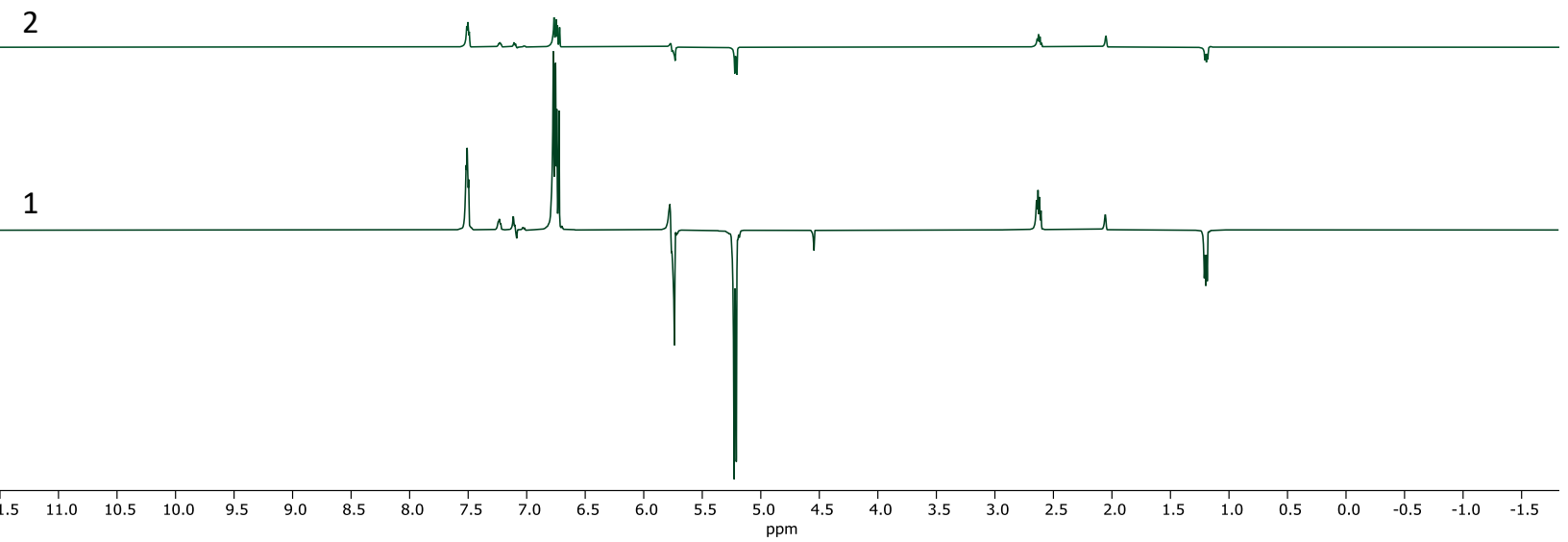

Figure S8. ${ }^{1} \mathrm{H}$ NMR spectra (acetone- $d_{6}(*), 600 \mathrm{MHz}, 37^{\circ} \mathrm{C}$ ) showing the decay of polarization over time of the reaction of 4-fluorostyrene $(65 \mathrm{mM})$ using $\left({ }^{\mathrm{Mes}} \mathrm{CCC}\right) \mathrm{Co}-\mathrm{py}(9 \mathrm{~mol} \%, 5.9 \mathrm{mM})$ and $p-\mathrm{H}_{2}(4 \mathrm{~atm})$ at the $50 \mathrm{G}$ fringe line of the magnet. No additional shaking occurred between transients. Bottom (dark green) spectrum is the first collected transient, followed by an acquisition time of $4.096 \mathrm{~s}$ to collect the next transient (second spectrum from the bottom), with no additional delay time in between transients. Subsequent transients were collected in the same fashion. 


\begin{tabular}{|l|c|c|c|}
\hline Proton $(\mathrm{ppm})$ & Thermal Integration & Hyperpolarized Integration & Enhancement (fold) \\
\hline $\mathrm{H}_{\mathrm{A}}(5.21)$ & 46.63 & -3493.93 & -74.9 \\
\hline $\mathrm{H}_{\mathrm{B}}(5.74)$ & 45.96 & -1212.07 & -26.4 \\
\hline $\mathrm{H}_{\mathrm{C}}(6.74)$ & 52.84 & 4312.23 & 81.6 \\
\hline $\mathrm{H}_{\mathrm{D}}(7.50)$ & 97.45 & 1462.1 & 15.0 \\
\hline $\mathrm{H}_{\mathrm{E}}(7.09)$ dispersive & 101.54 & 291.9 & 2.9 \\
\hline
\end{tabular}

Table S2. Signal enhancement calculated for the hyperpolarization of the ${ }^{1} \mathrm{H}$ of 4 -fluorostyrene. The thermal data is derived from the sample before $p-\mathrm{H}_{2}$ is introduced and the hyperpolarized data is derived from the first transient after shaking the sample. 
${ }^{13} \mathrm{C}\left\{{ }^{1} \mathrm{H}\right\}$ NMR Spectrum, $150 \mathrm{MHz}$, acetone- $d_{6}\left(90^{\circ}\right.$ pulse $)$ - Magnitude mode
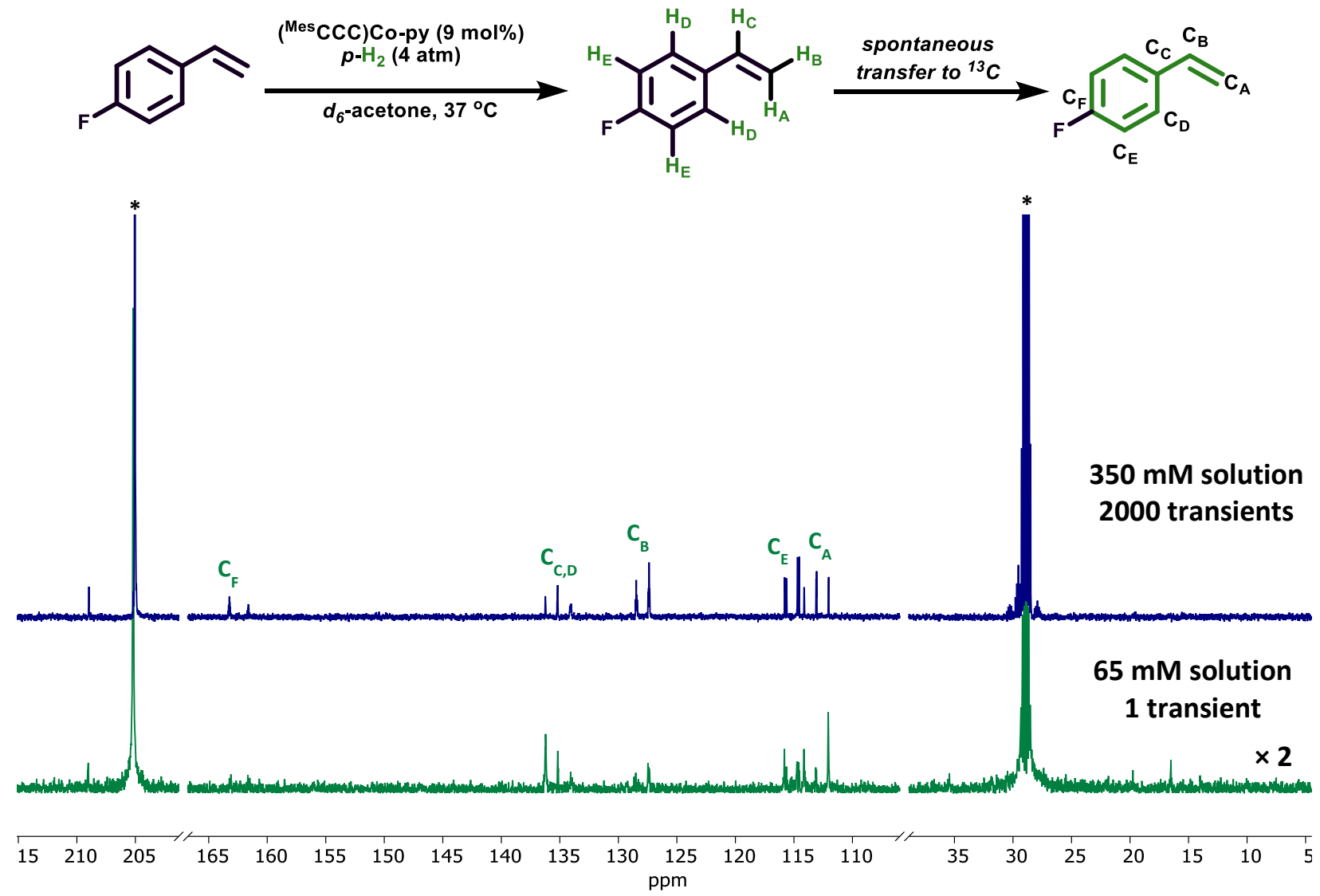

Figure S9. ${ }^{13} \mathrm{C}\left\{{ }^{1} \mathrm{H}\right\}$ NMR spectra (acetone- $d_{6}(*), 150 \mathrm{MHz}, 37{ }^{\circ} \mathrm{C}$ ) of the reaction of 4-fluorostyrene (65 $\mathrm{mM})$ using ( $\left.{ }^{\mathrm{Mes}} \mathrm{CCC}\right) \mathrm{Co}$-py $(9 \mathrm{~mol} \%, 5.9 \mathrm{mM})$ and $p-\mathrm{H}_{2}(4 \mathrm{~atm})$ at earth's magnetic field with peakless regions removed. Top spectrum is a thermal spectrum of 2000 transients of a $350 \mathrm{mM}$ solution of 4fluorostyrene. The bottom spectrum is the first transient, in magnitude mode, after the $\mathbf{2}^{\text {nd }}$ shake introducing $p-\mathrm{H}_{2}$ into the sample at earth's magnetic field, expanded 2-fold compared to the top. 
${ }^{13} \mathrm{C}\left\{{ }^{1} \mathrm{H}\right\}$ NMR Spectrum, $150 \mathrm{MHz}$, acetone- $d_{6}\left(90^{\circ}\right.$ pulse $)$ - Phased mode
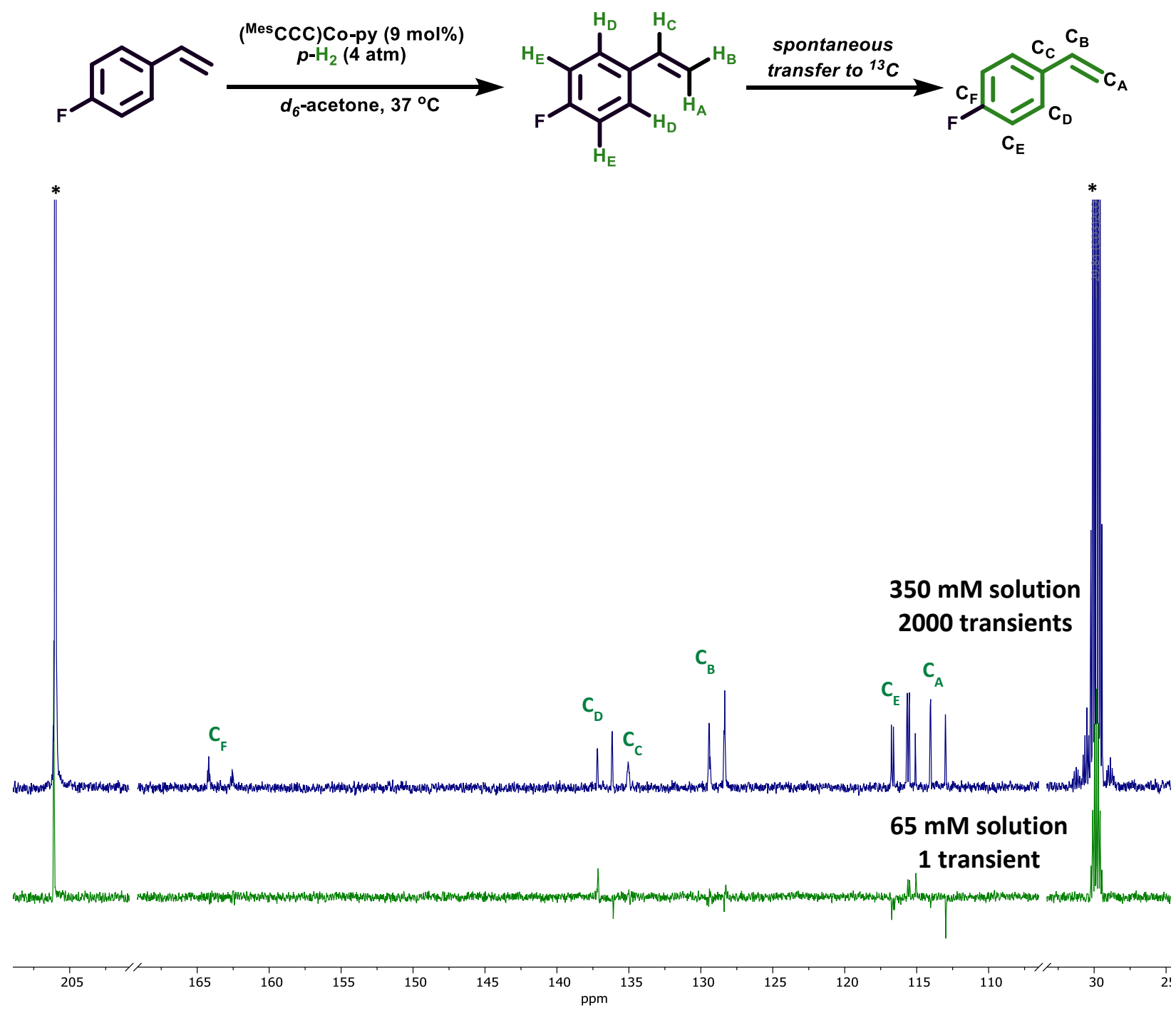

Figure S10. Olefinic region of the ${ }^{13} \mathrm{C}\left\{{ }^{1} \mathrm{H}\right\}$ NMR spectra (acetone- $d_{6}(*), 150 \mathrm{MHz}, 37{ }^{\circ} \mathrm{C}$ ) of the reaction of 4-fluorostyrene $(65 \mathrm{mM})$ using ( $\left.{ }^{\text {Mes }} \mathrm{CCC}\right) \mathrm{Co}-\mathrm{py}(9 \mathrm{~mol} \%, 5.9 \mathrm{mM})$ and $p-\mathrm{H}_{2}(4 \mathrm{~atm})$ at earth's magnetic field with peakless regions removed. Top spectrum is a thermal spectrum of 2000 transients of a $350 \mathrm{mM}$ solution of 4-fluorostyrene. The bottom spectrum is the first transient, in phased mode, after the $2^{\text {nd }}$ shake introducing $p-\mathrm{H}_{2}$ into the sample at earth's magnetic field. 
${ }^{13} \mathrm{C}$ NMR Spectrum, $150 \mathrm{MHz}$, acetone- $d_{6}\left(90^{\circ}\right.$ pulse $)$
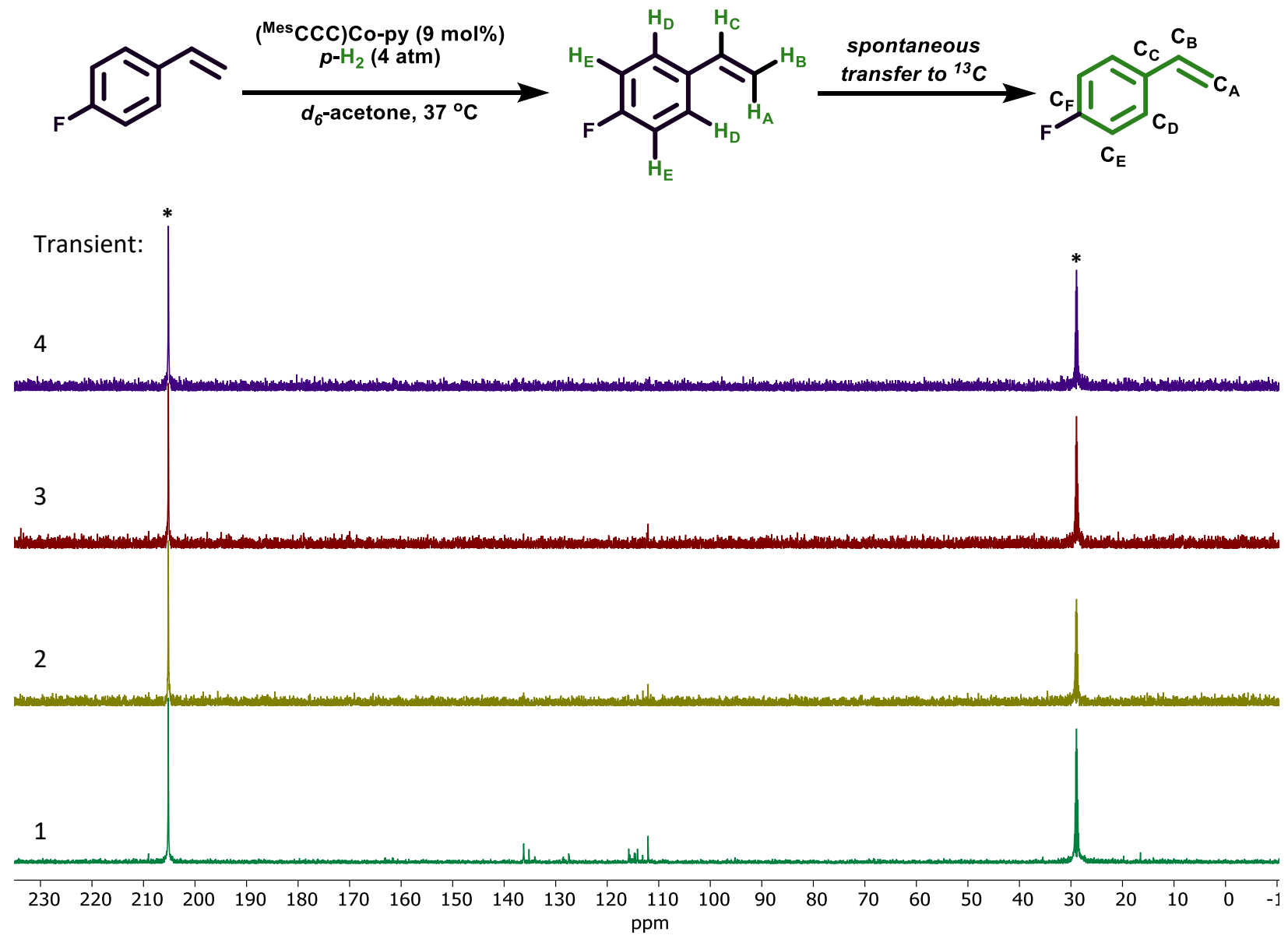

Figure S11. ${ }^{13} \mathrm{C}\left\{{ }^{1} \mathrm{H}\right\}$ NMR spectra (acetone- $d_{6}(*), 150 \mathrm{MHz}, 37{ }^{\circ} \mathrm{C}$ ), in absolute mode, showing the decay of polarization over time of the reaction of 4-fluorostyrene $(65 \mathrm{mM})$ using $\left({ }^{\mathrm{Mes}} \mathrm{CCC}\right) \mathrm{Co}-\mathrm{py}(9 \mathrm{~mol} \%, 5.9$ $\mathrm{mM})$ and $p-\mathrm{H}_{2}(4 \mathrm{~atm})$ at earth's magnetic field. No additional shaking occurred between transients. Bottom (green) spectrum is the first collected transient of the $\mathbf{2}^{\text {nd }}$ shake of $p-\mathrm{H}_{2}$ into the sample, followed by an acquisition time of $1.7695 \mathrm{~s}$ to collect the next transient (yellow), with no delay time in between. Subsequent transients were collected in the same fashion. 
${ }^{19} \mathrm{~F}$ NMR Spectrum, $564 \mathrm{MHz}$, acetone- $d_{6}\left(90^{\circ}\right.$ pulse $)$

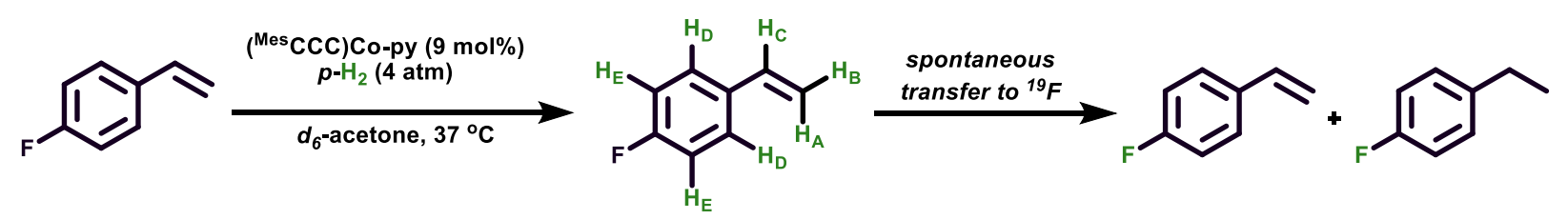

SABRE
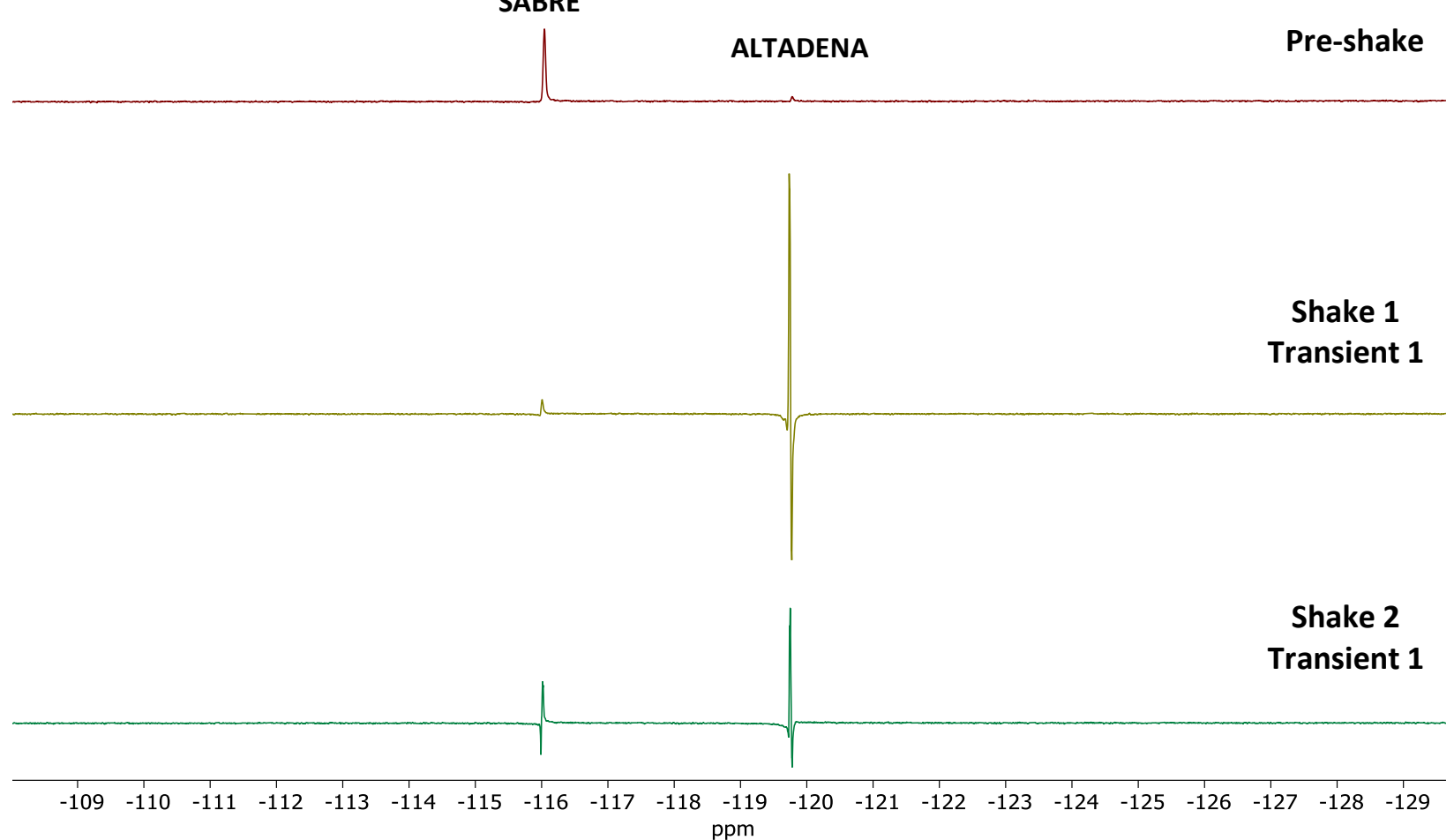

Figure S12. ${ }^{19} \mathrm{~F}$ NMR spectra (acetone- $d_{6}, 564 \mathrm{MHz}, 37{ }^{\circ} \mathrm{C}$ of the reaction of 4-fluorostyrene (65 mM)

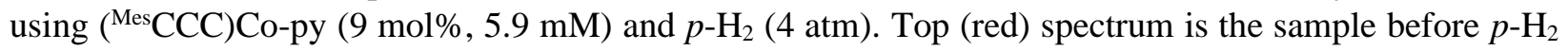
is introduced. Middle (yellow) spectrum is the first transient of the first shake of $p-\mathrm{H}_{2}$ into the solution at earth's magnetic field, which shows the dispersive polarization of the hydrogenated product through ALTADENA. Bottom (green) spectrum is the first transient of the second shake of $p-\mathrm{H}_{2}$ into the solution at the $50 \mathrm{G}$ fringe line of the magnet, which shows the dispersive polarization of both the hydrogenated product through ALTADENA and the SABRE product. 
${ }^{1} \mathrm{H}$ NMR Spectrum, $600 \mathrm{MHz}$, acetone- $d_{6}\left(45^{\circ}\right.$ pulse $)$
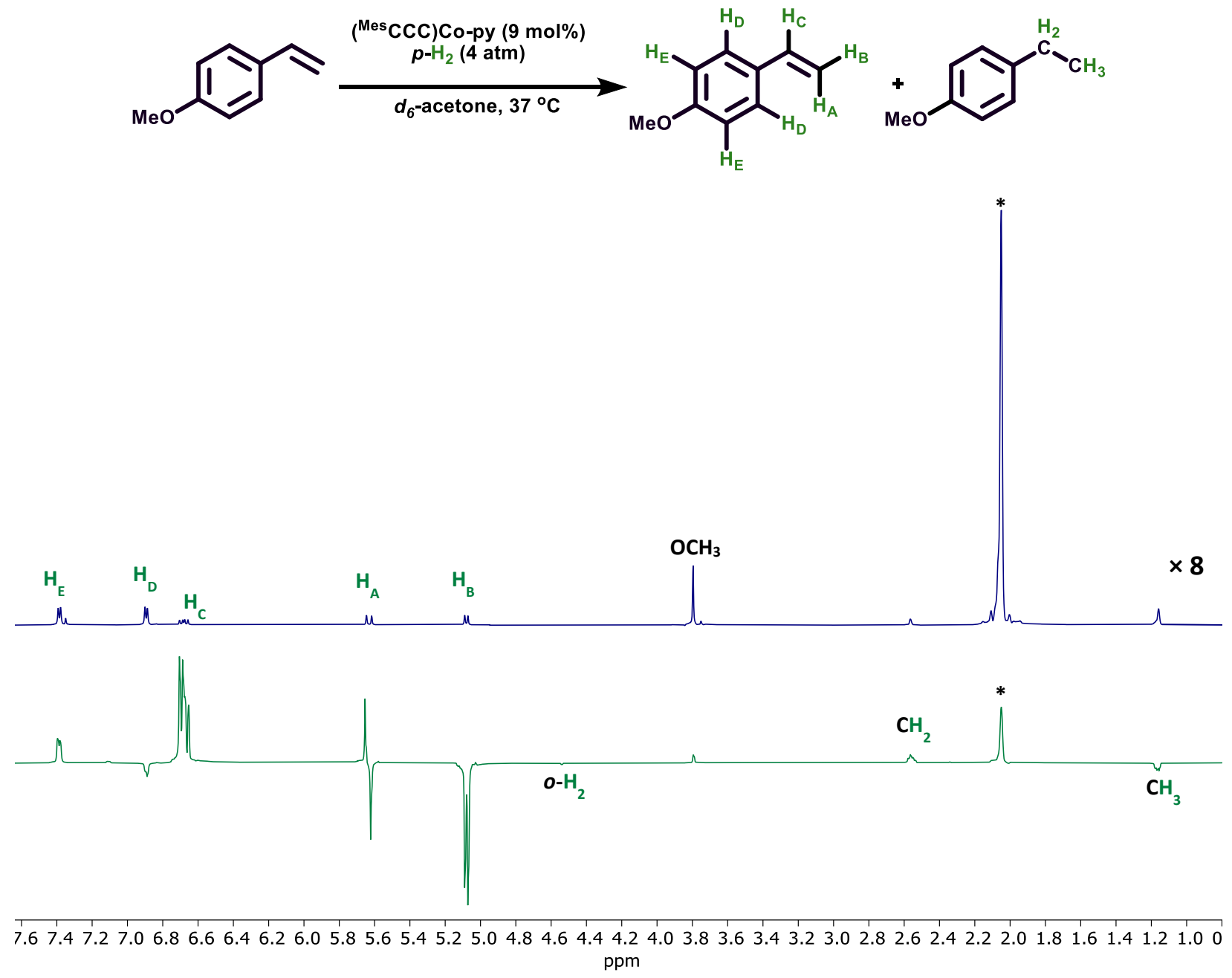

Figure S13. ${ }^{1} \mathrm{H}$ NMR spectra (acetone- $d_{6}(*), 600 \mathrm{MHz}, 37{ }^{\circ} \mathrm{C}$ ) of the reaction of 4-methoxystyrene $(65$ $\mathrm{mM})$ using $\left({ }^{\mathrm{Mes}} \mathrm{CCC}\right) \mathrm{Co}-\mathrm{py}(9 \mathrm{~mol} \%, 5.9 \mathrm{mM})$ and $p-\mathrm{H}_{2}(4 \mathrm{~atm})$ at the $50 \mathrm{G}$ fringe line of the magnet. Top: spectrum of the sample before $p-\mathrm{H}_{2}$ is introduced through shaking (thermal spectrum) expanded 8-fold compared to hyperpolarized spectrum. Bottom: First transient using a $45^{\circ}$ pulse after the $1^{\text {st }}$ shake introducing $p-\mathrm{H}_{2}$ to the sample, showing the hyperpolarization of 4-methoxystyrene resonances (SABRE) and resonances associated with ethyl-4-fluorobenzene (ALTADENA). 
${ }^{1} \mathrm{H}$ NMR Spectrum, $600 \mathrm{MHz}$, acetone- $d_{6}\left(45^{\circ}\right.$ pulse $)$

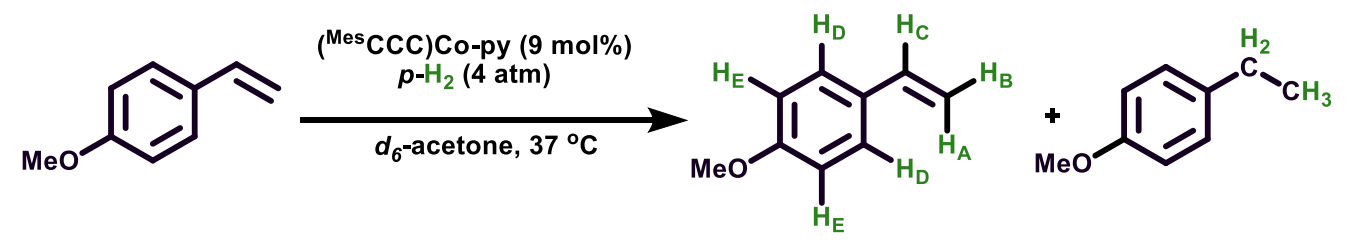

Transient:

4
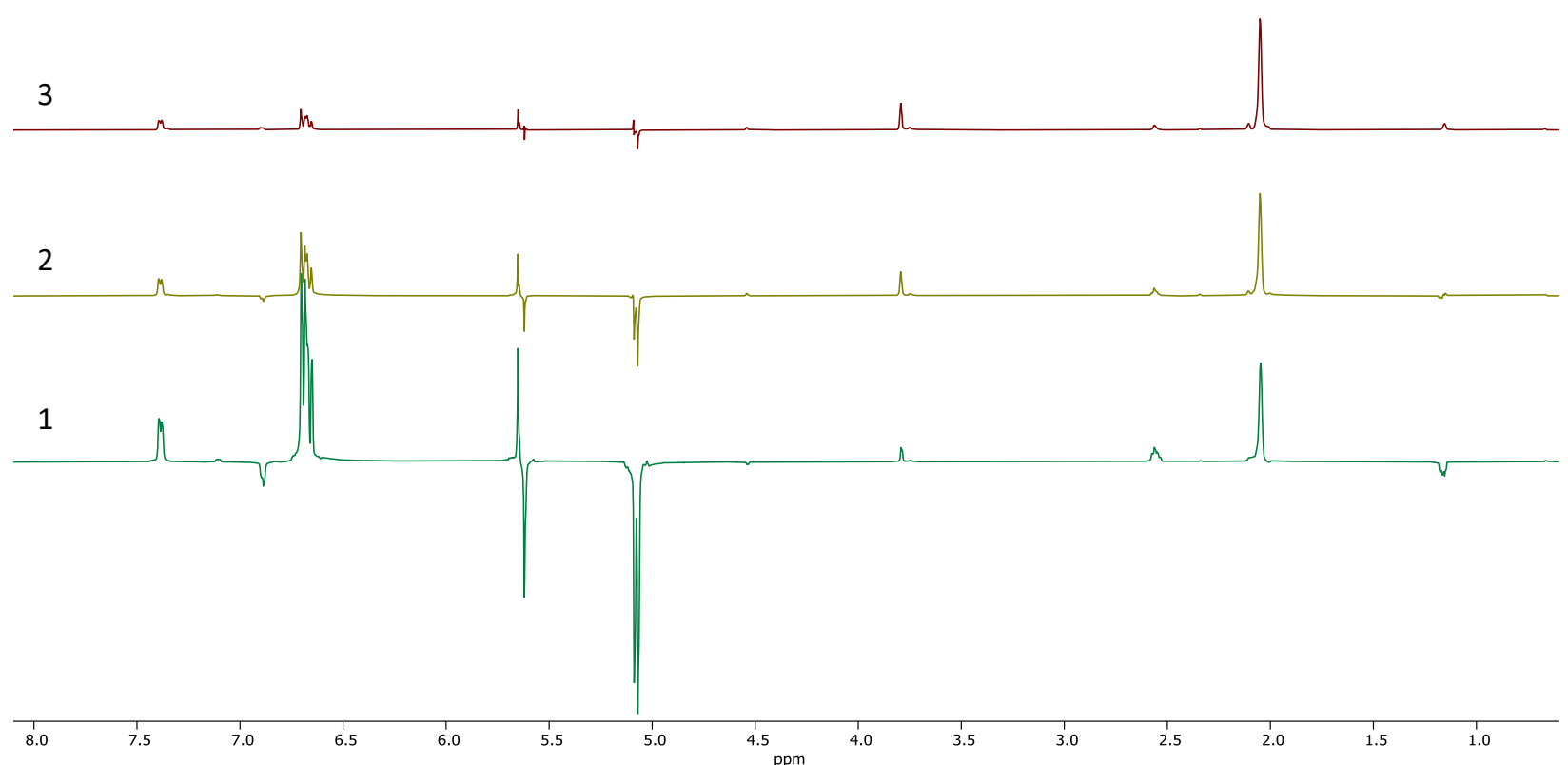

Figure S14. ${ }^{1} \mathrm{H}$ NMR spectra (acetone- $d_{6}(*), 600 \mathrm{MHz}, 37^{\circ} \mathrm{C}$ ) showing the decay of polarization over time of the reaction of 4-methoxystyrene $(65 \mathrm{mM})$ using $\left({ }^{\mathrm{Mes}} \mathrm{CCC}\right) \mathrm{Co}-\mathrm{py}(9 \mathrm{~mol} \%, 5.9 \mathrm{mM})$ and $p-\mathrm{H}_{2}(4$ atm) at the $50 \mathrm{G}$ fringe line of the magnet. No additional shaking occurred between transients. Bottom (green) spectrum is the first collected transient, followed by an acquisition time of $4.096 \mathrm{~s}$ to collect the next transient (yellow), with no additional delay time in between transients. Subsequent transients were collected in the same fashion. 
${ }^{1} \mathrm{H}$ NMR Spectrum, $600 \mathrm{MHz}$, acetone- $d_{6}\left(45^{\circ}\right.$ pulse $)$
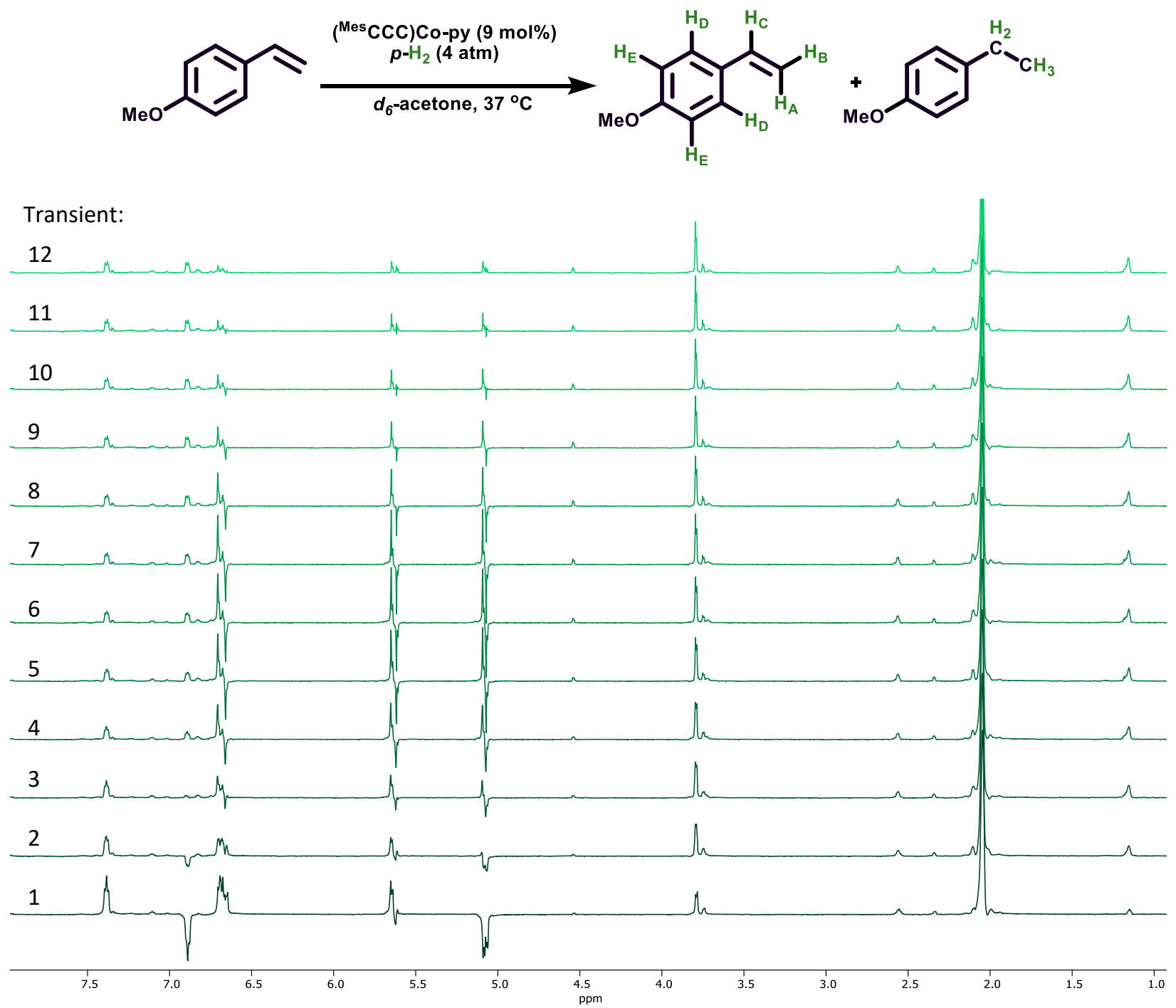

Figure S15. ${ }^{1} \mathrm{H}$ NMR spectra (acetone- $d_{6}(*), 600 \mathrm{MHz}, 37^{\circ} \mathrm{C}$ ) showing the decay of polarization over time of the reaction of 4-methoxystyrene $(65 \mathrm{mM})$ using $\left({ }^{\mathrm{Mes}} \mathrm{CCC}\right) \mathrm{Co}-\mathrm{py}(9 \mathrm{~mol} \%, 5.9 \mathrm{mM})$ and $p-\mathrm{H}_{2}(4$ atm) at the $50 \mathrm{G}$ fringe line of the magnet. Spectra represents the $2^{\text {nd }}$ shake introducing $p-\mathrm{H}_{2}$ into the sample, with no additional shaking between transients. Each transient with an acquisition time of $4.096 \mathrm{~s}$ and no additional delay time in between transients. 


\begin{tabular}{|l|c|c|c|}
\hline Proton $(\mathrm{ppm})$ & Thermal Integration & Hyperpolarized Integration & Enhancement (fold) \\
\hline $\mathrm{H}_{\mathrm{A}}(5.07)$ & 53.79 & -2227.87 & -41.4 \\
\hline $\mathrm{H}_{\mathrm{B}}(5.62)$ dispersive & 54.07 & -187.23 & -3.5 \\
\hline $\mathrm{H}_{\mathrm{C}}(6.67)$ & 58.51 & 2886.04 & 49.3 \\
\hline $\mathrm{H}_{\mathrm{D}}(6.88)$ & 113.27 & -208.58 & -1.8 \\
\hline $\mathrm{H}_{\mathrm{E}}(7.37)$ & 115.23 & 460.1 & 4.0 \\
\hline $\mathrm{OMe}(3.79)$ & 169.91 & 73.17 & 0.4 \\
\hline
\end{tabular}

Table S3. Signal enhancement calculated for the hyperpolarization of the ${ }^{1} \mathrm{H}$ of 4-methoxystyrene. The thermal data is derived from the sample before $p-\mathrm{H}_{2}$ is introduced and the hyperpolarized data is derived from the first transient after shaking the sample. 
${ }^{13} \mathrm{C}\left\{{ }^{1} \mathrm{H}\right\}$ NMR Spectrum, $150 \mathrm{MHz}$, acetone- $d_{6}\left(90^{\circ}\right.$ pulse $)$ - Magnitude mode
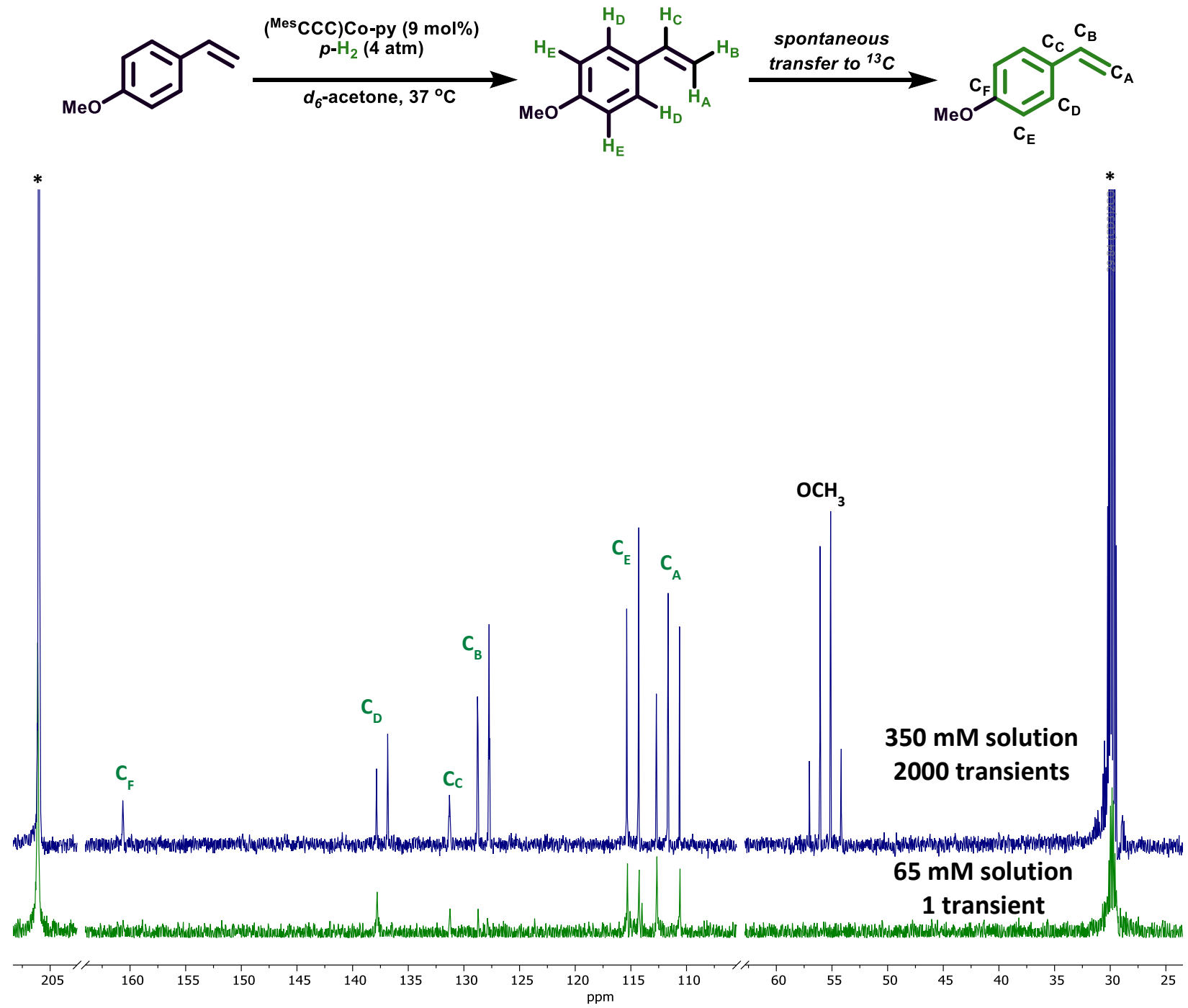

Figure S16. ${ }^{13} \mathrm{C}\left\{{ }^{1} \mathrm{H}\right\}$ NMR spectra (acetone- $d_{6}(*), 150 \mathrm{MHz}, 37{ }^{\circ} \mathrm{C}$ ) of the reaction of 4-methoxystyrene $(65 \mathrm{mM})$ using $\left({ }^{\mathrm{Mes}} \mathrm{CCC}\right) \mathrm{Co}-\mathrm{py}(9 \mathrm{~mol} \%, 5.9 \mathrm{mM})$ and $p-\mathrm{H}_{2}(4 \mathrm{~atm})$ at earth's magnetic field with peakless regions removed. Top spectrum is a thermal spectrum of 2000 transients of a $350 \mathrm{mM}$ solution of 4methoxystyrene. The bottom spectrum is the first transient, in magnitude mode, after the $\mathbf{3}^{\text {rd }}$ shake introducing $p-\mathrm{H}_{2}$ into the sample at earth's magnetic field. 
${ }^{13} \mathrm{C}\left\{{ }^{1} \mathrm{H}\right\}$ NMR Spectrum, $150 \mathrm{MHz}$, acetone- $d_{6}\left(90^{\circ}\right.$ pulse $)$ - Phased mode
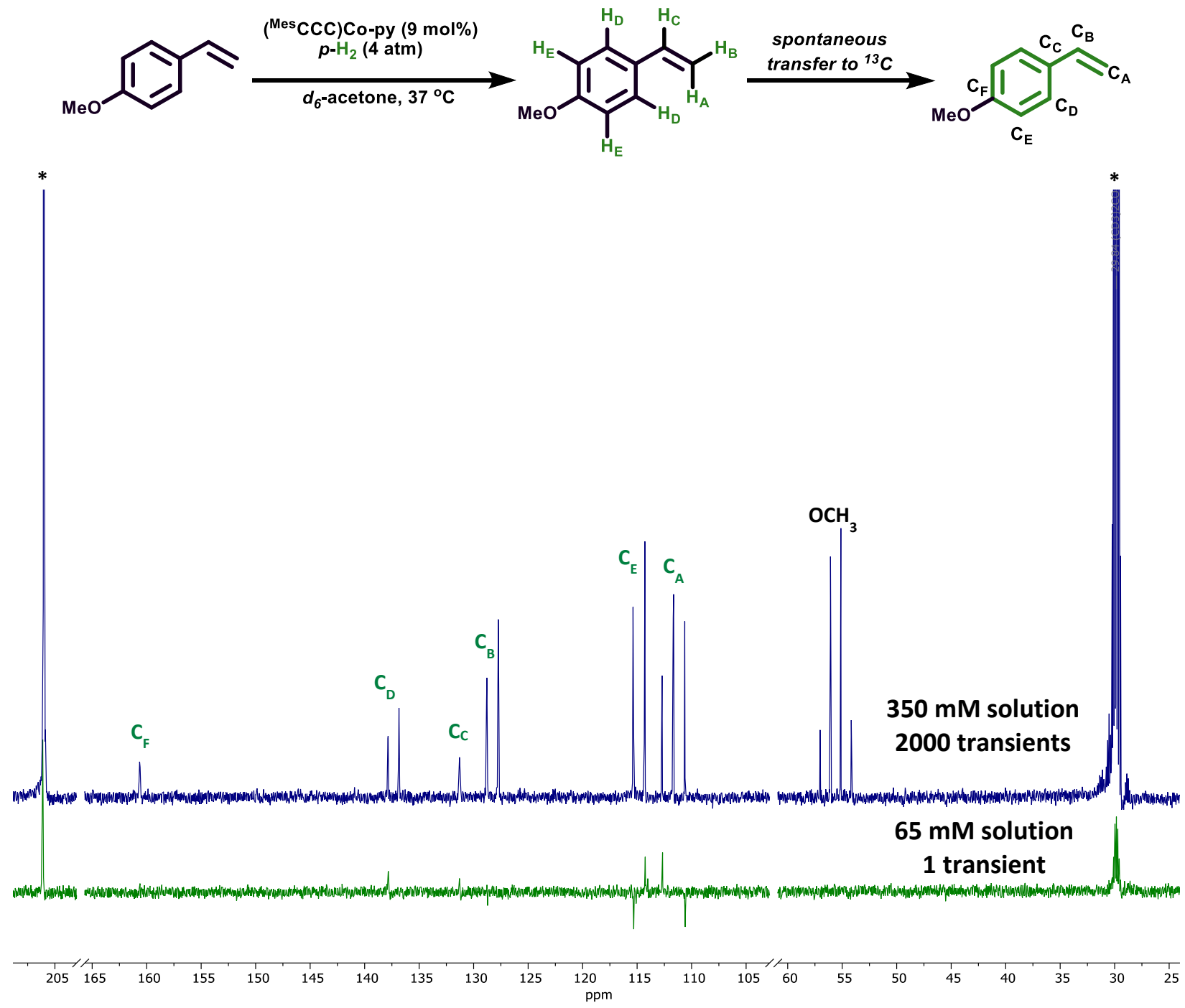

Figure S17. Olefinic region of the ${ }^{13} \mathrm{C}\left\{{ }^{1} \mathrm{H}\right\}$ NMR spectra (acetone- $d_{6}(*), 150 \mathrm{MHz}, 37{ }^{\circ} \mathrm{C}$ ) of the reaction of 4-methoxystyrene $(65 \mathrm{mM})$ using $\left({ }^{\mathrm{Mes}} \mathrm{CCC}\right) \mathrm{Co}$-py $(9 \mathrm{~mol} \%, 5.9 \mathrm{mM})$ and $p-\mathrm{H}_{2}(4 \mathrm{~atm})$ at earth's magnetic field. Top spectrum is a thermal spectrum of 2000 transients of a $350 \mathrm{mM}$ solution of 4methoxystyrene. The bottom spectrum is the first transient, in phased mode, after the $3^{\text {rd }}$ shake introducing $p-\mathrm{H}_{2}$ into the sample at earth's magnetic field. 
${ }^{13} \mathrm{C}$ NMR Spectrum, $150 \mathrm{MHz}$, acetone- $d_{6}\left(90^{\circ}\right.$ pulse $)$
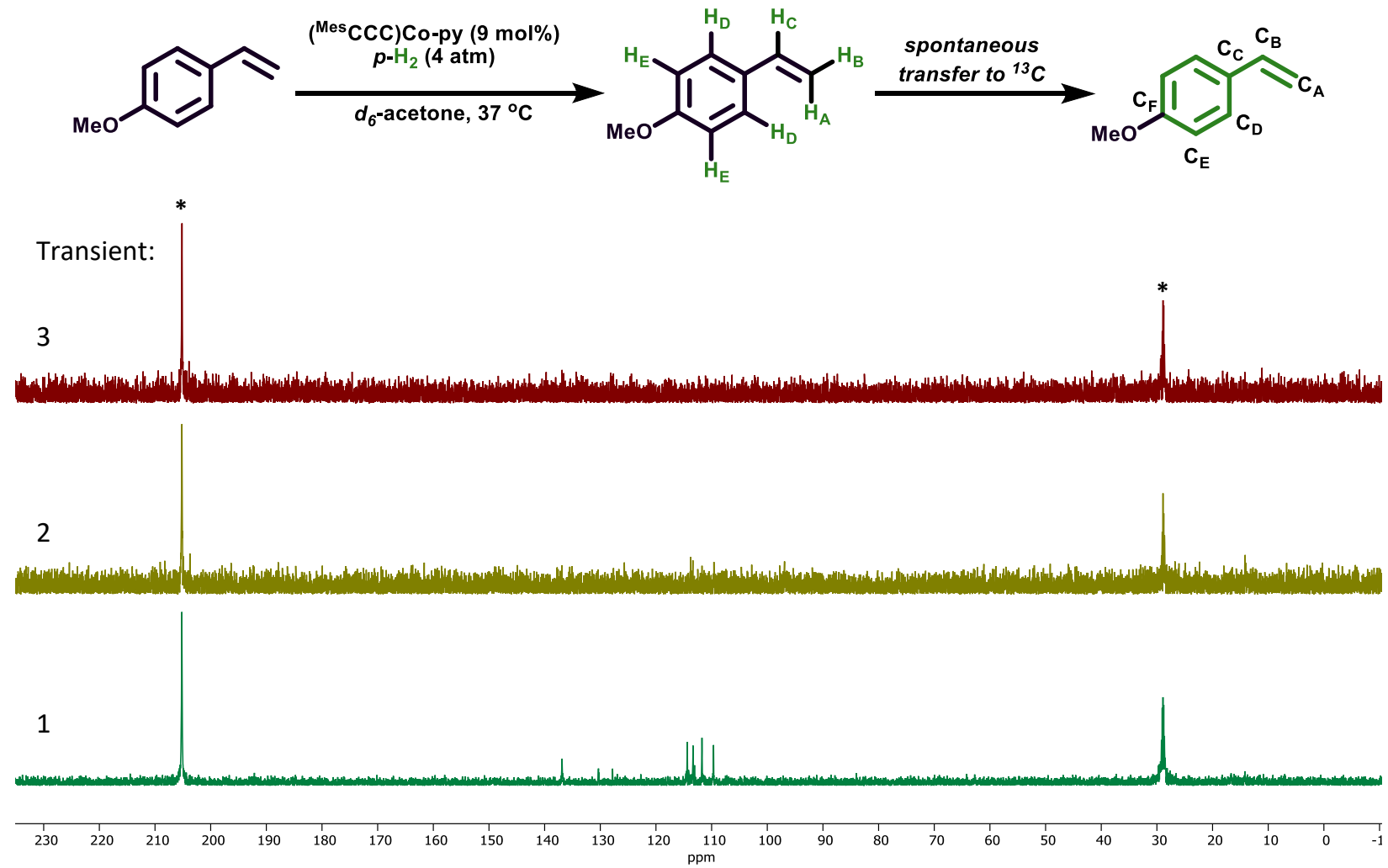

Figure S18. ${ }^{13} \mathrm{C}\left\{{ }^{1} \mathrm{H}\right\}$ NMR spectra (acetone- $d_{6}(*), 150 \mathrm{MHz}, 37{ }^{\circ} \mathrm{C}$ ), in absolute mode, showing the decay of polarization over time of the reaction of 4-methoxystyrene $(65 \mathrm{mM})$ using $\left({ }^{\mathrm{Mes}} \mathrm{CCC}\right) \mathrm{Co}-\mathrm{py}(9 \mathrm{~mol} \%, 5.9$ $\mathrm{mM}$ ) and $p-\mathrm{H}_{2}(4 \mathrm{~atm})$ at earth's magnetic field. No additional shaking occurred between transients. Bottom (green) spectrum is the first collected transient of the $\mathbf{3}^{\text {rd }}$ shake of $p-\mathrm{H}_{2}$ into the sample, followed by an acquisition time of $1.7695 \mathrm{~s}$ to collect the next transient (yellow), with no delay time in between. Subsequent transients were collected in the same fashion. 
${ }^{1} \mathrm{H}$ NMR Spectrum, $600 \mathrm{MHz}$, acetone- $d_{6}\left(45^{\circ}\right.$ pulse $)$
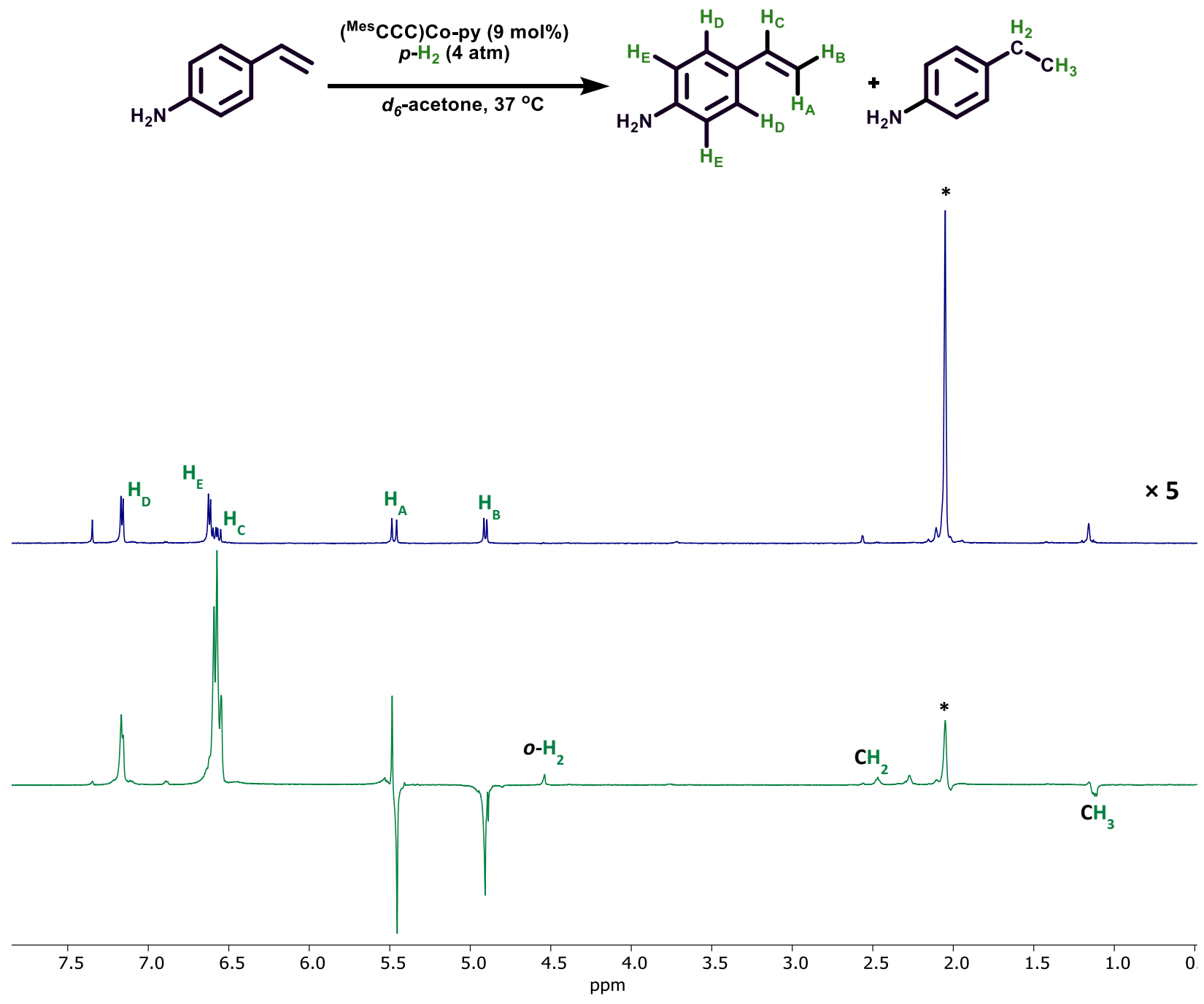

Figure S19. ${ }^{1} \mathrm{H}$ NMR spectra (acetone- $d_{6}(*), 600 \mathrm{MHz}, 37{ }^{\circ} \mathrm{C}$ ) of the reaction of 4-vinylaniline $(65 \mathrm{mM})$ using ( $\left.{ }^{\mathrm{Mes}} \mathrm{CCC}\right) \mathrm{Co}-\mathrm{py}(9 \mathrm{~mol} \%, 5.9 \mathrm{mM})$ and $p-\mathrm{H}_{2}(4 \mathrm{~atm})$ at the 50G fringe line of the magnet. Top: spectrum of the sample before $p-\mathrm{H}_{2}$ is introduced through shaking (thermal spectrum) expanded 5-fold compared to hyperpolarized spectrum. Bottom: First transient using a $45^{\circ}$ pulse after the $\mathbf{1}^{\text {st }}$ shake introducing $p-\mathrm{H}_{2}$ to the sample, showing the hyperpolarization of 4-vinylaniline resonances (SABRE) and resonances associated with 4-ethylaniline (ALTADENA). 
${ }^{1} \mathrm{H}$ NMR Spectrum, $600 \mathrm{MHz}$, acetone- $d_{6}\left(45^{\circ}\right.$ pulse $)$

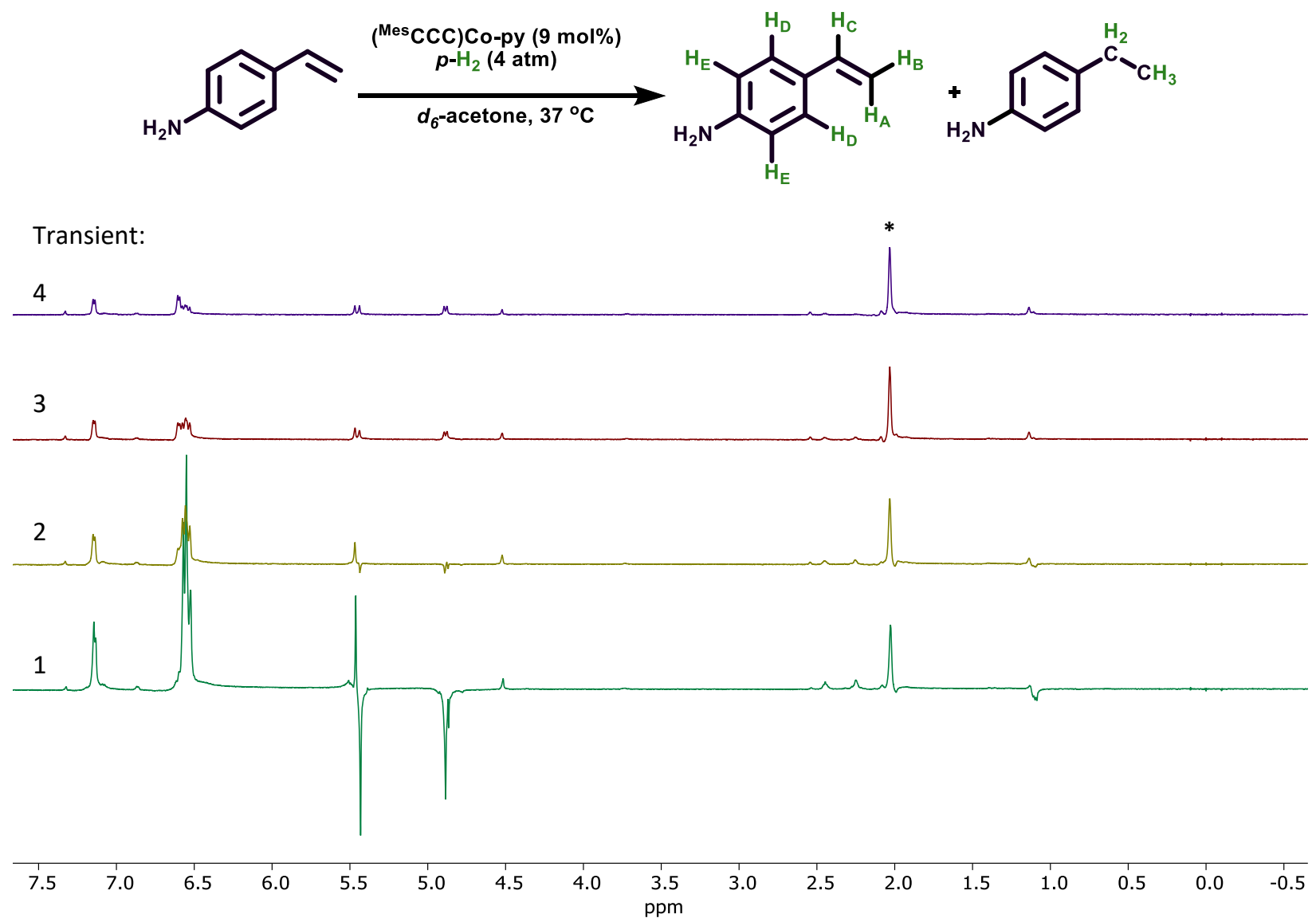

Figure S20. ${ }^{1} \mathrm{H}$ NMR spectra (acetone- $d_{6}(*), 600 \mathrm{MHz}, 37{ }^{\circ} \mathrm{C}$ ) showing the decay of polarization over time of the reaction of 4-vinylaniline $(65 \mathrm{mM})$ using ( $\left.{ }^{\mathrm{Mes}} \mathrm{CCC}\right) \mathrm{Co}$-py $(9 \mathrm{~mol} \%, 5.9 \mathrm{mM})$ and $p-\mathrm{H}_{2}(4 \mathrm{~atm})$ at the $50 \mathrm{G}$ fringe line of the magnet. No additional shaking occurred between transients. Bottom (dark green) spectrum is the first collected transient, followed by an acquisition time of $4.096 \mathrm{~s}$ to collect the next transient (yellow spectrum) with no additional delay between transients. Subsequent transients were collected in the same fashion.

\begin{tabular}{|l|c|c|c|}
\hline Proton $(\mathrm{ppm})$ & Thermal Integration & Hyperpolarized Integration & Enhancement (fold) \\
\hline $\mathrm{H}_{\mathrm{A}}(4.91)$ & 13.34 & -136.83 & -10.3 \\
\hline $\mathrm{H}_{\mathrm{B}}(5.74)$ dispersive & 13.38 & -240.44 & -18.0 \\
\hline $\mathrm{H}_{\mathrm{C}, \mathrm{E}}(6.58$ and 6.62) & 51.05 & 571.73 & 11.2 \\
\hline $\mathrm{H}_{\mathrm{D}}(7.16)$ & 23.13 & 114.32 & 4.9 \\
\hline
\end{tabular}

Table S4. Signal enhancement calculated for the hyperpolarization of the ${ }^{1} \mathrm{H}$ of 4 -vinylaniline. The thermal data is derived from the sample before $p-\mathrm{H}_{2}$ is introduced and the hyperpolarized data is derived from the $\mathbf{1}^{\text {st }}$ transient after shaking the sample. 
${ }^{13} \mathrm{C}\left\{{ }^{1} \mathrm{H}\right\}$ NMR Spectrum, $150 \mathrm{MHz}$, acetone- $d_{6}\left(90^{\circ}\right.$ pulse $)$ - Magnitude mode
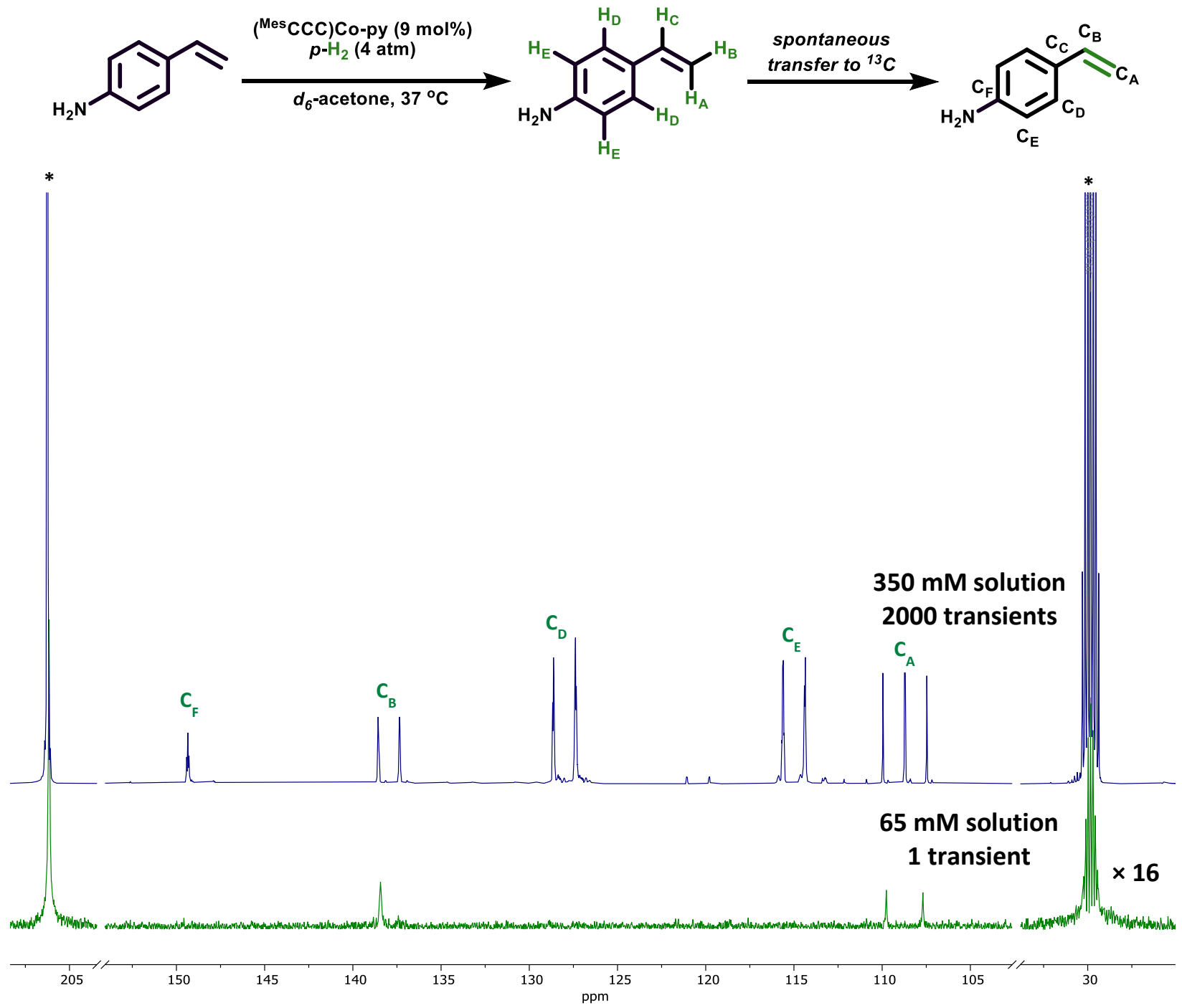

Figure S21. ${ }^{13} \mathrm{C}\left\{{ }^{1} \mathrm{H}\right\}$ NMR spectrum (acetone- $d_{6}(*), 150 \mathrm{MHz}, 37{ }^{\circ} \mathrm{C}$ ) of the reaction of 4-vinylaniline (65 $\mathrm{mM})$ using $\left({ }^{\mathrm{Mes}} \mathrm{CCC}\right) \mathrm{Co}-\mathrm{py}(9 \mathrm{~mol} \%, 5.9 \mathrm{mM})$ and $p-\mathrm{H}_{2}(4 \mathrm{~atm})$ at earth's magnetic field, with peakless regions removed. Top spectrum is a thermal spectrum of 2000 transients of a $350 \mathrm{mM}$ solution of 4vinylaniline. The bottom spectrum is the first transient, in magnitude mode, after the $3^{\text {rd }}$ shake introducing $p-\mathrm{H}_{2}$ into the sample at earth's magnetic field, expanded 16-fold compared to the top spectrum. The bottom sample shows the polarization of $\mathrm{C}_{\mathrm{A}}$ and $\mathrm{C}_{\mathrm{B}}$. 
${ }^{13} \mathrm{C}\left\{{ }^{1} \mathrm{H}\right\}$ NMR Spectrum, $150 \mathrm{MHz}$, acetone- $d_{6}\left(90^{\circ}\right.$ pulse $)$ - Phased mode
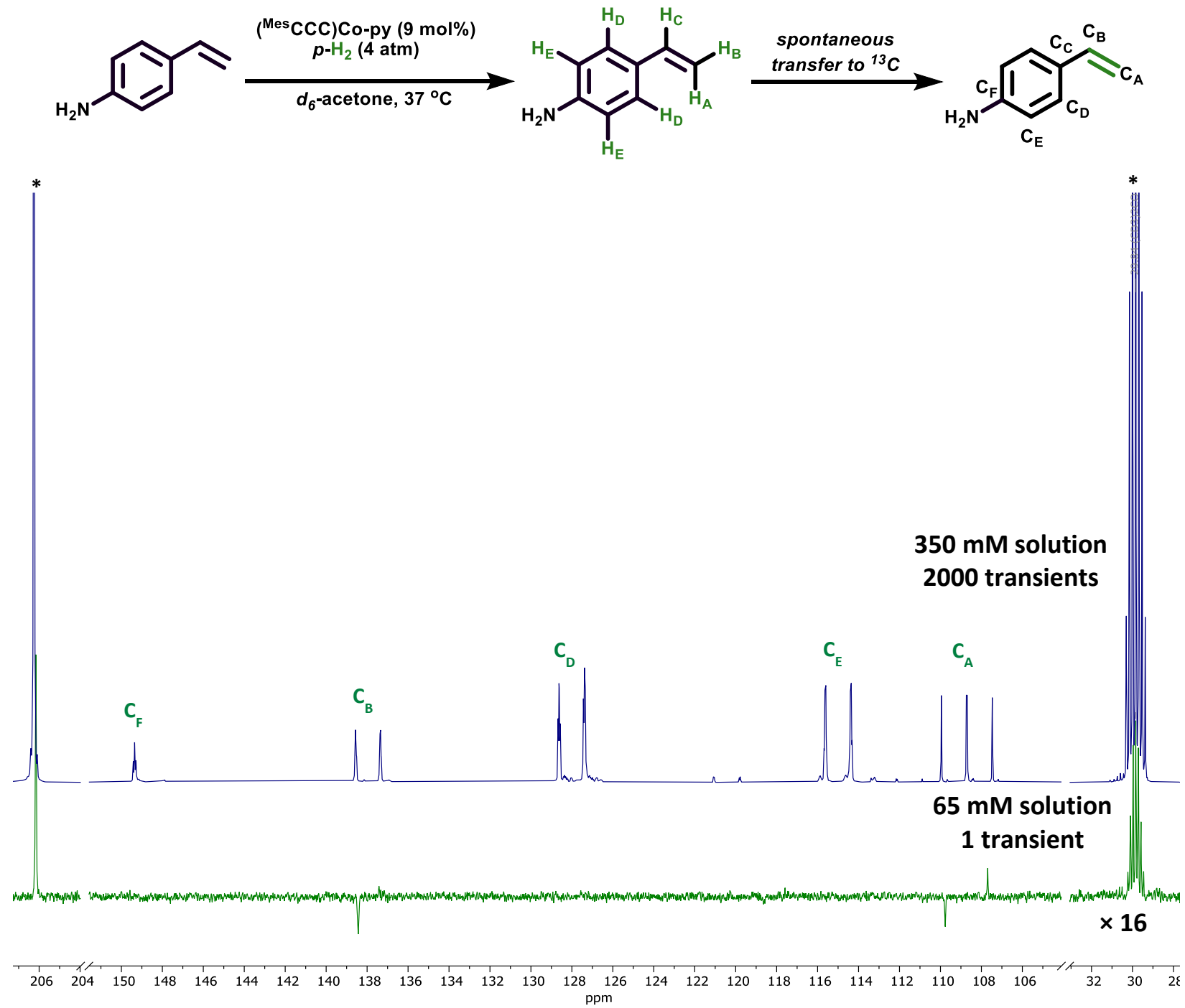

Figure S22. Olefinic region of the ${ }^{13} \mathrm{C}\left\{{ }^{1} \mathrm{H}\right\}$ NMR spectra (acetone- $d_{6}(*), 150 \mathrm{MHz}, 37{ }^{\circ} \mathrm{C}$ ) of the reaction of 4-vinylaniline $(65 \mathrm{mM})$ using $\left({ }^{\mathrm{Mes}} \mathrm{CCC}\right) \mathrm{Co}$-py $(9 \mathrm{~mol} \%, 5.9 \mathrm{mM})$ and $p-\mathrm{H}_{2}(4 \mathrm{~atm})$ at earth's magnetic field. Top spectrum is a thermal spectrum of 2000 transients of a $350 \mathrm{mM}$ solution of 4 -vinylaniline. The bottom spectrum is the first transient, in phased mode, after the $3^{\text {rd }}$ shake introducing $p-\mathrm{H}_{2}$ into the sample at earth's magnetic field, expanded 16-fold compared to the top spectrum. The bottom sample shows the polarization of $\mathrm{C}_{\mathrm{A}}$ and $\mathrm{C}_{\mathrm{B}}$. 
${ }^{13} \mathrm{C}\left\{{ }^{1} \mathrm{H}\right\}$ NMR Spectrum, $150 \mathrm{MHz}$, acetone- $d_{6}\left(90^{\circ}\right.$ pulse $)$
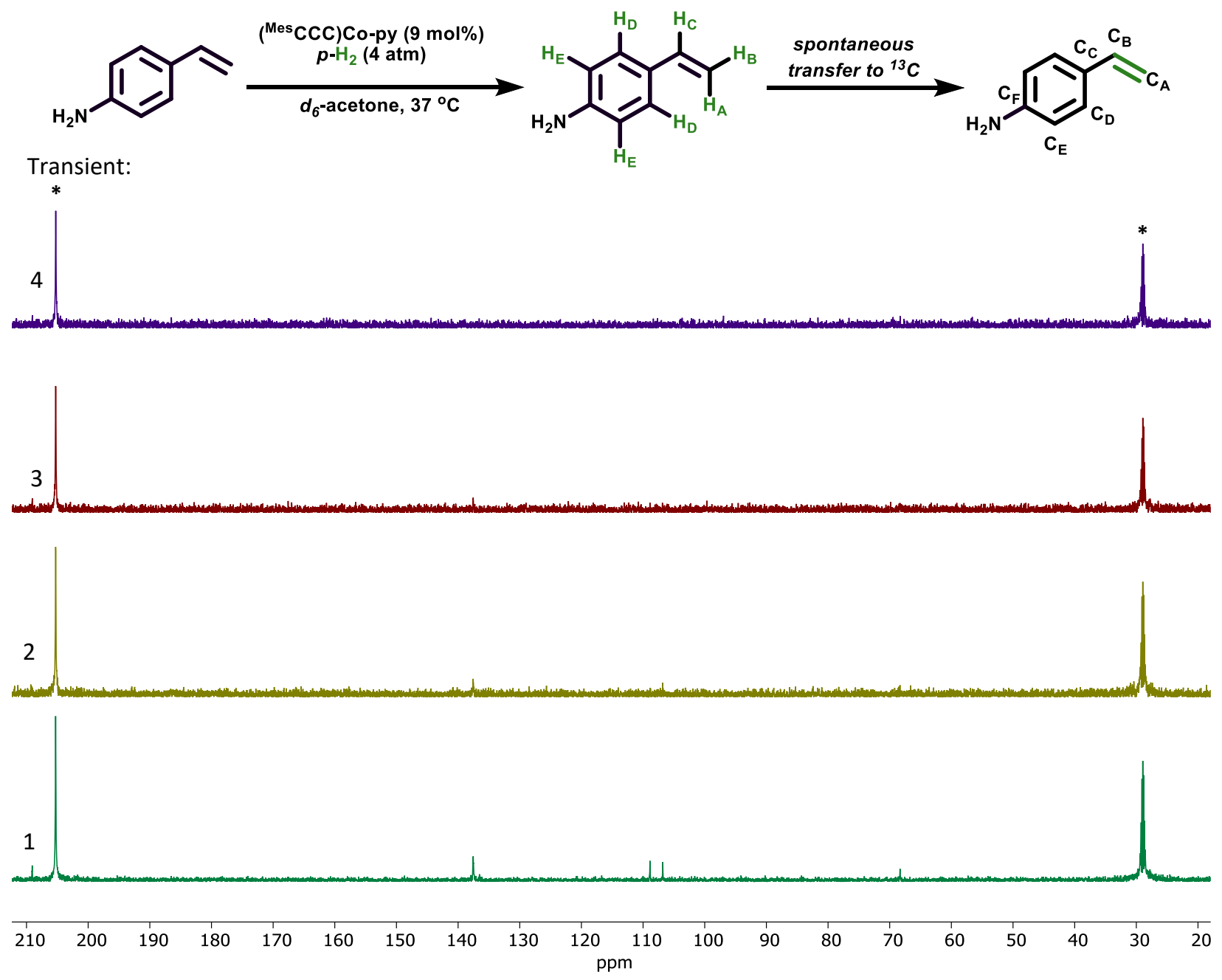

Figure S23. ${ }^{13} \mathrm{C}$ NMR spectra (acetone- $d_{6}(*), 150 \mathrm{MHz}, 37{ }^{\circ} \mathrm{C}$ ), in magnitude mode, showing the decay of polarization over time of the reaction of 4-vinylaniline $(65 \mathrm{mM})$ using $\left({ }^{\mathrm{Mes}} \mathrm{CCC}\right) \mathrm{Co}$-py $(9 \mathrm{~mol} \%, 5.9$ $\mathrm{mM}$ ) and $p-\mathrm{H}_{2}(4 \mathrm{~atm})$ at earth's magnetic field. No additional shaking occurred between transients. Bottom (green) spectrum is the first collected transient of the $\mathbf{3}^{\text {rd }}$ shake of $p-\mathrm{H}_{2}$ into the sample, followed by an acquisition time of $1.7695 \mathrm{~s}$ to collect the next transient (yellow), with no delay time in between. Subsequent transients were collected in the same fashion. 
${ }^{1} \mathrm{H}$ NMR Spectrum, $600 \mathrm{MHz}$, acetone- $d_{6}\left(45^{\circ}\right.$ pulse $)$
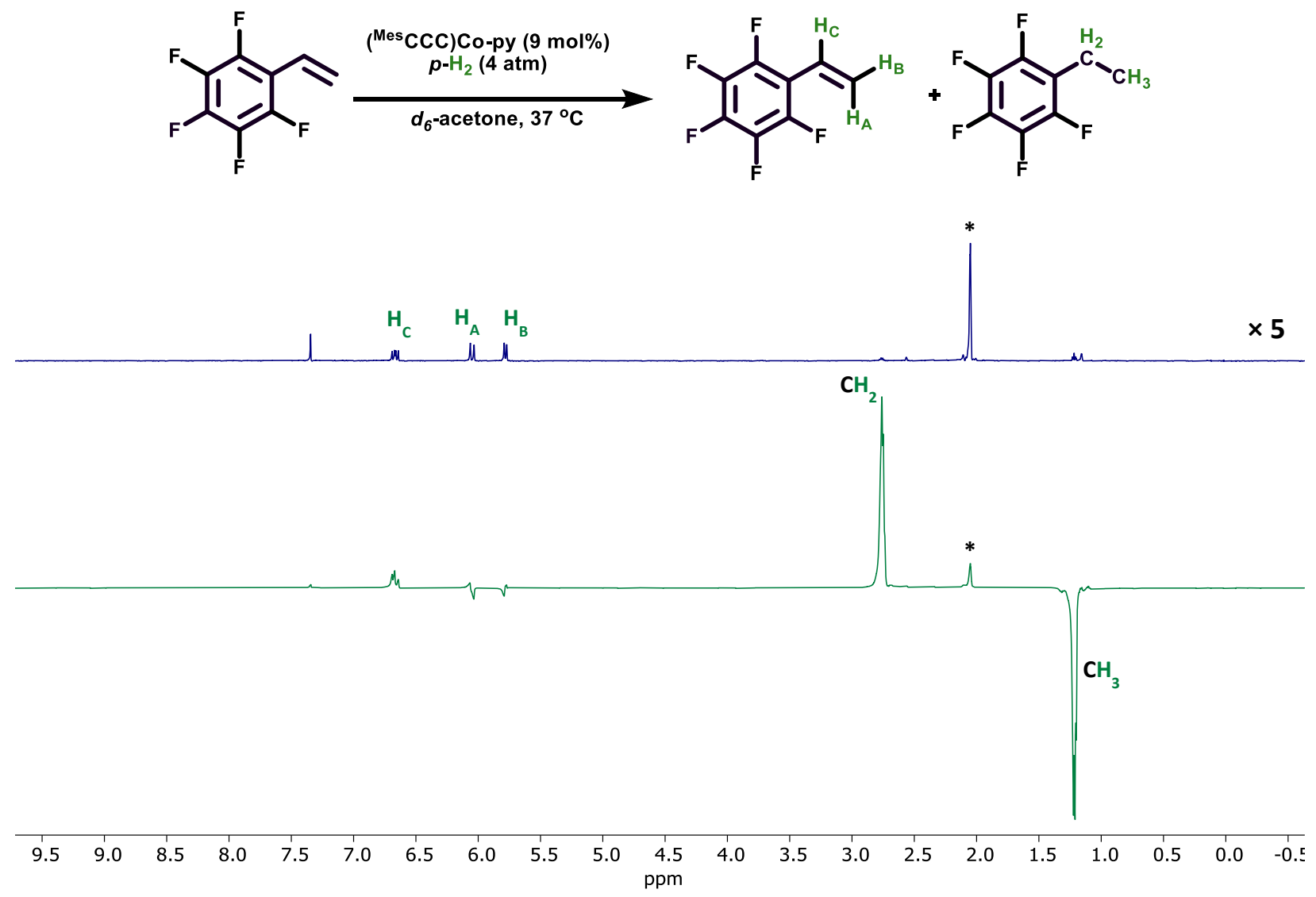

Figure S24. ${ }^{1} \mathrm{H}$ NMR spectra (acetone- $d_{6}(*), 600 \mathrm{MHz}, 37{ }^{\circ} \mathrm{C}$ ) of the reaction of 2,3,4,5,6pentafluorostyrene $(65 \mathrm{mM})$ using $\left({ }^{\mathrm{Mes}} \mathrm{CCC}\right) \mathrm{Co}-\mathrm{py}(9 \mathrm{~mol} \%, 5.9 \mathrm{mM})$ and $p-\mathrm{H}_{2}(4 \mathrm{~atm})$ at the $50 \mathrm{G}$ fringe line of the magnet. Top: spectrum of the sample before $p-\mathrm{H}_{2}$ is introduced through shaking (thermal spectrum) expanded 5-fold compared to hyperpolarized spectrum. Bottom: First transient using a $45^{\circ}$ pulse after the $\mathbf{1}^{\text {st }}$ shake introducing $p-\mathrm{H}_{2}$ to the sample, showing the hyperpolarization of 4-fluorostyrene resonances (SABRE) and resonances associated with ethyl-2,3,4,5,6-pentafluorobenzene (ALTADENA). 
${ }^{1} \mathrm{H}$ NMR Spectrum, $600 \mathrm{MHz}$, acetone- $d_{6}\left(45^{\circ}\right.$ pulse $)$

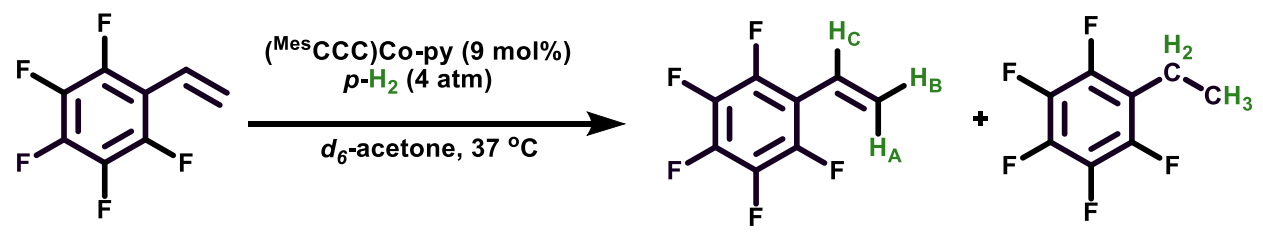

Transient:

3
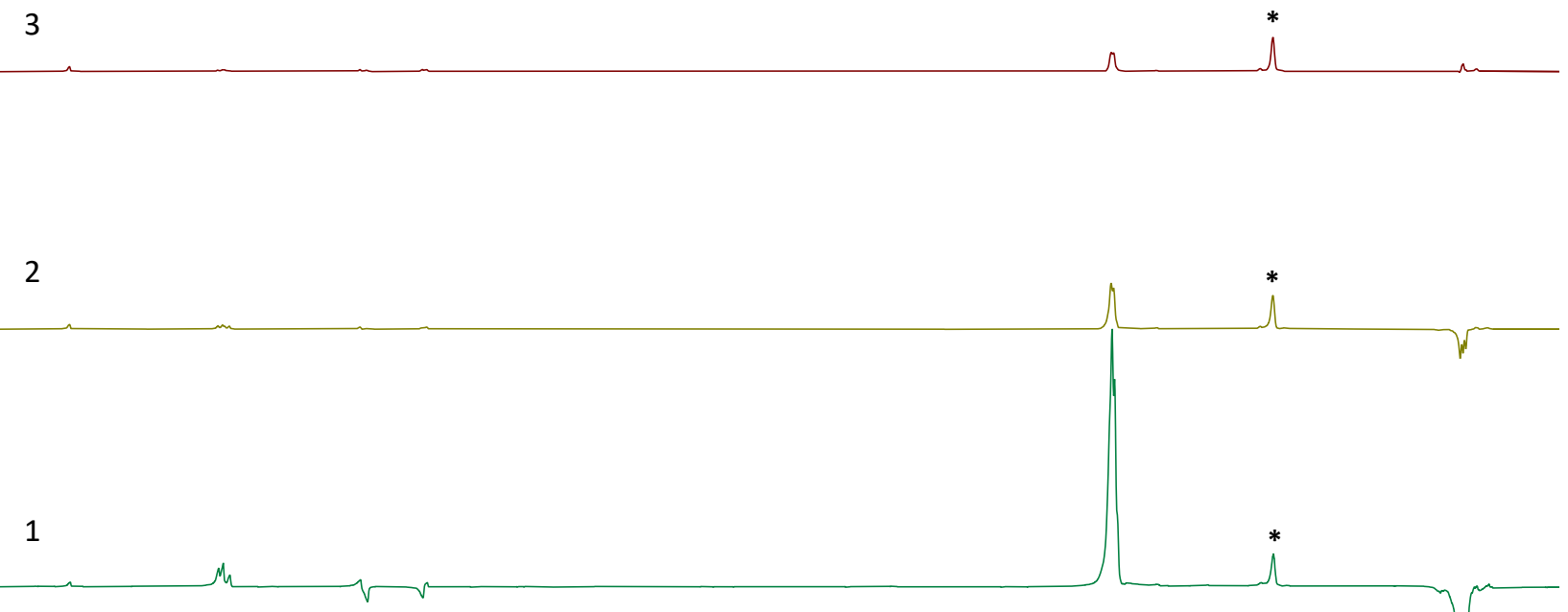

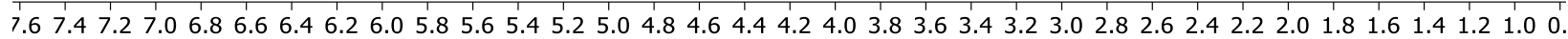
$\mathrm{ppm}$

Figure S25. ${ }^{1} \mathrm{H}$ NMR spectra (acetone- $d_{6}(*), 600 \mathrm{MHz}, 37^{\circ} \mathrm{C}$ ) showing the decay of polarization over time of the reaction of 2,3,4,5,6-pentafluorostyrene $(65 \mathrm{mM})$ using $\left({ }^{\mathrm{Mes}} \mathrm{CCC}\right) \mathrm{Co}-$ py $(9 \mathrm{~mol} \%, 5.9 \mathrm{mM})$ and $p-\mathrm{H}_{2}(4 \mathrm{~atm})$ at the $50 \mathrm{G}$ fringe line of the magnet. No additional shaking occurred between transients. Bottom (dark green) spectrum is the first collected transient of the $\mathbf{1}^{\text {st }}$ shake, followed by an acquisition time of $4.096 \mathrm{~s}$ to collect the next transient (second spectrum from the bottom) with no additional delay between transients. Subsequent transients were collected in the same fashion. 
${ }^{1} \mathrm{H}$ NMR Spectrum, $600 \mathrm{MHz}$, acetone- $d_{6}\left(45^{\circ}\right.$ pulse $)$
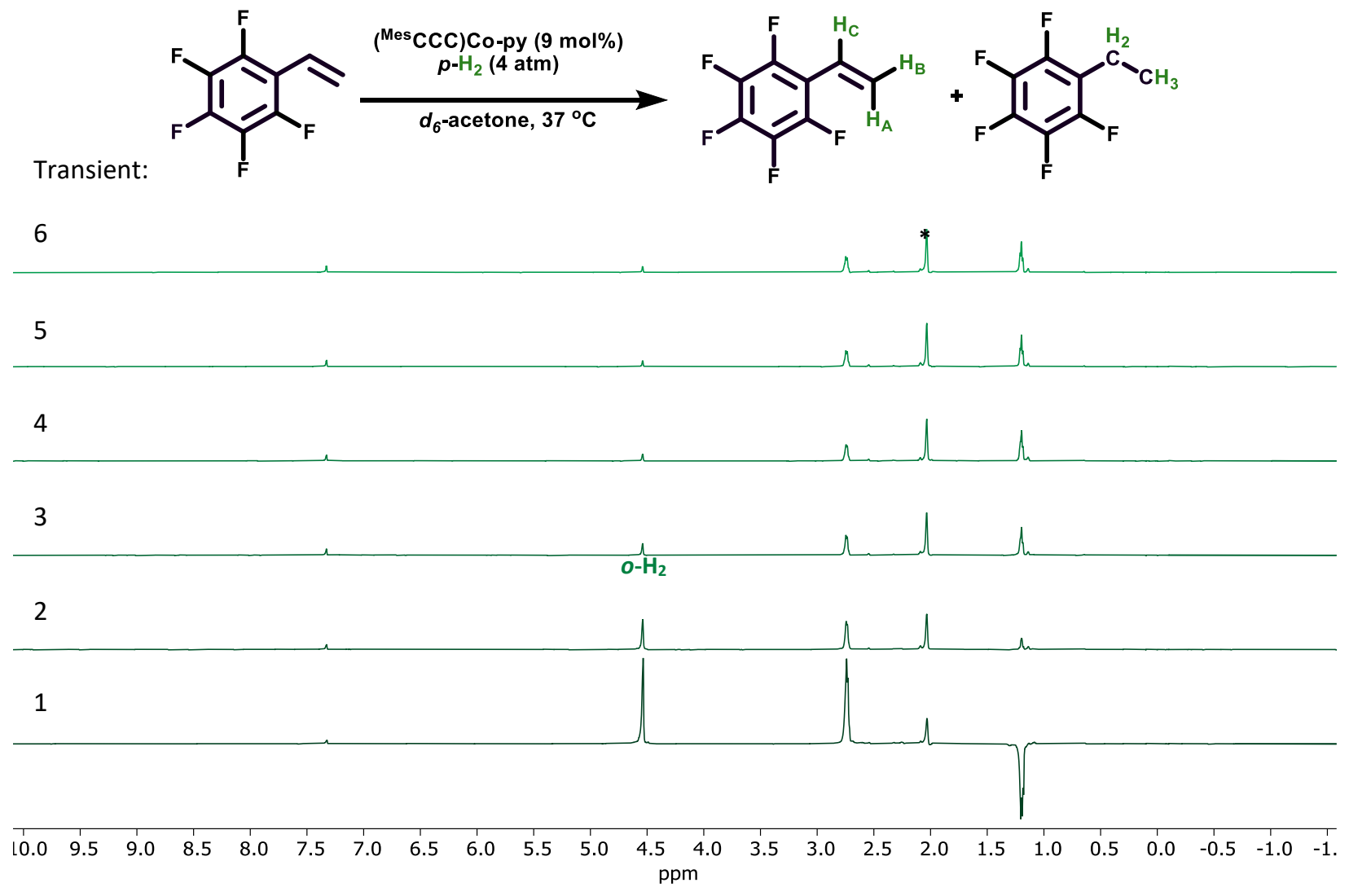

Figure S26. ${ }^{1} \mathrm{H}$ NMR spectra (acetone- $d_{6}(*), 600 \mathrm{MHz}, 37^{\circ} \mathrm{C}$ ) showing the decay of polarization over time of the reaction of 2,3,4,5,6-pentafluorostyrene $(65 \mathrm{mM})$ using $\left({ }^{\mathrm{Mes}} \mathrm{CCC}\right) \mathrm{Co}$-py $(9 \mathrm{~mol} \%, 5.9 \mathrm{mM})$ and $p-\mathrm{H}_{2}(4 \mathrm{~atm})$ at the $50 \mathrm{G}$ fringe line of the magnet. No additional shaking occurred between transients. Bottom (dark green) spectrum is the first collected transient of the $2^{\text {nd }}$ shake, followed by an acquisition time of $4.096 \mathrm{~s}$ to collect the next transient (second spectrum from the bottom) with no additional delay between transients. Subsequent transients were collected in the same fashion.

\begin{tabular}{|l|c|c|c|}
\hline Proton $(\mathrm{ppm})$ & Thermal Integration & Hyperpolarized Integration & Enhancement (fold) \\
\hline $\mathrm{H}_{\mathrm{A}}(5.79)$ & 56.55 & -59.36 & -1.0 \\
\hline $\mathrm{H}_{\mathrm{B}}(6.05)$ & 55.59 & -85.9 & -1.5 \\
\hline $\mathrm{H}_{\mathrm{C}}(6.67)$ & 56.49 & 140.22 & 2.5 \\
\hline
\end{tabular}

Table S5. Signal enhancement calculated for the hyperpolarization of the ${ }^{1} \mathrm{H}$ of 2,3,4,5,6pentafluorostyrene. The thermal data is derived from the sample before $p-\mathrm{H}_{2}$ is introduced and the hyperpolarized data is derived from the first transient after shaking the sample. 
${ }^{19}$ F NMR Spectrum, $564 \mathrm{MHz}$, acetone- $d_{6}\left(90^{\circ}\right.$ pulse $)$
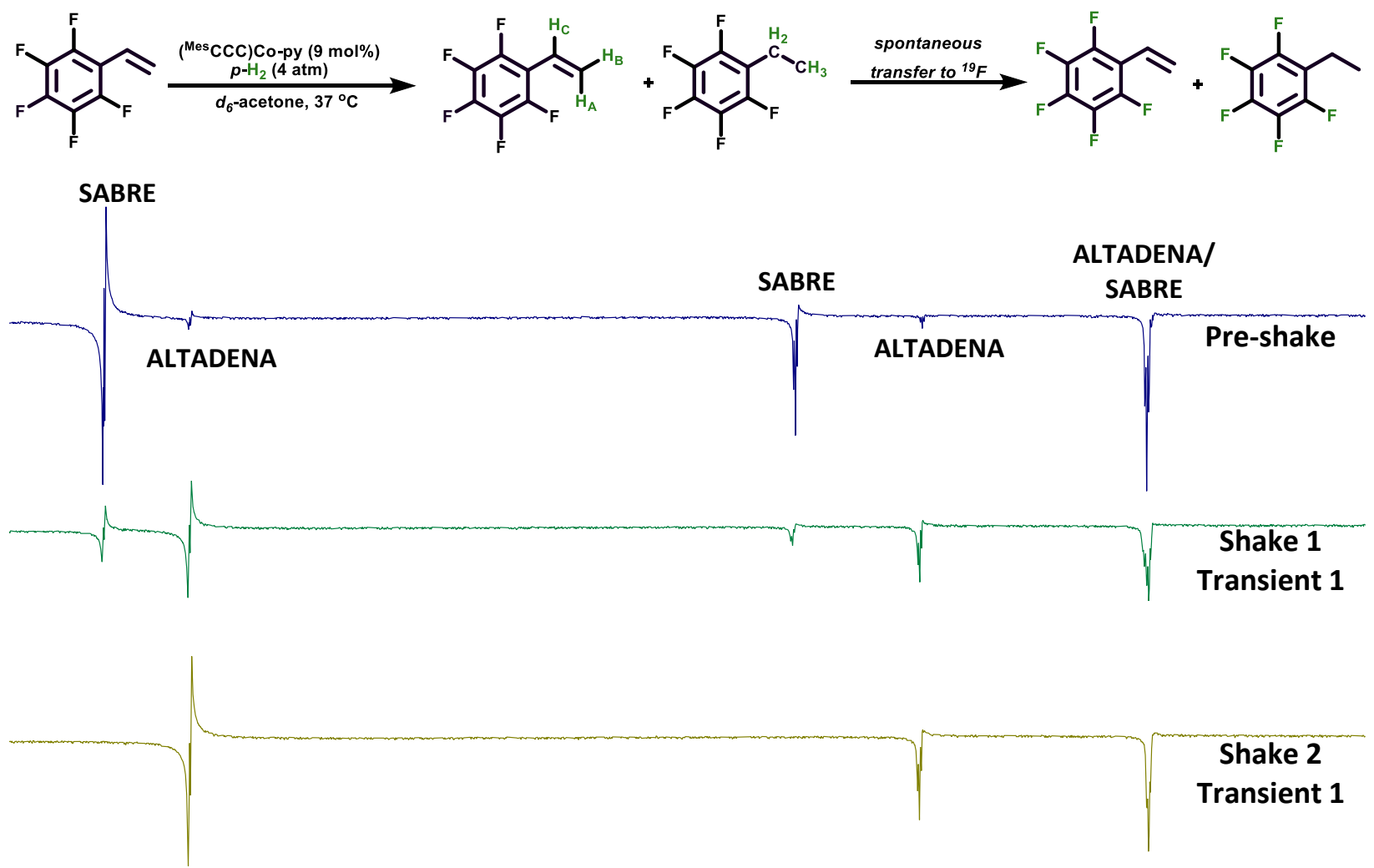

$\begin{array}{lllllllllllllllllllllllllllllllllll}-144 & -145 & -146 & -147 & -148 & -149 & -150 & -151 & -152 & -153 & -154 & -155 & -156 & -157 & -158 & -159 & -160 & -161 & -162 & -163 & -164 & -165 & -166 & -167 & -168 & -169\end{array}$

Figure S27. ${ }^{19} \mathrm{~F}$ NMR spectra (acetone- $d_{6}, 564 \mathrm{MHz}, 37{ }^{\circ} \mathrm{C}$ of the reaction of 2,3,4,5,6-pentafluorostyrene (65 mM) using ( $\left.{ }^{\mathrm{Mes}} \mathrm{CCC}\right) \mathrm{Co}-\mathrm{py}(9 \mathrm{~mol} \%, 5.9 \mathrm{mM})$ and $p-\mathrm{H}_{2}$ (4 atm) displayed in phased mode. Top (blue) spectrum is the sample before $p-\mathrm{H}_{2}$ is introduced. Middle (green) spectrum is the first transient of the first shake of $p-\mathrm{H}_{2}$ into the solution at the 50G fringe line of the magnet, which shows the growth of the hydrogenated product resonances. Bottom (yellow) spectrum is the first transient of the second shake of $p$ $\mathrm{H}_{2}$ into the solution at earth's magnetic field, which shows the disappearance of the olefin. 
${ }^{1} \mathrm{H}$ NMR Spectrum, $600 \mathrm{MHz}$, acetone- $d_{6}\left(45^{\circ}\right.$ pulse $)$
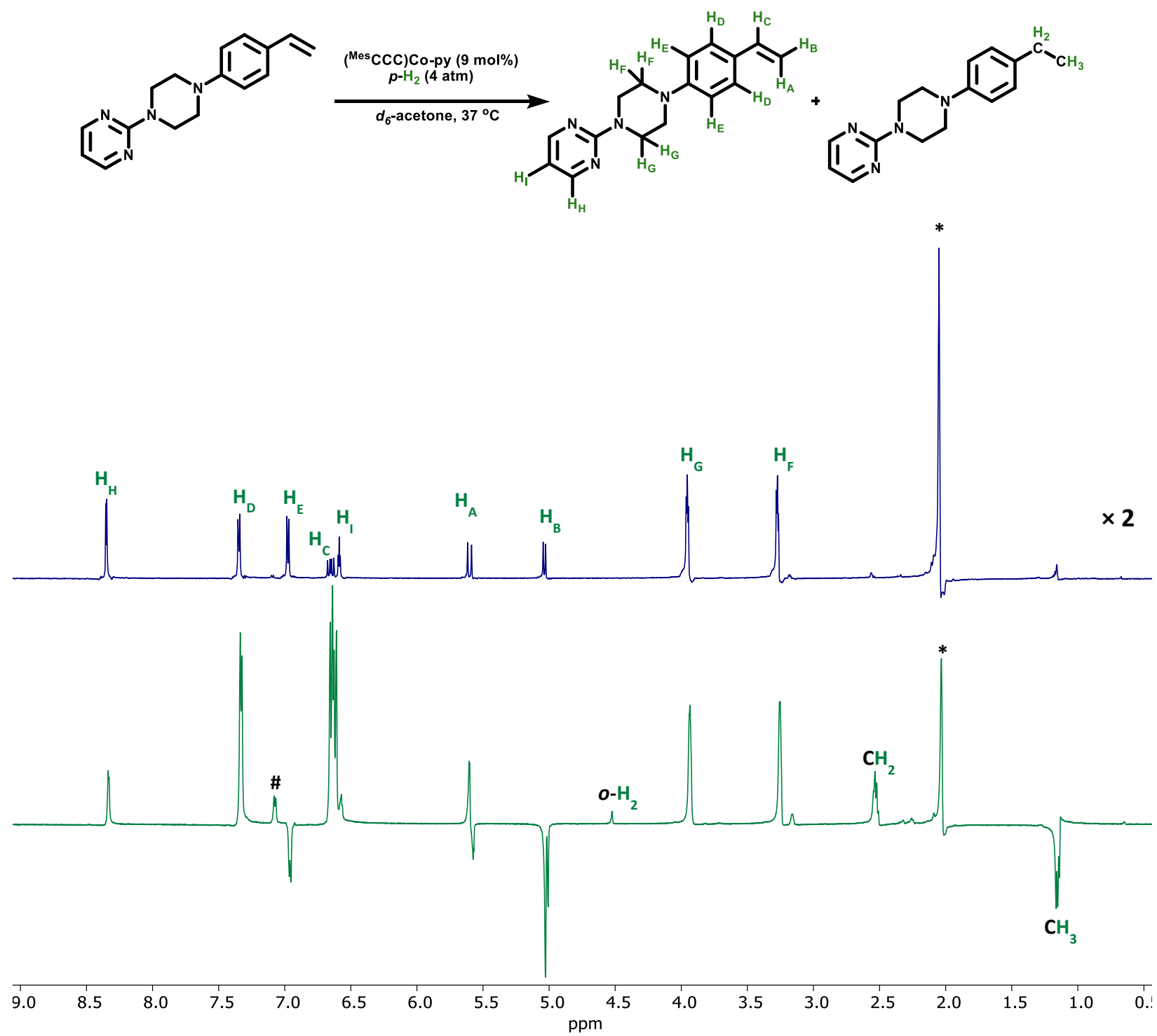

Figure S28. ${ }^{1} \mathrm{H}$ NMR spectra (acetone- $\left.d_{6}(*), 600 \mathrm{MHz}, 37{ }^{\circ} \mathrm{C}\right)$ of the reaction of 2-(4-(4vinylphenyl)piperazin-1-yl)pyrimidine $(65 \mathrm{mM})$ using $\left({ }^{\mathrm{Mes}} \mathrm{CCC}\right) \mathrm{Co}-\mathrm{py}(9 \mathrm{~mol} \%, 5.9 \mathrm{mM})$ and $p-\mathrm{H}_{2}(4 \mathrm{~atm})$ at the 50G fringe line of the magnet. Top: spectrum of the sample before $p-\mathrm{H}_{2}$ is introduced through shaking (thermal spectrum) expanded 2-fold compared to hyperpolarized spectrum. Bottom: First transient using a $45^{\circ}$ pulse after the $\mathbf{1}^{\text {st }}$ shake introducing $p-\mathrm{H}_{2}$ to the sample, showing the hyperpolarization of 2-(4-(4vinylphenyl)piperazin-1-yl)pyrimidine resonances (SABRE) and resonances associated with hydrogenated product (ALTADENA, \#). 
${ }^{1} \mathrm{H}$ NMR Spectrum, $600 \mathrm{MHz}$, acetone- $d_{6}\left(45^{\circ}\right.$ pulse $)$
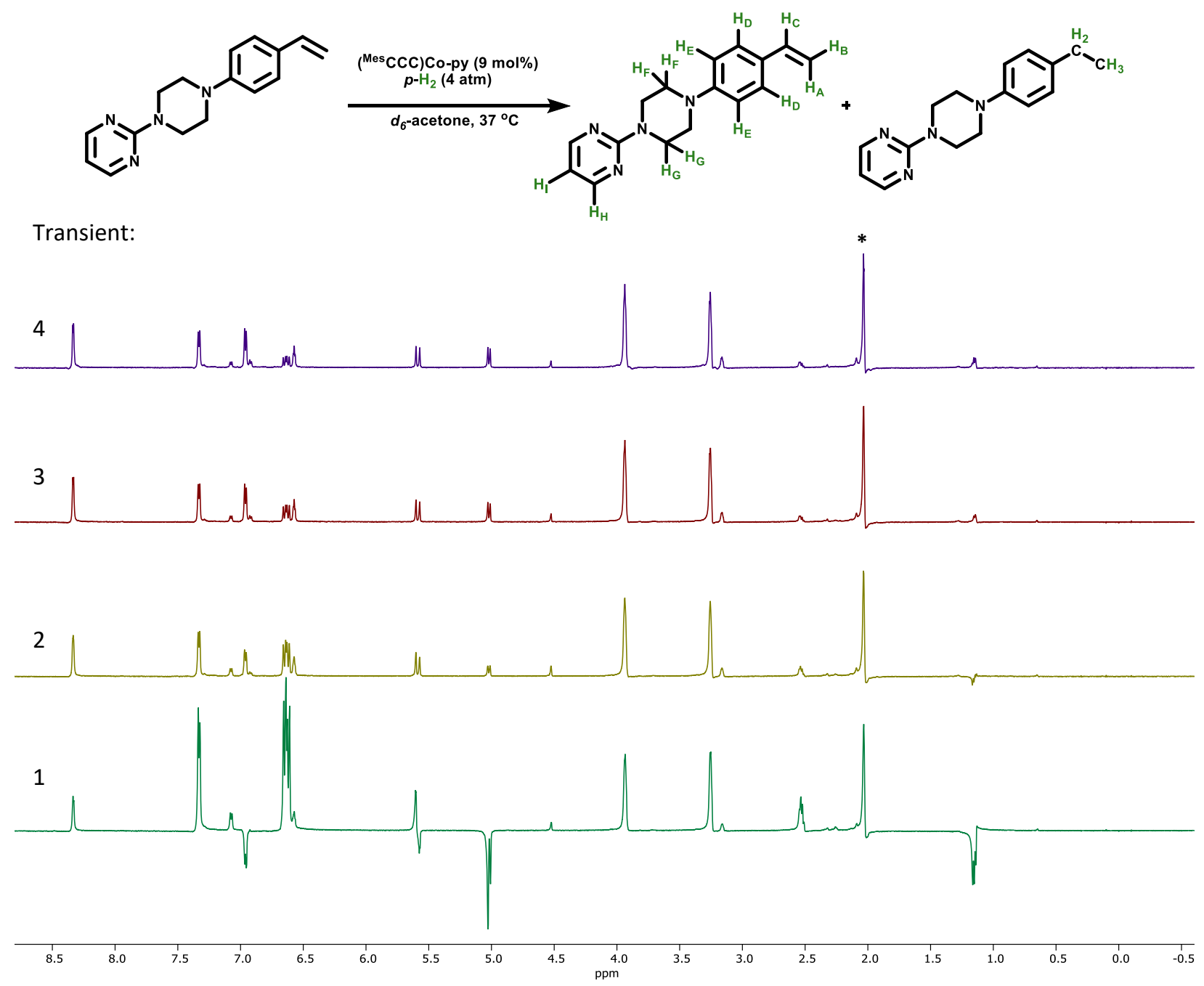

Figure S29. ${ }^{1} \mathrm{H}$ NMR spectra (acetone- $d_{6}(*), 600 \mathrm{MHz}, 37^{\circ} \mathrm{C}$ ) showing the decay of polarization over time of the reaction of 2-(4-(4-vinylphenyl)piperazin-1-yl)pyrimidine $(65 \mathrm{mM})$ using $\left({ }^{\mathrm{Mes}} \mathrm{CCC}\right) \mathrm{Co}-\mathrm{py}(9$ $\mathrm{mol} \%, 5.9 \mathrm{mM})$ and $p-\mathrm{H}_{2}(4 \mathrm{~atm})$ at the $50 \mathrm{G}$ fringe line of the magnet. No additional shaking occurred between transients. Bottom (dark green) spectrum is the first collected transient, followed by an acquisition time of $4.096 \mathrm{~s}$ to collect the next transient (yellow spectrum) with no additional delay between transients. Subsequent transients were collected in the same fashion. 


\begin{tabular}{|l|c|c|c|}
\hline Proton $(\mathrm{ppm})$ & Thermal Integration & Hyperpolarized Integration & Enhancement (fold) \\
\hline $\mathrm{H}_{\mathrm{A}}(5.03)$ & 42.04 & -185.88 & -4.4 \\
\hline $\mathrm{H}_{\mathrm{B}}(5.60)$ dispersive & 41.95 & 92.86 & 2.2 \\
\hline $\mathrm{H}_{\mathrm{C}, \mathrm{I}}(6.74,6.58)$ & 44.07 & 559.19 & 12.7 \\
\hline $\mathrm{H}_{\mathrm{D}}(7.34)$ & 97.48 & 275.36 & 2.8 \\
\hline $\mathrm{H}_{\mathrm{E}}(6.97)$ & 90.19 & -80.53 & -0.9 \\
\hline $\mathrm{H}_{\mathrm{F}}(3.28)$ & 175.85 & 182.21 & 1.0 \\
\hline $\mathrm{H}_{\mathrm{G}}(3.95)$ & 185.78 & 184.11 & 1.0 \\
\hline $\mathrm{H}_{\mathrm{H}}(8.35)$ & 89.52 & 56.08 & 0.6 \\
\hline
\end{tabular}

Table S6. Signal enhancement calculated for the hyperpolarization of the ${ }^{1} \mathrm{H}$ of 2-(4-(4vinylphenyl)piperazin-1-yl)pyrimidine. The thermal data is derived from the sample before $p-\mathrm{H}_{2}$ is introduced and the hyperpolarized data is derived from the first transient after shaking the sample. 
${ }^{1} \mathrm{H}$ NMR Spectrum, $600 \mathrm{MHz}$, acetone- $d_{6}\left(45^{\circ}\right.$ pulse $)$<smiles>C=Cc1ccc(N(C)CC(=O)OCC)cc1</smiles>

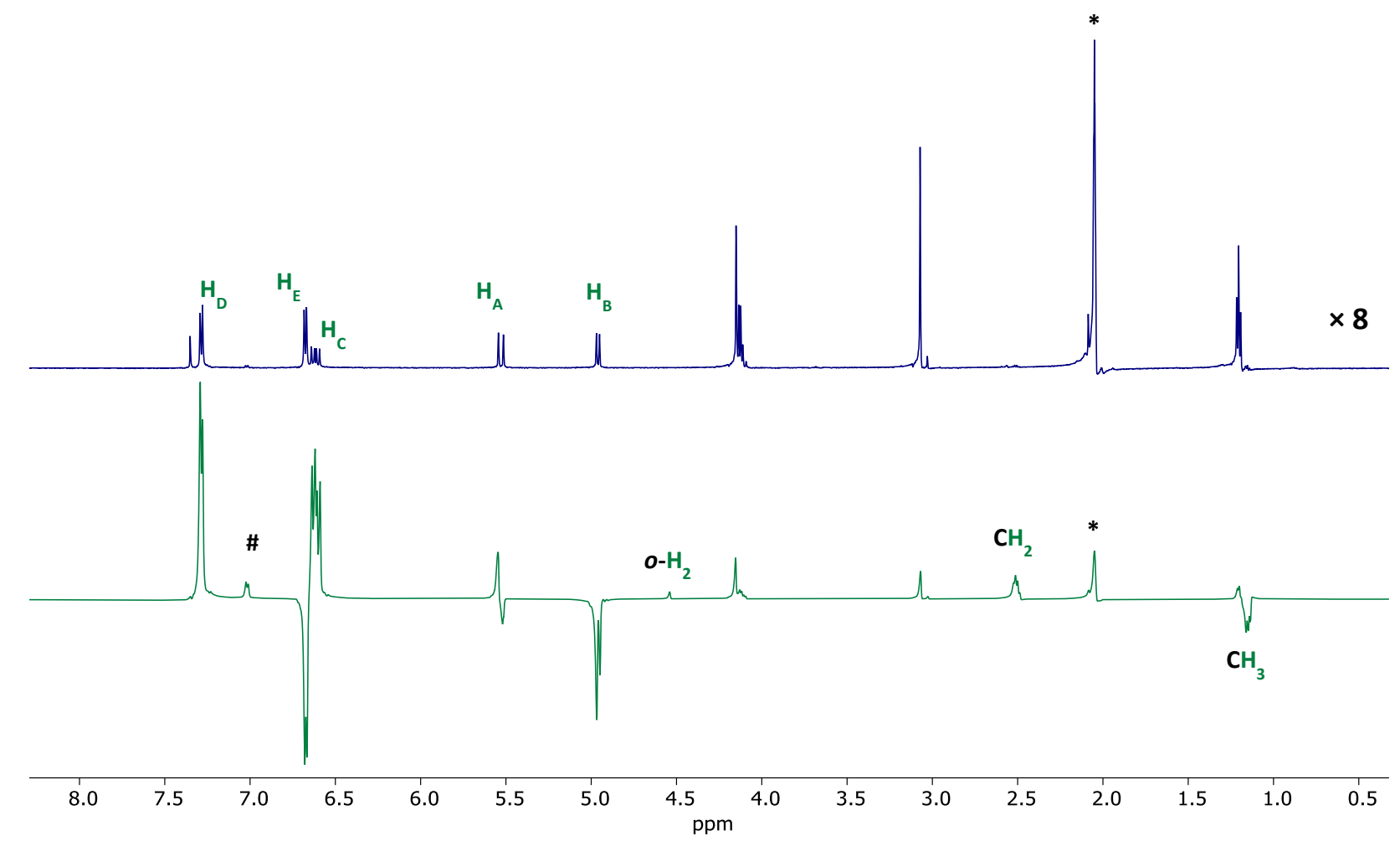

Figure S30. ${ }^{1} \mathrm{H}$ NMR spectra (acetone- $\left.d_{6}(*), 600 \mathrm{MHz}, 37^{\circ} \mathrm{C}\right)$ of the reaction of ethyl N-methyl-N-(4vinylphenyl)glycinate $(65 \mathrm{mM})$ using $\left({ }^{\mathrm{Mes}} \mathrm{CCC}\right) \mathrm{Co}-\mathrm{py}(9 \mathrm{~mol} \%, 5.9 \mathrm{mM})$ and $p-\mathrm{H}_{2}(4 \mathrm{~atm})$ at the $50 \mathrm{G}$ fringe line of the magnet. Top: spectrum of the sample before $p-\mathrm{H}_{2}$ is introduced through shaking (thermal spectrum) expanded 8-fold compared to hyperpolarized spectrum. Bottom: First transient using a $45^{\circ}$ pulse after the $\mathbf{1}^{\text {st }}$ shake introducing $p-\mathrm{H}_{2}$ to the sample, showing the hyperpolarization of Ethyl N-methyl-N-(4vinylphenyl)glycinate resonances (SABRE) and resonances associated with hydrogenated product (ALTADENA, \#). 
${ }^{1} \mathrm{H}$ NMR Spectrum, $600 \mathrm{MHz}$, acetone- $d_{6}\left(45^{\circ}\right.$ pulse $)$
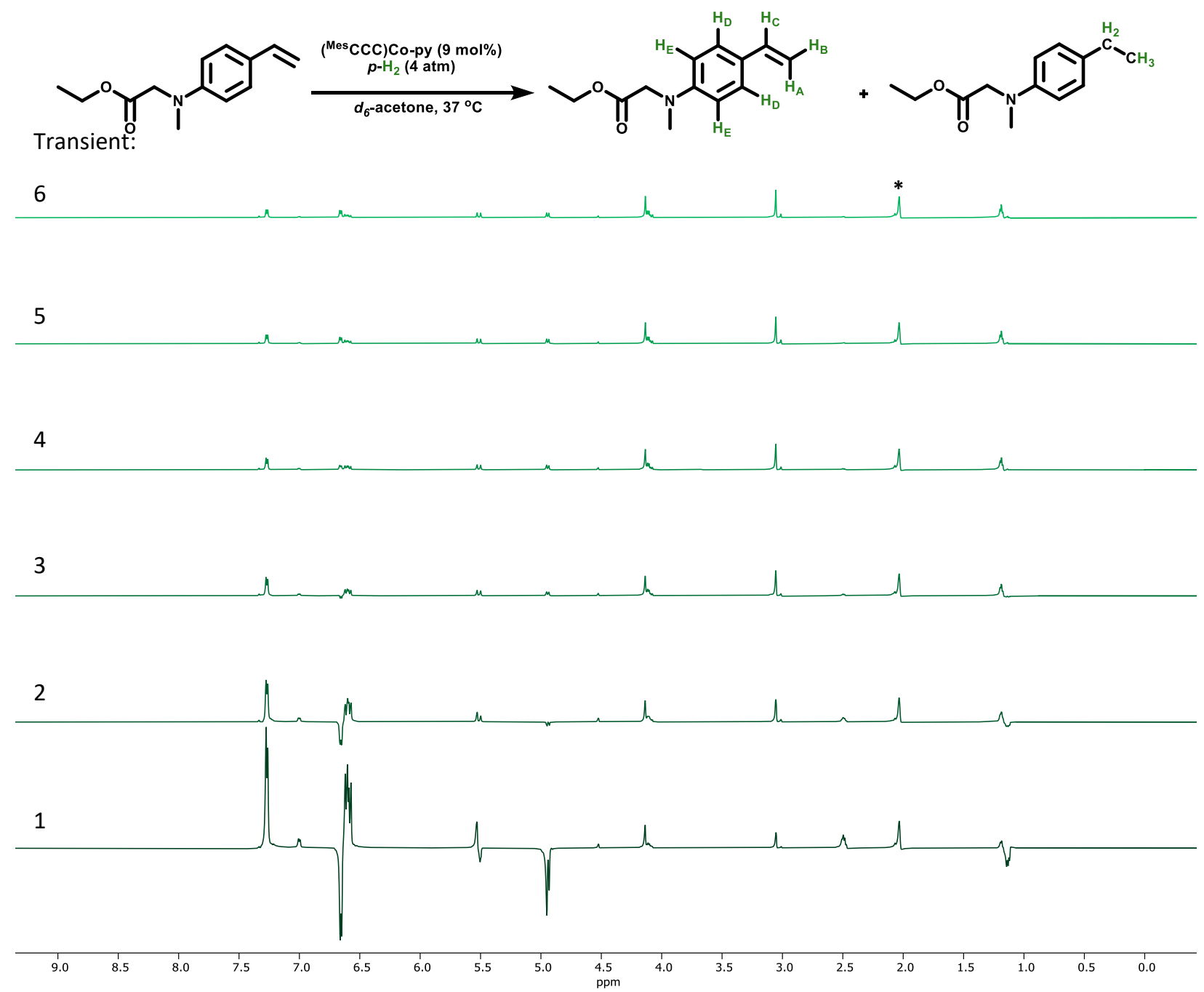

Figure S31. ${ }^{1} \mathrm{H}$ NMR spectra (acetone- $d_{6}(*), 600 \mathrm{MHz}, 37^{\circ} \mathrm{C}$ ) showing the decay of polarization over time of the reaction of ethyl N-methyl-N-(4-vinylphenyl)glycinate $(65 \mathrm{mM})$ using $\left({ }^{\mathrm{Mes}} \mathrm{CCC}\right) \mathrm{Co}-\mathrm{py}(9 \mathrm{~mol} \%$, $5.9 \mathrm{mM})$ and $p-\mathrm{H}_{2}(4 \mathrm{~atm})$ at the $50 \mathrm{G}$ fringe line of the magnet. No additional shaking occurred between transients. Bottom (dark green) spectrum is the first collected transient, followed by an acquisition time of $4.096 \mathrm{~s}$ to collect the next transient with no additional delay between transients. Subsequent transients were collected in the same fashion. 


\begin{tabular}{|l|c|c|c|}
\hline Proton $(\mathrm{ppm})$ & Thermal Integration & Hyperpolarized Integration & Enhancement (fold) \\
\hline $\mathrm{H}_{\mathrm{A}}(4.95)$ & 78.79 & -910.9 & -11.6 \\
\hline $\mathrm{H}_{\mathrm{B}}(5.52)$ dispersive & 79.79 & 598.64 & 7.5 \\
\hline $\mathrm{H}_{\mathrm{C}}(6.61)$ & 95.6 & 1980.98 & 20.7 \\
\hline $\mathrm{H}_{\mathrm{D}}(7.28)$ & 165.86 & 1801.8 & 10.9 \\
\hline $\mathrm{H}_{\mathrm{E}}(6.67)$ & 155.48 & -1276.08 & -8.2 \\
\hline
\end{tabular}

Table S7. Signal enhancement calculated for the hyperpolarization of the ${ }^{1} \mathrm{H}$ of ethyl N-methyl-N-(4vinylphenyl)glycinate. The thermal data is derived from the sample before $p-\mathrm{H}_{2}$ is introduced and the hyperpolarized data is derived from the first transient after shaking the sample. 
${ }^{13} \mathrm{C}$ and ${ }^{13} \mathrm{C}\left\{{ }^{1} \mathrm{H}\right\}$ NMR Spectrum, $150 \mathrm{MHz}$, acetone- $d_{6}\left(90^{\circ}\right.$ pulse $)$ - Magnitude mode

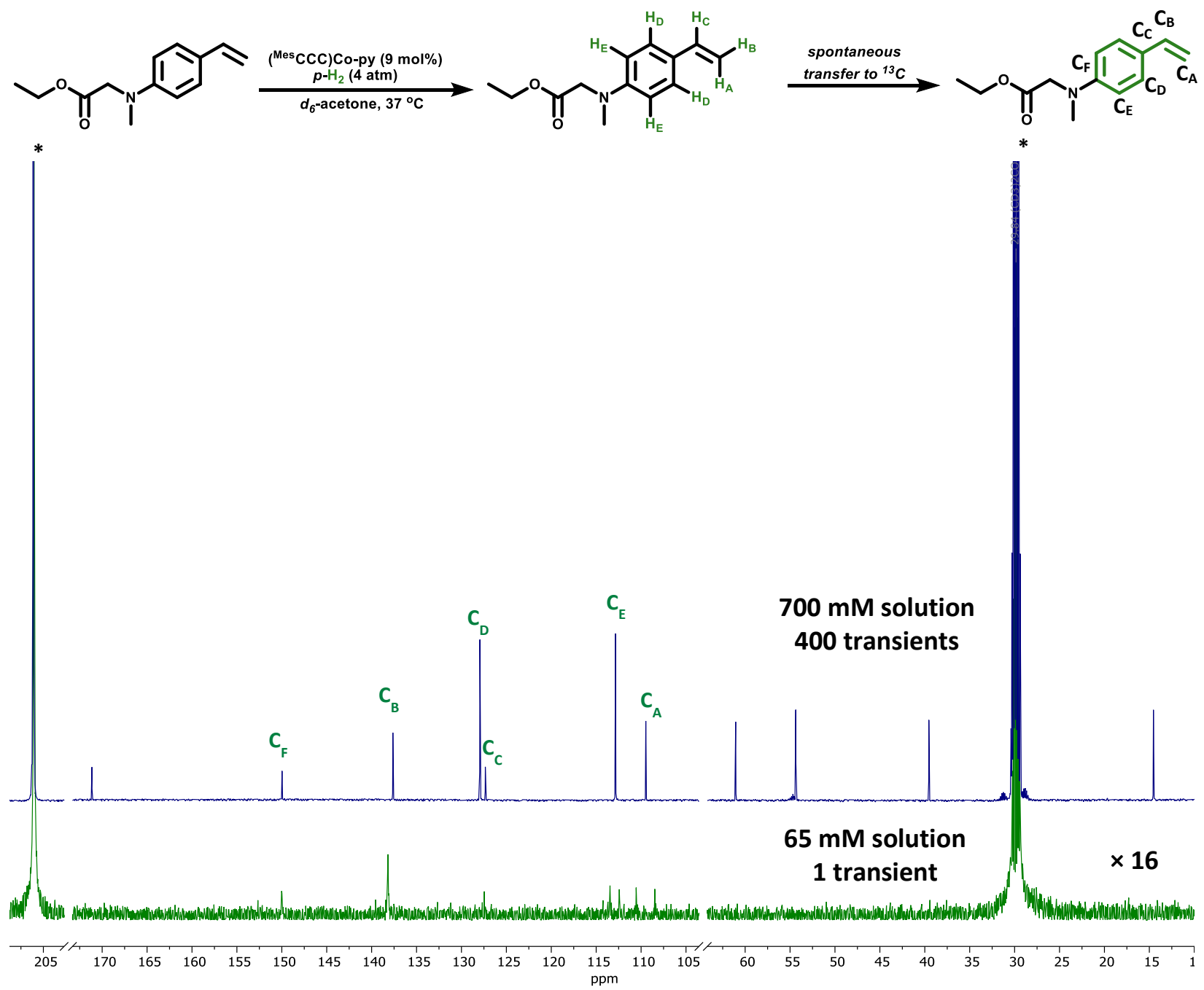

Figure S32. ${ }^{13} \mathrm{C}$ NMR spectrum (acetone- $d_{6}(*), 150 \mathrm{MHz}, 37{ }^{\circ} \mathrm{C}$ ) of the reaction of ethyl N-methyl-N-(4vinylphenyl)glycinate $(65 \mathrm{mM})$ using $\left({ }^{\mathrm{Mes}} \mathrm{CCC}\right) \mathrm{Co}-\mathrm{py}(9 \mathrm{~mol} \%, 5.9 \mathrm{mM})$ and $p-\mathrm{H}_{2}(4 \mathrm{~atm})$ at earth's magnetic field, with peakless regions removed. Top spectrum is a thermal ${ }^{13} \mathrm{C}$ NMR spectrum of 400 transients of a $700 \mathrm{mM}$ solution of ethyl $\mathrm{N}$-methyl-N-(4-vinylphenyl)glycinate. The bottom spectrum is the ${ }^{13} \mathrm{C}\left\{{ }^{1} \mathrm{H}\right\}$ first transient, in magnitude mode, after the $2^{\text {nd }}$ shake introducing $p-\mathrm{H}_{2}$ into the sample at earth's magnetic field, expanded 16-fold compared to the top spectrum. 
${ }^{13} \mathrm{C}\left\{{ }^{1} \mathrm{H}\right\}$ NMR Spectrum, $150 \mathrm{MHz}$, acetone- $d_{6}\left(90^{\circ}\right.$ pulse $)$ - Phased mode

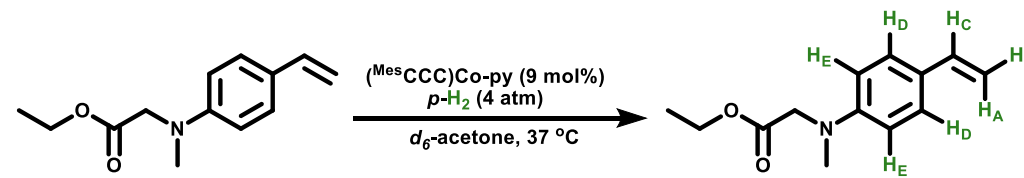<smiles>CN(CC(=O)OCCC1CC2CCCCC21)c1ccc(C(C)(C)C)cc1</smiles>
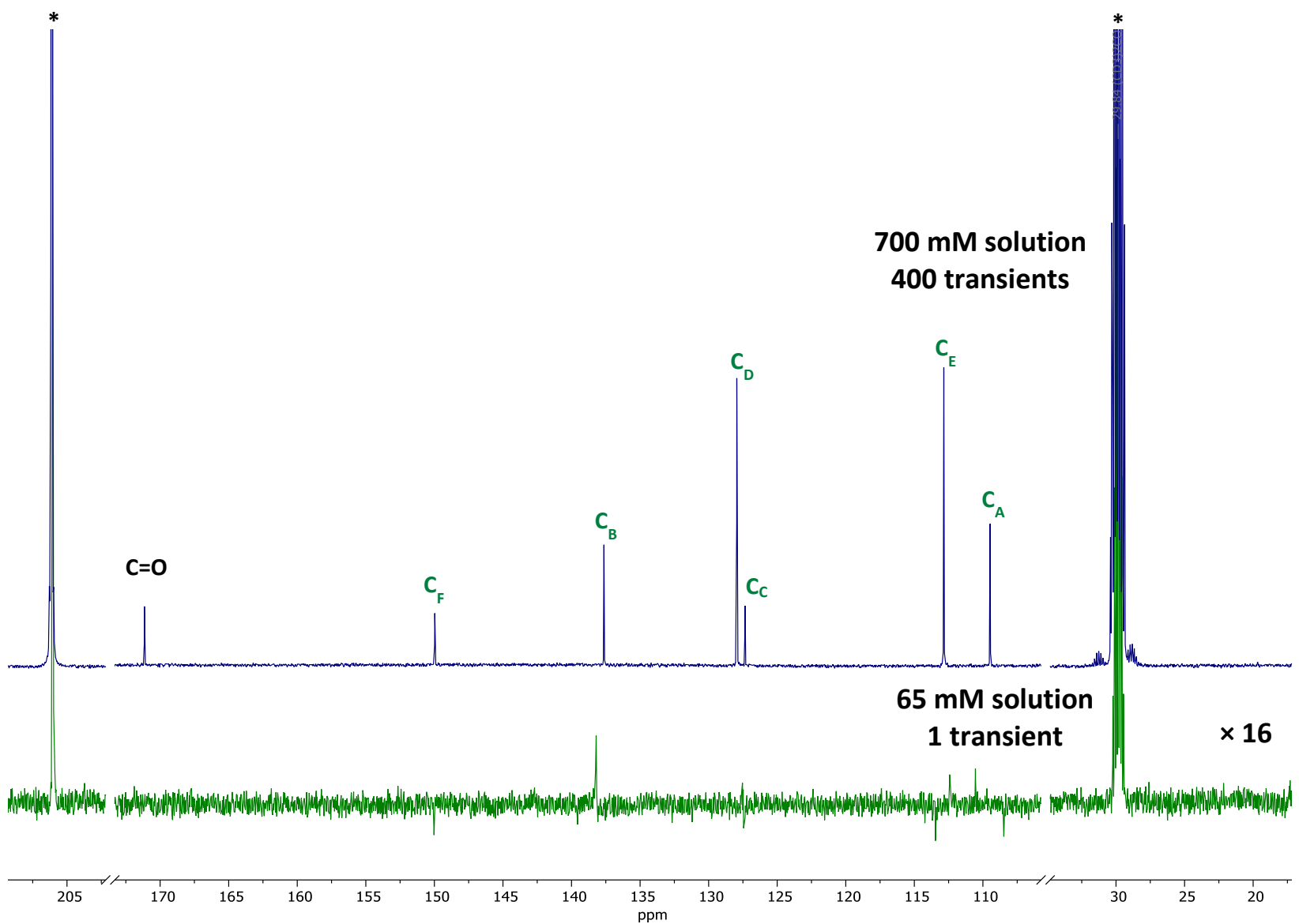

Figure S33. Olefinic region of the ${ }^{13} \mathrm{C}$ NMR spectra (acetone- $d_{6}(*), 150 \mathrm{MHz}, 37{ }^{\circ} \mathrm{C}$ ) of the reaction of ethyl N-methyl-N-(4-vinylphenyl)glycinate (65 mM) using $\left({ }^{\mathrm{Mes}} \mathrm{CCC}\right) \mathrm{Co}-\mathrm{py}(9 \mathrm{~mol} \%, 5.9 \mathrm{mM})$ and $p-\mathrm{H}_{2}(4$ atm) at earth's magnetic field. Top spectrum is a thermal ${ }^{13} \mathrm{C}$ spectrum of 400 transients of a $700 \mathrm{mM}$ solution of ethyl N-methyl-N-(4-vinylphenyl)glycinate. The bottom spectrum is the first transient of a ${ }^{13} \mathrm{C}\left\{{ }^{1} \mathrm{H}\right\}$ NMR spectrum, in phased mode, after the $2^{\text {nd }}$ shake introducing $p-\mathrm{H}_{2}$ into the sample at earth's magnetic field, expanded 16-fold compared to the top spectrum. 
${ }^{13} \mathrm{C}\left\{{ }^{1} \mathrm{H}\right\}$ NMR Spectrum, $150 \mathrm{MHz}$, acetone- $d_{6}\left(90^{\circ}\right.$ pulse $)$

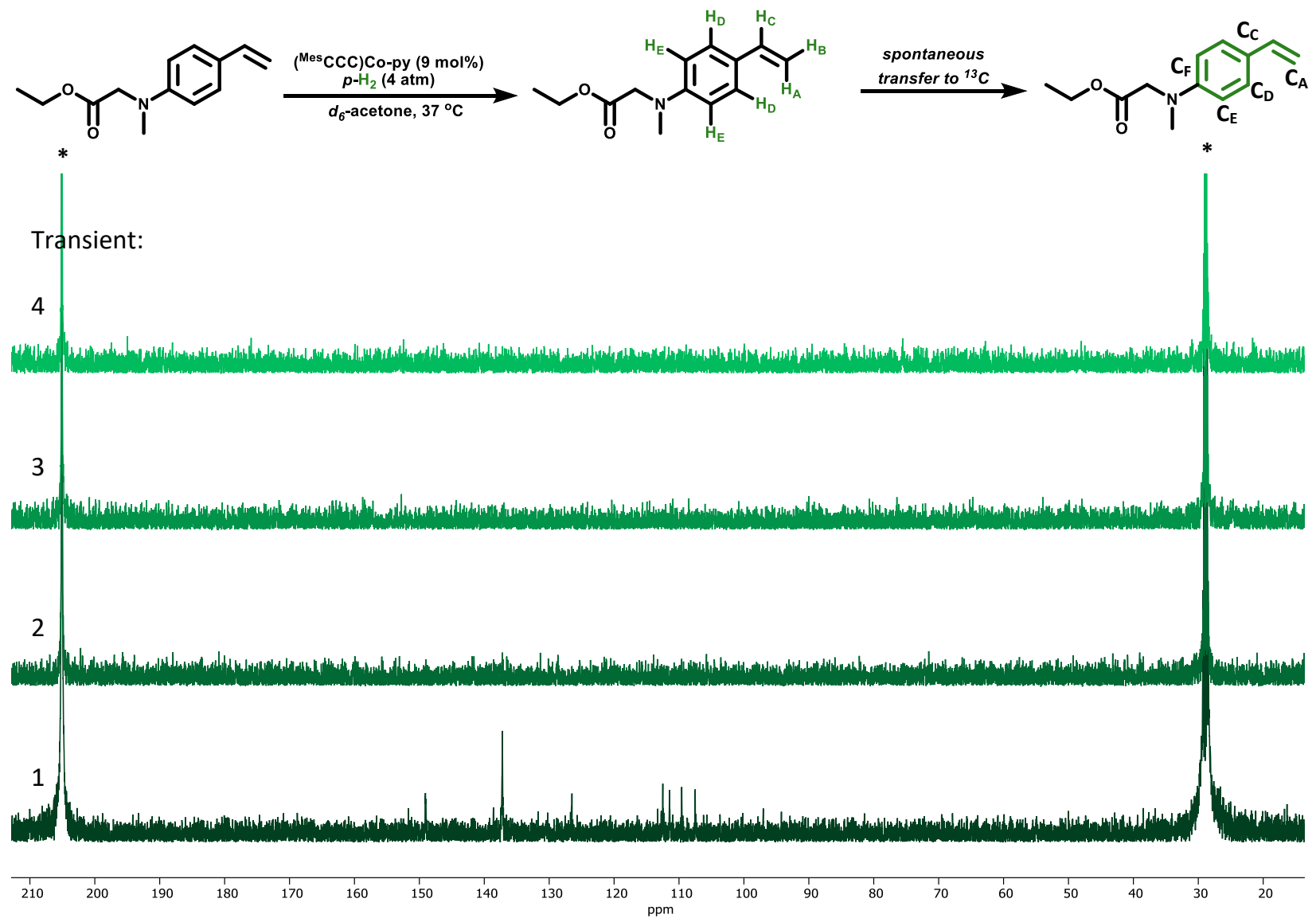

Figure S34. ${ }^{13} \mathrm{C}$ NMR spectra (acetone- $d_{6}(*), 150 \mathrm{MHz}, 37{ }^{\circ} \mathrm{C}$ ), in magnitude mode, showing the decay of polarization over time of the reaction of ethyl N-methyl-N-(4-vinylphenyl)glycinate $(65 \mathrm{mM})$ using $\left({ }^{\mathrm{Mes}} \mathrm{CCC}\right) \mathrm{Co}-\mathrm{py}(9 \mathrm{~mol} \%, 5.9 \mathrm{mM})$ and $p-\mathrm{H}_{2}(4 \mathrm{~atm})$ at earth's magnetic field. No additional shaking occurred between transients. Bottom (green) spectrum is the first collected transient of the $\mathbf{2}^{\text {nd }}$ shake of $p$ $\mathrm{H}_{2}$ into the sample, followed by an acquisition time of $1.7695 \mathrm{~s}$ to collect the next transient above it, with no delay time in between. Subsequent transients were collected in the same fashion. 
${ }^{1} \mathrm{H}$ NMR Spectrum, $600 \mathrm{MHz}$, acetone- $d_{6}\left(45^{\circ}\right.$ pulse $)$
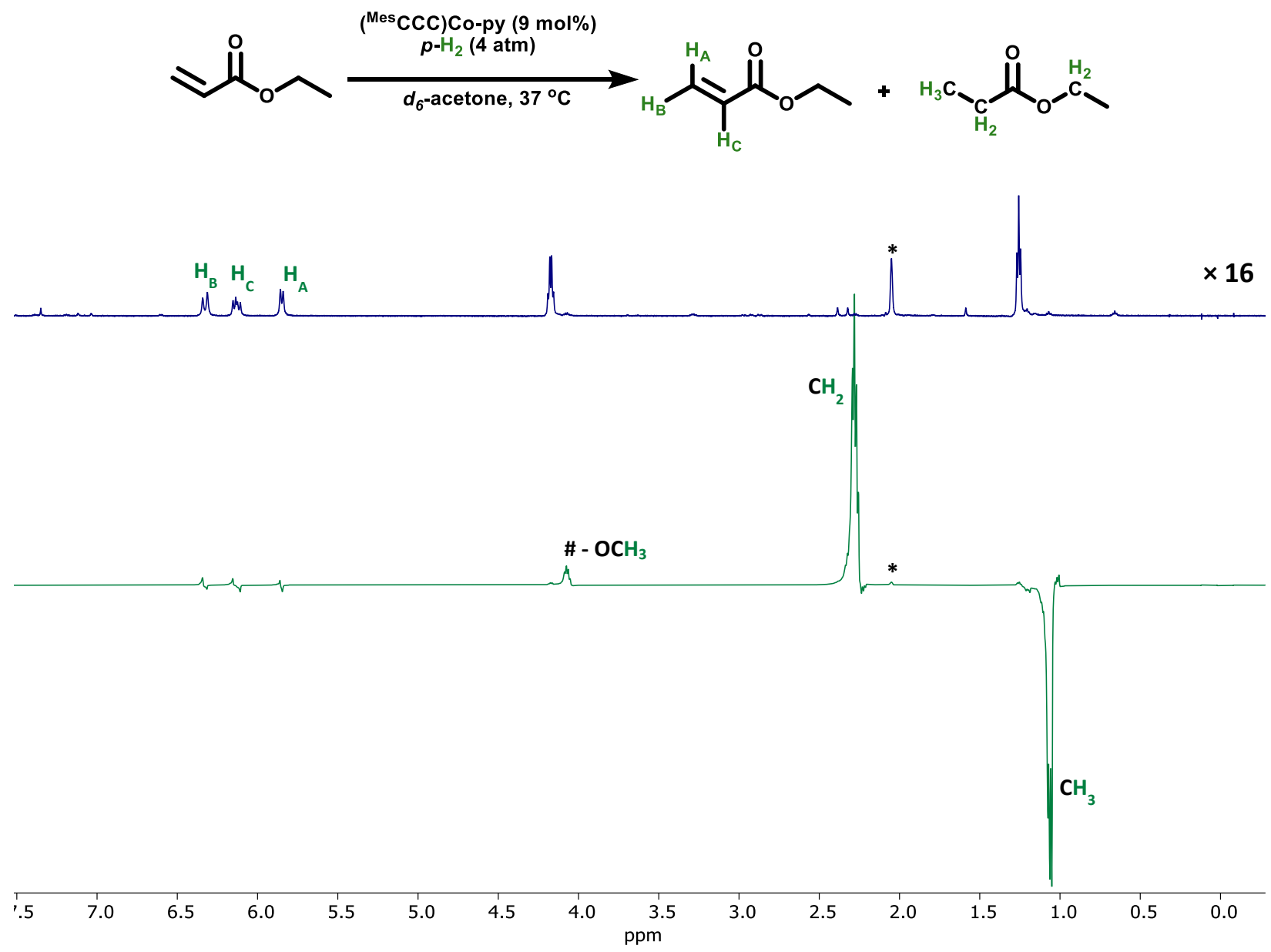

Figure S35. ${ }^{1} \mathrm{H}$ NMR spectra (acetone- $d_{6}(*), 600 \mathrm{MHz}, 37^{\circ} \mathrm{C}$ ) of the reaction of ethyl acrylate $(65 \mathrm{mM})$ using $\left({ }^{\mathrm{Mes}} \mathrm{CCC}\right) \mathrm{Co}-\mathrm{py}(9 \mathrm{~mol} \%, 5.9 \mathrm{mM})$ and $p-\mathrm{H}_{2}(4 \mathrm{~atm})$ at the $50 \mathrm{G}$ fringe line of the magnet. Top: spectrum of the sample before $p-\mathrm{H}_{2}$ is introduced through shaking (thermal spectrum) expanded 8-fold compared to hyperpolarized spectrum. Bottom: First transient using a $45^{\circ}$ pulse after the $\mathbf{1}^{\text {st }}$ shake introducing $p-\mathrm{H}_{2}$ to the sample, showing the hyperpolarization of ethyl acrylate resonances (SABRE) and resonances associated with ethyl propionate (ALTADENA, \#). 
${ }^{1} \mathrm{H}$ NMR Spectrum, $600 \mathrm{MHz}$, acetone- $d_{6}\left(45^{\circ}\right.$ pulse $)$

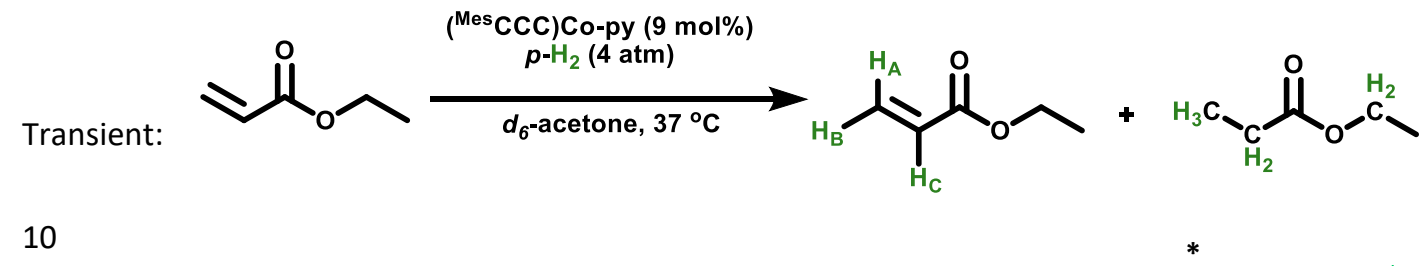

9

8

7

6

5

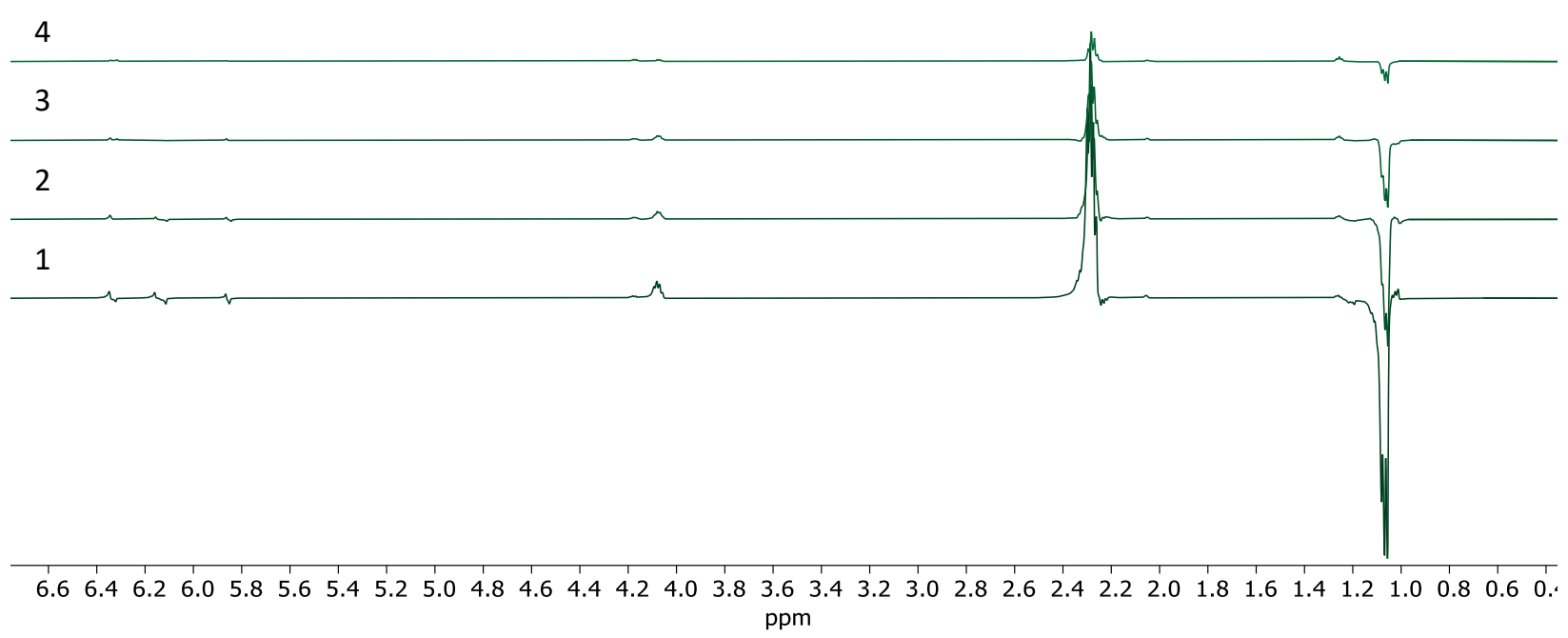

Figure S36. ${ }^{1} \mathrm{H}$ NMR spectra (acetone- $d_{6}(*), 600 \mathrm{MHz}, 37{ }^{\circ} \mathrm{C}$ ) showing the decay of polarization over time of the $1^{\text {st }}$ shake of the reaction of ethyl acrylate $(65 \mathrm{mM})$ using $\left({ }^{\text {Mes }} \mathrm{CCC}\right) \mathrm{Co}-\mathrm{py}(9 \mathrm{~mol} \%, 5.9 \mathrm{mM})$ and $p-\mathrm{H}_{2}(4 \mathrm{~atm})$ at the $50 \mathrm{G}$ fringe line of the magnet. No additional shaking occurred between transients. Bottom (dark green) spectrum is the first collected transient, followed by an acquisition time of $4.096 \mathrm{~s}$ to collect the next transient with no additional delay between transients. Subsequent transients were collected in the same fashion. 
${ }^{1} \mathrm{H}$ NMR Spectrum, $600 \mathrm{MHz}$, acetone- $d_{6}\left(45^{\circ}\right.$ pulse $)$
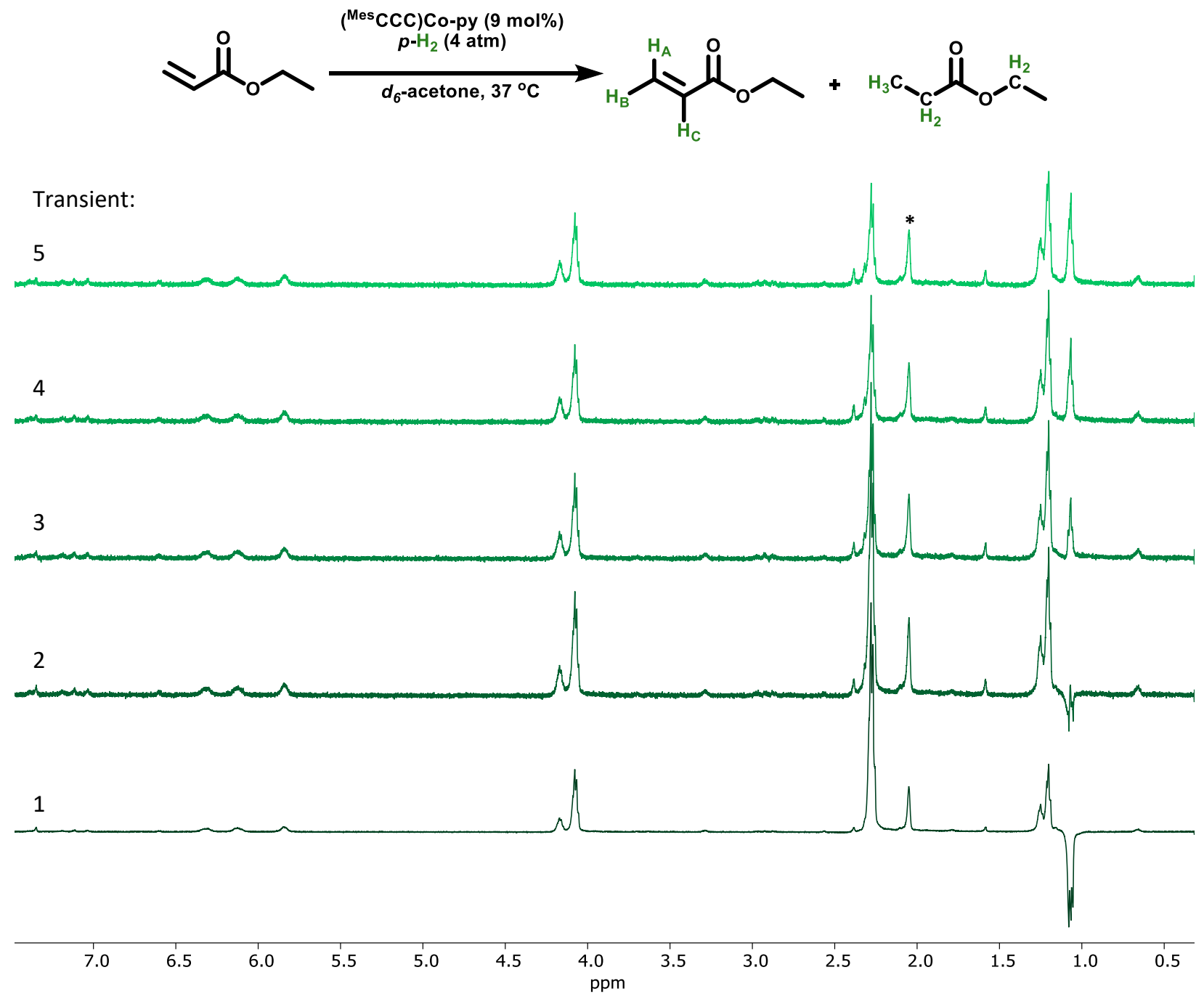

Figure S37. ${ }^{1} \mathrm{H}$ NMR spectra (acetone- $d_{6}(*), 600 \mathrm{MHz}, 37^{\circ} \mathrm{C}$ ) showing the decay of polarization over time of the $2^{\text {nd }}$ shake of the reaction of ethyl acrylate $(65 \mathrm{mM})$ using $\left({ }^{\mathrm{Mes}} \mathrm{CCC}\right) \mathrm{Co}-\mathrm{py}(9 \mathrm{~mol} \%, 5.9 \mathrm{mM})$ and $p-\mathrm{H}_{2}(4 \mathrm{~atm})$ at earth's magnetic field. No additional shaking occurred between transients. Bottom (dark green) spectrum is the first collected transient, followed by an acquisition time of $4.096 \mathrm{~s}$ to collect the next transient with no additional delay between transients. Subsequent transients were collected in the same fashion. Note: no polarization of the olefin observed.

\begin{tabular}{|l|c|c|c|}
\hline Proton $(\mathrm{ppm})$ & Thermal Integration & Hyperpolarized Integration & Enhancement (fold) \\
\hline $\mathrm{H}_{\mathrm{A}}(5.85)$ dispersive & 20.8 & 31.5 & 1.5 \\
\hline $\mathrm{H}_{\mathrm{B}}(6.33)$ dispersive & 21.36 & 39.42 & 1.8 \\
\hline $\mathrm{H}_{\mathrm{C}}(6.13)$ dispersive & 21.64 & 52.06 & 2.4 \\
\hline
\end{tabular}

Table S8. Signal enhancement calculated for the hyperpolarization of the ${ }^{1} \mathrm{H}$ of ethyl acrylate. The thermal data is derived from the sample before $p-\mathrm{H}_{2}$ is introduced and the hyperpolarized data is derived from the first transient after shaking the sample. 
${ }^{13} \mathrm{C}\left\{{ }^{1} \mathrm{H}\right\}$ NMR Spectrum, $150 \mathrm{MHz}$, acetone- $d_{6}\left(90^{\circ}\right.$ pulse $)$ - Magnitude mode
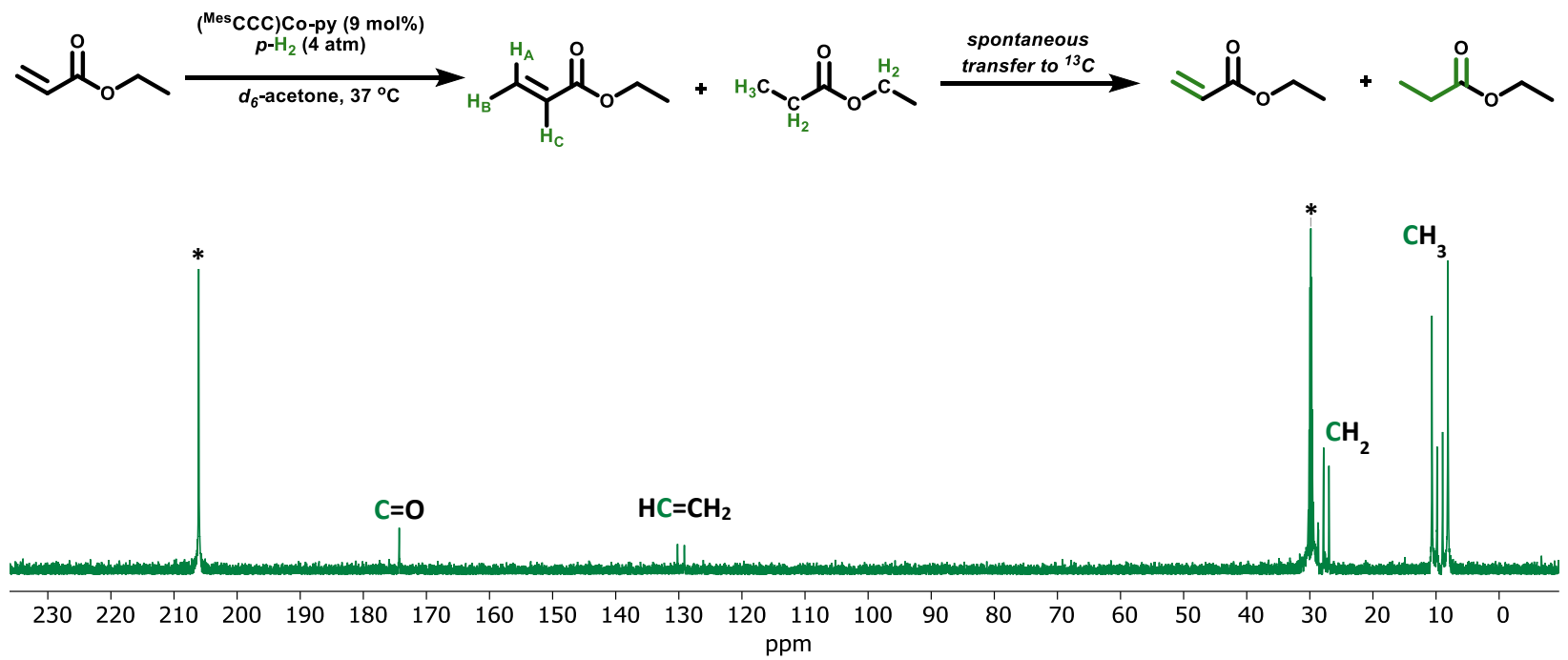

Figure S38. ${ }^{13} \mathrm{C}\left\{{ }^{1} \mathrm{H}\right\}$ NMR spectra (acetone- $d_{6}(*), 150 \mathrm{MHz}, 37{ }^{\circ} \mathrm{C}$ ) of the reaction of ethyl acrylate (65 $\mathrm{mM})$ using ( $\left.{ }^{\mathrm{Mes}} \mathrm{CCC}\right) \mathrm{Co}$-py $(9 \mathrm{~mol} \%, 5.9 \mathrm{mM})$ and $p-\mathrm{H}_{2}(4 \mathrm{~atm})$ at earth's magnetic field. Spectrum is the first transient, in magnitude mode, after the $2^{\text {nd }}$ shake introducing $p-\mathrm{H}_{2}$ into the sample at earth's magnetic field.

${ }^{13} \mathrm{C}\left\{{ }^{1} \mathrm{H}\right\}$ NMR Spectrum, $150 \mathrm{MHz}$, acetone- $d_{6}\left(90^{\circ}\right.$ pulse $)$ - Phased mode
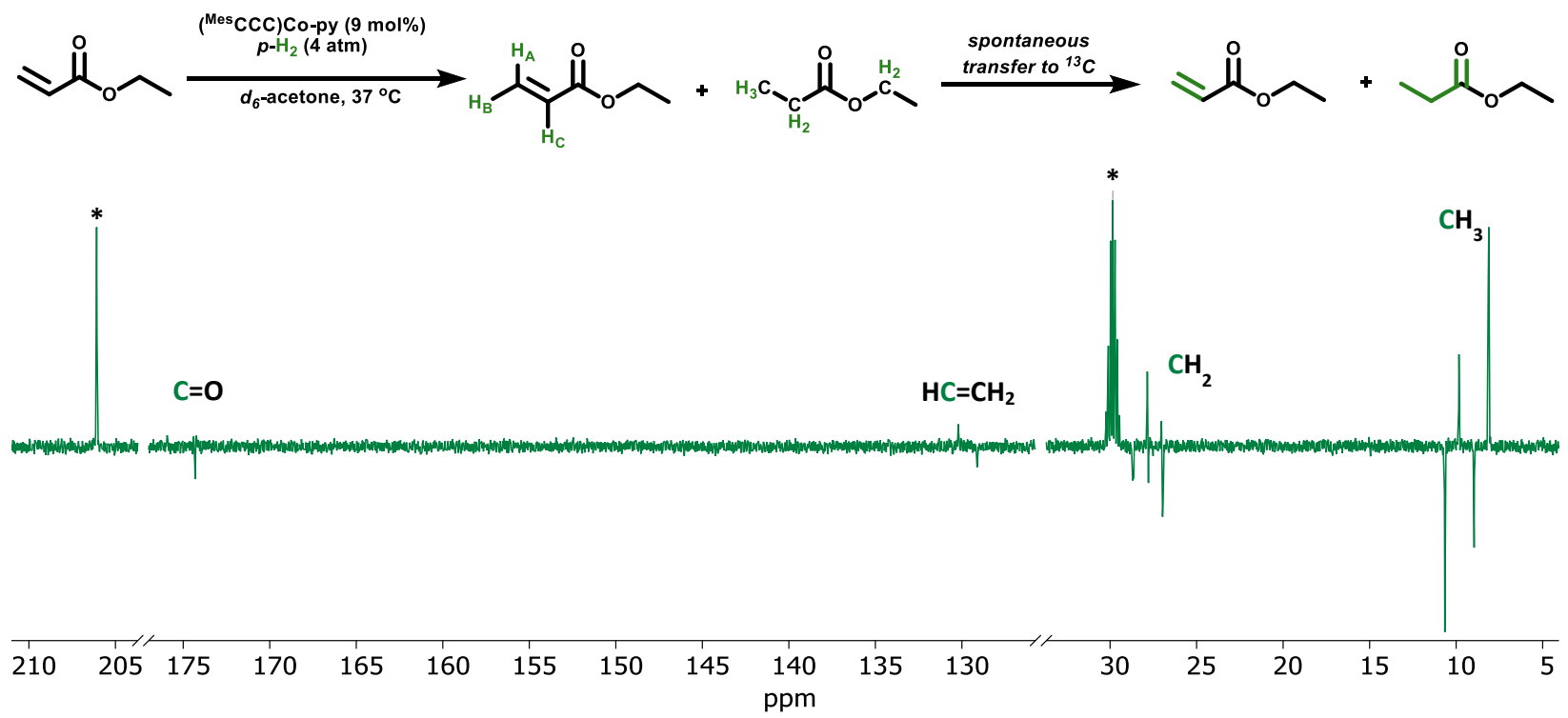

Figure S39. ${ }^{13} \mathrm{C}\left\{{ }^{1} \mathrm{H}\right\}$ NMR spectra (acetone- $d_{6}(*), 150 \mathrm{MHz}, 37{ }^{\circ} \mathrm{C}$ ) of the reaction of ethyl acrylate (65 $\mathrm{mM})$ using $\left({ }^{\mathrm{Mes}} \mathrm{CCC}\right) \mathrm{Co}-\mathrm{py}(9 \mathrm{~mol} \%, 5.9 \mathrm{mM})$ and $p-\mathrm{H}_{2}(4 \mathrm{~atm})$ at earth's magnetic field. Spectrum is the first transient, in phased mode, after the $2^{\text {nd }}$ shake introducing $p-\mathrm{H}_{2}$ into the sample at earth's magnetic field with peakless region removed. 
${ }^{1} \mathrm{H}$ NMR Spectrum, $500 \mathrm{MHz}$, acetone- $d_{6}\left(45^{\circ}\right.$ pulse $)$
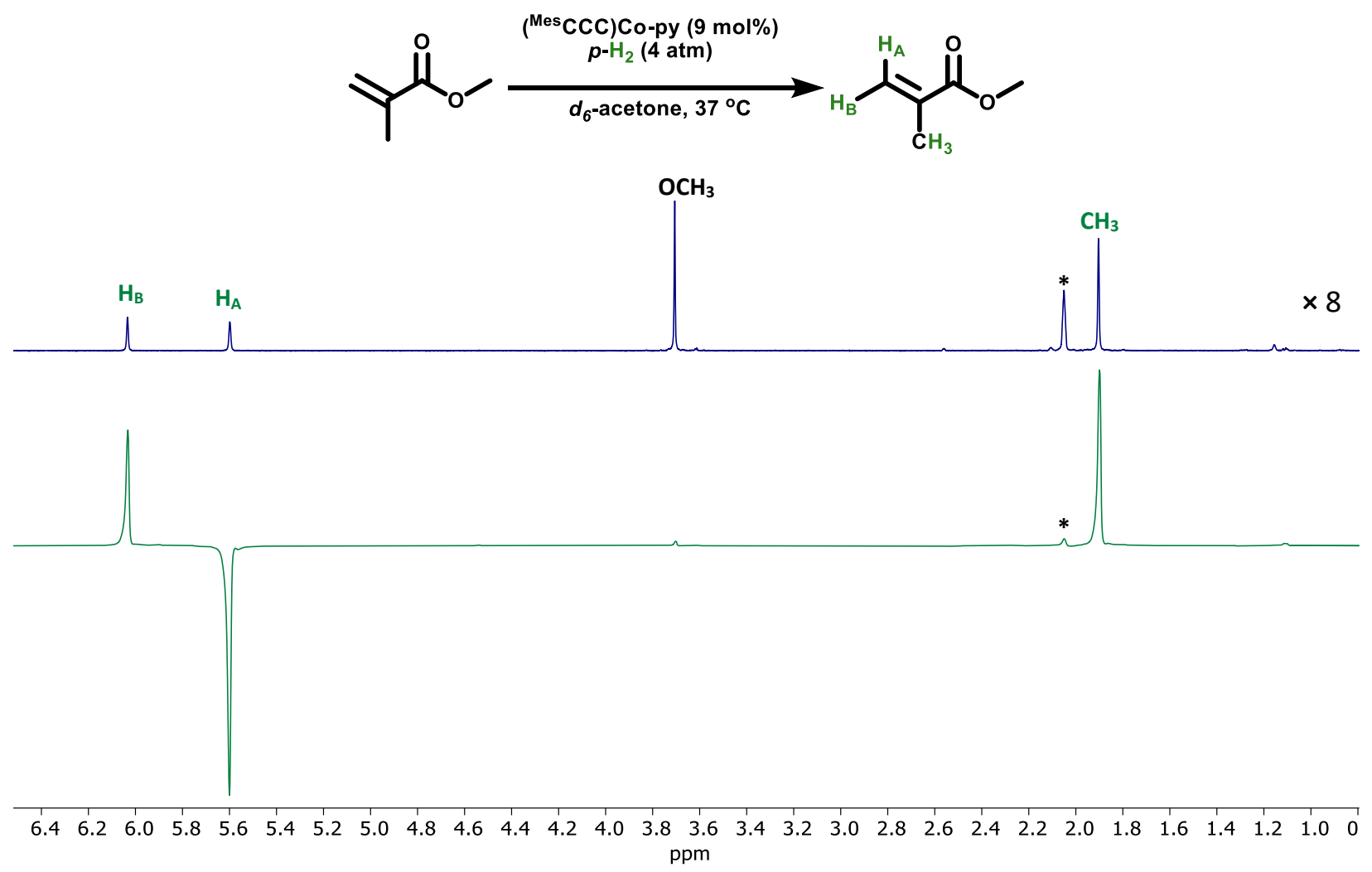

Figure S40. ${ }^{1} \mathrm{H}$ NMR spectra (acetone- $d_{6}(*), 500 \mathrm{MHz}, 37{ }^{\circ} \mathrm{C}$ ) of the reaction of methyl methacrylate (65 $\mathrm{mM})$ using $\left({ }^{\mathrm{Mes}} \mathrm{CCC}\right) \mathrm{Co}-\mathrm{py}(9 \mathrm{~mol} \%, 5.9 \mathrm{mM})$ and $p-\mathrm{H}_{2}(4 \mathrm{~atm})$ at the $50 \mathrm{G}$ fringe line of the magnet. Top: spectrum of the sample before $p-\mathrm{H}_{2}$ is introduced through shaking (thermal spectrum) expanded 8-fold compared to hyperpolarized spectrum. Bottom: First transient using a $45^{\circ}$ pulse after the $\mathbf{1}^{\text {st }}$ shake introducing $p-\mathrm{H}_{2}$ to the sample, showing the hyperpolarization of the olefin and methyl moiety of methyl methacrylate (SABRE). 
${ }^{1} \mathrm{H}$ NMR Spectrum, $500 \mathrm{MHz}$, acetone- $d_{6}\left(45^{\circ}\right.$ pulse $)$

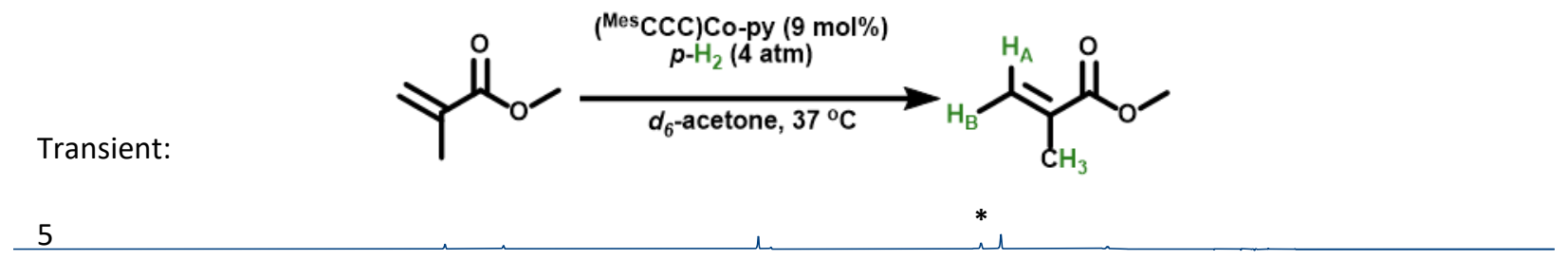

4

3

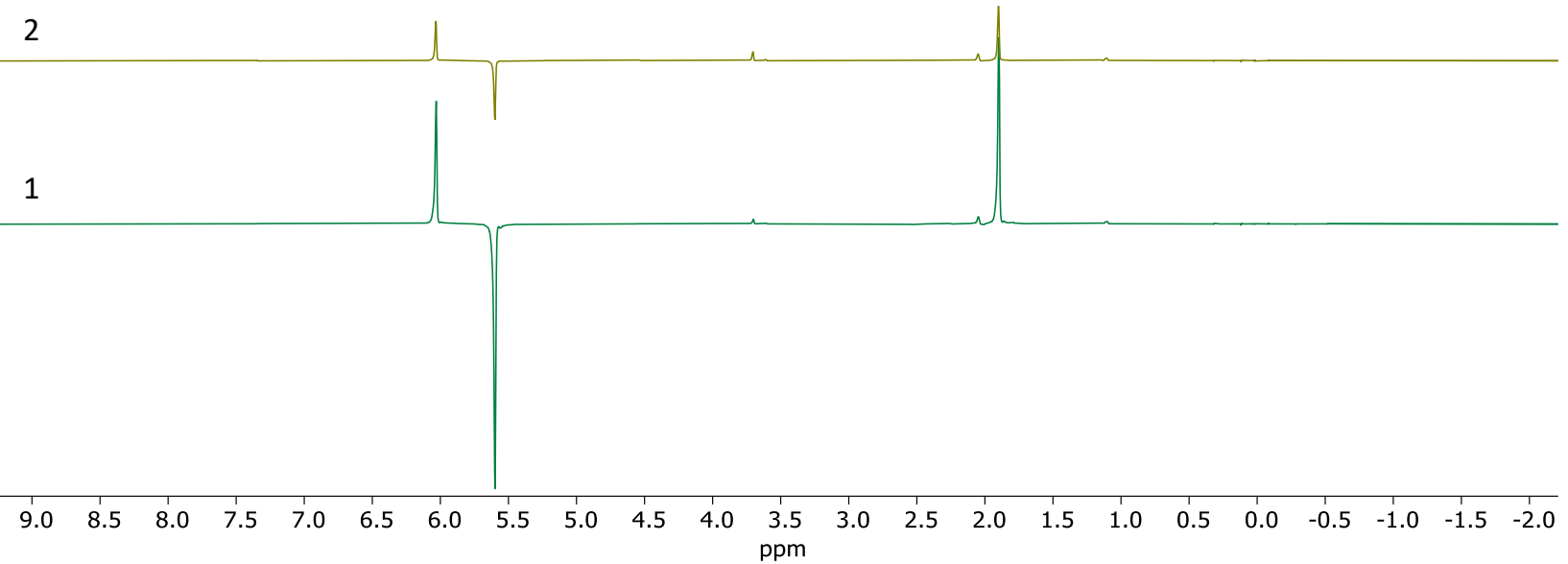

Figure S41. ${ }^{1} \mathrm{H}$ NMR spectra (acetone- $d_{6}(*), 500 \mathrm{MHz}, 37^{\circ} \mathrm{C}$ ) showing the decay of polarization over time of the reaction of methyl methacrylate $(65 \mathrm{mM})$ using $\left({ }^{\mathrm{Mes}} \mathrm{CCC}\right) \mathrm{Co}-\mathrm{py}(9 \mathrm{~mol} \%, 5.9 \mathrm{mM})$ and $p-\mathrm{H}_{2}$ (4 atm) at the $50 \mathrm{G}$ fringe line of the magnet. No additional shaking occurred between transients. Bottom (dark green) spectrum is the first collected transient, followed by an acquisition time of $4.096 \mathrm{~s}$ to collect the next transient (yellow spectrum) with no additional delay between transients. Subsequent transients were collected in the same fashion.

\begin{tabular}{|l|c|c|c|}
\hline Proton $(\mathrm{ppm})$ & Thermal Integration & Hyperpolarized Integration & Enhancement (fold) \\
\hline $\mathrm{CH}_{3}(1.90)$ & 31.77 & 287.67 & 9.1 \\
\hline $\mathrm{H}_{\mathrm{A}}(5.60)$ & 10.36 & -419.45 & -40.5 \\
\hline $\mathrm{H}_{\mathrm{B}}(6.04)$ & 10.38 & 189.58 & 18.3 \\
\hline $\mathrm{OCH}_{3}(3.71)$ & 31.4 & 6.26 & 0.2 \\
\hline
\end{tabular}

Table S9. Signal enhancement calculated for the hyperpolarization of the ${ }^{1} \mathrm{H}$ of methyl methacrylate. The thermal data is derived from the sample before $p-\mathrm{H}_{2}$ is introduced and the hyperpolarized data is derived from the first transient after shaking the sample. 
${ }^{13} \mathrm{C}\left\{{ }^{1} \mathrm{H}\right\}$ NMR Spectrum, $150 \mathrm{MHz}$, acetone- $d_{6}\left(90^{\circ}\right.$ pulse $)$ - Magnitude mode
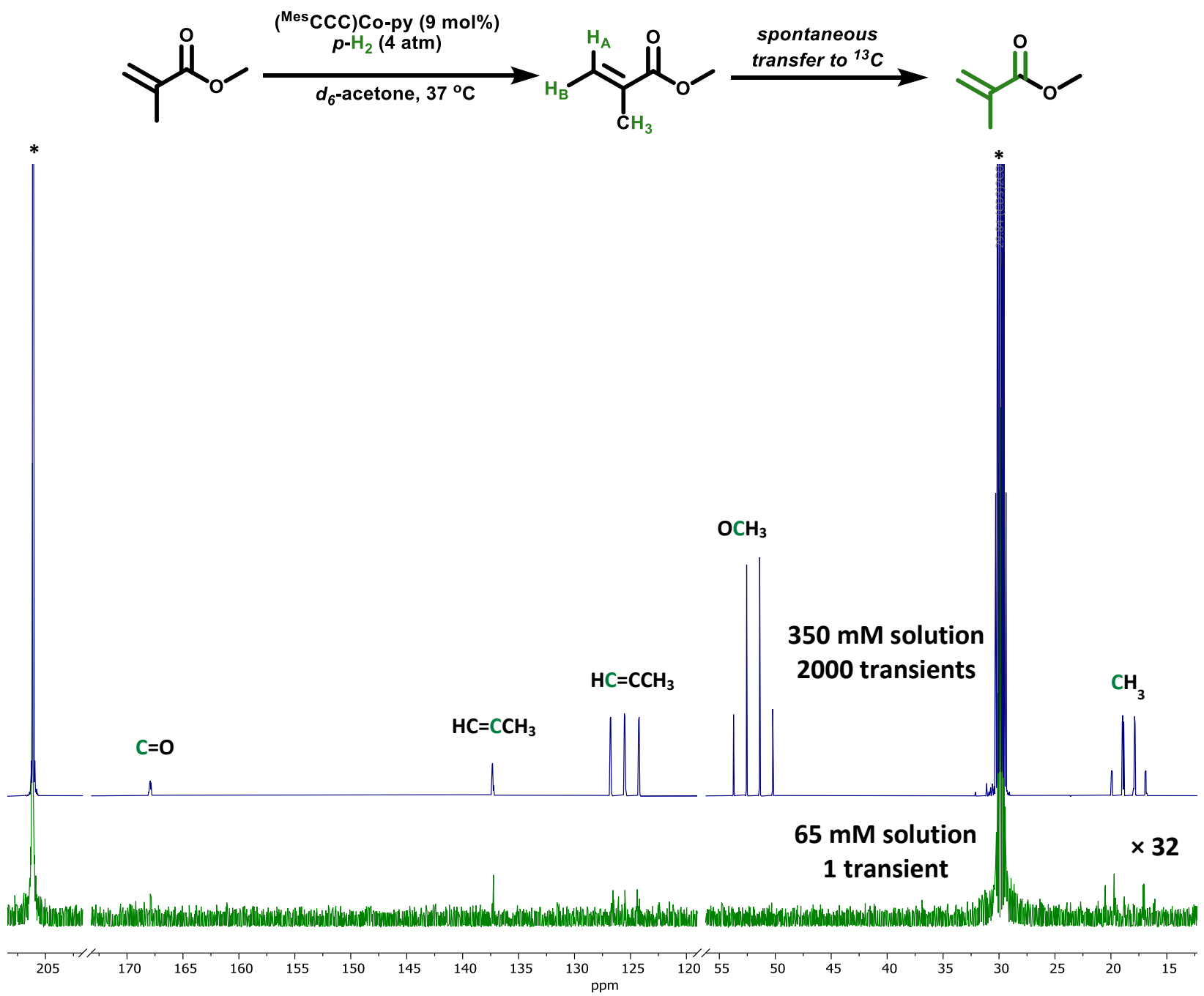

Figure S42. ${ }^{13} \mathrm{C}\left\{{ }^{1} \mathrm{H}\right\}$ NMR spectra (acetone- $d_{6}(*), 150 \mathrm{MHz}, 37{ }^{\circ} \mathrm{C}$ ) of the reaction of methyl methacrylate $(65 \mathrm{mM})$ using $\left({ }^{\mathrm{Mes}} \mathrm{CCC}\right) \mathrm{Co}$-py $(9 \mathrm{~mol} \%, 5.9 \mathrm{mM})$ and $p-\mathrm{H}_{2}(4 \mathrm{~atm})$ at earth's magnetic field with peakless regions removed. Top spectrum is a thermal spectrum of 2000 transients of a $350 \mathrm{mM}$ solution of methyl methacrylate, magnified 2-fold compared to the bottom spectrum. The bottom spectrum is the first transient, in magnitude mode, after the $\mathbf{2}^{\text {nd }}$ shake introducing $p-\mathrm{H}_{2}$ into the sample at earth's magnetic field, expanded 32-fold compared to the top spectrum. 
${ }^{13} \mathrm{C}\left\{{ }^{1} \mathrm{H}\right\}$ NMR Spectrum, $150 \mathrm{MHz}$, acetone- $d_{6}\left(90^{\circ}\right.$ pulse $)$ - Phased mode
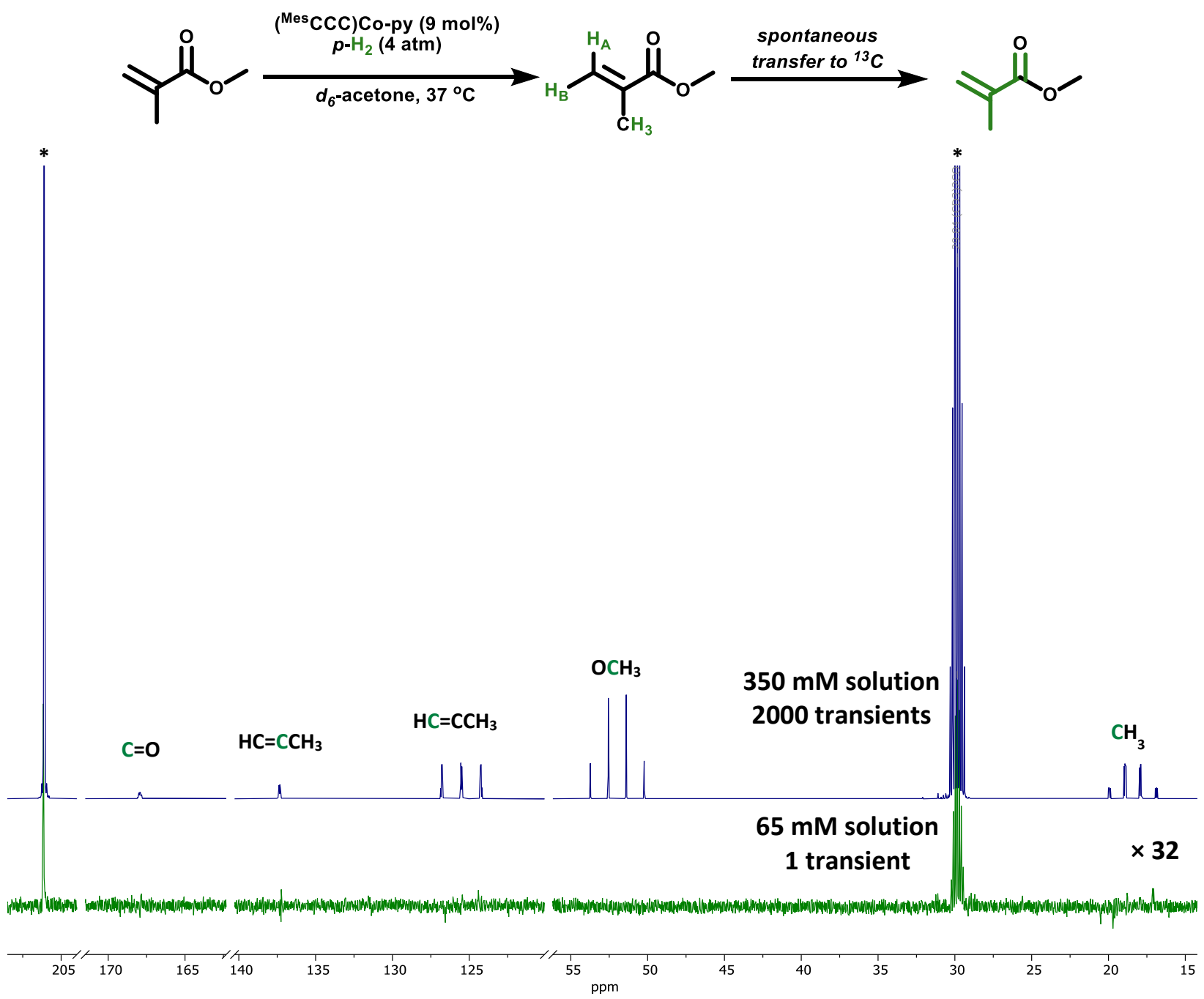

Figure S43. ${ }^{13} \mathrm{C}\left\{{ }^{1} \mathrm{H}\right\}$ NMR spectra (acetone- $d_{6}(*), 150 \mathrm{MHz}, 37{ }^{\circ} \mathrm{C}$ ) of the reaction of methyl methacrylate $(65 \mathrm{mM})$ using $\left({ }^{\mathrm{Mes}} \mathrm{CCC}\right) \mathrm{Co}$-py $(9 \mathrm{~mol} \%, 5.9 \mathrm{mM})$ and $p-\mathrm{H}_{2}(4 \mathrm{~atm})$ at earth's magnetic field with peakless regions removed. Top spectrum is a thermal spectrum of 2000 transients of a $350 \mathrm{mM}$ solution of methyl methacrylate, magnified 2-fold compared to the bottom spectrum. The bottom spectrum is the first transient, in phased mode, after the $2^{\text {nd }}$ shake introducing $p-\mathrm{H}_{2}$ into the sample at earth's magnetic field, expanded 32-fold compared to the top spectrum. 
${ }^{13} \mathrm{C}\left\{{ }^{1} \mathrm{H}\right\}$ NMR Spectrum, $150 \mathrm{MHz}$, acetone- $d_{6}\left(90^{\circ}\right.$ pulse $)$
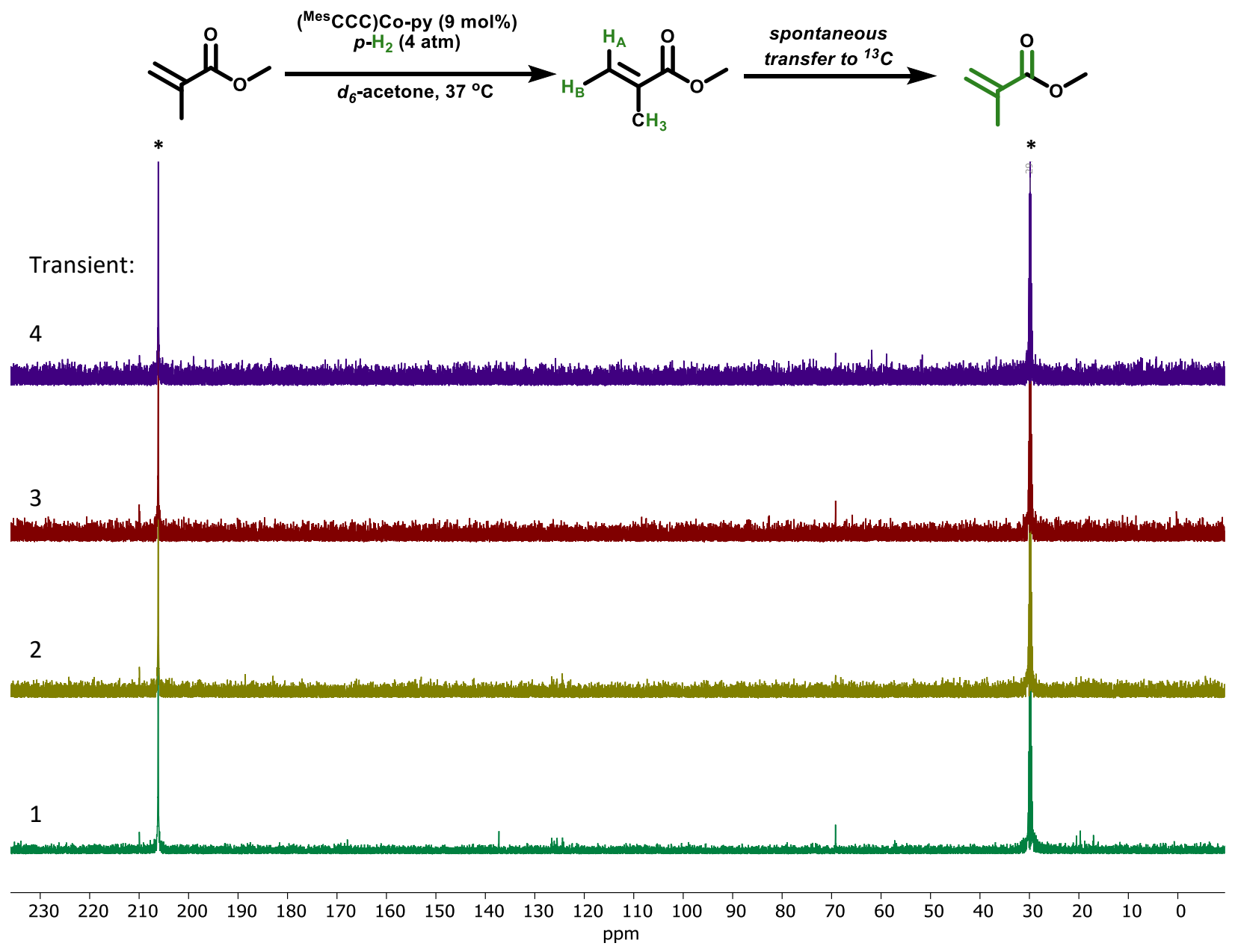

Figure S44. ${ }^{13} \mathrm{C}\left\{{ }^{1} \mathrm{H}\right\}$ NMR spectra (acetone- $d_{6}(*), 150 \mathrm{MHz}, 37{ }^{\circ} \mathrm{C}$ ), in magnitude mode, showing the decay of polarization over time of the reaction of methyl methacrylate $(65 \mathrm{mM})$ using $\left({ }^{\mathrm{Mes}} \mathrm{CCC}\right) \mathrm{Co}-\mathrm{py}(9$ mol\%, $5.9 \mathrm{mM})$ and $p-\mathrm{H}_{2}(4 \mathrm{~atm})$ at earth's magnetic field. No addition shaking occurred between transients. Bottom (green) spectrum is the first collected transient of the $2^{\text {nd }}$ shake of $p-\mathrm{H}_{2}$ into the sample, followed by an acquisition time of $1.7695 \mathrm{~s}$ to collect the next transient (yellow), with no delay time in between. Subsequent transients were collected in the same fashion. 
${ }^{1} \mathrm{H}$ NMR Spectrum, $600 \mathrm{MHz}$, acetone- $d_{6}\left(45^{\circ}\right.$ pulse $)$
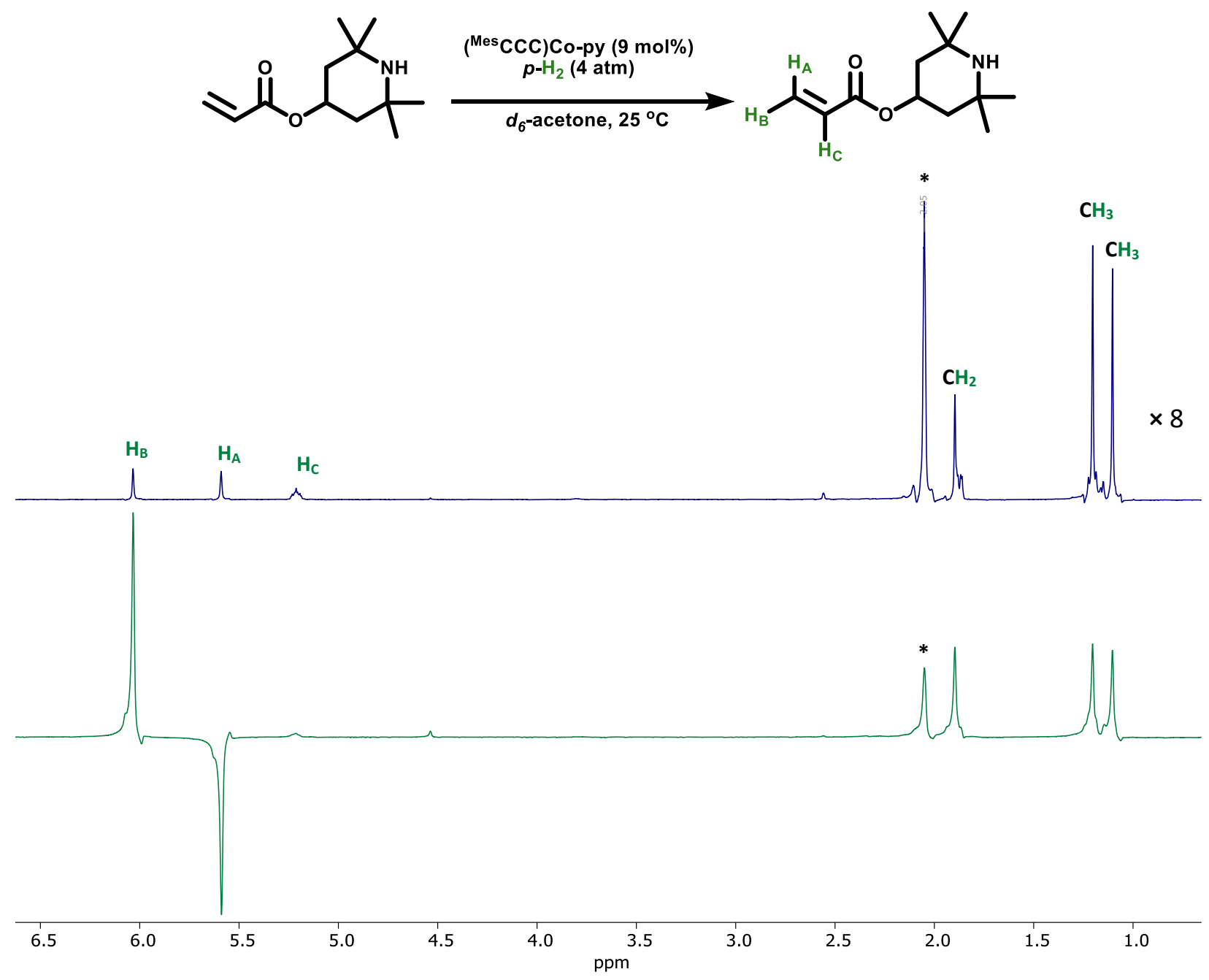

Figure S45. ${ }^{1} \mathrm{H}$ NMR spectra (acetone- $d_{6}(*), 600 \mathrm{MHz}, 25{ }^{\circ} \mathrm{C}$ ) of the reaction of 2,2,6,6-tetramethyl-4piperidyl acrylate $(65 \mathrm{mM})$ using $\left({ }^{\mathrm{Mes}} \mathrm{CCC}\right) \mathrm{Co}-\mathrm{py}(9 \mathrm{~mol} \%, 5.9 \mathrm{mM})$ and $p-\mathrm{H}_{2}(4 \mathrm{~atm})$ at the $50 \mathrm{G}$ fringe line of the magnet. Top: spectrum of the sample before $p-\mathrm{H}_{2}$ is introduced through shaking (thermal spectrum) expanded 8-fold compared to hyperpolarized spectrum. Bottom: First transient using a $45^{\circ}$ pulse after the $\mathbf{1}^{\text {st }}$ shake introducing $p-\mathrm{H}_{2}$ to the sample, showing the hyperpolarization of the terminal protons of the olefin (SABRE). 
${ }^{1} \mathrm{H}$ NMR Spectrum, $600 \mathrm{MHz}$, acetone- $d_{6}\left(45^{\circ}\right.$ pulse $)$
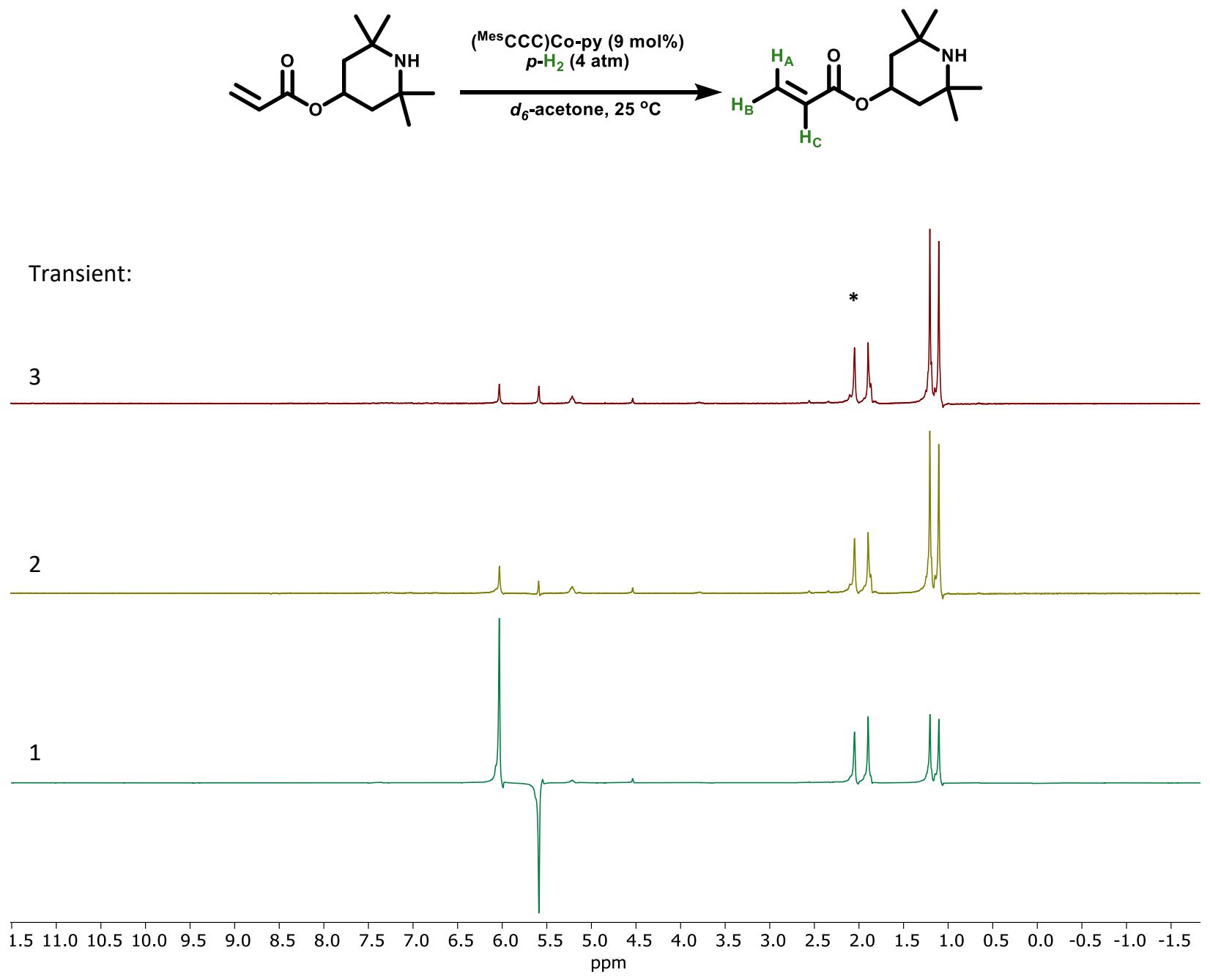

Figure S46. ${ }^{1} \mathrm{H}$ NMR spectra (acetone- $d_{6}(*), 600 \mathrm{MHz}, 25^{\circ} \mathrm{C}$ ) showing the decay of polarization over time of the reaction of 2,2,6,6-tetramethyl-4-piperidyl acrylate $(65 \mathrm{mM})$ using $\left({ }^{\mathrm{Mes}} \mathrm{CCC}\right) \mathrm{Co}-\mathrm{py}(9 \mathrm{~mol} \%$, $5.9 \mathrm{mM})$ and $p-\mathrm{H}_{2}(4 \mathrm{~atm})$ at the $50 \mathrm{G}$ fringe line of the magnet. No additional shaking occurred between transients. Bottom (dark green) spectrum is the first collected transient, followed by an acquisition time of $4.096 \mathrm{~s}$ to collect the next transient (yellow spectrum) with no additional delay between transients. Subsequent transients were collected in the same fashion.

\begin{tabular}{|l|c|c|c|}
\hline Proton $(\mathrm{ppm})$ & Thermal Integration & Hyperpolarized Integration & Enhancement (fold) \\
\hline $\mathrm{H}_{\mathrm{A}}(6.03)$ & 61.08 & 717.15 & 11.7 \\
\hline $\mathrm{H}_{\mathrm{B}}(5.59)$ & 61.73 & -638.66 & -10.3 \\
\hline $\mathrm{H}_{\mathrm{C}}(5.21)$ & 62.84 & 29.38 & 0.5 \\
\hline $\mathrm{CH}_{2}(1.90)$ & 219.78 & 305 & 1.4 \\
\hline $\mathrm{CH}_{3 \mathrm{~A}}(1.20)$ & 440.48 & 297.95 & 0.7 \\
\hline $\mathrm{CH}_{3 \mathrm{~B}}(1.10)$ & 372.76 & 272.02 & 0.7 \\
\hline
\end{tabular}


Table S10. Signal enhancement calculated for the hyperpolarization of the ${ }^{1} \mathrm{H}$ of 2,2,6,6-tetramethyl-4piperidyl acrylate. The thermal data is derived from the sample before $p-\mathrm{H}_{2}$ is introduced and the hyperpolarized data is derived from the first transient after shaking the sample.

${ }^{1} \mathrm{H}$ NMR Spectrum, $600 \mathrm{MHz}$, acetone- $d_{6}\left(45^{\circ}\right.$ pulse $)$
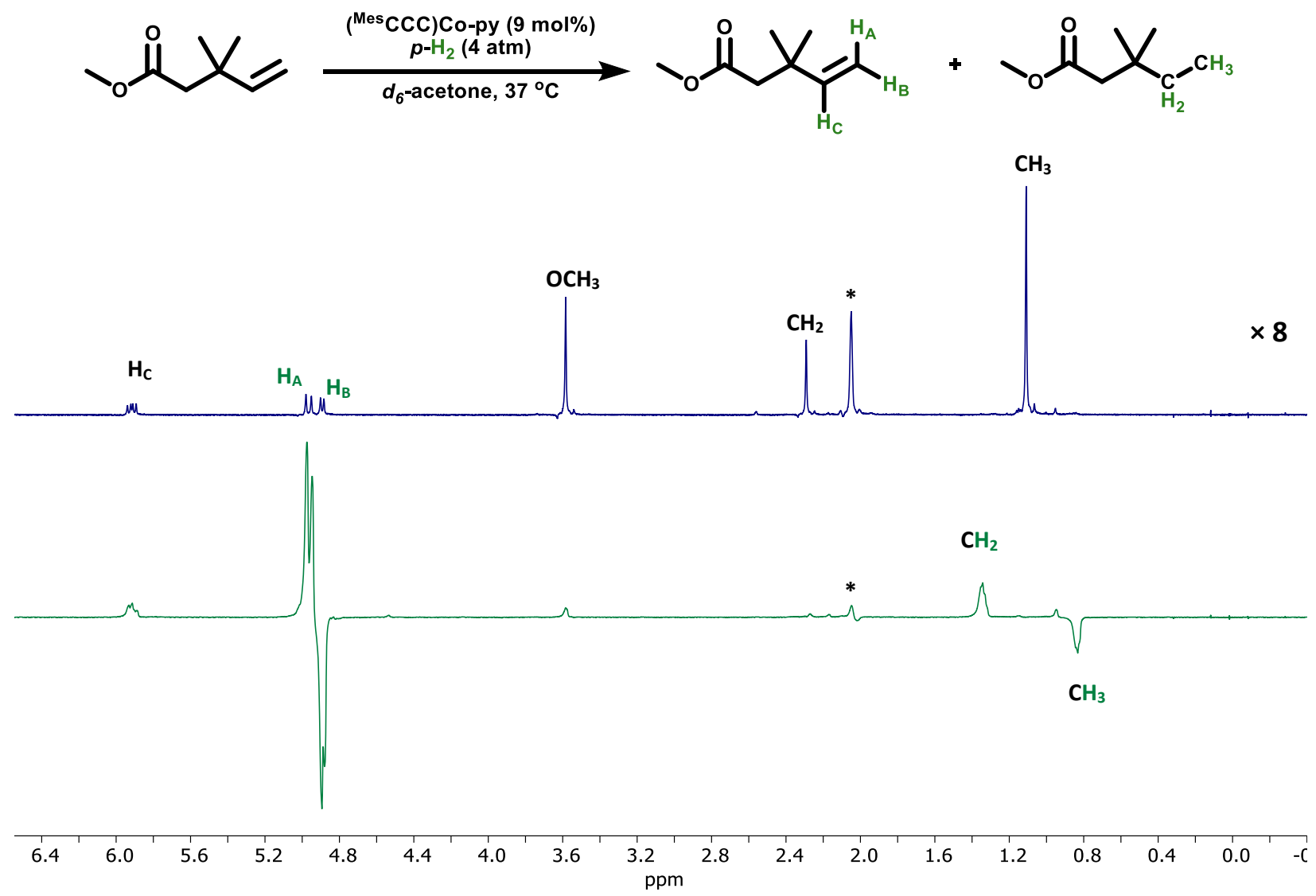

Figure S47. ${ }^{1} \mathrm{H}$ NMR spectra (acetone- $d_{6}(*), 600 \mathrm{MHz}, 37^{\circ} \mathrm{C}$ ) of the reaction of methyl-3,3-dimethylpent4-enoate $(65 \mathrm{mM})$ using $\left({ }^{\mathrm{Mes}} \mathrm{CCC}\right) \mathrm{Co}-\mathrm{py}(9 \mathrm{~mol} \%, 5.9 \mathrm{mM})$ and $p-\mathrm{H}_{2}(4 \mathrm{~atm})$ at the $50 \mathrm{G}$ fringe line of the magnet. Top: spectrum of the sample before $p-\mathrm{H}_{2}$ is introduced through shaking (thermal spectrum) expanded 8-fold compared to hyperpolarized spectrum. Bottom: First transient using a $45^{\circ}$ pulse after the $3^{\text {rd }}$ shake introducing $p-\mathrm{H}_{2}$ to the sample, showing the hyperpolarization of the terminal protons of the olefin (SABRE) and some hyperpolarization of the ALTADENA product. 
${ }^{1} \mathrm{H}$ NMR Spectrum, $600 \mathrm{MHz}$, acetone- $d_{6}\left(45^{\circ}\right.$ pulse $)$

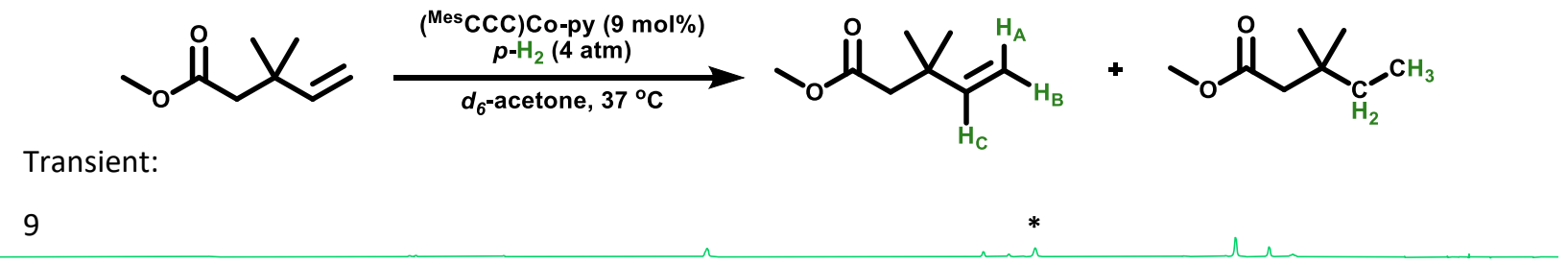

8

7

6

5

4

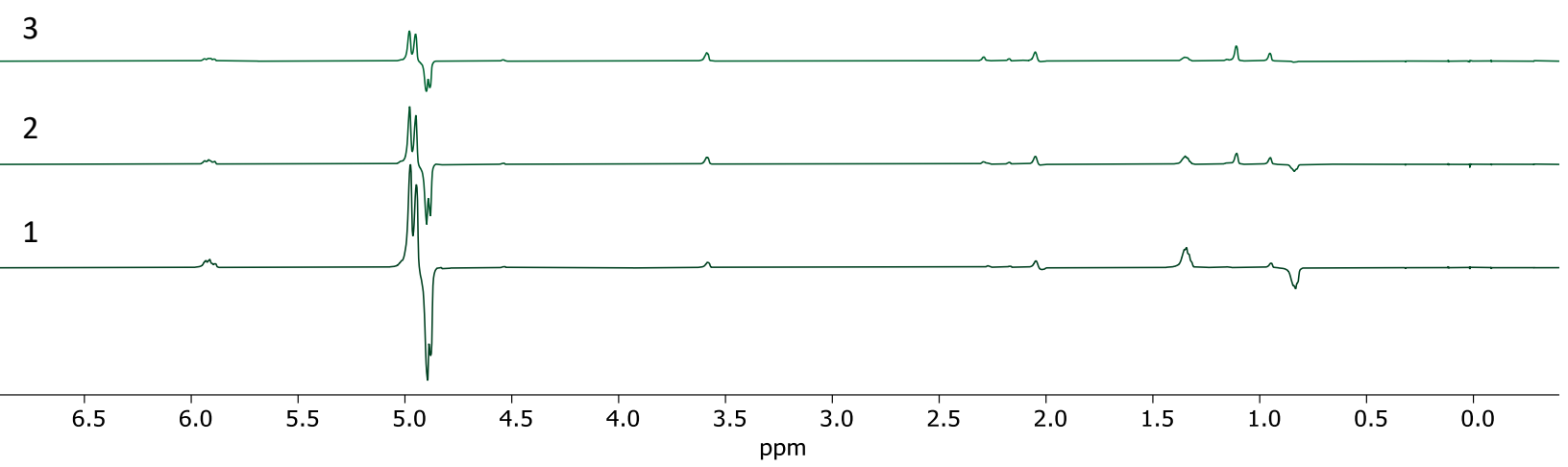

Figure S48. ${ }^{1} \mathrm{H}$ NMR spectra (acetone- $d_{6}(*), 600 \mathrm{MHz}, 37{ }^{\circ} \mathrm{C}$ ) showing the decay of polarization over time of the reaction of methyl-3,3-dimethylpent-4-enoate $(65 \mathrm{mM})$ using $\left({ }^{\mathrm{Mes}} \mathrm{CCC}\right) \mathrm{Co}-\mathrm{py}(9 \mathrm{~mol} \%, 5.9$ $\mathrm{mM})$ and $p-\mathrm{H}_{2}(4 \mathrm{~atm})$ at the $50 \mathrm{G}$ fringe line of the magnet. No additional shaking occurred between transients. Bottom (dark green) spectrum is the first collected transient, followed by an acquisition time of $4.096 \mathrm{~s}$ to collect the next transient above it with no additional delay between transients. Subsequent transients were collected in the same fashion.

\begin{tabular}{|l|c|c|c|}
\hline Proton $(\mathrm{ppm})$ & Thermal Integration & Hyperpolarized Integration & Enhancement (fold) \\
\hline $\mathrm{H}_{\mathrm{A}}(4.89)$ & 8.26 & -316.21 & -38.3 \\
\hline $\mathrm{H}_{\mathrm{B}}(4.96)$ & 9.6 & 318.4 & 33.2 \\
\hline $\mathrm{H}_{\mathrm{C}}(5.92)$ & 8.84 & 33.26 & 3.8 \\
\hline
\end{tabular}

Table S11. Signal enhancement calculated for the hyperpolarization of the ${ }^{1} \mathrm{H}$ of methyl-3,3-dimethylpent4-enoate. The thermal data is derived from the sample before $p-\mathrm{H}_{2}$ is introduced and the hyperpolarized data is derived from the first transient after shaking the sample. 
${ }^{1} \mathrm{H}$ NMR Spectrum, $600 \mathrm{MHz}$, acetone- $d_{6}\left(45^{\circ}\right.$ pulse $)$<smiles>C=CCC(C)C(=O)OCC</smiles>

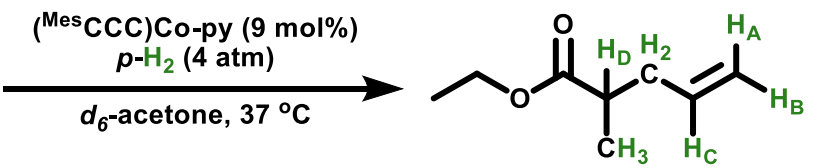

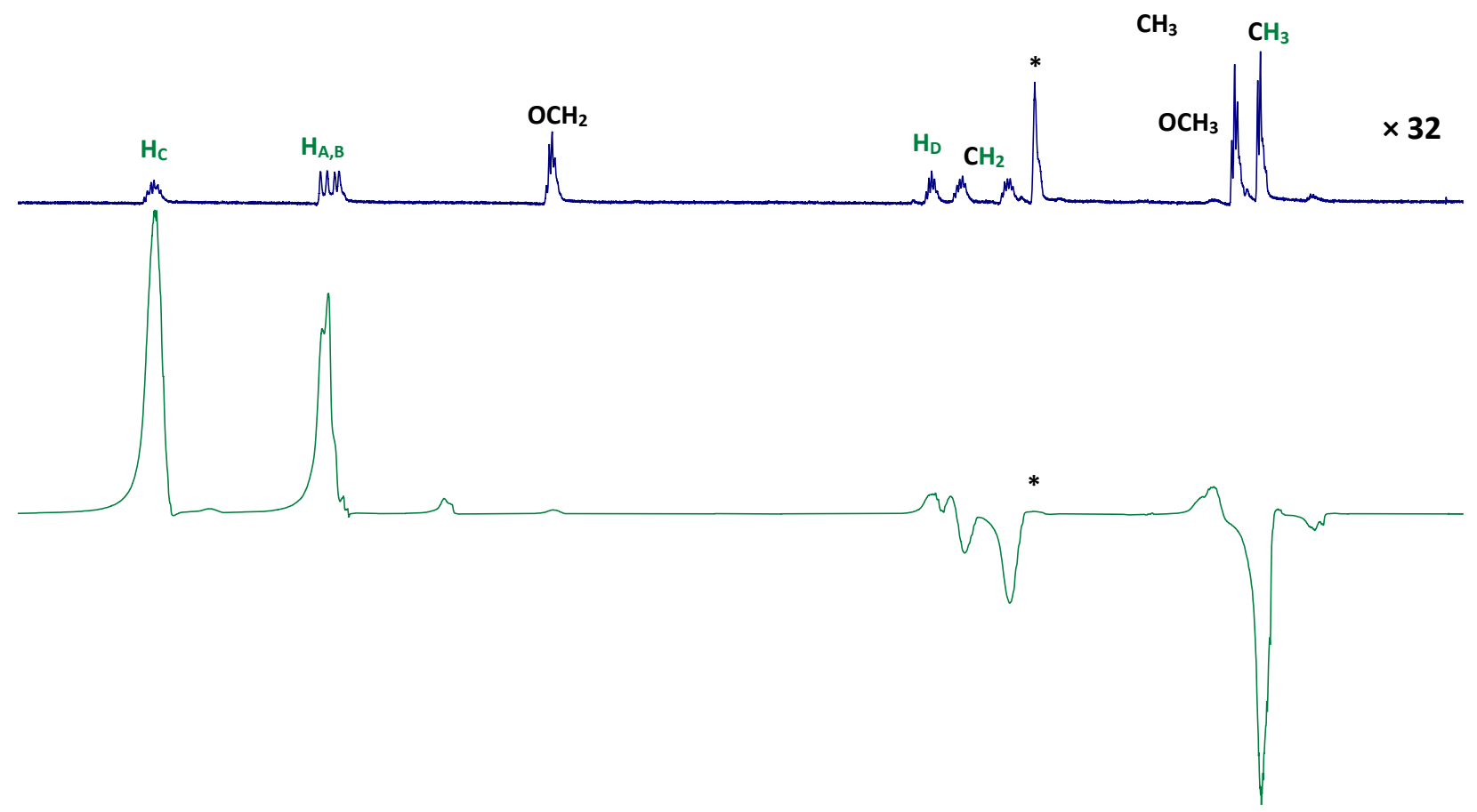

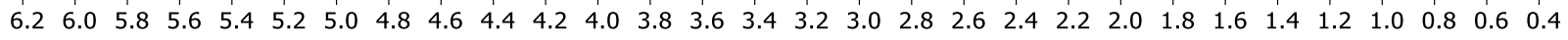
$\mathrm{ppm}$

Figure S49. ${ }^{1} \mathrm{H}$ NMR spectra (acetone- $d_{6}(*), 600 \mathrm{MHz}, 37{ }^{\circ} \mathrm{C}$ ) of the reaction of ethyl-2-methylpent-4enoate $(65 \mathrm{mM})$ using $\left({ }^{\text {Mes }} \mathrm{CCC}\right) \mathrm{Co}-\mathrm{py}(9 \mathrm{~mol} \%, 5.9 \mathrm{mM})$ and $p-\mathrm{H}_{2}(4 \mathrm{~atm})$ at the $50 \mathrm{G}$ fringe line of the magnet. Top: spectrum of the sample before $p-\mathrm{H}_{2}$ is introduced through shaking (thermal spectrum) expanded 32-fold compared to hyperpolarized spectrum. Bottom: First transient using a $45^{\circ}$ pulse after the $\mathbf{1}^{\text {st }}$ shake introducing $p-\mathrm{H}_{2}$ to the sample, showing the hyperpolarization of the terminal protons of the olefin (SABRE). 
${ }^{1} \mathrm{H}$ NMR Spectrum, $600 \mathrm{MHz}$, acetone- $d_{6}\left(45^{\circ}\right.$ pulse $)$

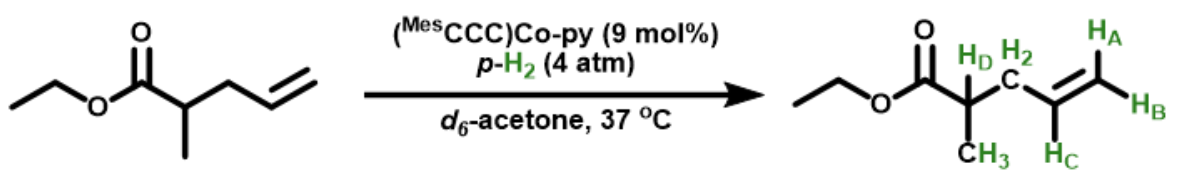

Transient:

6

5

4
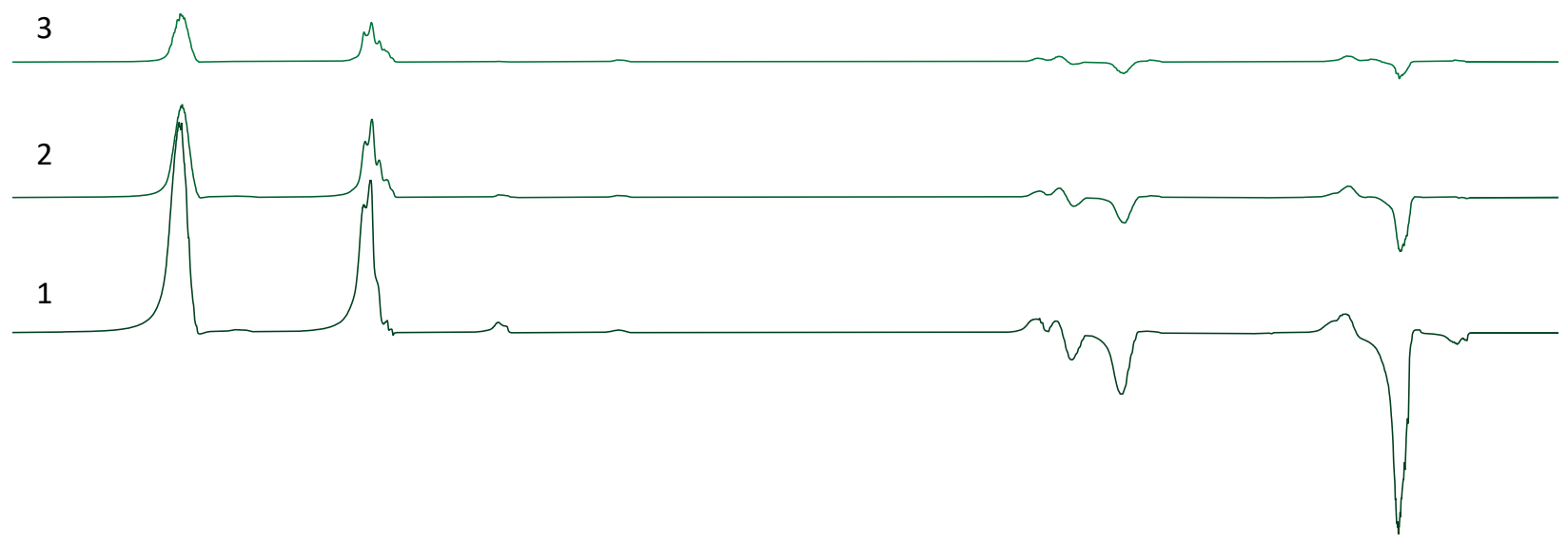

\begin{tabular}{lllllllllllllllllllllllllllllllllllllllllllllll}
\hline 4 & 6.2 & 6.0 & 5.8 & 5.6 & 5.4 & 5.2 & 5.0 & 4.8 & 4.6 & 4.4 & 4.2 & 4.0 & 3.8 & 3.6 & 3.4 & 3.2 & 3.0 & 2.8 & 2.6 & 2.4 & 2.2 & 2.0 & 1.8 & 1.6 & 1.4 & 1.2 & 1.0 & 0.8 & 0.6
\end{tabular}

Figure S50. ${ }^{1} \mathrm{H}$ NMR spectra (acetone- $d_{6}(*), 600 \mathrm{MHz}, 37^{\circ} \mathrm{C}$ ) showing the decay of polarization over time of the reaction of ethyl-2-methylpent-4-enoate $(65 \mathrm{mM})$ using $\left({ }^{\mathrm{Mes}} \mathrm{CCC}\right) \mathrm{Co}-\mathrm{py}(9 \mathrm{~mol} \%, 5.9 \mathrm{mM})$ and $p-\mathrm{H}_{2}(4 \mathrm{~atm})$ at the $50 \mathrm{G}$ fringe line of the magnet. No additional shaking occurred between transients. Bottom (dark green) spectrum is the first collected transient, followed by an acquisition time of $4.096 \mathrm{~s}$ to collect the next transient above it with no additional delay between transients. Subsequent transients were collected in the same fashion. 


\begin{tabular}{|l|c|c|c|}
\hline Proton $(\mathrm{ppm})$ & Thermal Integration & Hyperpolarized Integration & Enhancement (fold) \\
\hline $\mathrm{H}_{\mathrm{A}, \mathrm{B}}(4.99$ and 5.05) & 21.55 & 1142.87 & 53.0 \\
\hline $\mathrm{H}_{\mathrm{C}}(5.76)$ & 11.23 & 1708.39 & 152.1 \\
\hline $\mathrm{H}_{\mathrm{D}}(2.48)$ & 10.83 & 100.11 & 9.2 \\
\hline $\mathrm{CH}_{2}(2.16)$ & 13.58 & -461.98 & -34.0 \\
\hline $\mathrm{CH}_{2}(2.36)$ & 12.13 & -99.06 & -8.2 \\
\hline $\mathrm{CH}_{3}(1.10)$ & 34.7 & -1174.56 & -33.8 \\
\hline
\end{tabular}

Table S12. Signal enhancement calculated for the hyperpolarization of the ${ }^{1} \mathrm{H}$ of ethyl-2-methylpent-4enoate. The thermal data is derived from the sample before $p-\mathrm{H}_{2}$ is introduced and the hyperpolarized data is derived from the first transient after shaking the sample. 
${ }^{13} \mathrm{C}\left\{{ }^{1} \mathrm{H}\right\}$ NMR Spectrum, $150 \mathrm{MHz}$, acetone- $d_{6}\left(90^{\circ}\right.$ pulse $)$ - Magnitude mode

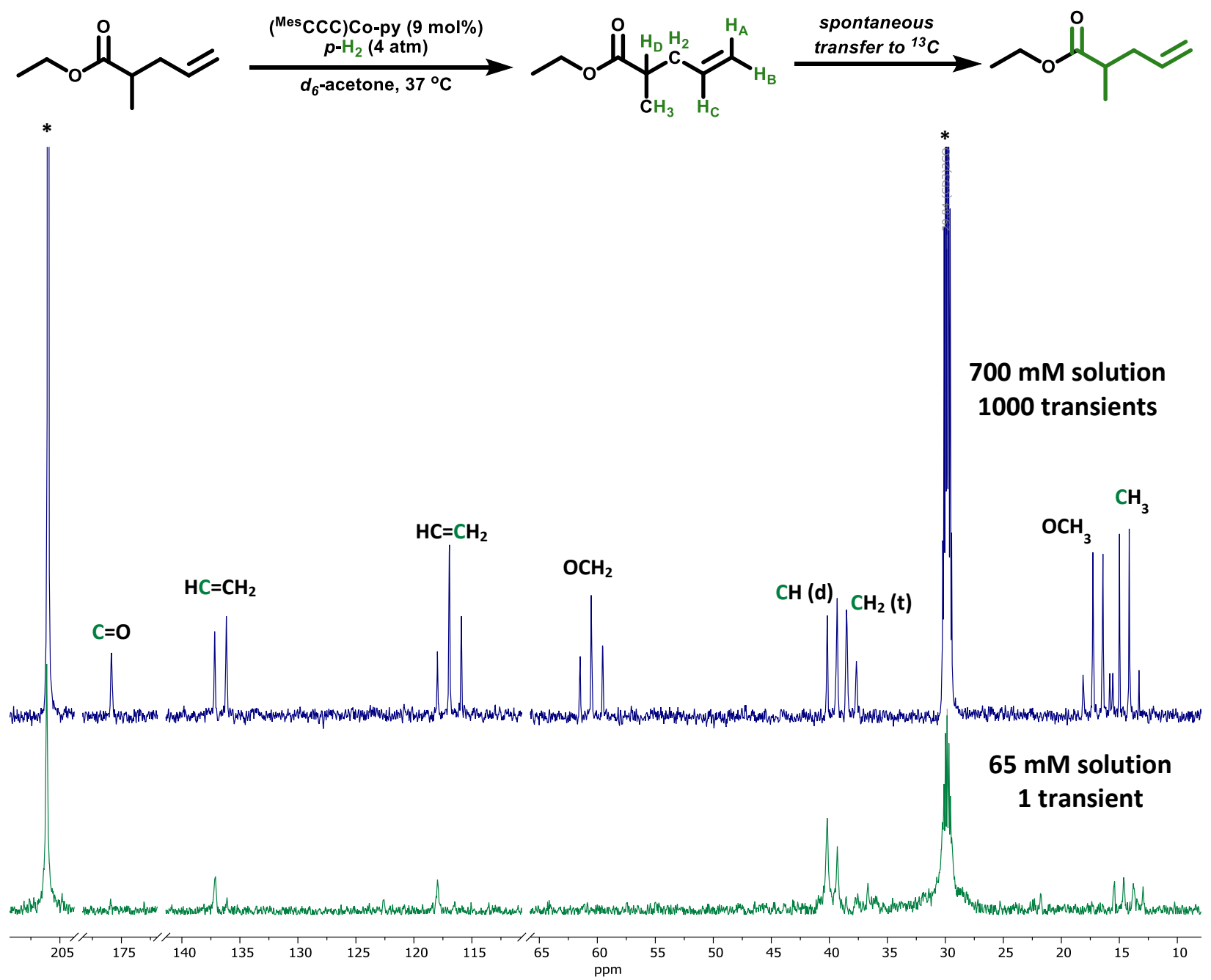

Figure S51. ${ }^{13} \mathrm{C}\left\{{ }^{1} \mathrm{H}\right\}$ NMR spectra (acetone- $d_{6}(*), 150 \mathrm{MHz}, 37{ }^{\circ} \mathrm{C}$ ) of the reaction of ethyl-2methylpentenoate $(65 \mathrm{mM})$ using $\left({ }^{\mathrm{Mes}} \mathrm{CCC}\right) \mathrm{Co}-\mathrm{py}(9 \mathrm{~mol} \%, 5.9 \mathrm{mM})$ and $p-\mathrm{H}_{2}(4 \mathrm{~atm})$ at earth's magnetic field with peakless regions removed. Top spectrum is a thermal ${ }^{13} \mathrm{C}\left\{{ }^{1} \mathrm{H}\right\}$ spectrum of 1000 transients of a $700 \mathrm{mM}$ solution of ethyl-2-methylpentenoate. The bottom spectrum is the first transient, in magnitude mode, after the $2^{\text {nd }}$ shake introducing $p-\mathrm{H}_{2}$ into the sample at earth's magnetic field. 
${ }^{13} \mathrm{C}\left\{{ }^{1} \mathrm{H}\right\}$ NMR Spectrum, $150 \mathrm{MHz}$, acetone- $d_{6}\left(90^{\circ}\right.$ pulse $)$ - Phased mode
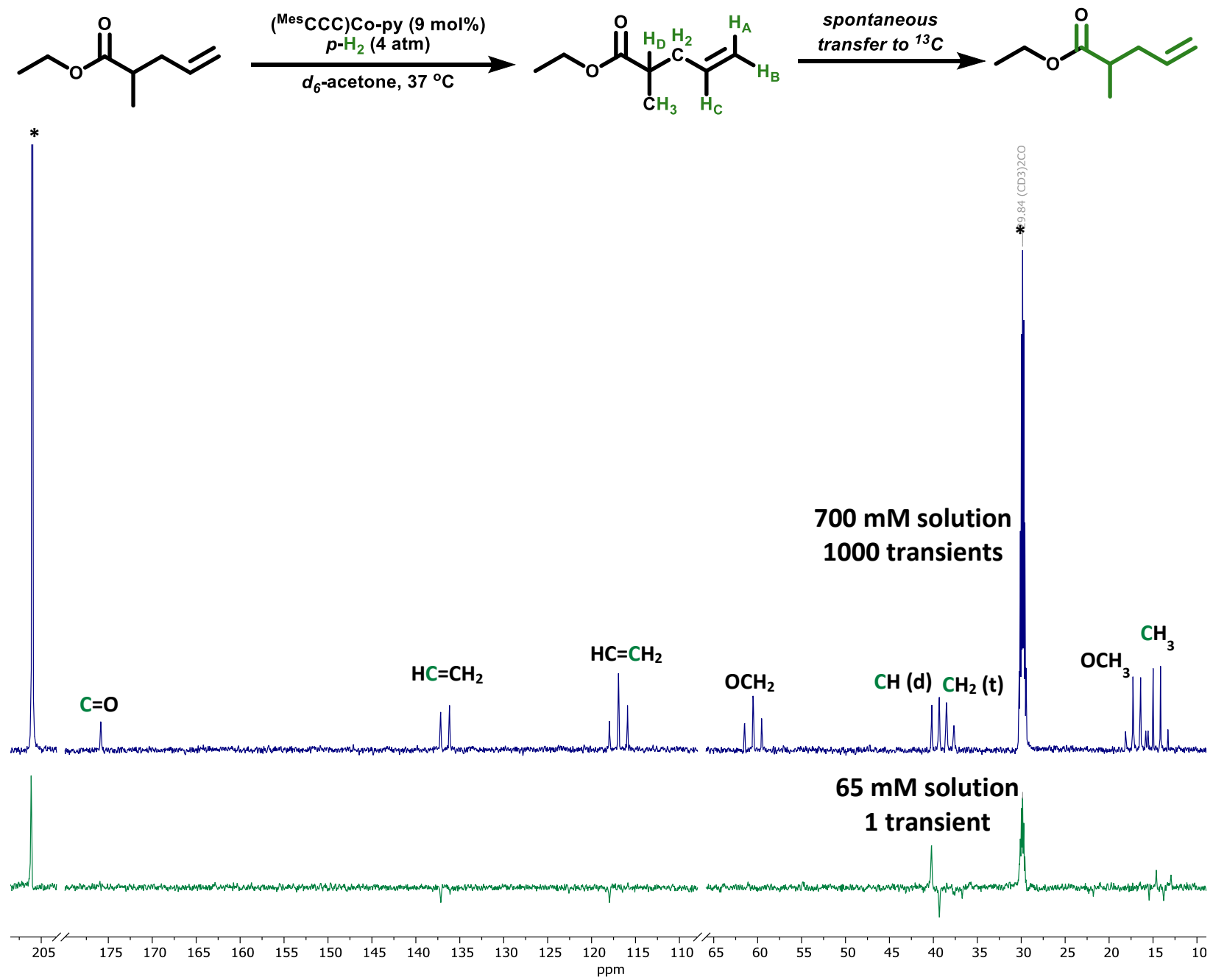

Figure S52. ${ }^{13} \mathrm{C}\left\{{ }^{1} \mathrm{H}\right\}$ NMR spectra (acetone- $d_{6}(*), 150 \mathrm{MHz}, 37{ }^{\circ} \mathrm{C}$ ) of the reaction of ethyl-2methylpentenoate $(65 \mathrm{mM})$ using $\left({ }^{\mathrm{Mes}} \mathrm{CCC}\right) \mathrm{Co}-\mathrm{py}(9 \mathrm{~mol} \%, 5.9 \mathrm{mM})$ and $p-\mathrm{H}_{2}(4 \mathrm{~atm})$ at earth's magnetic field with peakless regions removed. Top spectrum is a thermal ${ }^{13} \mathrm{C}\left\{{ }^{1} \mathrm{H}\right\}$ spectrum of 1000 transients of a $700 \mathrm{mM}$ solution of ethyl-2-methylpentenoate. The bottom spectrum is the first transient, in phased mode, after the $2^{\text {nd }}$ shake introducing $p-\mathrm{H}_{2}$ into the sample at earth's magnetic field. 
${ }^{13} \mathrm{C}\left\{{ }^{1} \mathrm{H}\right\}$ NMR Spectrum, $150 \mathrm{MHz}$, acetone- $d_{6}\left(90^{\circ}\right.$ pulse $)$

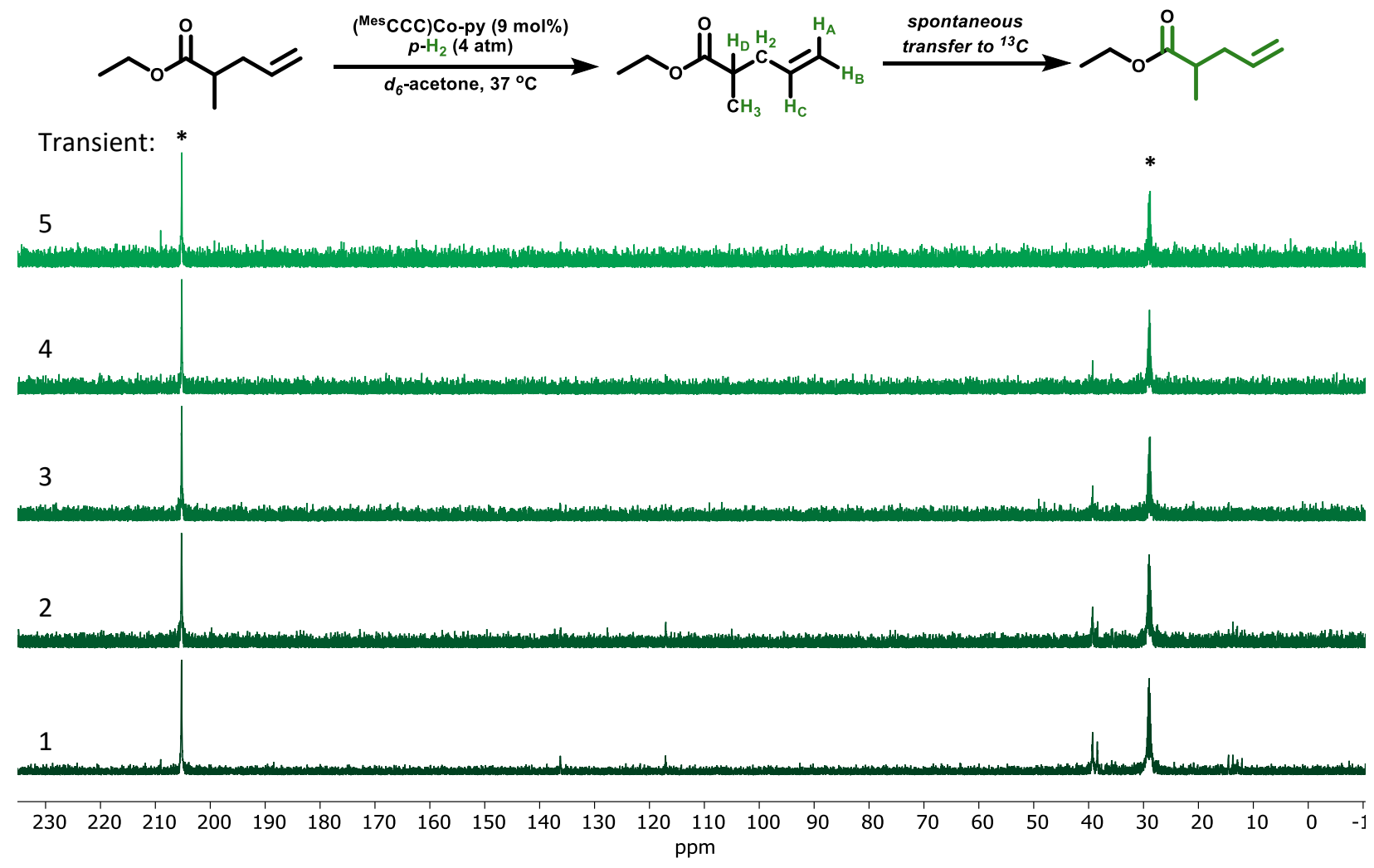

Figure S53. ${ }^{13} \mathrm{C}\left\{{ }^{1} \mathrm{H}\right\}$ NMR spectra (acetone- $d_{6}(*), 150 \mathrm{MHz}, 37{ }^{\circ} \mathrm{C}$ ), in magnitude mode, showing the decay of polarization over time of the reaction of ethyl-2-methylpentenoate $(65 \mathrm{mM})$ using $\left({ }^{\mathrm{Mes}} \mathrm{CCC}\right) \mathrm{Co}-$ py $(9 \mathrm{~mol} \%, 5.9 \mathrm{mM})$ and $p-\mathrm{H}_{2}(4 \mathrm{~atm})$ at earth's magnetic field. No additional shaking occurred between transients. Bottom (dark green) spectrum is the first collected transient of the $2^{\text {nd }}$ shake of $p-\mathrm{H}_{2}$ into the sample, followed by an acquisition time of $1.7695 \mathrm{~s}$ to collect the next transient above it, with no delay time in between. Subsequent transients were collected in the same fashion. 
${ }^{13} \mathrm{C}$ NMR Spectrum, $150 \mathrm{MHz}$, acetone- $d_{6}\left(90^{\circ}\right.$ pulse $)$ - Magnitude mode
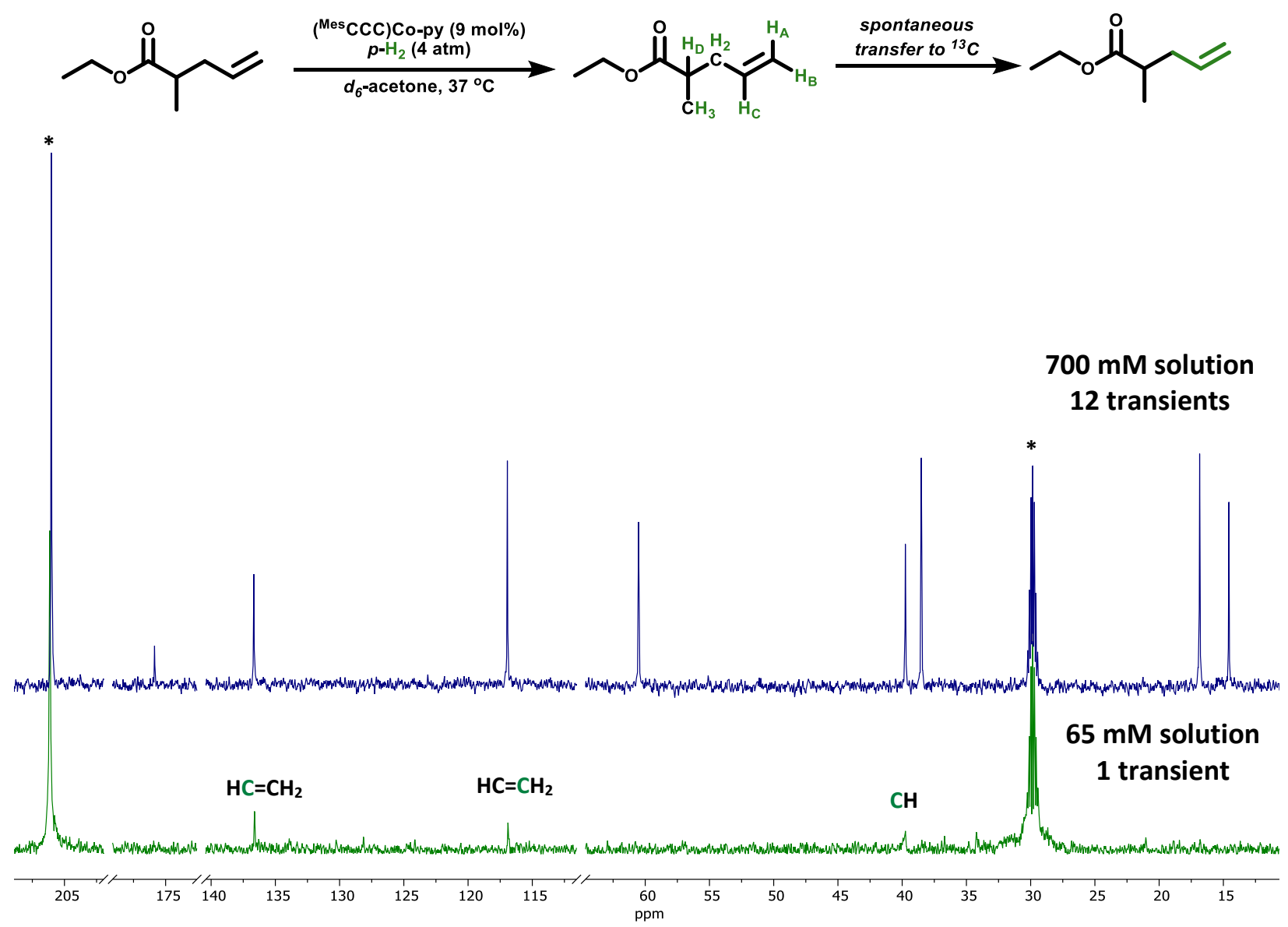

Figure S54. ${ }^{13} \mathrm{C}$ NMR spectra (acetone- $d_{6}(*), 150 \mathrm{MHz}, 37^{\circ} \mathrm{C}$ ) of the reaction of ethyl-2-methylpentenoate $(65 \mathrm{mM})$ using ( $\left.{ }^{\text {Mes }} \mathrm{CCC}\right) \mathrm{Co}$-py $(9 \mathrm{~mol} \%, 5.9 \mathrm{mM})$ and $p-\mathrm{H}_{2}(4 \mathrm{~atm})$ at earth's magnetic field with peakless regions removed. Top spectrum is a thermal spectrum of 12 transients of a $700 \mathrm{mM}$ solution of ethyl-2methylpentenoate. The bottom spectrum is the first transient, in magnitude mode, after the $2^{\text {nd }}$ shake introducing $p-\mathrm{H}_{2}$ into the sample at earth's magnetic field. 
${ }^{13} \mathrm{C}$ NMR Spectrum, $150 \mathrm{MHz}$, acetone- $d_{6}\left(90^{\circ}\right.$ pulse $)$ - Phased mode

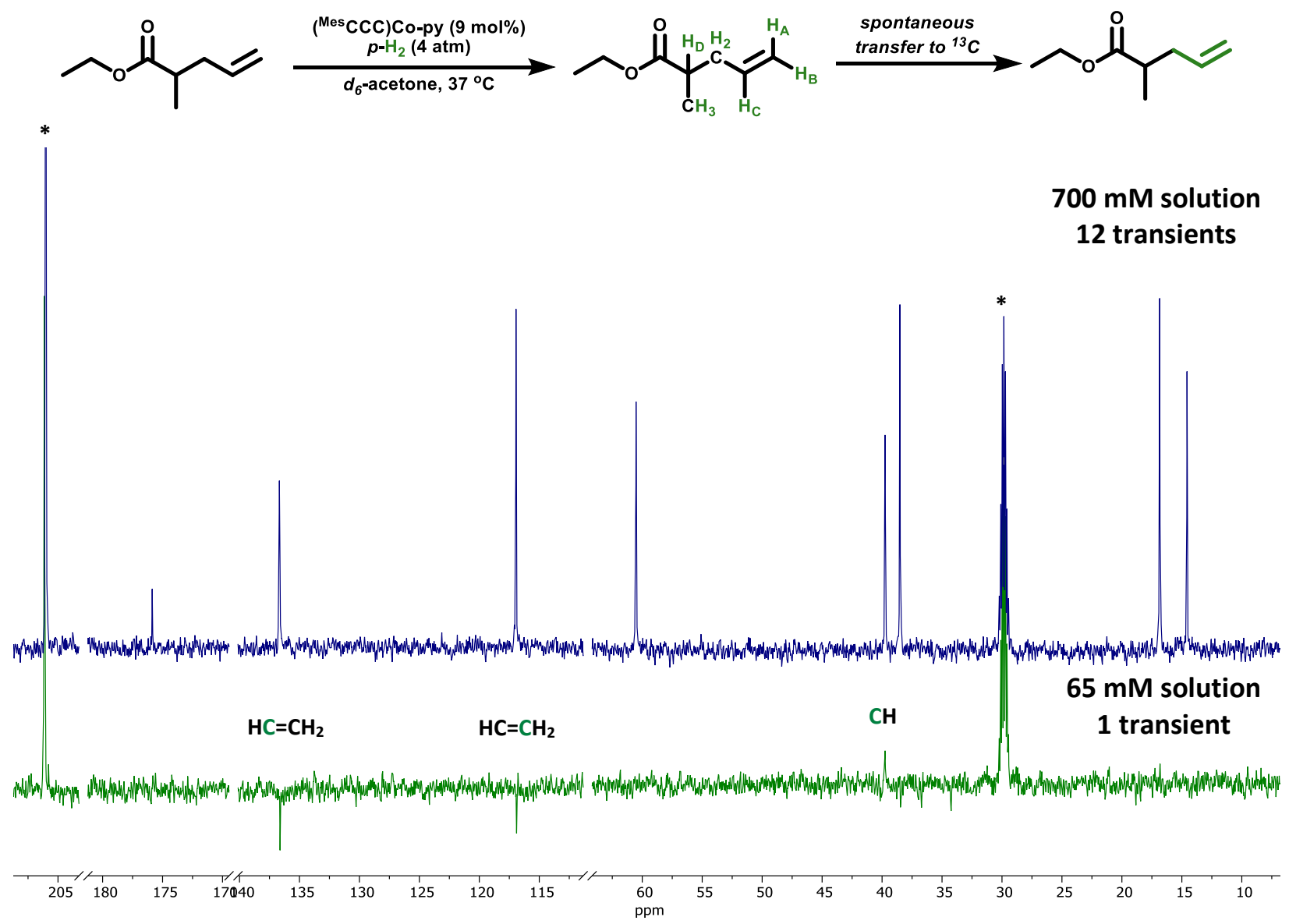

Figure S55. ${ }^{13} \mathrm{C}$ NMR spectra (acetone- $d_{6}(*), 150 \mathrm{MHz}, 37^{\circ} \mathrm{C}$ ) of the reaction of ethyl-2-methylpentenoate $(65 \mathrm{mM})$ using ( $\left.{ }^{\mathrm{Mes}} \mathrm{CCC}\right) \mathrm{Co}-\mathrm{py}(9 \mathrm{~mol} \%, 5.9 \mathrm{mM})$ and $p-\mathrm{H}_{2}(4 \mathrm{~atm})$ at earth's magnetic field with peakless regions removed. Top spectrum is a thermal spectrum of 12 transients of a $700 \mathrm{mM}$ solution of ethyl-2methylpentenoate. The bottom spectrum is the first transient, in phased mode, after the $2^{\text {nd }}$ shake introducing $p-\mathrm{H}_{2}$ into the sample at earth's magnetic field. 
${ }^{13} \mathrm{C}$ NMR Spectrum, $150 \mathrm{MHz}$, acetone- $d_{6}\left(90^{\circ}\right.$ pulse $)$

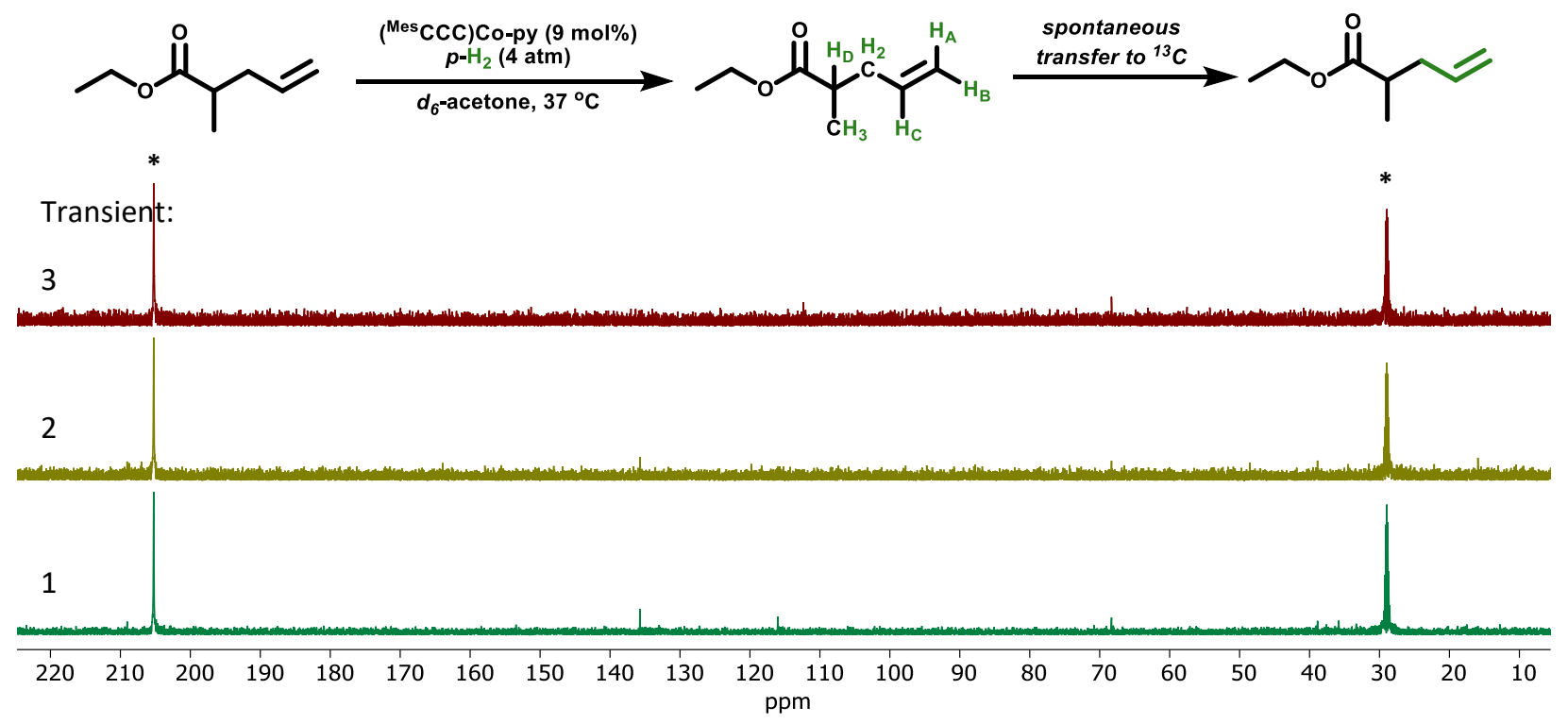

Figure S56. ${ }^{13} \mathrm{C}$ NMR spectra (acetone- $d_{6}(*), 150 \mathrm{MHz}, 37{ }^{\circ} \mathrm{C}$ ), in magnitude mode, showing the decay of polarization over time of the reaction of ethyl-2-methylpentenoate $(65 \mathrm{mM})$ using $\left({ }^{\mathrm{Mes}} \mathrm{CCC}\right) \mathrm{Co}-\mathrm{py}(9$ $\mathrm{mol} \%, 5.9 \mathrm{mM})$ and $p-\mathrm{H}_{2}(4 \mathrm{~atm})$ at earth's magnetic field. No additional shaking occurred between transients. Bottom (green) spectrum is the first collected transient of the $2^{\text {nd }}$ shake of $p-\mathrm{H}_{2}$ into the sample, followed by an acquisition time of $1.7695 \mathrm{~s}$ to collect the next transient (yellow), with no delay time in between. Subsequent transients were collected in the same fashion. 
${ }^{13} \mathrm{C}$ NMR Spectrum, $150 \mathrm{MHz}$, acetone- $d_{6}\left(90^{\circ}\right.$ pulse $)$ - Magnitude mode
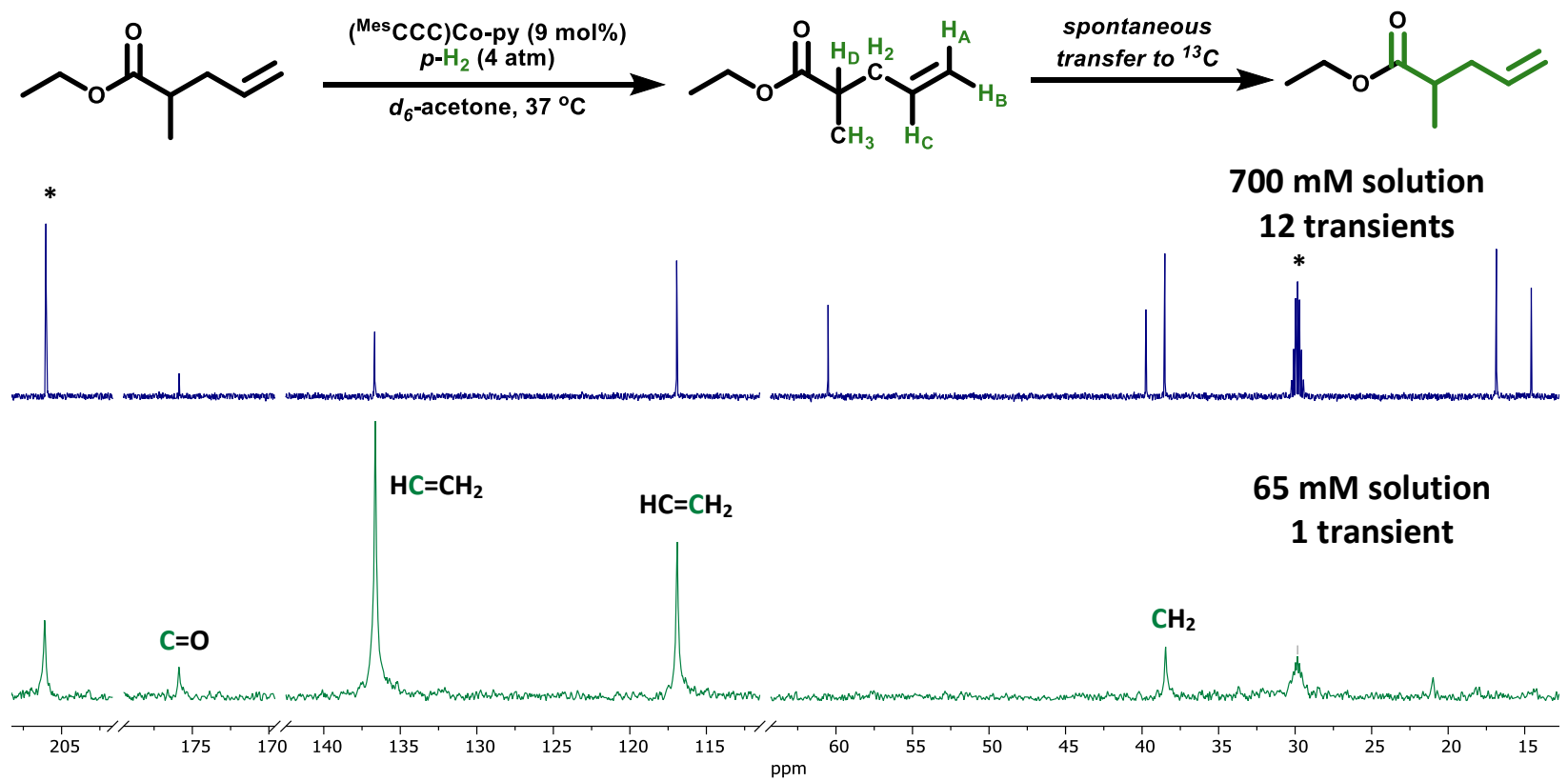

Figure S57. ${ }^{13} \mathrm{C}$ NMR spectra (acetone- $d_{6}(*), 150 \mathrm{MHz}, 37^{\circ} \mathrm{C}$ ) of the reaction of ethyl-2-methylpentenoate $(65 \mathrm{mM})$ using $\left({ }^{\mathrm{Mes}} \mathrm{CCC}\right) \mathrm{Co}-\mathrm{py}(9 \mathrm{~mol} \%, 5.9 \mathrm{mM})$ and $p-\mathrm{H}_{2}(4 \mathrm{~atm})$ in mu-Metal with peakless region removed. Top spectrum is a thermal spectrum of 12 transients of a $700 \mathrm{mM}$ solution of ethyl-2methylpentenoate. The bottom spectrum is the first transient, in magnitude mode, after the $3^{\text {rd }}$ shake introducing $p-\mathrm{H}_{2}$ into the sample in the $\mu \mathrm{T}$ fields afforded by mu-Metal. 
${ }^{13} \mathrm{C}$ NMR Spectrum, $150 \mathrm{MHz}$, acetone- $d_{6}\left(90^{\circ}\right.$ pulse $)$ - Phased mode
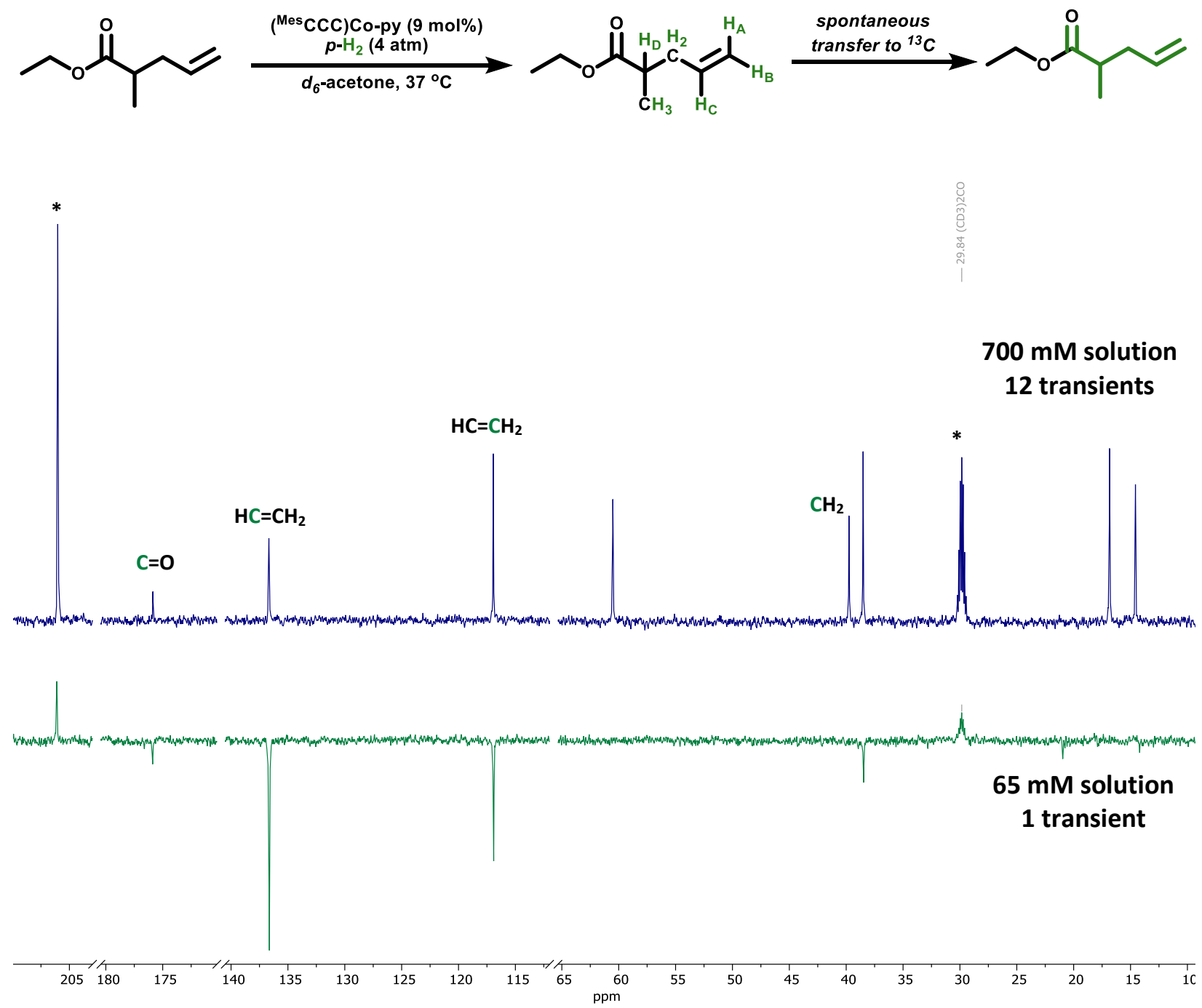

Figure S58. ${ }^{13} \mathrm{C}$ NMR spectra (acetone- $d_{6}(*), 150 \mathrm{MHz}, 37^{\circ} \mathrm{C}$ ) of the reaction of ethyl-2-methylpentenoate $(65 \mathrm{mM})$ using $\left({ }^{\mathrm{Mes}} \mathrm{CCC}\right) \mathrm{Co}-\mathrm{py}(9 \mathrm{~mol} \%, 5.9 \mathrm{mM})$ and $p-\mathrm{H}_{2}(4 \mathrm{~atm})$ in mu-Metal with peakless region removed. Top spectrum is a thermal spectrum of 12 transients of a $700 \mathrm{mM}$ solution of ethyl-2methylpentenoate. The bottom spectrum is the first transient, in phased mode, after the $3^{\text {rd }}$ shake introducing $p-\mathrm{H}_{2}$ into the sample in the $\mu \mathrm{T}$ fields afforded by mu-Metal. 
${ }^{13} \mathrm{C}$ NMR Spectrum, $150 \mathrm{MHz}$, acetone- $d_{6}\left(90^{\circ}\right.$ pulse $)$

Transient:
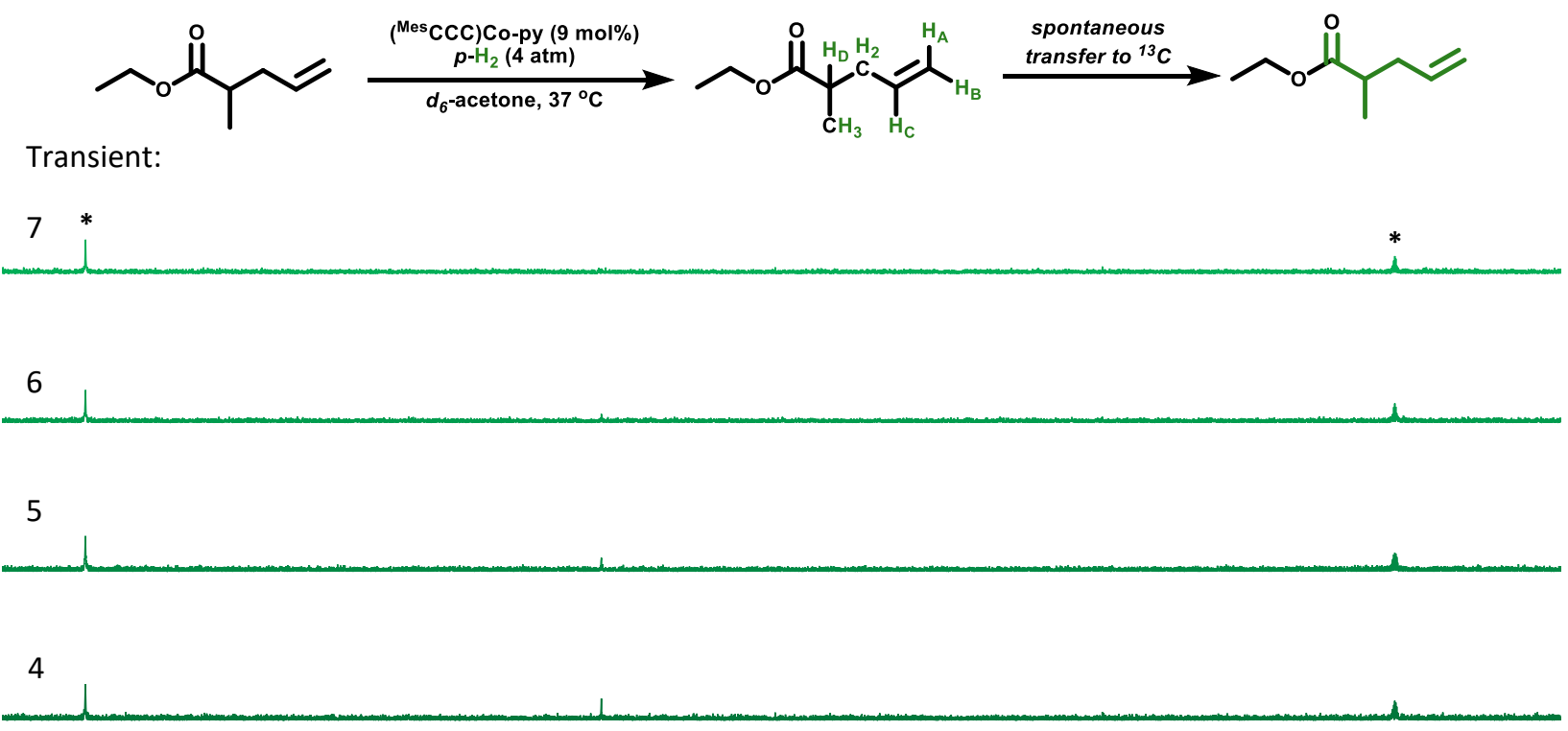

3

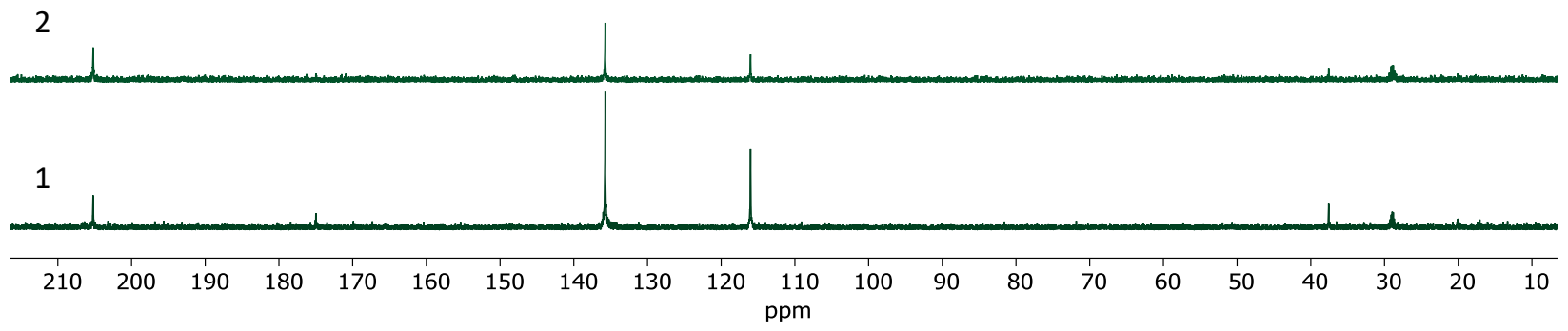

Figure S59. ${ }^{13} \mathrm{C}$ NMR spectra (acetone- $d_{6}(*), 150 \mathrm{MHz}, 37{ }^{\circ} \mathrm{C}$ ), in magnitude mode, showing the decay of polarization over time of the reaction of ethyl-2-methylpentenoate $(65 \mathrm{mM})$ using $\left({ }^{\mathrm{Mes}} \mathrm{CCC}\right) \mathrm{Co}-\mathrm{py}(9$ $\mathrm{mol} \%, 5.9 \mathrm{mM})$ and $p-\mathrm{H}_{2}(4 \mathrm{~atm})$ in mu-Metal. No additional shaking occurred between transients. Bottom (green) spectrum is the first collected transient of the $\mathbf{2}^{\text {nd }}$ shake of $p-\mathrm{H}_{2}$ into the sample, followed by an acquisition time of $1.7695 \mathrm{~s}$ to collect the next transient (yellow), with no delay time in between. Subsequent transients were collected in the same fashion. 
${ }^{1} \mathrm{H}$ NMR Spectrum, $600 \mathrm{MHz}$, acetone- $d_{6}\left(45^{\circ}\right.$ pulse $)$
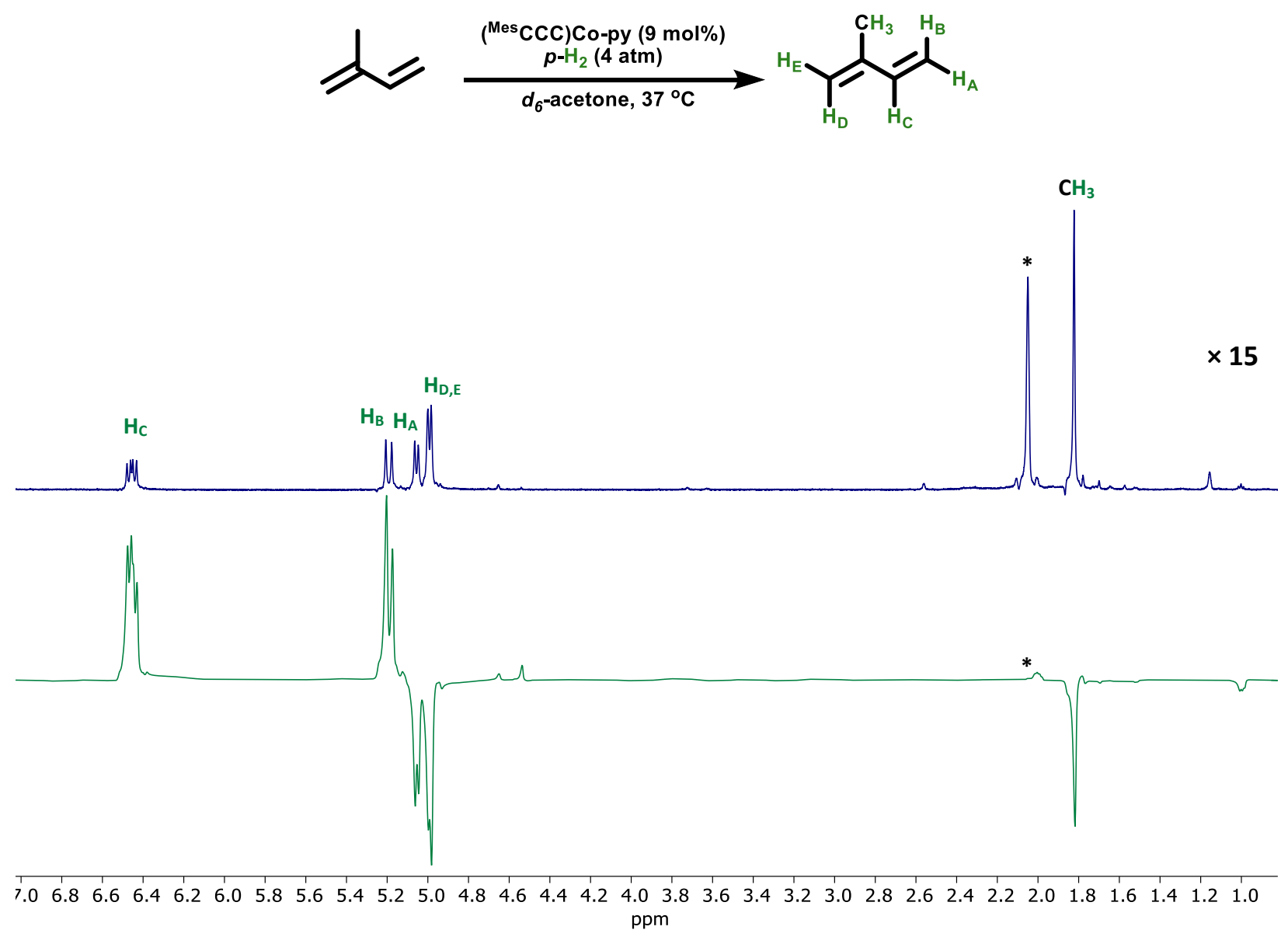

Figure S60. ${ }^{1} \mathrm{H}$ NMR spectra (acetone- $d_{6}(*), 600 \mathrm{MHz}, 37^{\circ} \mathrm{C}$ ) of the reaction of isoprene $(65 \mathrm{mM})$ using ( $\left.{ }^{\mathrm{Mes}} \mathrm{CCC}\right) \mathrm{Co}$-py $(9 \mathrm{~mol} \%, 5.9 \mathrm{mM})$ and $p-\mathrm{H}_{2}(4 \mathrm{~atm})$ at the $50 \mathrm{G}$ fringe line of the magnet. Top: spectrum of the sample before $p-\mathrm{H}_{2}$ is introduced through shaking (thermal spectrum) expanded 15-fold compared to hyperpolarized spectrum. Bottom: First transient using a $45^{\circ}$ pulse after the $\mathbf{1}^{\text {st }}$ shake introducing $p-\mathrm{H}_{2}$ to the sample, showing the hyperpolarization of entire molecule (SABRE). 
${ }^{1} \mathrm{H}$ NMR Spectrum, $600 \mathrm{MHz}$, acetone- $d_{6}\left(45^{\circ}\right.$ pulse $)$

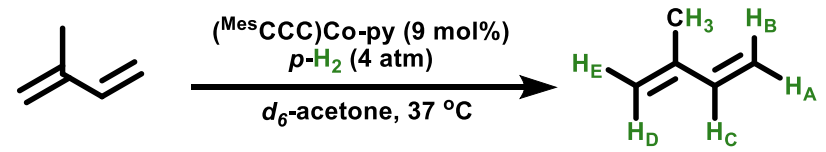

7

6

5

4

3
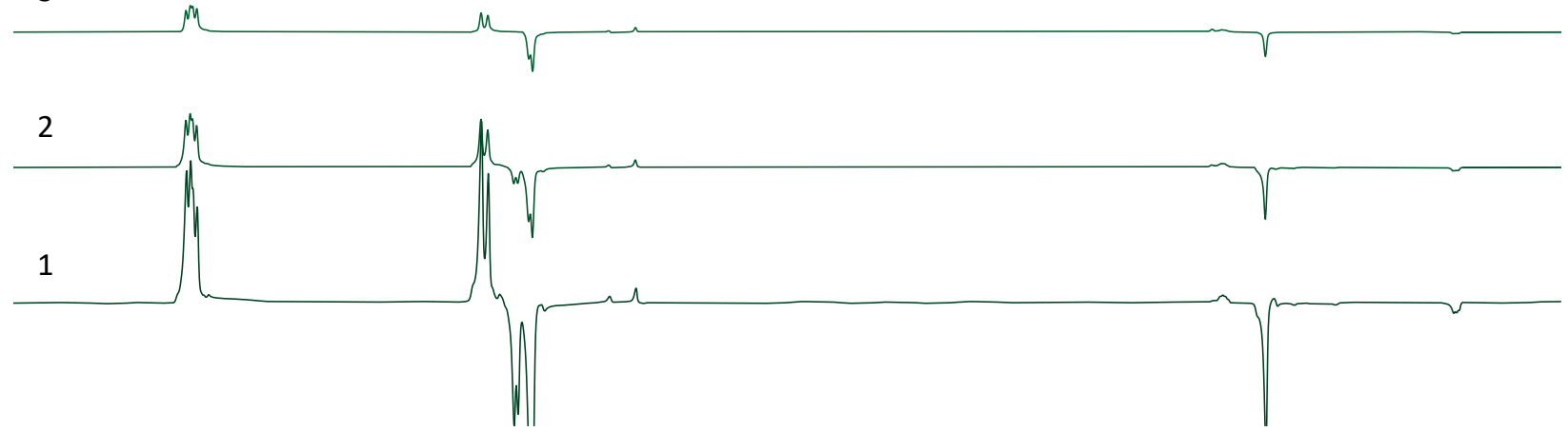

$\begin{array}{llllllllllllllllllllllllllllllllllllllllllllllll}7.2 & 7.0 & 6.8 & 6.6 & 6.4 & 6.2 & 6.0 & 5.8 & 5.6 & 5.4 & 5.2 & 5.0 & 4.8 & 4.6 & 4.4 & 4.2 & 4.0 & 3.8 & 3.6 & 3.4 & 3.2 & 3.0 & 2.8 & 2.6 & 2.4 & 2.2 & 2.0 & 1.8 & 1.6 & 1.4 & 1.2 & 1.0 & 0.8 & 0.4\end{array}$ ppm

Figure S61. ${ }^{1} \mathrm{H}$ NMR spectra (acetone- $d_{6}(*), 600 \mathrm{MHz}, 37{ }^{\circ} \mathrm{C}$ ) showing the decay of polarization over time of the reaction of isoprene $(65 \mathrm{mM})$ using $\left({ }^{\mathrm{Mes}} \mathrm{CCC}\right) \mathrm{Co}-\mathrm{py}(9 \mathrm{~mol} \%, 5.9 \mathrm{mM})$ and $p-\mathrm{H}_{2}(4 \mathrm{~atm})$ at the $50 \mathrm{G}$ fringe line of the magnet. No additional shaking occurred between transients. Bottom (dark green) spectrum is the first collected transient, followed by an acquisition time of $4.096 \mathrm{~s}$ to collect the next transient above it, with no additional delay between transients. Subsequent transients were collected in the same fashion.

\begin{tabular}{|l|c|c|c|}
\hline Proton $(\mathrm{ppm})$ & Thermal Integration & Hyperpolarized Integration & Enhancement (fold) \\
\hline $\mathrm{H}_{\mathrm{A}}(5.19)$ & 54.2 & 5770.38 & 106.5 \\
\hline $\mathrm{H}_{\mathrm{B}}(5.05)$ & 53.32 & -3732.91 & -70.0 \\
\hline $\mathrm{H}_{\mathrm{C}}(6.45)$ & 53.83 & 6713.5 & 124.7 \\
\hline $\mathrm{H}_{\mathrm{D}, \mathrm{E}}(5.00$ and 4.98$)$ & 106.88 & -5088.33 & -47.6 \\
\hline $\mathrm{CH}_{3}(1.83)$ & 161.75 & -2640.01 & -16.3 \\
\hline
\end{tabular}

Table S13. Signal enhancement calculated for the hyperpolarization of the ${ }^{1} \mathrm{H}$ of isoprene. The thermal data is derived from the sample before $p-\mathrm{H}_{2}$ is introduced and the hyperpolarized data is derived from the first transient after shaking the sample. 
${ }^{13} \mathrm{C}\left\{{ }^{1} \mathrm{H}\right\}$ NMR Spectrum, $150 \mathrm{MHz}$, acetone- $d_{6}\left(90^{\circ}\right.$ pulse $)$ - Magnitude mode
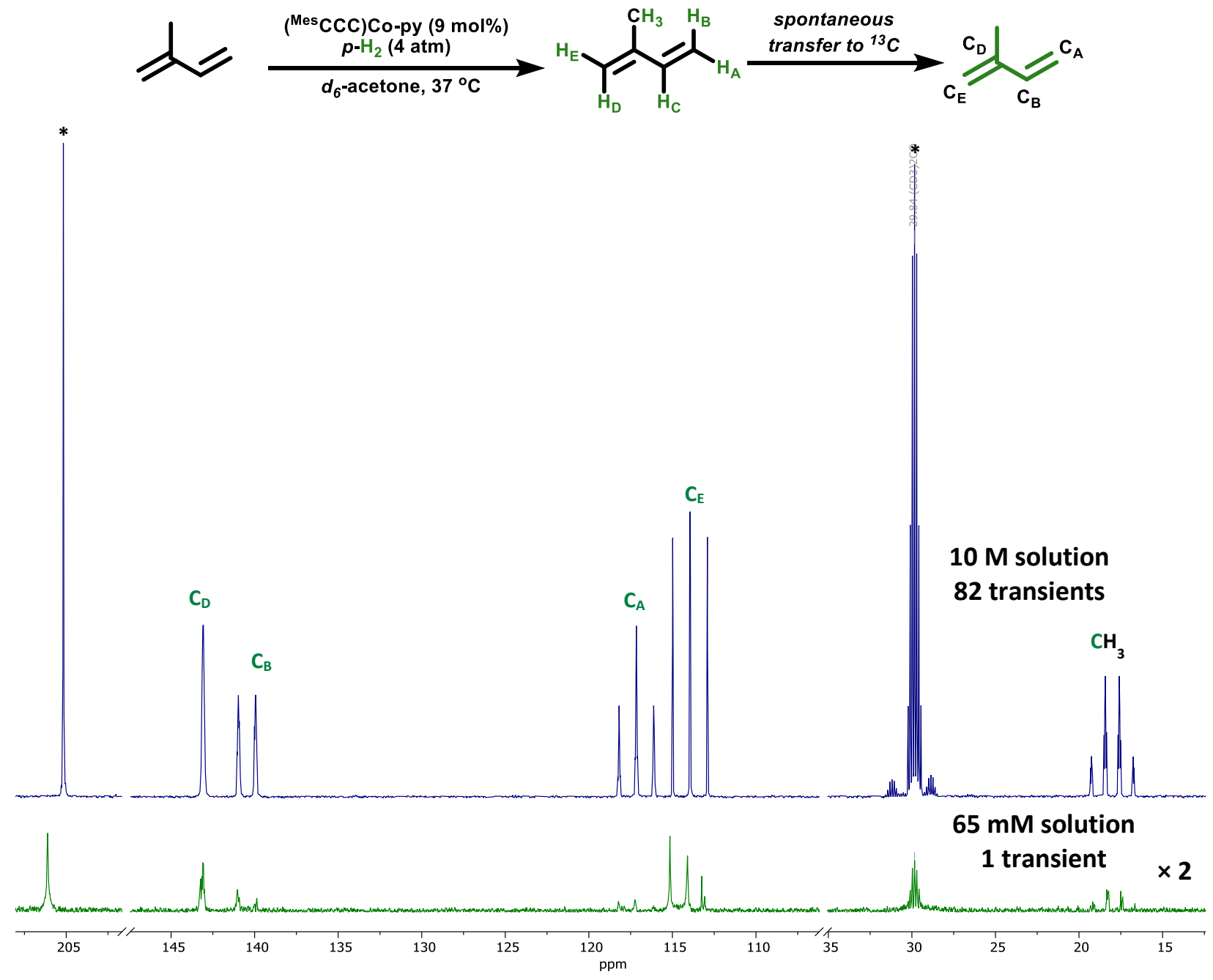

Figure S62. ${ }^{13} \mathrm{C}\left\{{ }^{1} \mathrm{H}\right\}$ NMR spectra (acetone- $d_{6}(*), 150 \mathrm{MHz}, 37{ }^{\circ} \mathrm{C}$ ) of the reaction of isoprene $(65 \mathrm{mM})$ using ( $\left.{ }^{\text {Mes }} \mathrm{CCC}\right) \mathrm{Co}-\mathrm{py}(9 \mathrm{~mol} \%, 5.9 \mathrm{mM})$ and $p-\mathrm{H}_{2}(4 \mathrm{~atm})$ at earth's magnetic field with peakless regions removed. Top spectrum is a thermal spectrum of 82 transients of a $10 \mathrm{M}$ solution of isoprene. The bottom spectrum is the first transient, in magnitude mode, after the $4^{\text {th }}$ shake introducing $p-\mathrm{H}_{2}$ into the sample at earth's magnetic field, expanded 2-fold compared to the top spectrum. 
${ }^{13} \mathrm{C}\left\{{ }^{1} \mathrm{H}\right\}$ NMR Spectrum, $150 \mathrm{MHz}$, acetone- $d_{6}\left(90^{\circ}\right.$ pulse $)$ - Phased mode
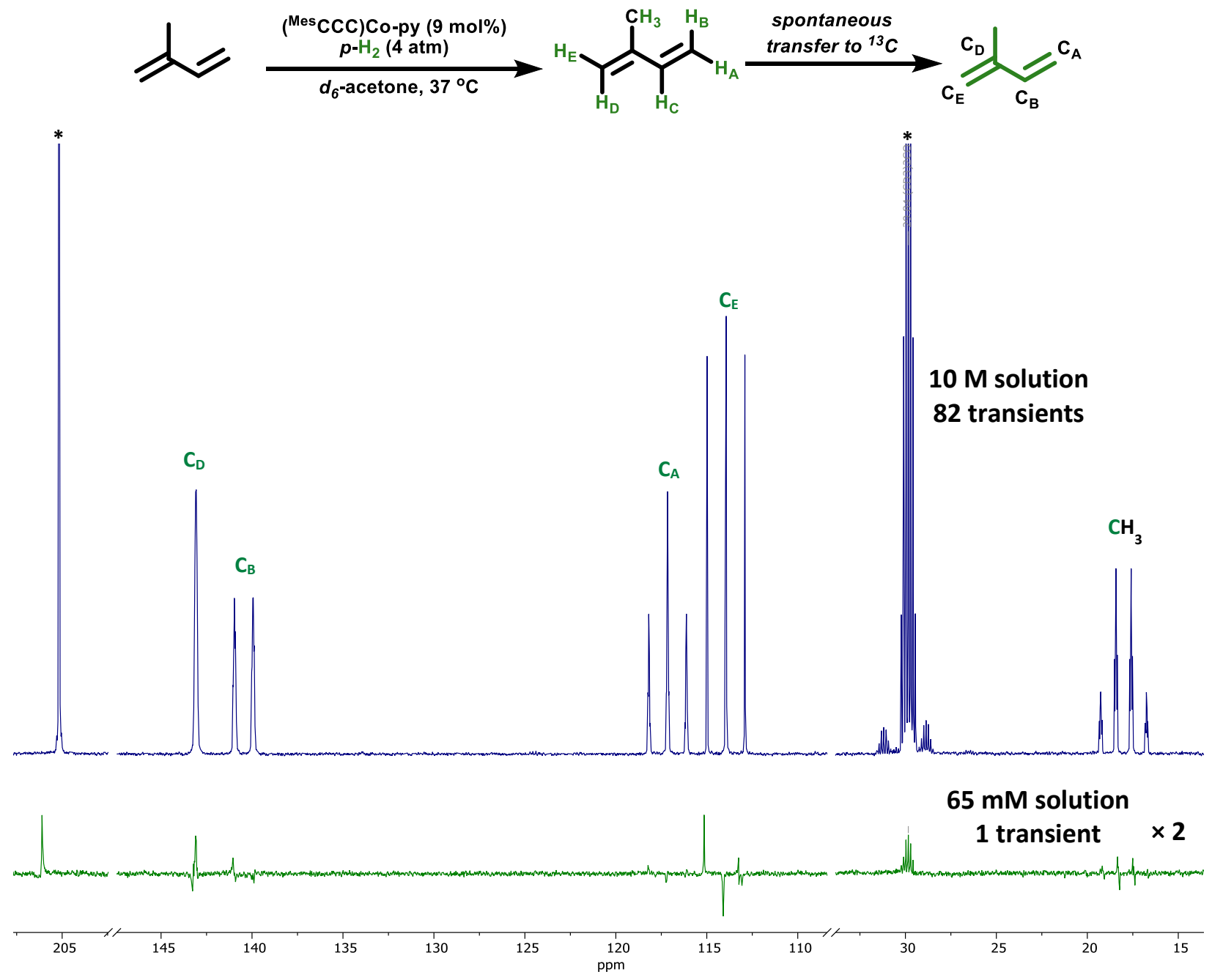

Figure S63. ${ }^{13} \mathrm{C}\left\{{ }^{1} \mathrm{H}\right\}$ NMR spectra (acetone- $d_{6}(*), 150 \mathrm{MHz}, 37{ }^{\circ} \mathrm{C}$ ) of the reaction of isoprene $(65 \mathrm{mM})$ using ( $\left.{ }^{\text {Mes }} \mathrm{CCC}\right)$ Co-py $(9 \mathrm{~mol} \%, 5.9 \mathrm{mM})$ and $p-\mathrm{H}_{2}(4 \mathrm{~atm})$ at earth's magnetic field with peakless regions removed. Top spectrum is a thermal spectrum of 1000 transients of a $1306 \mathrm{mM}$ solution of isoprene. The bottom spectrum is the first transient, in phased mode, after the $4^{\text {th }}$ shake introducing $p-\mathrm{H}_{2}$ into the sample at earth's magnetic field, expanded 2-fold compared to the top spectrum. 
${ }^{13} \mathrm{C}\left\{{ }^{1} \mathrm{H}\right\}$ NMR Spectrum, $150 \mathrm{MHz}$, acetone- $d_{6}\left(90^{\circ}\right.$ pulse $)$
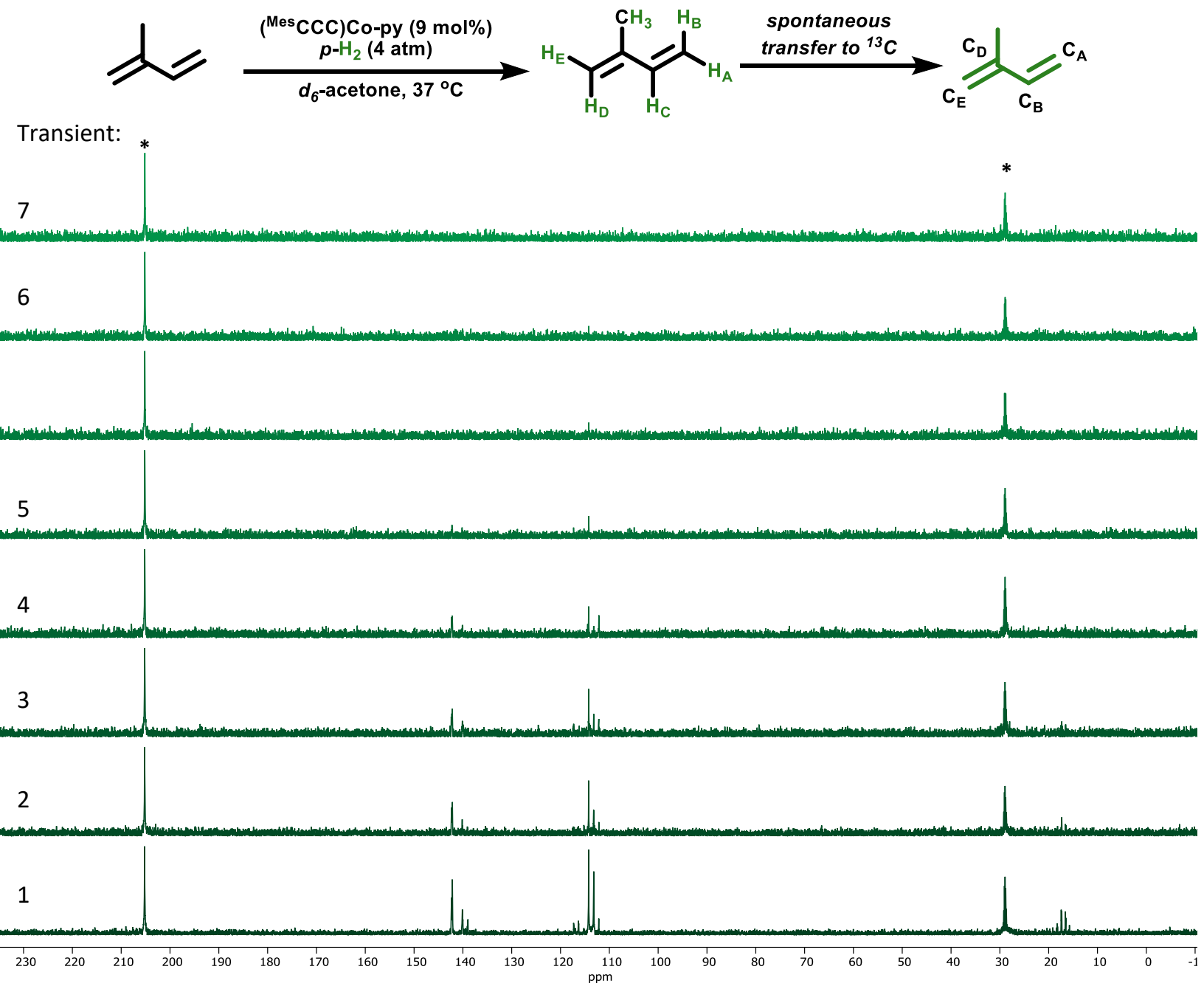

Figure S64. ${ }^{13} \mathrm{C}\left\{{ }^{1} \mathrm{H}\right\}$ NMR spectra (acetone- $d_{6}(*), 150 \mathrm{MHz}, 37{ }^{\circ} \mathrm{C}$ ), in magnitude mode, showing the decay of polarization over time of the reaction of isoprene $(65 \mathrm{mM})$ using $\left({ }^{\text {Mes }} \mathrm{CCC}\right)$ Co-py $(9 \mathrm{~mol} \%, 5.9$ $\mathrm{mM})$ and $p-\mathrm{H}_{2}(4 \mathrm{~atm})$ at earth's magnetic field. No additional shaking occurred between transients. Bottom (dark green) spectrum is the first collected transient of the $4^{\text {th }}$ shake of $p-\mathrm{H}_{2}$ into the sample, followed by an acquisition time of $1.7695 \mathrm{~s}$ to collect the next transient above it, with no delay time in between. Subsequent transients were collected in the same fashion. 
${ }^{1} \mathrm{H}$ NMR Spectrum, $600 \mathrm{MHz}$, acetone- $d_{6}\left(45^{\circ}\right.$ pulse $)$
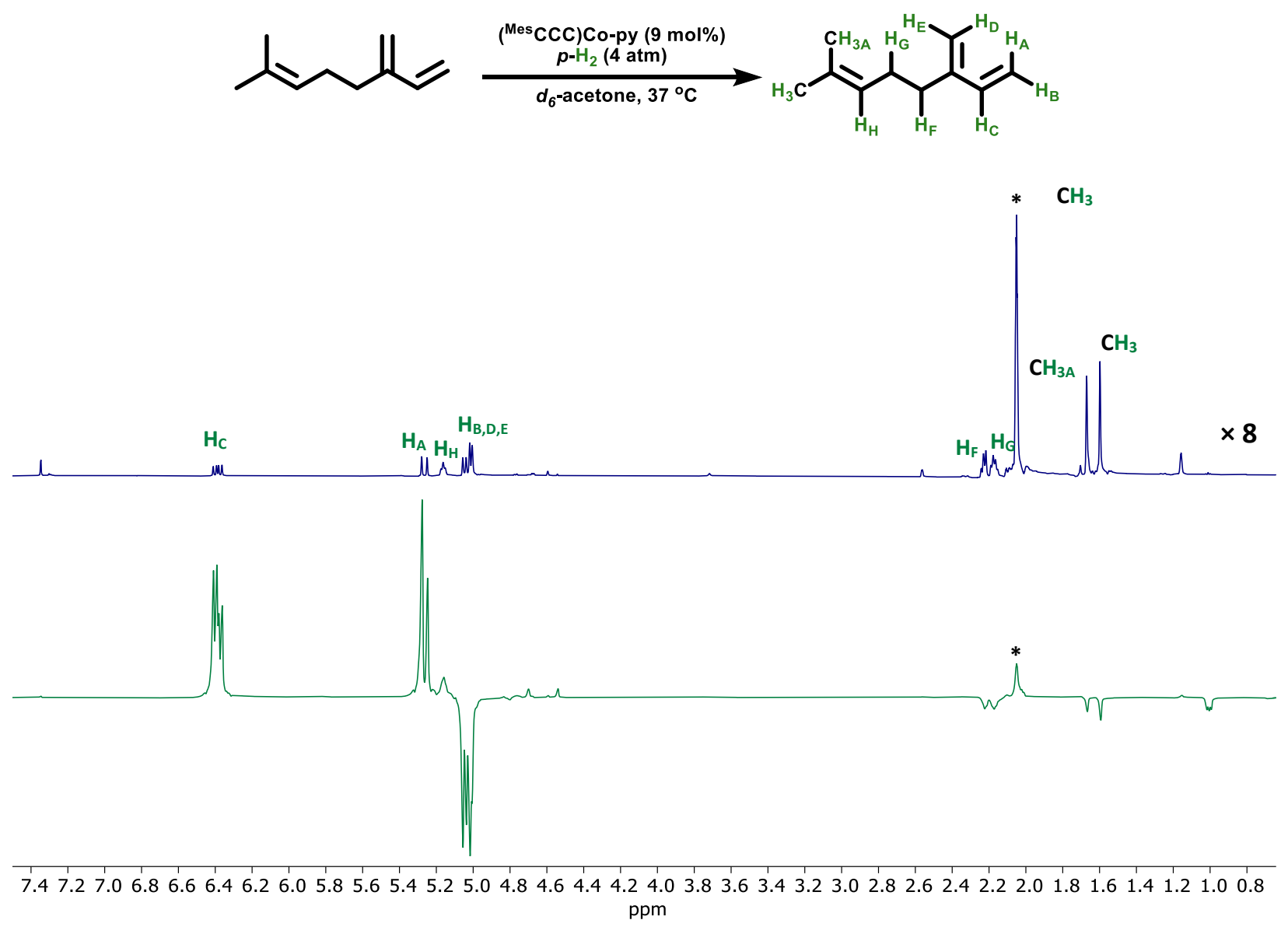

Figure S65. ${ }^{1} \mathrm{H}$ NMR spectra (acetone- $d_{6}(*), 600 \mathrm{MHz}, 37^{\circ} \mathrm{C}$ ) of the reaction of myrcene $(65 \mathrm{mM})$ using $\left({ }^{\mathrm{Mes}} \mathrm{CCC}\right) \mathrm{Co}-\mathrm{py}(9 \mathrm{~mol} \%, 5.9 \mathrm{mM})$ and $p-\mathrm{H}_{2}(4 \mathrm{~atm})$ at the $50 \mathrm{G}$ fringe line of the magnet. Top: spectrum of the sample before $p-\mathrm{H}_{2}$ is introduced through shaking (thermal spectrum) expanded 8-fold compared to hyperpolarized spectrum. Bottom: First transient using a $45^{\circ}$ pulse after the $\mathbf{1}^{\text {st }}$ shake introducing $p-\mathrm{H}_{2}$ to the sample, showing the hyperpolarization of entire molecule (SABRE). 
${ }^{1} \mathrm{H}$ NMR Spectrum, $600 \mathrm{MHz}$, acetone- $d_{6}\left(45^{\circ}\right.$ pulse $)$

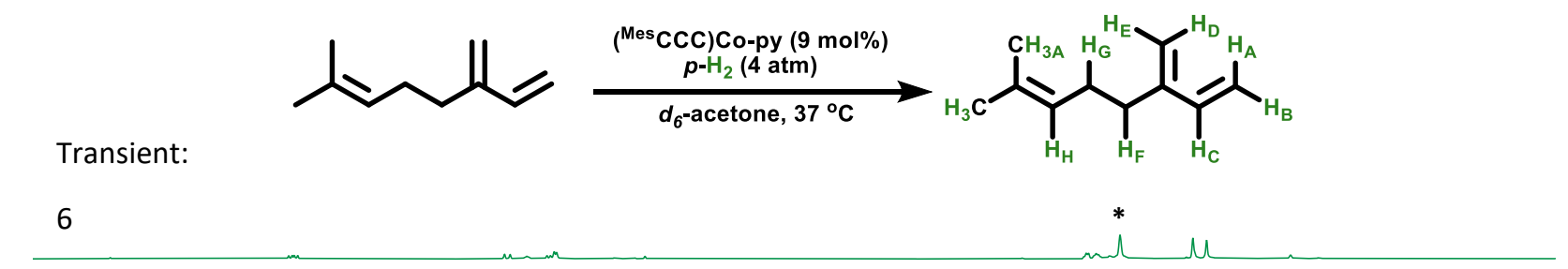

5

4

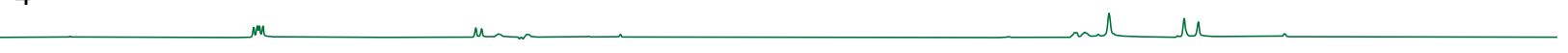

3

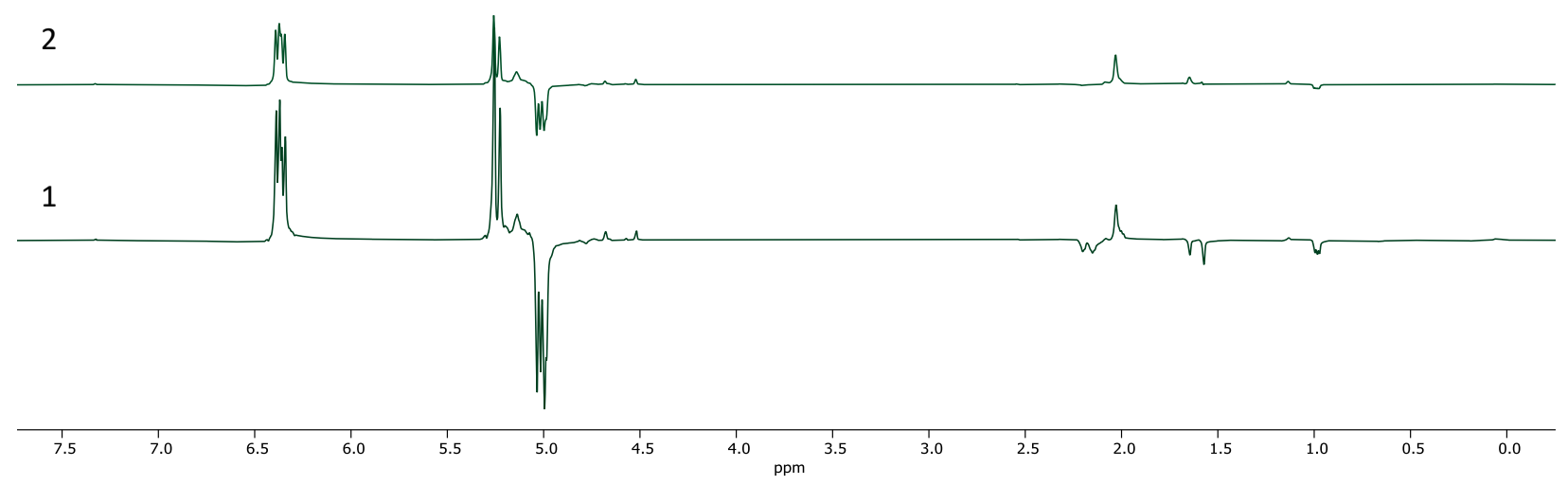

Figure S66. ${ }^{1} \mathrm{H}$ NMR spectra (acetone- $d_{6}(*), 600 \mathrm{MHz}, 37^{\circ} \mathrm{C}$ ) showing the decay of polarization over time of the reaction of myrcene $(65 \mathrm{mM})$ using $\left({ }^{\mathrm{Mes}} \mathrm{CCC}\right) \mathrm{Co}-\mathrm{py}(9 \mathrm{~mol} \%, 5.9 \mathrm{mM})$ and $p-\mathrm{H}_{2}(4 \mathrm{~atm})$ at the 50G fringe line of the magnet. No additional shaking occurred between transients. Bottom (dark green) spectrum is the first collected transient, followed by an acquisition time of $4.096 \mathrm{~s}$ to collect the next transient above it with no additional delay between transients. Subsequent transients were collected in the same fashion. 


\begin{tabular}{|l|c|c|c|}
\hline Proton $(\mathrm{ppm})$ & Thermal Integration & Hyperpolarized Integration & Enhancement (fold) \\
\hline $\mathrm{H}_{\mathrm{A}}(5.03)$ & 72.17 & -1849.09 & -25.6 \\
\hline $\mathrm{H}_{\mathrm{D}, \mathrm{E}}(5.00$ and 4.99) & 123.46 & -1613.46 & -13.1 \\
\hline $\mathrm{H}_{\mathrm{B}}(5.26)$ & 59.36 & 2504.01 & 42.2 \\
\hline $\mathrm{H}_{\mathrm{C}}(6.39)$ & 61.37 & 2815.99 & 45.9 \\
\hline $\mathrm{H}_{\mathrm{F}}(2.23)$ & 123.95 & -151.58 & -1.2 \\
\hline $\mathrm{H}_{\mathrm{G}}(2.17)$ & 132.43 & -189.68 & -1.4 \\
\hline $\mathrm{H}_{\mathrm{H}}(5.16)$ & 70.58 & 281.98 & 4.0 \\
\hline $\mathrm{CH}_{3}(1.60)$ & 217.41 & -154.29 & -0.7 \\
\hline $\mathrm{CH}_{3 \mathrm{~A}}(1.67)$ & 210.66 & -98.81 & -0.5 \\
\hline
\end{tabular}

Table S14. Signal enhancement calculated for the hyperpolarization of the ${ }^{1} \mathrm{H}$ of myrcene. The thermal data is derived from the sample before $p-\mathrm{H}_{2}$ is introduced and the hyperpolarized data is derived from the first transient after shaking the sample. 
${ }^{13} \mathrm{C}\left\{{ }^{1} \mathrm{H}\right\}$ NMR Spectrum, $150 \mathrm{MHz}$, acetone- $d_{6}\left(90^{\circ}\right.$ pulse $)$ - Magnitude mode

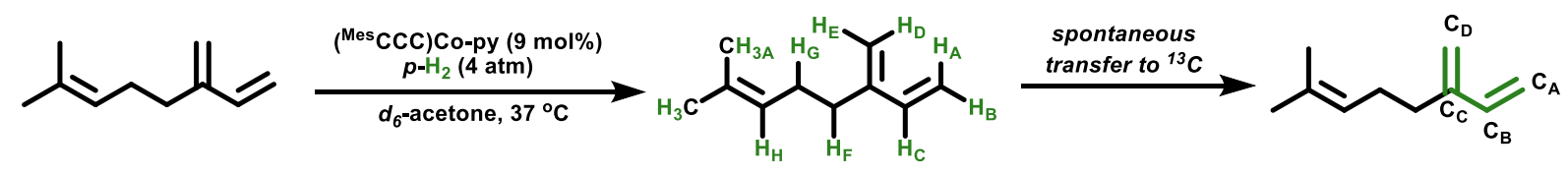

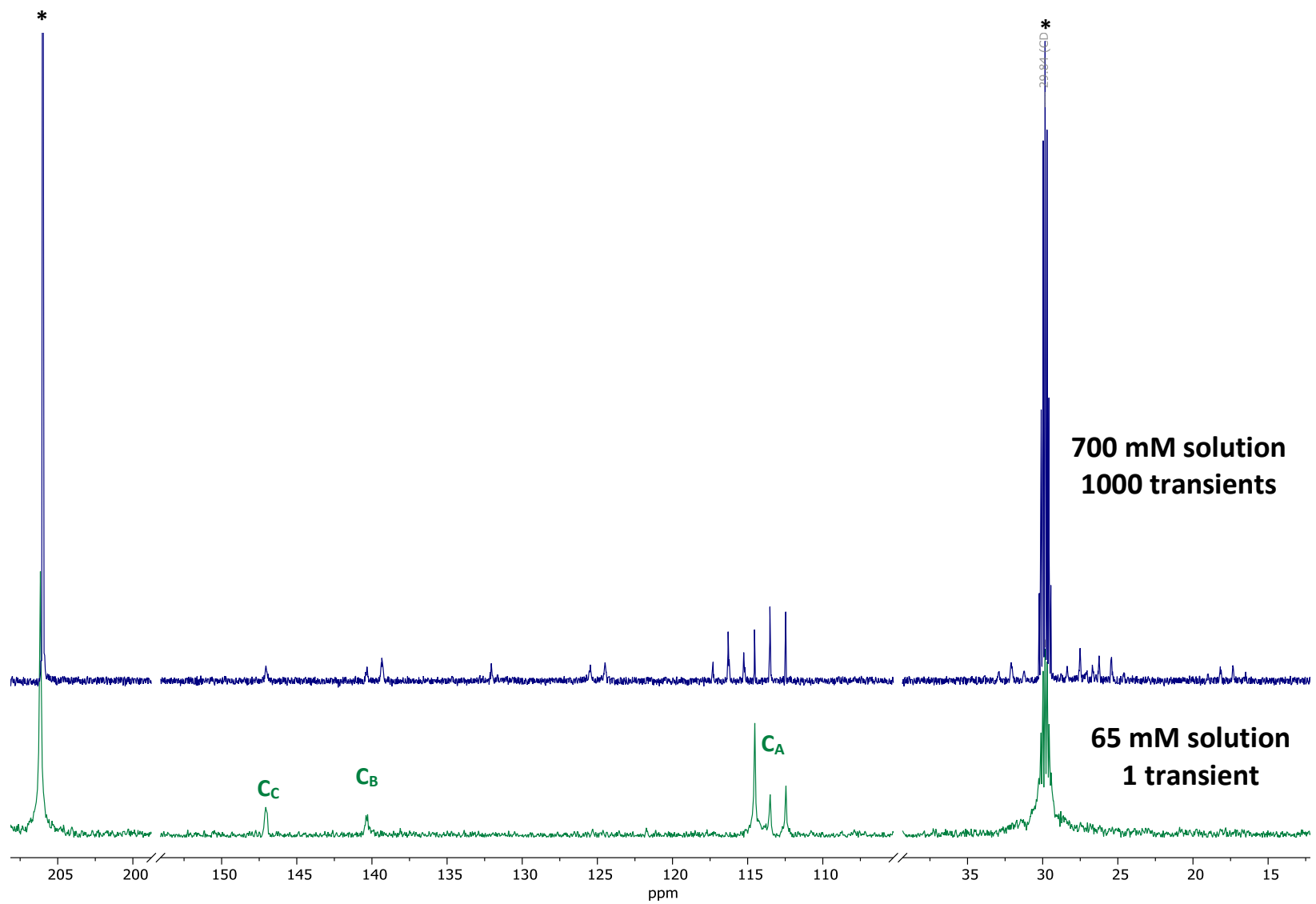

Figure S67. ${ }^{13} \mathrm{C}\left\{{ }^{1} \mathrm{H}\right\}$ NMR spectra (acetone- $\left.d_{6}(*), 150 \mathrm{MHz}, 37{ }^{\circ} \mathrm{C}\right)$ of the reaction of myrcene $(65 \mathrm{mM})$ using ( $\left.{ }^{\text {Mes }} \mathrm{CCC}\right) \mathrm{Co}-\mathrm{py}(9 \mathrm{~mol} \%, 5.9 \mathrm{mM})$ and $p-\mathrm{H}_{2}(4 \mathrm{~atm})$ at earth's magnetic field with peakless regions removed. Top spectrum is a thermal spectrum of 1000 transients of a $700 \mathrm{mM}$ solution of myrcene. The bottom spectrum is the first transient, in magnitude mode, after the $\mathbf{1}^{\text {st }}$ shake introducing $p-\mathrm{H}_{2}$ into the sample at earth's magnetic field. 
${ }^{13} \mathrm{C}\left\{{ }^{1} \mathrm{H}\right\}$ NMR Spectrum, $150 \mathrm{MHz}$, acetone- $d_{6}\left(90^{\circ}\right.$ pulse $)$ - Phased mode
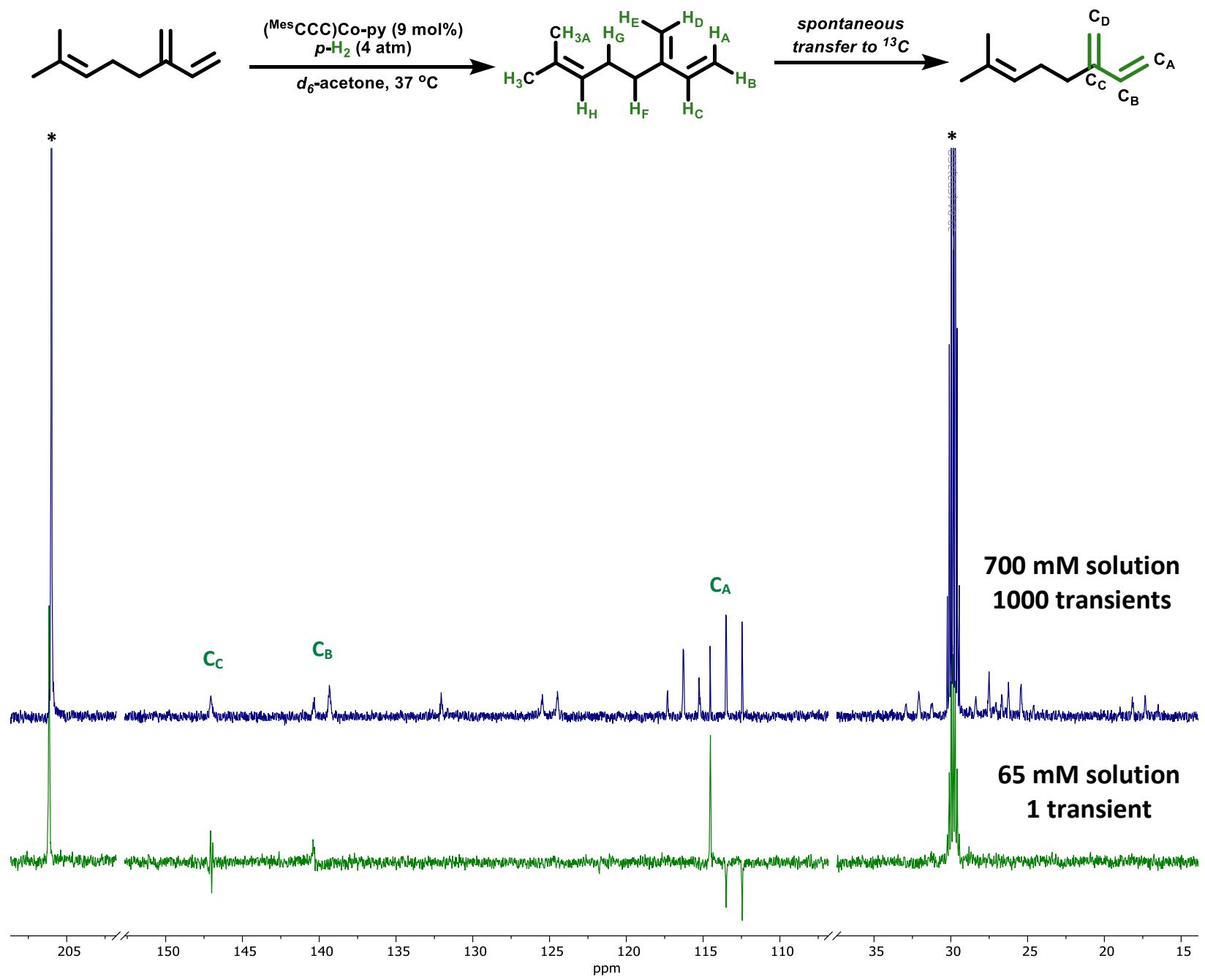

Figure S68. ${ }^{13} \mathrm{C}\left\{{ }^{1} \mathrm{H}\right\}$ NMR spectra (acetone- $\left.d_{6}(*), 150 \mathrm{MHz}, 37{ }^{\circ} \mathrm{C}\right)$ of the reaction of myrcene $(65 \mathrm{mM})$ using ( $\left.{ }^{\text {Mes }} \mathrm{CCC}\right)$ Co-py $(9 \mathrm{~mol} \%, 5.9 \mathrm{mM})$ and $p-\mathrm{H}_{2}$ (4 atm) at earth's magnetic field with peakless regions removed. Top spectrum is a thermal spectrum of 1000 transients of a $700 \mathrm{mM}$ solution of myrcene, magnified 4-fold. The bottom spectrum is the first transient, in phased mode, after the $\mathbf{1}^{\text {st }}$ shake introducing $p-\mathrm{H}_{2}$ into the sample at earth's magnetic field. 
${ }^{13} \mathrm{C}\left\{{ }^{1} \mathrm{H}\right\}$ NMR Spectrum, $150 \mathrm{MHz}$, acetone- $d_{6}\left(90^{\circ}\right.$ pulse $)$
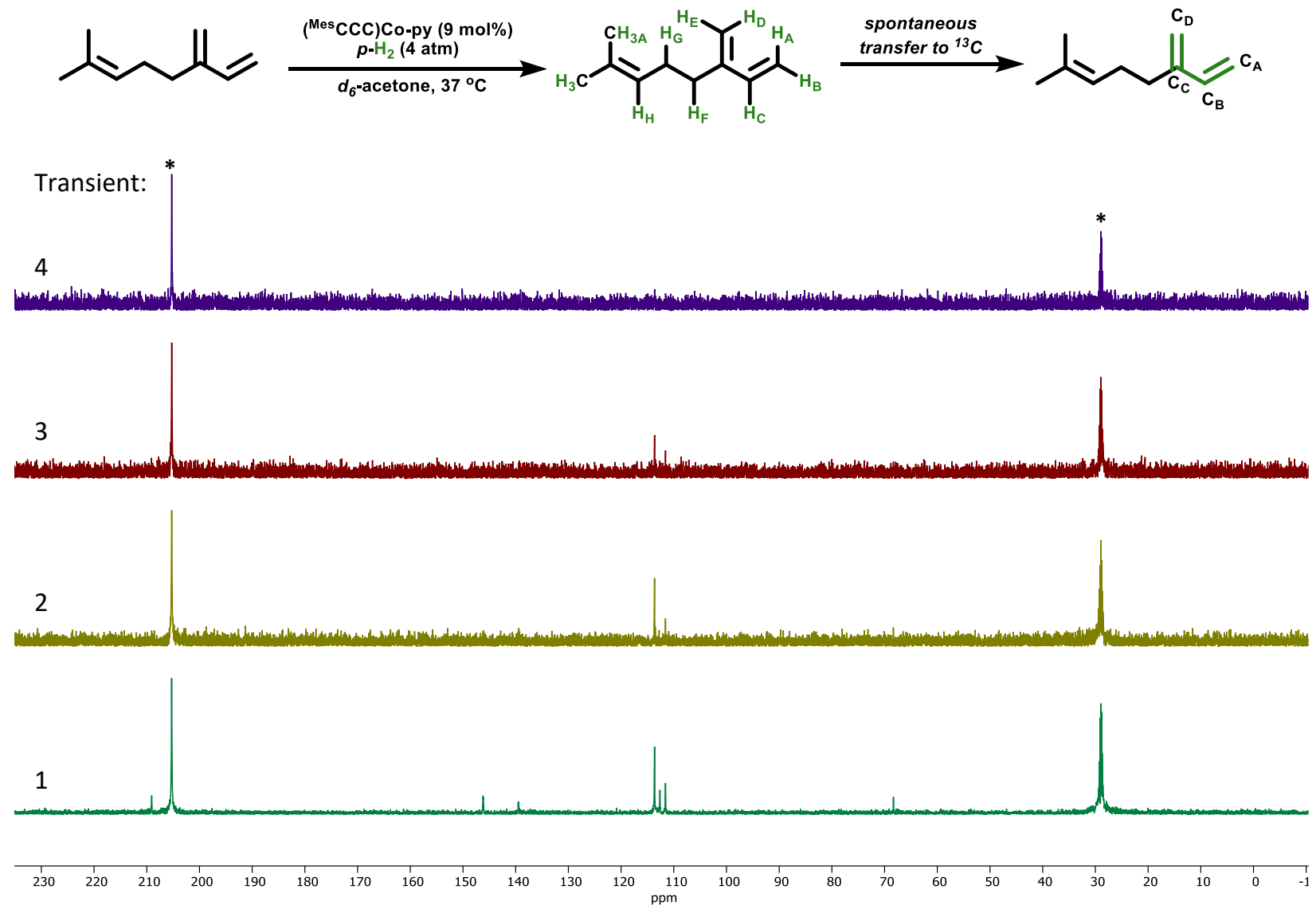

Figure S69. ${ }^{13} \mathrm{C}\left\{{ }^{1} \mathrm{H}\right\}$ NMR spectra (acetone- $d_{6}(*), 150 \mathrm{MHz}, 37{ }^{\circ} \mathrm{C}$ ), in magnitude mode, showing the decay of polarization over time of the reaction of myrcene $(65 \mathrm{mM})$ using $\left({ }^{\text {Mes }} \mathrm{CCC}\right)$ Co-py $(9 \mathrm{~mol} \%, 5.9$ $\mathrm{mM})$ and $p-\mathrm{H}_{2}(4 \mathrm{~atm})$ at earth's magnetic field. No additional shaking occurred between transients. Bottom (green) spectrum is the first collected transient of the $\mathbf{1}^{\text {st }}$ shake of $p-\mathrm{H}_{2}$ into the sample, followed by an acquisition time of $1.7695 \mathrm{~s}$ to collect the next transient (yellow), with no delay time in between. Subsequent transients were collected in the same fashion. 
${ }^{1} \mathrm{H}$ NMR Spectrum, $600 \mathrm{MHz}$, acetone- $d_{6}\left(45^{\circ}\right.$ pulse $)$
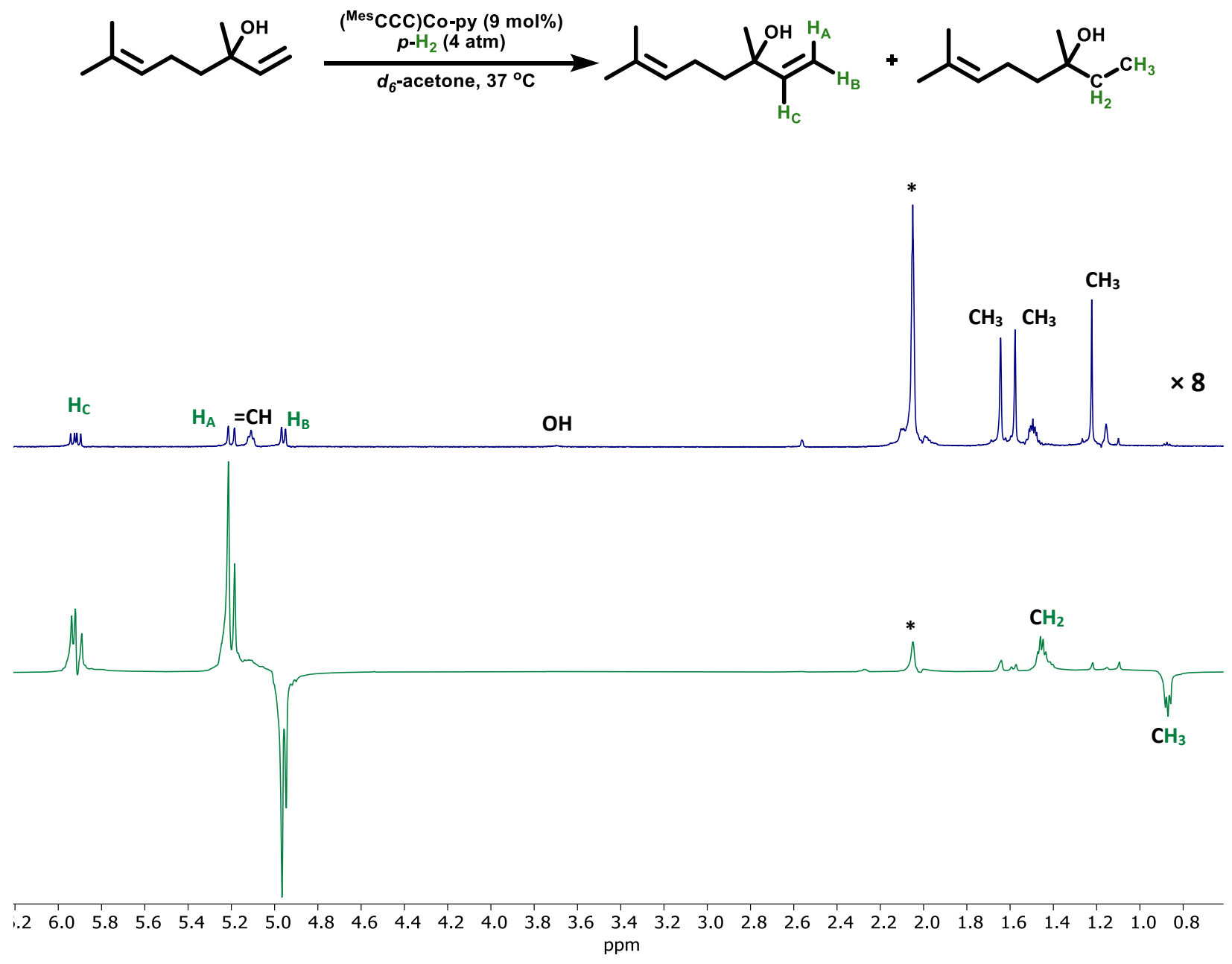

Figure S70. ${ }^{1} \mathrm{H}$ NMR spectra (acetone- $d_{6}(*), 600 \mathrm{MHz}, 37^{\circ} \mathrm{C}$ ) of the reaction of linalool $(65 \mathrm{mM})$ using ( $\left.{ }^{\mathrm{Mes}} \mathrm{CCC}\right) \mathrm{Co}-\mathrm{py}(9 \mathrm{~mol} \%, 5.9 \mathrm{mM})$ and $p-\mathrm{H}_{2}(4 \mathrm{~atm})$ at the $50 \mathrm{G}$ fringe line of the magnet. Top: spectrum of the sample before $p-\mathrm{H}_{2}$ is introduced through shaking (thermal spectrum) expanded 8 -fold compared to hyperpolarized spectrum. Bottom: First transient using a $45^{\circ}$ pulse after the $\mathbf{2}^{\text {nd }}$ shake introducing $p-\mathrm{H}_{2}$ to the sample, showing the hyperpolarization of olefin (SABRE) and the hydrogenated product (ALTADENA). 
${ }^{1} \mathrm{H}$ NMR Spectrum, $600 \mathrm{MHz}$, acetone- $d_{6}\left(45^{\circ}\right.$ pulse $)$

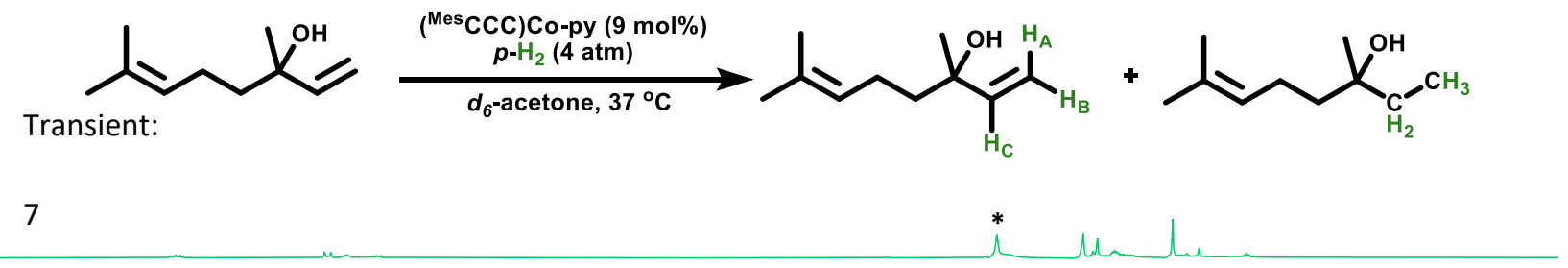

6

5

4

3

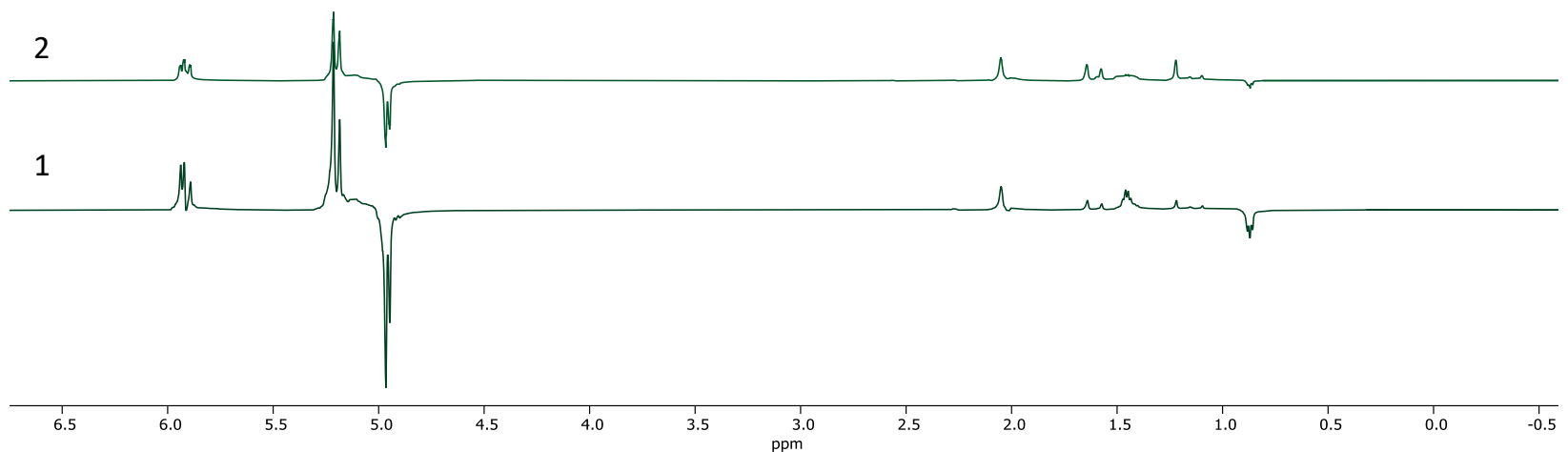

Figure S71. ${ }^{1} \mathrm{H}$ NMR spectra (acetone- $d_{6}(*), 600 \mathrm{MHz}, 37^{\circ} \mathrm{C}$ ) showing the decay of polarization over time of the reaction of linalool $(65 \mathrm{mM})$ using $\left({ }^{\mathrm{Mes}} \mathrm{CCC}\right) \mathrm{Co}-\mathrm{py}(9 \mathrm{~mol} \%, 5.9 \mathrm{mM})$ and $p-\mathrm{H}_{2}(4 \mathrm{~atm})$ at the $50 \mathrm{G}$ fringe line of the magnet. No additional shaking occurred between transients. Bottom (dark green) spectrum is the first collected transient, followed by an acquisition time of $4.096 \mathrm{~s}$ to collect the next transient above it, with no additional delay between transients. Subsequent transients were collected in the same fashion.

\begin{tabular}{|l|c|c|c|}
\hline Proton $(\mathrm{ppm})$ & Thermal Integration & Hyperpolarized Integration & Enhancement (fold) \\
\hline $\mathrm{H}_{\mathrm{A}}(4.96)$ & 32.35 & 2490.32 & 77.0 \\
\hline $\mathrm{H}_{\mathrm{B}}(5.20)$ & 37.21 & 2518.9 & 67.7 \\
\hline $\mathrm{H}_{\mathrm{C}}(5.92)$ & 31.55 & 912.43 & 29.0 \\
\hline$=\mathrm{CH}(5.11)$ & 34.59 & 159.74 & 4.6 \\
\hline
\end{tabular}

Table S15. Signal enhancement calculated for the hyperpolarization of the ${ }^{1} \mathrm{H}$ of linalool. The thermal data is derived from the sample before $p-\mathrm{H}_{2}$ is introduced and the hyperpolarized data is derived from the first transient after shaking the sample. 
${ }^{13} \mathrm{C}\left\{{ }^{1} \mathrm{H}\right\}$ NMR Spectrum, $150 \mathrm{MHz}$, acetone- $d_{6}\left(90^{\circ}\right.$ pulse $)$ - Magnitude mode
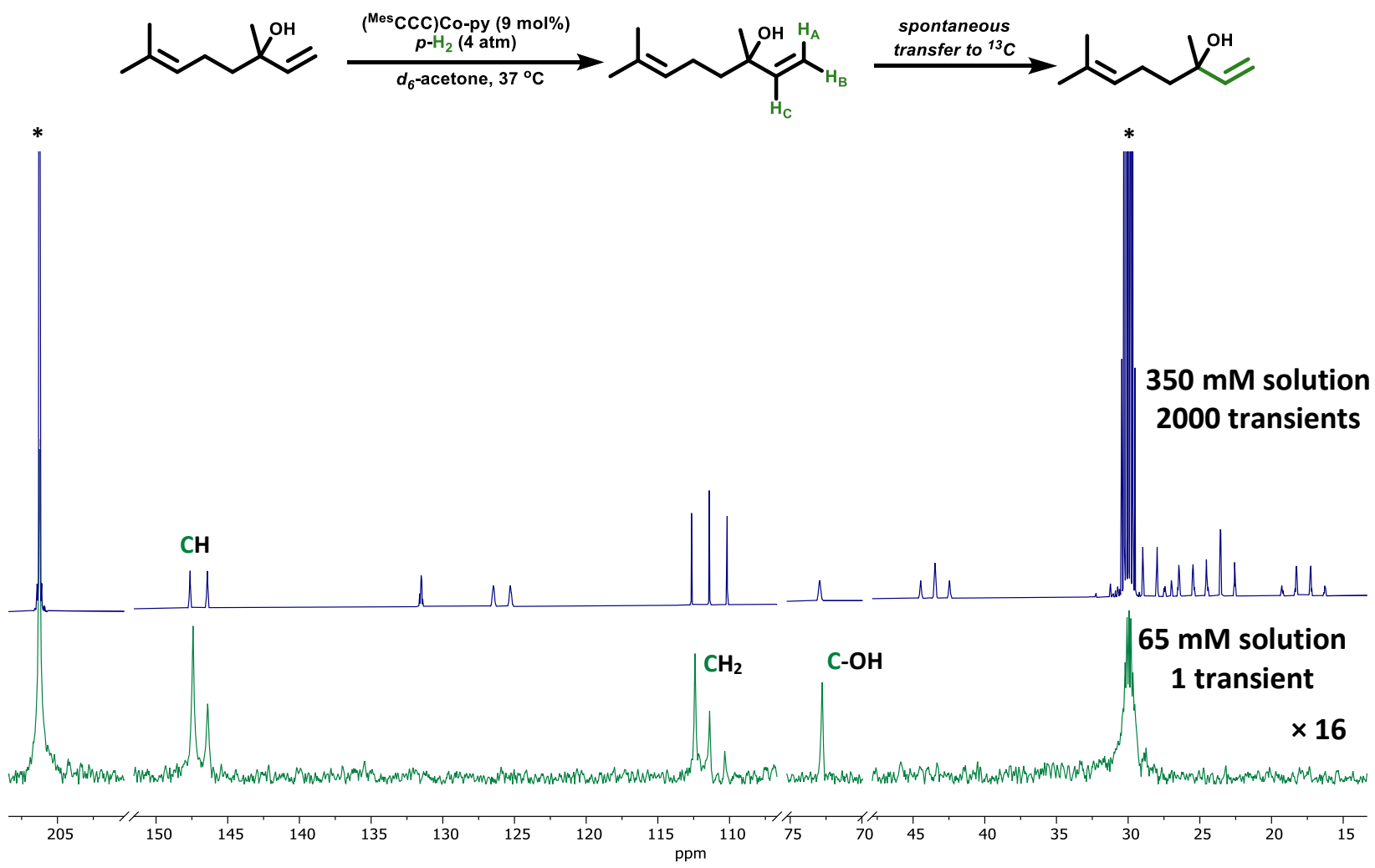

Figure S72. ${ }^{13} \mathrm{C}\left\{{ }^{1} \mathrm{H}\right\}$ NMR spectra (acetone- $\left.d_{6}(*), 150 \mathrm{MHz}, 37{ }^{\circ} \mathrm{C}\right)$ of the reaction of linalool $(65 \mathrm{mM})$ using ( $\left.{ }^{\text {Mes }} \mathrm{CCC}\right) \mathrm{Co}-\mathrm{py}(9 \mathrm{~mol} \%, 5.9 \mathrm{mM})$ and $p-\mathrm{H}_{2}$ (4 atm) at earth's magnetic field with peakless regions removed. Top spectrum is a thermal spectrum of 2000 transients of a $350 \mathrm{mM}$ solution of linalool. The bottom spectrum is the first transient, in magnitude mode, after the $3^{\text {rd }}$ shake introducing $p-\mathrm{H}_{2}$ into the sample at earth's magnetic field, expanded 16-fold compared to the top spectrum. 
${ }^{13} \mathrm{C}\left\{{ }^{1} \mathrm{H}\right\}$ NMR Spectrum, $150 \mathrm{MHz}$, acetone- $d_{6}\left(90^{\circ}\right.$ pulse $)$ - Phased mode
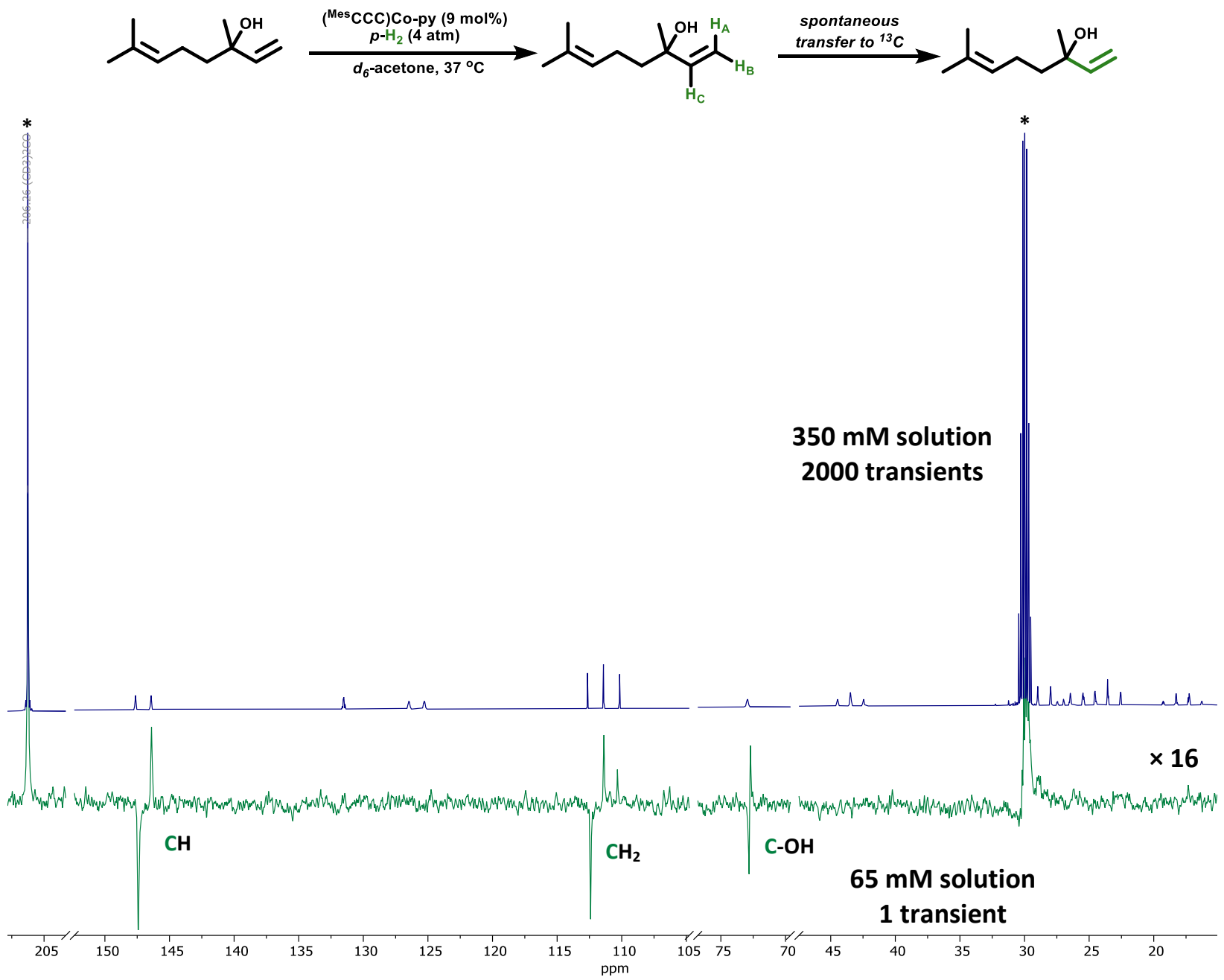

Figure S73. ${ }^{13} \mathrm{C}\left\{{ }^{1} \mathrm{H}\right\}$ NMR spectra (acetone- $\left.d_{6}(*), 150 \mathrm{MHz}, 37{ }^{\circ} \mathrm{C}\right)$ of the reaction of linalool $(65 \mathrm{mM})$ using ( $\left.{ }^{\text {Mes }} \mathrm{CCC}\right)$ Co-py $(9 \mathrm{~mol} \%, 5.9 \mathrm{mM})$ and $p-\mathrm{H}_{2}$ (4 atm) at earth's magnetic field with peakless regions removed. Top spectrum is a thermal spectrum of 2000 transients of a $350 \mathrm{mM}$ solution of linalool. The bottom spectrum is the first transient, in phased mode, after the $3^{\text {rd }}$ shake introducing $p-\mathrm{H}_{2}$ into the sample at earth's magnetic field, expanded 16-fold compared to the top spectrum. 
${ }^{13} \mathrm{C}\left\{{ }^{1} \mathrm{H}\right\}$ NMR Spectrum, $150 \mathrm{MHz}$, acetone- $d_{6}\left(90^{\circ}\right.$ pulse $)$

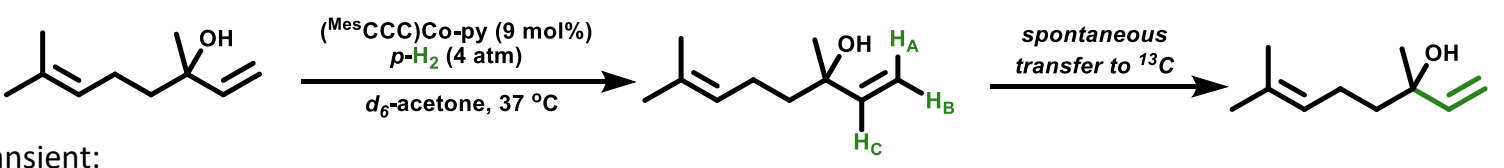

Transient:
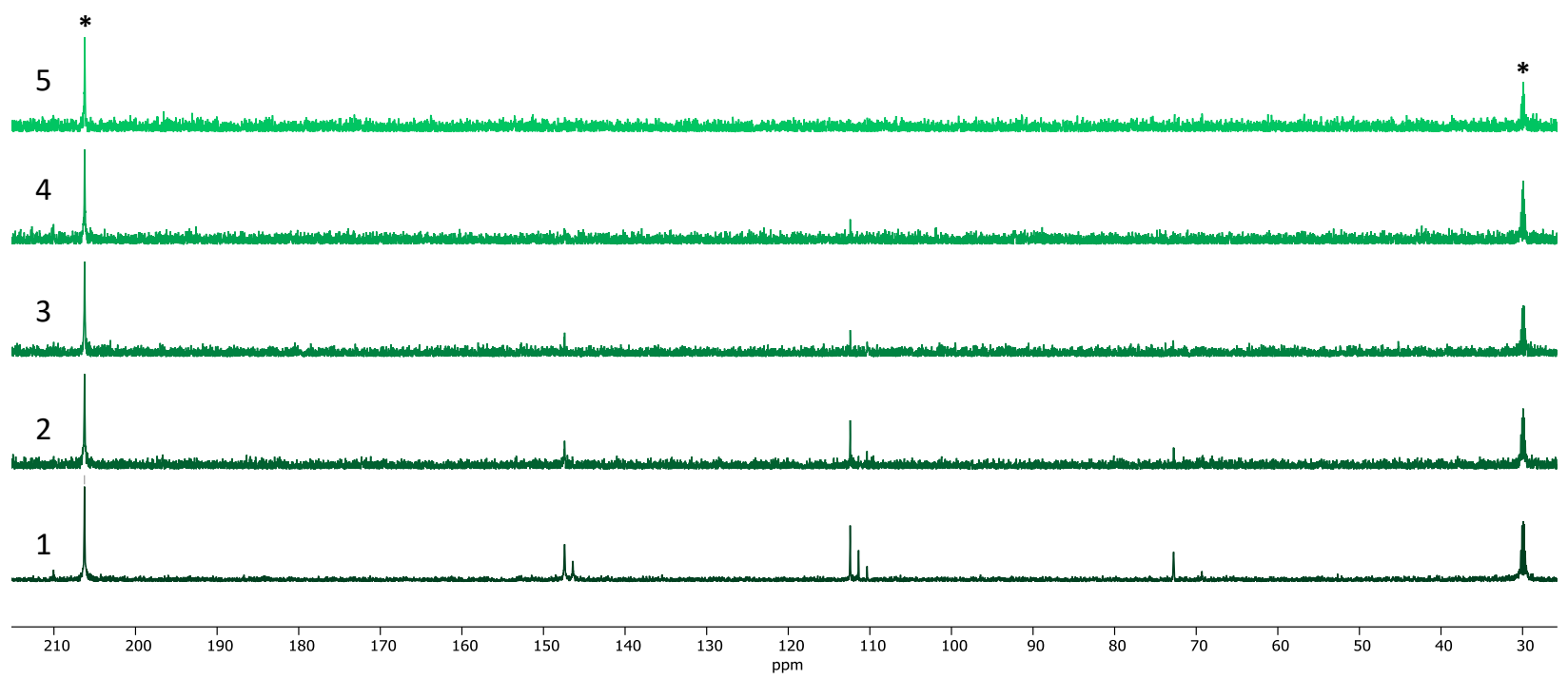

Figure S74. ${ }^{13} \mathrm{C}\left\{{ }^{1} \mathrm{H}\right\}$ NMR spectra (acetone- $d_{6}(*), 150 \mathrm{MHz}, 37{ }^{\circ} \mathrm{C}$ ), in magnitude mode, showing the decay of polarization over time of the reaction of linalool $(65 \mathrm{mM})$ using $\left({ }^{\mathrm{Mes}} \mathrm{CCC}\right) \mathrm{Co}-\mathrm{py}(9 \mathrm{~mol} \%, 5.9$ $\mathrm{mM})$ and $p-\mathrm{H}_{2}(4 \mathrm{~atm})$ at earth's magnetic field. No additional shaking occurred between transients. Bottom (dark green) spectrum is the first collected transient of the $3^{\text {rd }}$ shake of $p-\mathrm{H}_{2}$ into the sample, followed by an acquisition time of $1.7695 \mathrm{~s}$ to collect the next transient, with no delay time in between. Subsequent transients were collected in the same fashion. 
${ }^{1} \mathrm{H}$ NMR Spectrum, $600 \mathrm{MHz}$, acetone- $d_{6}\left(45^{\circ}\right.$ pulse $)$

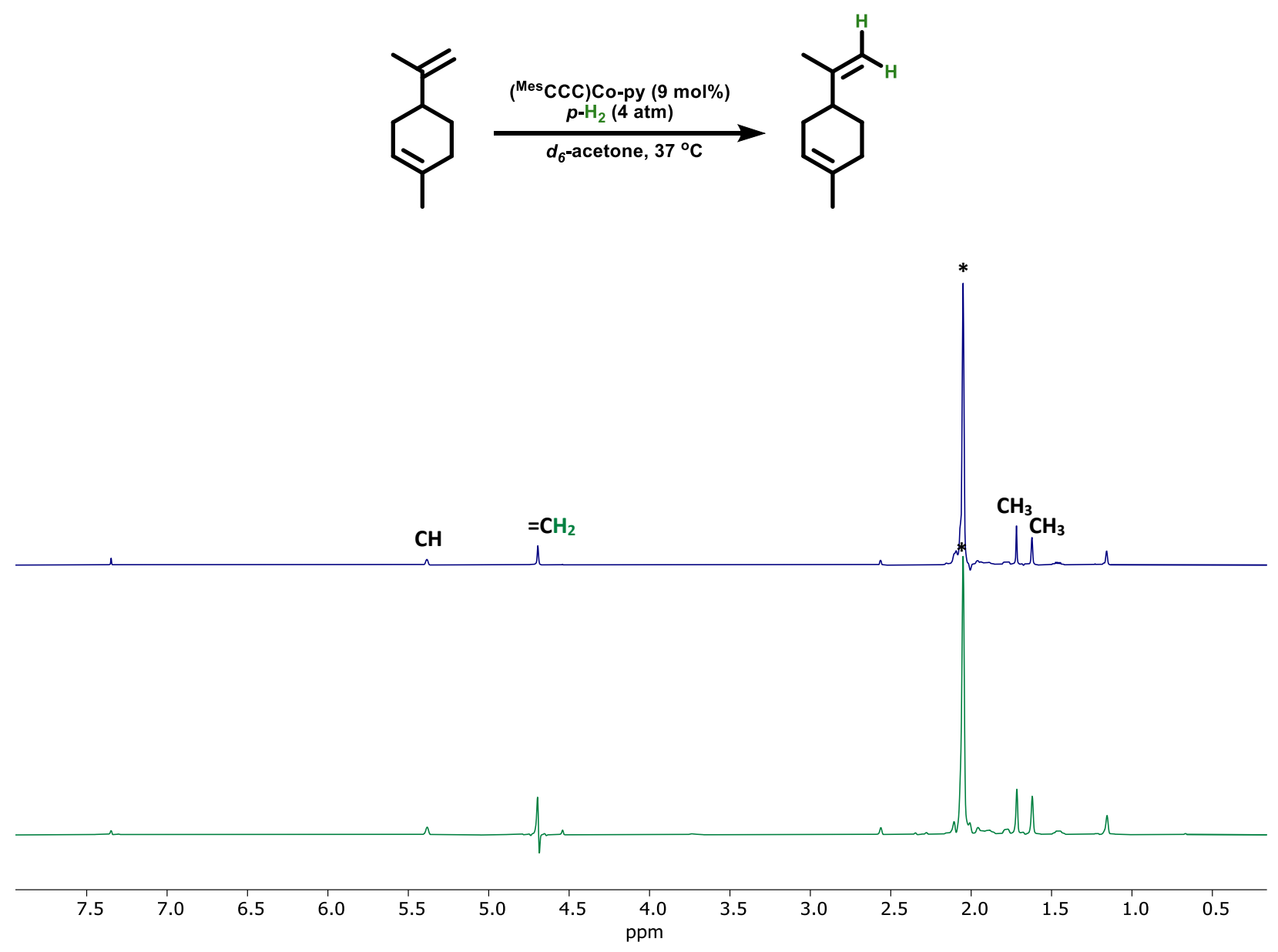

Figure S75. ${ }^{1} \mathrm{H}$ NMR spectra (acetone- $d_{6}(*), 600 \mathrm{MHz}, 37^{\circ} \mathrm{C}$ ) of the reaction of limonene $(65 \mathrm{mM})$ using ( $\left.{ }^{\mathrm{Mes}} \mathrm{CCC}\right) \mathrm{Co}$-py $(9 \mathrm{~mol} \%, 5.9 \mathrm{mM})$ and $p-\mathrm{H}_{2}(4 \mathrm{~atm})$ at the $50 \mathrm{G}$ fringe line of the magnet. Top: spectrum of the sample before $p-\mathrm{H}_{2}$ is introduced through shaking (thermal spectrum). Bottom: First transient using a $45^{\circ}$ pulse after the $2^{\text {nd }}$ shake introducing $p-\mathrm{H}_{2}$ to the sample. 
${ }^{1} \mathrm{H}$ NMR Spectrum, $600 \mathrm{MHz}$, acetone- $d_{6}\left(45^{\circ}\right.$ pulse $)$

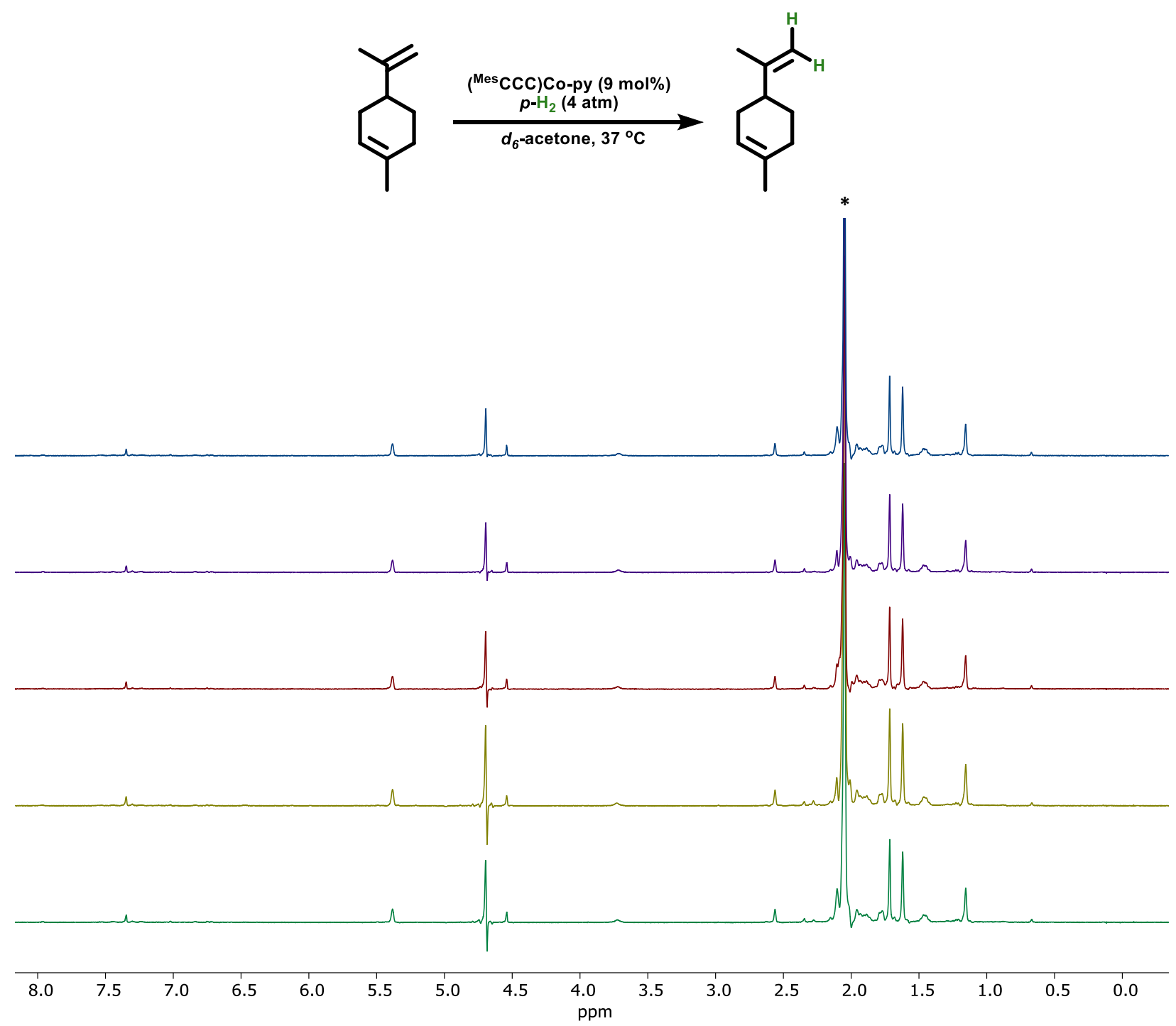

Figure S76. ${ }^{1} \mathrm{H}$ NMR spectra (acetone- $d_{6}(*), 600 \mathrm{MHz}, 37{ }^{\circ} \mathrm{C}$ ) showing the decay of polarization over time of the reaction of limonene $(65 \mathrm{mM})$ using $\left({ }^{\mathrm{Mes}} \mathrm{CCC}\right) \mathrm{Co}-\mathrm{py}(9 \mathrm{~mol} \%, 5.9 \mathrm{mM})$ and $p-\mathrm{H}_{2}(4 \mathrm{~atm})$ at the $50 \mathrm{G}$ fringe line of the magnet. No additional shaking occurred between transients. Bottom (dark green) spectrum is the first collected transient, followed by an acquisition time of $4.096 \mathrm{~s}$ to collect the next transient (yellow) with no additional delay between transients. Subsequent transients were collected in the same fashion.

\begin{tabular}{|l|c|c|c|}
\hline Proton $(\mathrm{ppm})$ & Thermal Integration & Hyperpolarized Integration & Enhancement (fold) \\
\hline $\mathrm{CH}(5.38)$ & 55.86 & 22.22 & 0.4 \\
\hline $\mathrm{CH}_{2}(4.96)$ dispersive & 115.58 & 321.8 & 2.8 \\
\hline
\end{tabular}

Table S16. Signal enhancement calculated for the hyperpolarization of the ${ }^{1} \mathrm{H}$ of limonene. The thermal data is derived from the sample before $p-\mathrm{H}_{2}$ is introduced and the hyperpolarized data is derived from the first transient after shaking the sample. 
${ }^{1} \mathrm{H}$ NMR Spectrum, $600 \mathrm{MHz}$, acetone- $d_{6}\left(45^{\circ}\right.$ pulse $)$

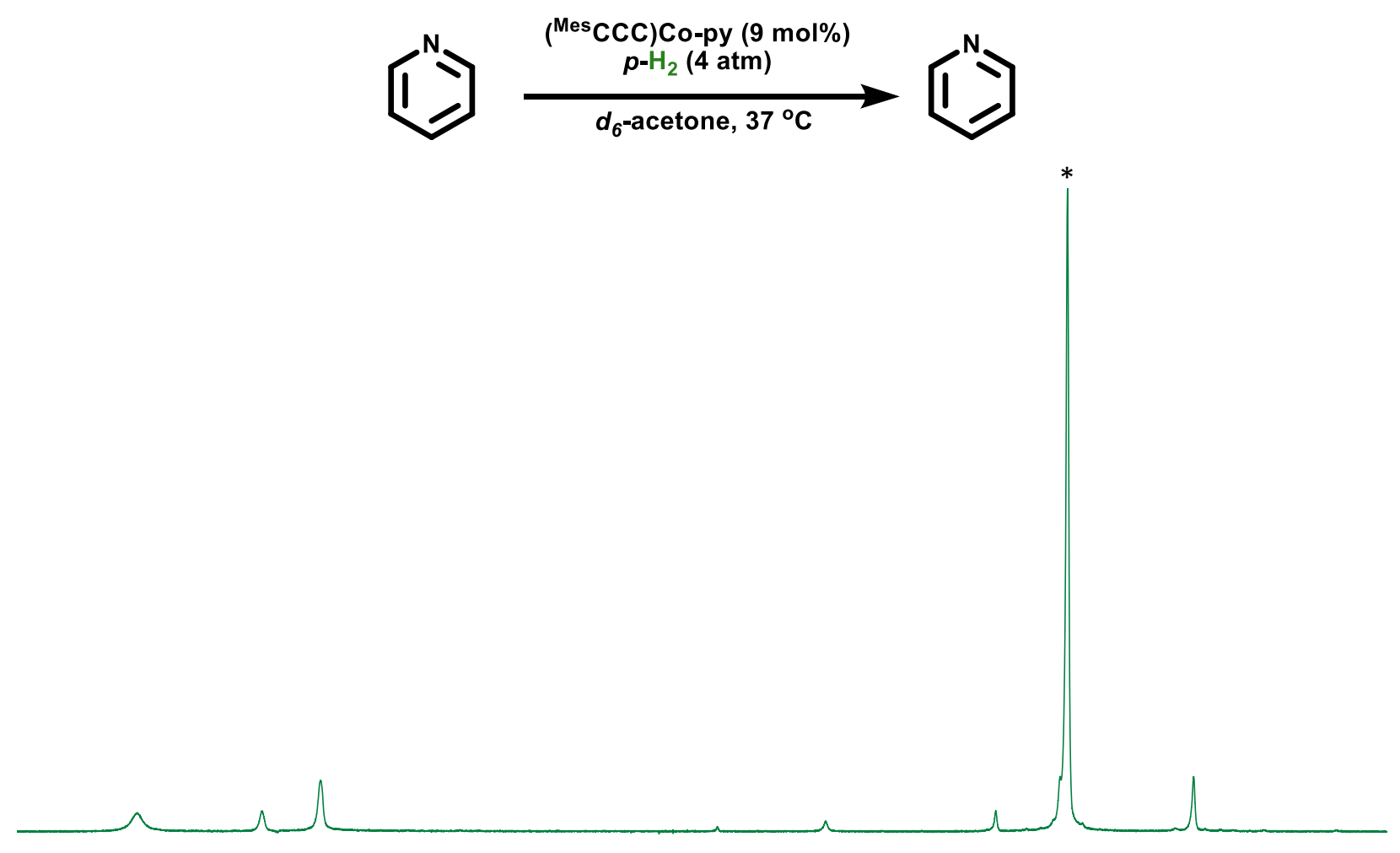

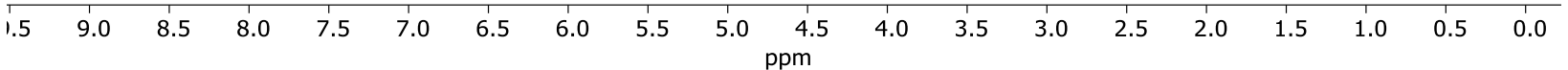

Figure S78. ${ }^{1} \mathrm{H}$ NMR spectrum (acetone- $d_{6}(*), 600 \mathrm{MHz}, 37{ }^{\circ} \mathrm{C}$ ) of an attempt at SABRE of pyridine (65 $\mathrm{mM})$ using $\left({ }^{\mathrm{Mes}} \mathrm{CCC}\right) \mathrm{Co}-\mathrm{py}(9 \mathrm{~mol} \%, 5.9 \mathrm{mM})$ and $p-\mathrm{H}_{2}(4 \mathrm{~atm})$. Single initial transient using a $45^{\circ}$ pulse after shaking. 
${ }^{1} \mathrm{H}$ NMR Spectrum, $600 \mathrm{MHz}$, acetone- $d_{6}\left(45^{\circ}\right.$ pulse $)$
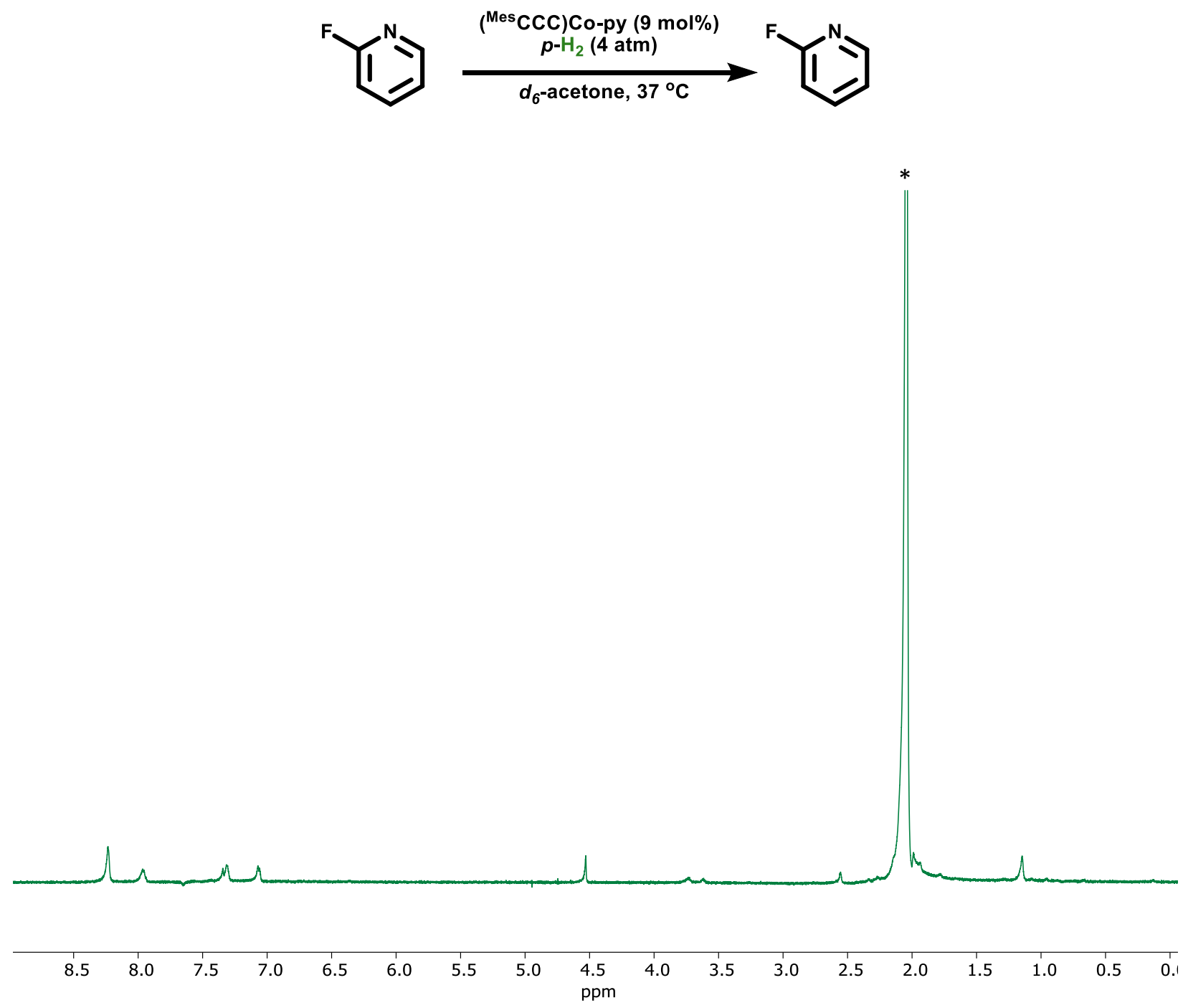

Figure S79. ${ }^{1} \mathrm{H}$ NMR spectrum (acetone- $d_{6}(*), 600 \mathrm{MHz}, 37{ }^{\circ} \mathrm{C}$ ) of an attempt at SABRE of 2fluoropyridine $(65 \mathrm{mM})$ using $\left({ }^{\mathrm{Mes}} \mathrm{CCC}\right) \mathrm{Co}-\mathrm{py}(9 \mathrm{~mol} \%, 5.9 \mathrm{mM})$ and $p-\mathrm{H}_{2}(4 \mathrm{~atm})$. Single initial transient using a $45^{\circ}$ pulse after shaking. 
${ }^{1} \mathrm{H}$ NMR Spectrum, $600 \mathrm{MHz}$, acetone- $d_{6}\left(45^{\circ}\right.$ pulse $)$
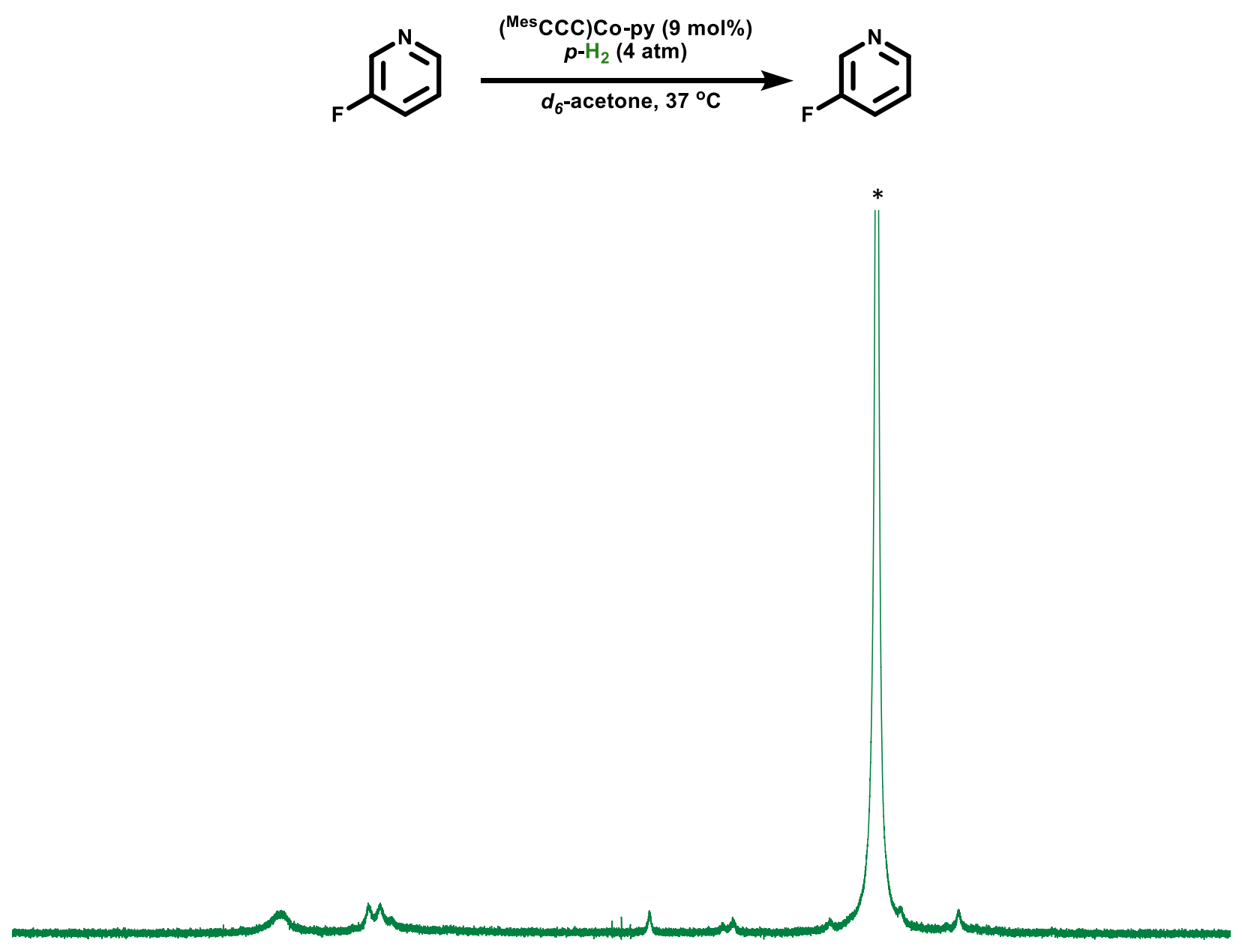

\begin{tabular}{lllllllllllllllllllllllllllllllllll}
\hline 1.5 & 11.0 & 10.5 & 10.0 & 9.5 & 9.0 & 8.5 & 8.0 & 7.5 & 7.0 & 6.5 & 6.0 & 5.5 & 5.0 & 4.5 & 4.0 & 3.5 & 3.0 & 2.5 & 2.0 & 1.5 & 1.0 & 0.5 & 0.0 & -0.5 & -1.0 & -1.5
\end{tabular}

Figure S80. ${ }^{1} \mathrm{H}$ NMR spectrum (acetone- $d_{6}(*), 600 \mathrm{MHz}, 37{ }^{\circ} \mathrm{C}$ ) of an attempt at SABRE of 3fluoropyridine $(65 \mathrm{mM})$ using $\left({ }^{\mathrm{Mes}} \mathrm{CCC}\right) \mathrm{Co}-\mathrm{py}(9 \mathrm{~mol} \%, 5.9 \mathrm{mM})$ and $p-\mathrm{H}_{2}(4 \mathrm{~atm})$. Single initial transient using a $45^{\circ}$ pulse after shaking. 
${ }^{1} \mathrm{H}$ NMR Spectrum, $600 \mathrm{MHz}$, acetone- $d_{6}\left(45^{\circ}\right.$ pulse $)$

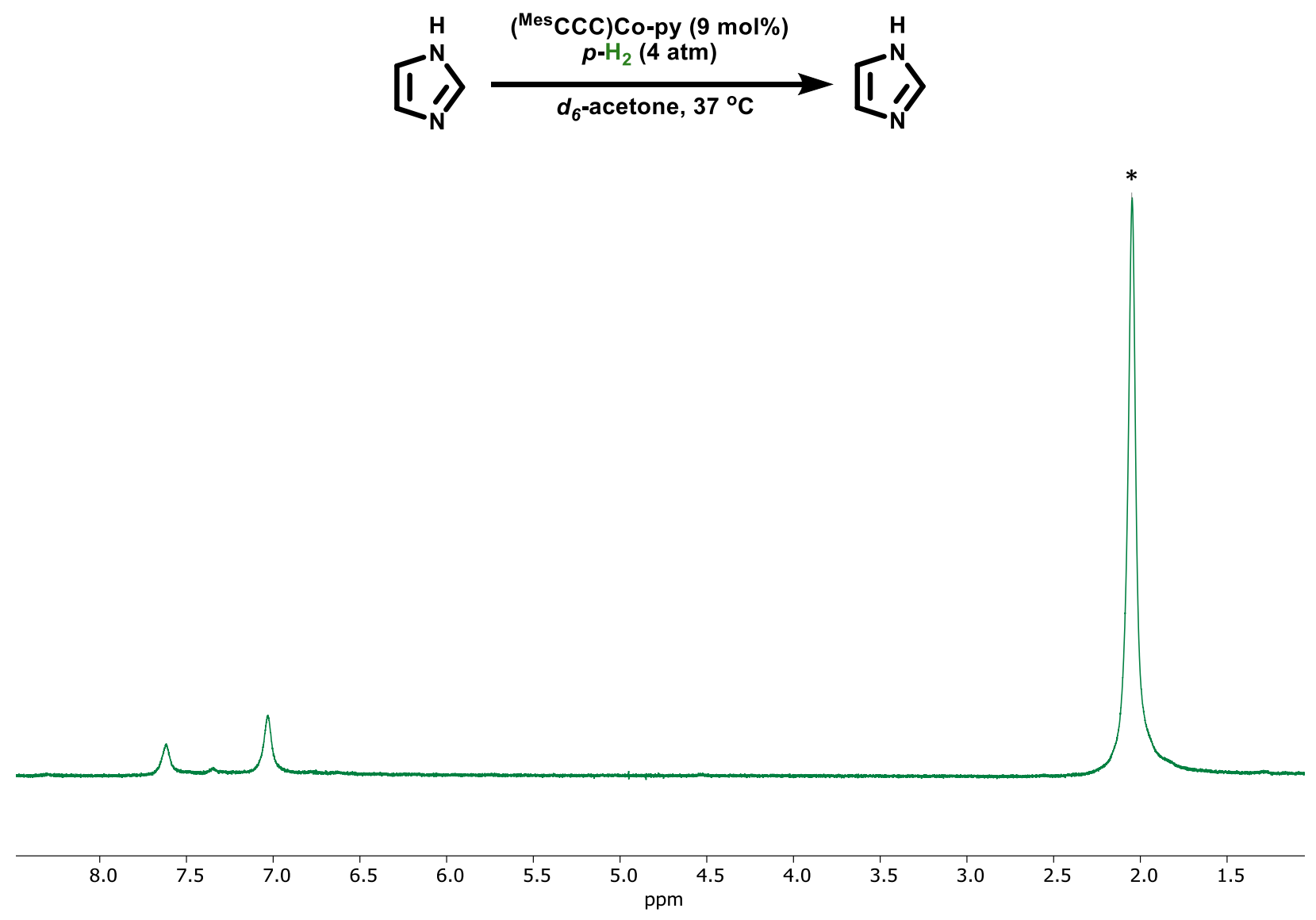

Figure S81. ${ }^{1} \mathrm{H}$ NMR spectrum (acetone- $d_{6}(*), 600 \mathrm{MHz}, 37{ }^{\circ} \mathrm{C}$ ) of an attempt at SABRE of imidazole $(65 \mathrm{mM})$ using $\left({ }^{\text {Mes }} \mathrm{CCC}\right) \mathrm{Co}-\mathrm{py}(9 \mathrm{~mol} \%, 5.9 \mathrm{mM})$ and $p-\mathrm{H}_{2}(4 \mathrm{~atm})$. Single initial transient using a $45^{\circ}$ pulse after shaking. 


\section{Field-dependence of ${ }^{1} \mathrm{H}$ Nuclear Enhancement}

The following data demonstrates the field dependence of the proton signal enhancement of a selection of substrates by the introduction of $p-\mathrm{H}_{2}$ at earth's field $(1.8 \mathrm{G})$ and at $50 \mathrm{G}$. Spectra were taken as the first transient of subsequent shakes and integrations were taken as the absolute integration.

Case 1: 4-fluorostyrene (50G $\rightarrow$ 1.8G $\rightarrow$ 50G)<smiles>CC=Cc1c(C)c(C)c(F)c(C)c1C</smiles><smiles>C1CCCCCCCCCCCC1</smiles>
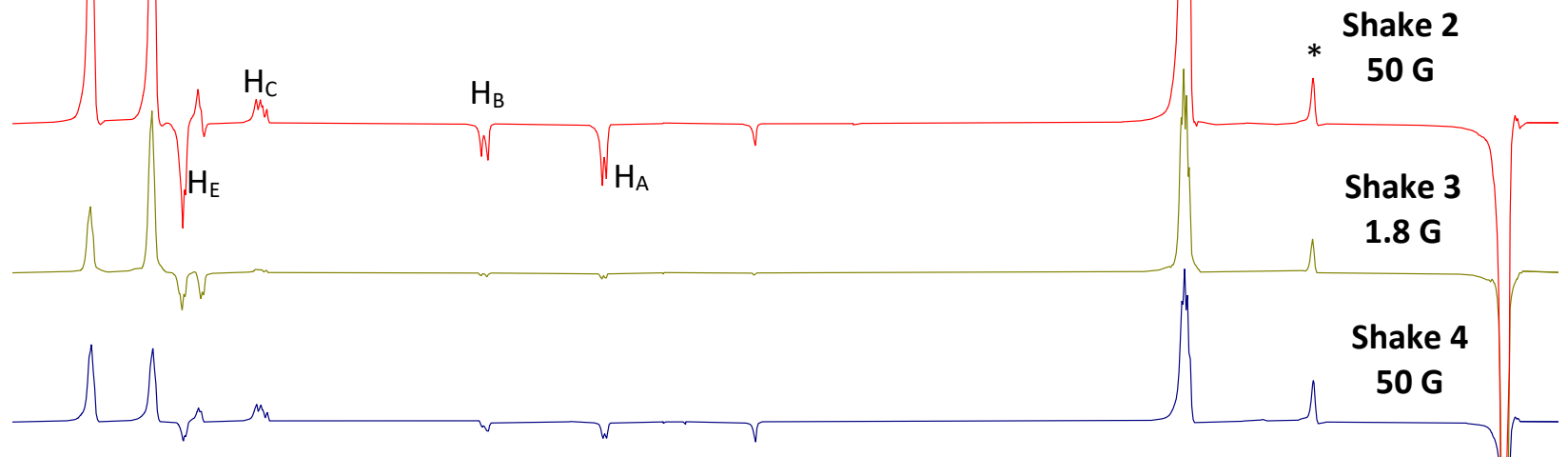

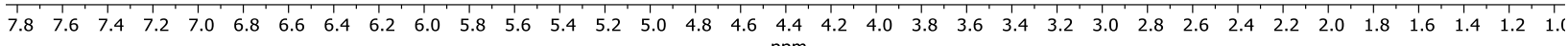

Figure S82. ${ }^{1} \mathrm{H}$ NMR spectra (acetone- $d_{6}(*), 600 \mathrm{MHz}, 37^{\circ} \mathrm{C}$ ) of the $1^{\text {st }}$ transients of subsequent shakes of the hyperpolarization of 4-fluorostyrene $(65 \mathrm{mM})$ using $\left({ }^{\mathrm{Mes}} \mathrm{CCC}\right) \mathrm{Co}-\mathrm{py}(9 \mathrm{~mol} \%, 5.9 \mathrm{mM})$ and $p$ - $\mathrm{H}_{2}(4$ atm). All spectra are scaled to have the same vertical expansion.

\begin{tabular}{|l|l|l|l|}
\hline$p p m$ & Shake 2 Integration & Shake 3 Integration & Shake 4 Integration \\
\hline $\mathrm{H}_{\mathrm{A}}(5.21)$ & -236.46 & -23.00 & -65.94 \\
\hline $\mathrm{H}_{\mathrm{B}}(5.74)$ & -143.95 & -13.19 & -31.09 \\
\hline $\mathrm{H}_{\mathrm{C}}(6.74)$ & 149.04 & 23.08 & 112.87 \\
\hline $\mathrm{H}_{\mathrm{D}}(7.50)$ & 1176.12 & 278.87 & 336.17 \\
\hline $\mathrm{H}_{\mathrm{E}}(7.09)$ dispersive & -365.81 & -132.77 & -61.10 \\
\hline
\end{tabular}

Table S17. Absolute integration of SABRE hyperpolarized resonances of subsequent shakes at alternating fields. Shakes 2 and 4: 50G, shake 3:1.8G. Partial restoration of hyperpolarization is attributed to the field of mixing. Decay of polarization from Shake 2 to Shake 4 is consistent with the consumption of substrate via hydrogenation. 
Case 2: Isoprene (1.8G $\rightarrow$ 50G)<smiles>C=C(C)C(C)=CC</smiles>

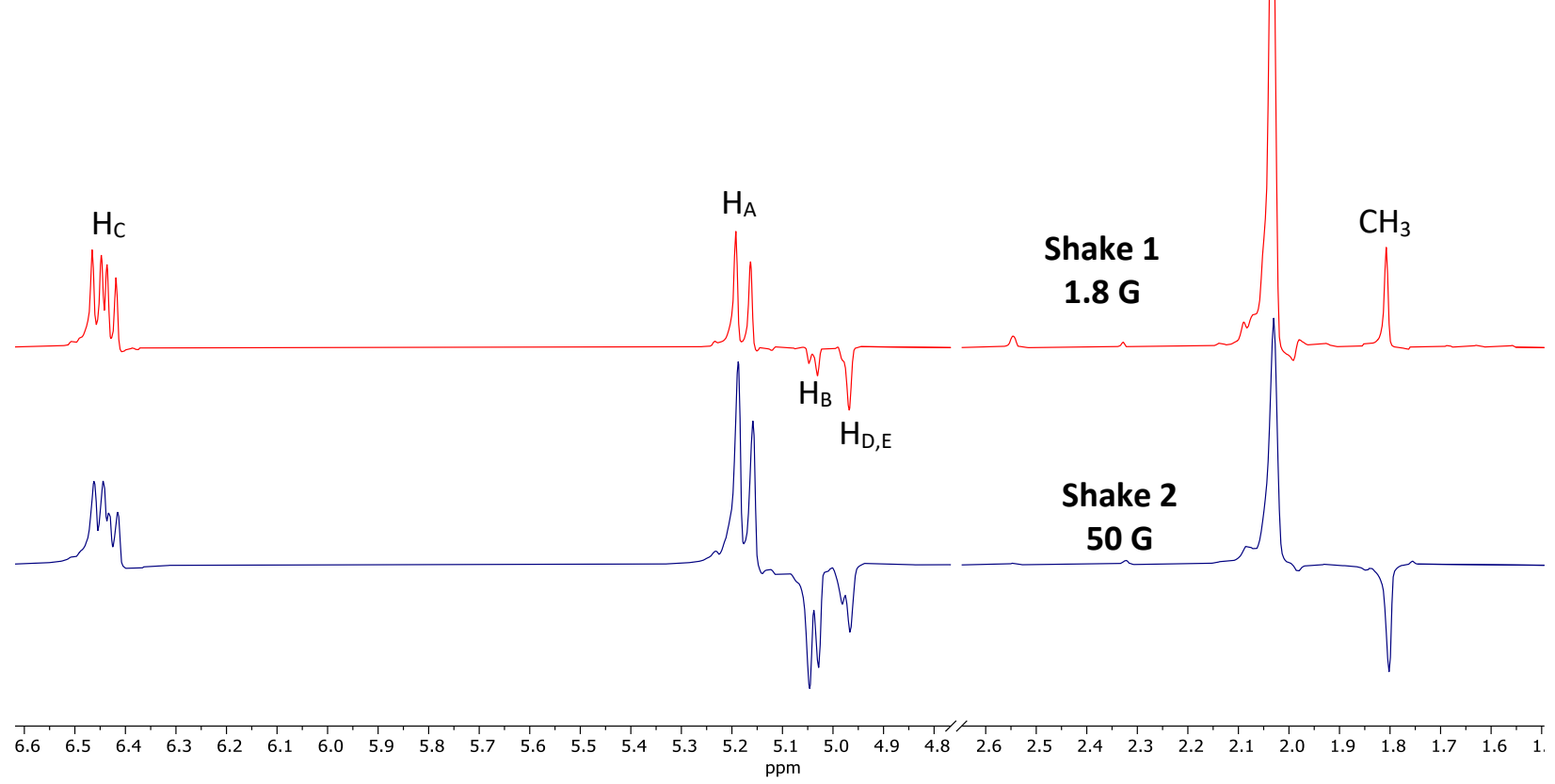

Figure S83. ${ }^{1} \mathrm{H}$ NMR spectra (acetone- $d_{6}(*), 600 \mathrm{MHz}, 37^{\circ} \mathrm{C}$ ) of the $1^{\text {st }}$ transients of subsequent shakes of the hyperpolarization of isoprene $(65 \mathrm{mM})$ using $\left({ }^{\mathrm{Mes}} \mathrm{CCC}\right) \mathrm{Co}-\mathrm{py}(9 \mathrm{~mol} \%, 5.9 \mathrm{mM})$ and $p-\mathrm{H}_{2}(4 \mathrm{~atm})$. All spectra are scaled to have the same vertical expansion, with peakless region removed.

\begin{tabular}{|l|l|l|}
\hline Proton $(\mathrm{ppm})$ & Shake 1 Integration & Shake 2 Integration \\
\hline $\mathrm{H}_{\mathrm{A}}(5.19)$ & 455.25 & 1109.99 \\
\hline $\mathrm{H}_{\mathrm{B}}(5.05)$ & -89.26 & -673.09 \\
\hline $\mathrm{H}_{\mathrm{C}}(6.45)$ & 691.99 & 782.46 \\
\hline $\mathrm{H}_{\mathrm{D}, \mathrm{E}}(5.00$ and 4.98$)$ & -165.71 & -310.85 \\
\hline $\mathrm{CH}_{3}(1.83)$ & 239.34 & -364.09 \\
\hline
\end{tabular}

Table S18. Absolute integration of SABRE hyperpolarized resonances of subsequent shakes at alternating fields. Shake 1: $1.8 \mathrm{G}$, shake 2: 50G. Increase of hyperpolarization is attributed to the field of mixing. 
Case 3: ethyl-N-methyl-N-(4-vinylphenyl)-glycinate (50G $\rightarrow 1.8 \mathrm{G} \rightarrow 50 \mathrm{G})$

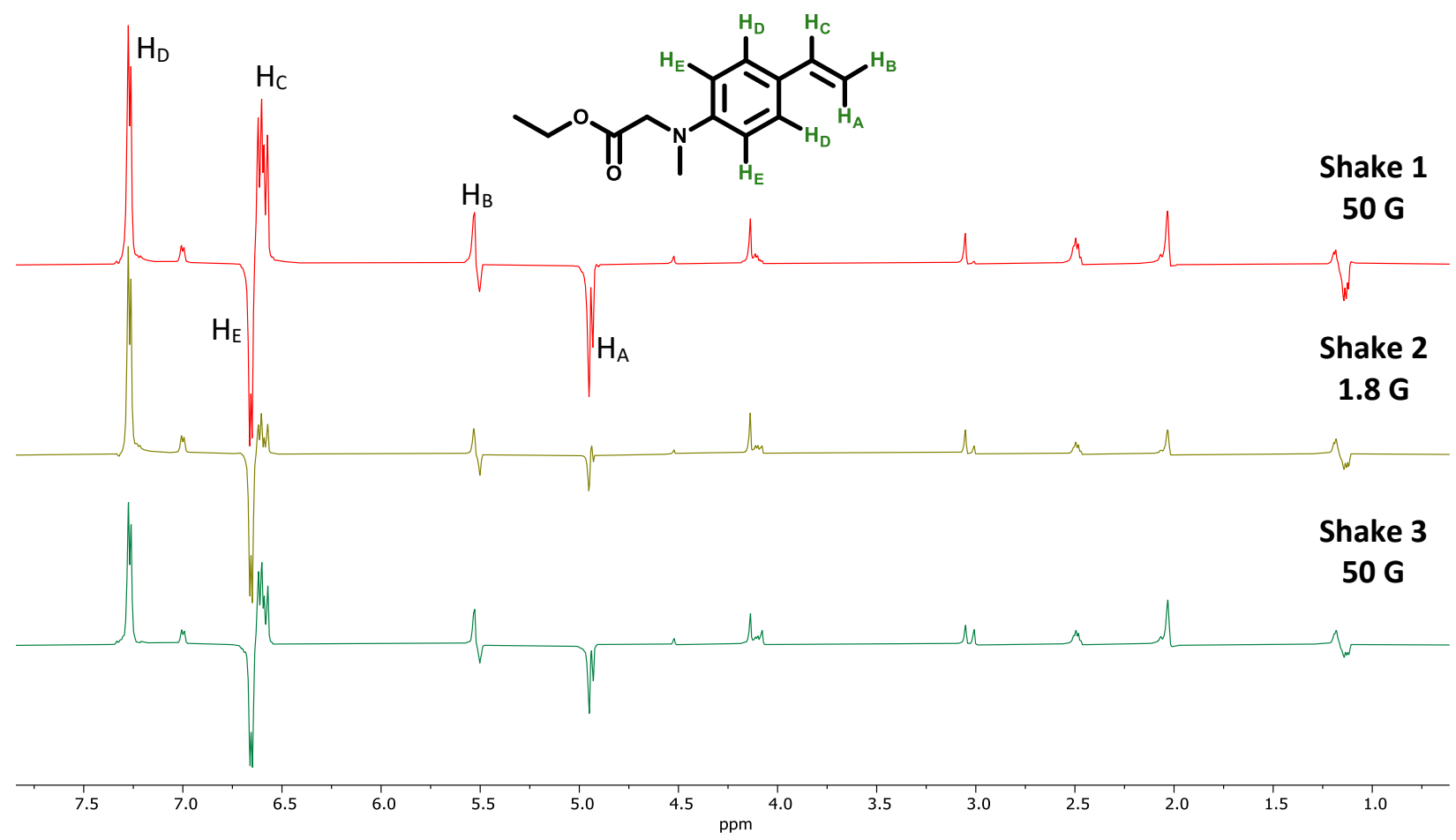

Figure S83. ${ }^{1} \mathrm{H}$ NMR spectra (acetone- $d_{6}(*), 600 \mathrm{MHz}, 37{ }^{\circ} \mathrm{C}$ ) of the $1^{\text {st }}$ transients of subsequent shakes of the hyperpolarization of ethyl-N-methyl-N-(4-vinylphenyl)-glycinate $(65 \mathrm{mM})$ using $\left({ }^{\mathrm{Mes}} \mathrm{CCC}\right) \mathrm{Co}-\mathrm{py}(9$ $\mathrm{mol} \%, 5.9 \mathrm{mM})$ and $p-\mathrm{H}_{2}(4 \mathrm{~atm})$. All spectra are scaled to have the same vertical expansion.

\begin{tabular}{|l|l|l|l|}
\hline Proton $(\mathrm{ppm})$ & Shake 1 Integration & Shake 2 Integration & Shake 3 Integration \\
\hline $\mathrm{H}_{\mathrm{A}}(4.95)$ & -970.09 & -160.34 & -446.66 \\
\hline $\mathrm{H}_{\mathrm{B}}(5.52)$ dispersive & 568.12 & 218.84 & 344.34 \\
\hline $\mathrm{H}_{\mathrm{C}}(6.61)$ & 2065.83 & 383.34 & 958.39 \\
\hline $\mathrm{H}_{\mathrm{D}}(7.28)$ & 1928.64 & 1579.69 & 1134.80 \\
\hline $\mathrm{H}_{\mathrm{E}}(6.67)$ & -1322.14 & -1058.35 & -896.22 \\
\hline
\end{tabular}

Table S19. Absolute integration of SABRE hyperpolarized resonances of subsequent shakes at alternating fields. Shake 2: 1.8G, shakes 1 and 3: 50G. Partial restoration of hyperpolarization is attributed to the field of mixing. Decay of polarization from Shake 1 to Shake 3 is consistent with the consumption of substrate via hydrogenation. 
Case 4: Myrcene (1.8G $\rightarrow$ 50G $\rightarrow 1.8 G \rightarrow 50 G \rightarrow 1.8 G)$

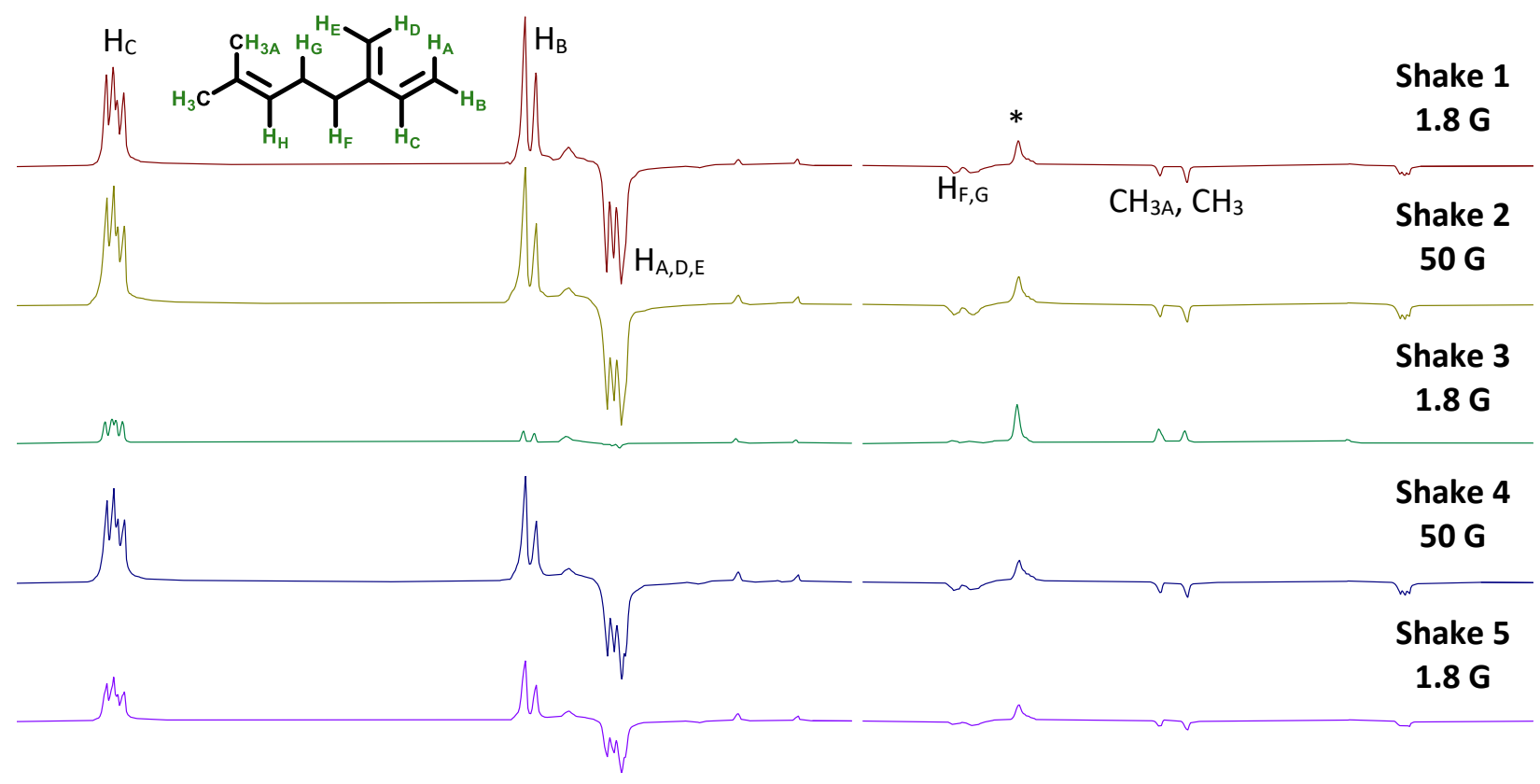

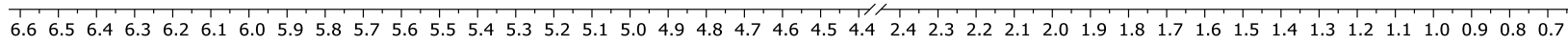
$\mathrm{ppm}$

Figure S85. ${ }^{1} \mathrm{H}$ NMR spectra (acetone- $d_{6}(*), 600 \mathrm{MHz}, 37^{\circ} \mathrm{C}$ ) of the $1^{\text {st }}$ transients of subsequent shakes of the hyperpolarization of myrcene $(65 \mathrm{mM})$ using $\left({ }^{\text {Mes }} \mathrm{CCC}\right)$ Co-py $(9 \mathrm{~mol} \%, 5.9 \mathrm{mM})$ and $p$ - $\mathrm{H}_{2}(4 \mathrm{~atm})$. All spectra are scaled to have the same vertical expansion, with peakless region removed.

\begin{tabular}{|l|c|c|c|c|c|}
\hline Proton (ppm) & $\begin{array}{c}\text { Shake 1 } \\
\text { Integration }\end{array}$ & $\begin{array}{c}\text { Shake 2 } \\
\text { Integration }\end{array}$ & $\begin{array}{c}\text { Shake 3 } \\
\text { Integration }\end{array}$ & $\begin{array}{c}\text { Shake 4 } \\
\text { Integration }\end{array}$ & $\begin{array}{c}\text { Shake 3 } \\
\text { Integration }\end{array}$ \\
\hline $\begin{array}{l}\mathrm{H} \text { A,D,E (5.00, 5.03 } \\
\text { and 4.99) }\end{array}$ & -3579.45 & -3962.76 & -93.88 & -3014.26 & -1497.42 \\
\hline $\mathrm{H}_{\mathrm{B}}(5.26)$ & 2516.29 & 2635.95 & 192.95 & 1986.59 & 1098.11 \\
\hline $\mathrm{H}_{\mathrm{C}}(6.39)$ & 2875.28 & 3611.01 & 722.16 & 2783.69 & 1285.79 \\
\hline $\mathrm{H}_{\mathrm{F}}(2.23)$ & -150.20 & -211.41 & 48.19 & -177.37 & -87.03 \\
\hline $\mathrm{H}_{\mathrm{G}}(2.17)$ & -216.66 & -254.24 & 55.87 & -213.37 & -114.49 \\
\hline $\mathrm{CH}_{3}(1.60)$ & -169.92 & -204.24 & 153.59 & -169.75 & -92.55 \\
\hline $\mathrm{CH}_{3 \mathrm{~A}}(1.67)$ & -98.58 & -126.18 & 189.70 & -109.91 & -44.83 \\
\hline
\end{tabular}

Table S20. Absolute integration of SABRE hyperpolarized resonances of subsequent shakes at alternating fields. Shakes 1, 3, and 5: 1.8G, shakes 2 and 4: 50G. Partial restoration of hyperpolarization is attributed to the field of mixing. Decay of polarization from Shake 2 to Shake 4 is consistent with the consumption of substrate via hydrogenation. 


\section{${ }^{13} \mathrm{C}$ Nuclear Enhancement Values}

Table 21: Styrene

\begin{tabular}{|l|l|}
\hline Carbon & Enhancement \\
\hline A & $53($ disp $)$ \\
\hline B & -37 \\
\hline C & 23 \\
\hline$D$ & $28($ disp $)$ \\
\hline E & $28($ disp) \\
\hline$F$ & - \\
\hline
\end{tabular}

Table 23: 4-methoxystyrene

\begin{tabular}{|l|l|}
\hline Carbon & Enhancement \\
\hline A & 30 (disp) \\
\hline B & -3 \\
\hline C & 2 \\
\hline D & 17 (disp) \\
\hline E & 31 (disp) \\
\hline F & 2 \\
\hline
\end{tabular}

Table 26: Ethyl Acrylate

\begin{tabular}{|l|l|}
\hline Carbon & Enhancement \\
\hline$=\mathrm{CH}$ & $23($ disp $)$ \\
\hline
\end{tabular}<smiles>C=CC(=O)OCC</smiles>

Table 27: Methyl Methacrylate

\begin{tabular}{|l|l|}
\hline Carbon & Enhancement \\
\hline $\mathrm{C}=\mathrm{O}$ & 9 (disp) \\
\hline$=\mathrm{CCH}_{3}$ & 4 (disp) \\
\hline $\mathrm{CH}_{2}$ & 29 (disp) \\
\hline $\mathrm{CH}_{3}$ & 36 (disp) \\
\hline
\end{tabular}

Table 29: Ethyl Pentenoate (decoupled 1.8 G)

\begin{tabular}{|l|l|}
\hline Carbon & Enhancement \\
\hline $\mathrm{CH}=\mathrm{CH}_{2}$ & -10 \\
\hline $\mathrm{CH}=\mathrm{CH}_{2}$ & -6 \\
\hline $\mathrm{CH}$ & 9 \\
\hline $\mathrm{CH}_{2}$ & -3 \\
\hline
\end{tabular}<smiles>C=CCC(C)C(=O)OCC</smiles>

Table 31: Isoprene

\begin{tabular}{|l|l|}
\hline Carbon & Enhancement \\
\hline A & $\mathbf{3 0}$ (disp) \\
\hline $\mathrm{B}$ & $\mathbf{4 3}$ (disp) \\
\hline $\mathrm{E}$ & $\mathbf{1 1 2}$ (disp) \\
\hline $\mathrm{D}$ & $\mathbf{7 0}$ (disp) \\
\hline $\mathrm{CH}_{3}$ & $\mathbf{5 5}$ (disp) \\
\hline
\end{tabular}

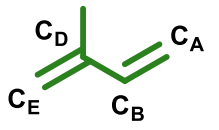

Table 33: Linalool

\begin{tabular}{|l|l|}
\hline Carbon & Enhancement \\
\hline $\mathrm{CH}$ & 65 (disp) \\
\hline $\mathrm{CH}_{2}$ & 45 (disp) \\
\hline $\mathrm{C}-\mathrm{OH}$ & $\mathbf{3 1}$ (disp) \\
\hline
\end{tabular}

Table 22: 4-fluorostyrene

\begin{tabular}{|l|l|}
\hline Carbon & Enhancement \\
\hline A & $\mathbf{3 8}$ (disp) \\
\hline B & $\mathbf{2 0}$ (disp) \\
\hline C & $\mathbf{9}$ (disp) \\
\hline D & $\mathbf{2 7}($ disp) \\
\hline E & $\mathbf{3 1}$ (disp) \\
\hline F & $\mathbf{6}$ (disp) \\
\hline
\end{tabular}

Table 24: 4-vinylaniline

\begin{tabular}{|l|l|}
\hline Carbon & Enhancement \\
\hline A & 31 (disp) \\
\hline B & $\mathbf{4 0}$ (disp) \\
\hline
\end{tabular}<smiles>C=Cc1ccc(N)cc1</smiles>

Table 25: Ethyl Glycinate

\begin{tabular}{|l|l|}
\hline Carbon & Enhancement \\
\hline A & $\mathbf{2}($ disp) \\
\hline B & $\mathbf{3}$ (disp) \\
\hline C & 2 (disp) \\
\hline E & $\mathbf{2}($ disp) \\
\hline F & - \\
\hline
\end{tabular}<smiles>C=Cc1ccc(N(C)CC(=O)OCC)cc1</smiles>

Table 28: Ethyl Pentenoate (coupled 1.8 G)

\begin{tabular}{|l|l|}
\hline Carbon & Enhancement \\
\hline $\mathrm{C}=\mathrm{O}$ & -2 \\
\hline $\mathrm{CH}=\mathrm{CH}_{2}$ & -34 \\
\hline $\mathrm{CH}=\mathrm{CH}_{2}$ & -33 \\
\hline $\mathrm{CH}$ & 98 (disp) \\
\hline $\mathrm{CH}_{2}$ & -16 \\
\hline $\mathrm{CH}_{3}$ & $\mathbf{5 7}$ (disp) \\
\hline
\end{tabular}

Table 30: Ethyl Pentenoate (decoupled mu-Metal)

\begin{tabular}{|l|l|}
\hline Carbon & Enhancement \\
\hline $\mathrm{C}=\mathrm{O}$ & -15 \\
\hline $\mathrm{CH}=\mathrm{CH}_{2}$ & -147 \\
\hline $\mathrm{CH}=\mathrm{CH}_{2}$ & -76 \\
\hline $\mathrm{CH}$ & -28 \\
\hline
\end{tabular}

Table 32: Myrcene

\begin{tabular}{|l|l|}
\hline Carbon & Enhancement \\
\hline A & $94($ disp) \\
\hline$B$ & 19 \\
\hline$C$ & 26 (disp) \\
\hline
\end{tabular}


Figure S86. A) Proposed scheme for the formation of hyperpolarized orthohydrogen through a dihydridedihydrogen intermediate. B) The initial hyperpolarization of the resonance at $4.54 \mathrm{ppm}$ for 2,3,4,5,6pentafluorosytrene after the introduction of $p-\mathrm{H}_{2}$, followed by the decay to the thermal composition, with transient 0 being the thermal spectrum taken before introduction of $p-\mathrm{H}_{2}$.

A
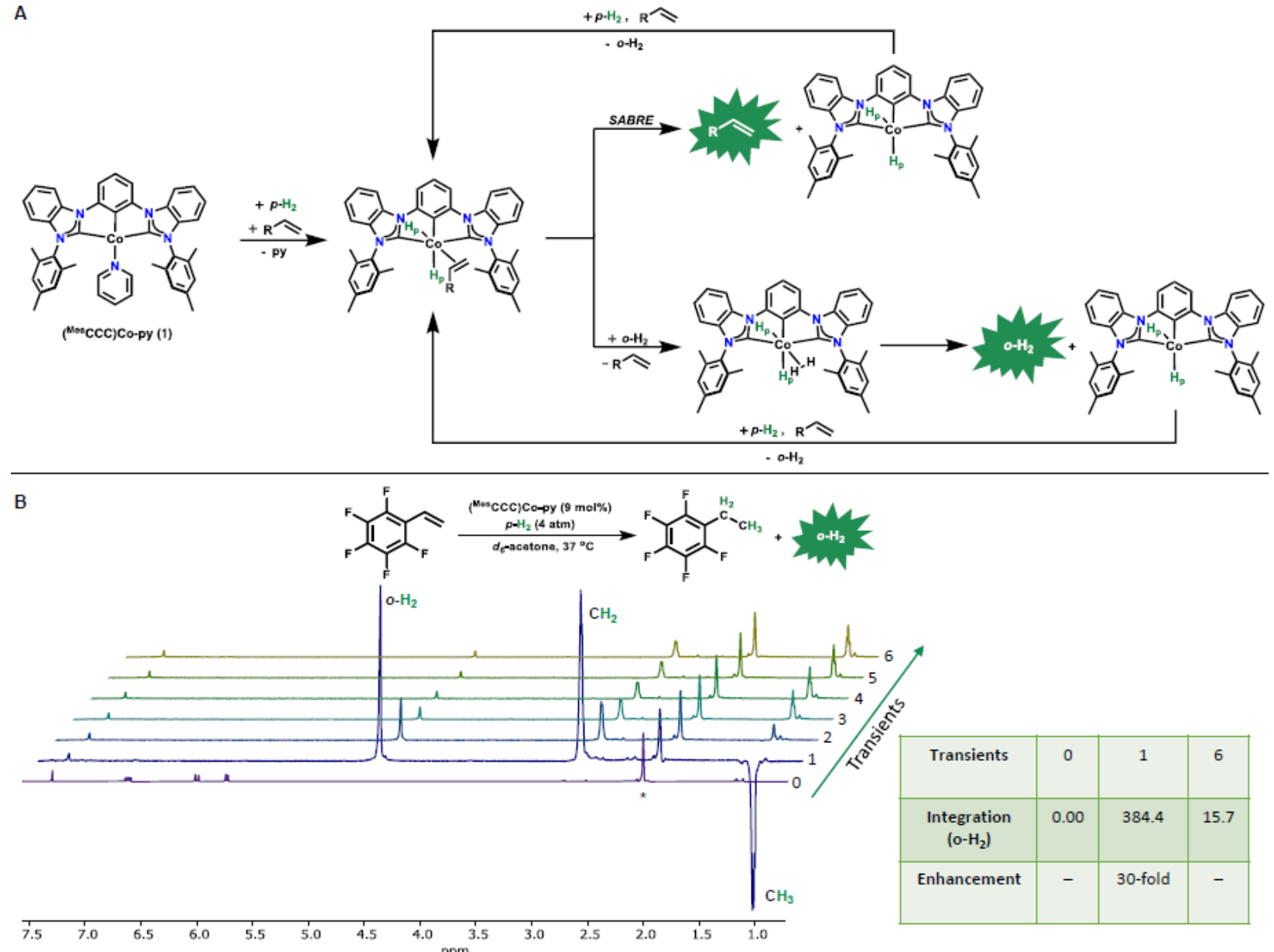
${ }^{1} \mathrm{H}$ NMR Spectrum, $600 \mathrm{MHz}$, acetone- $d_{6}\left(45^{\circ}\right.$ pulse $)$

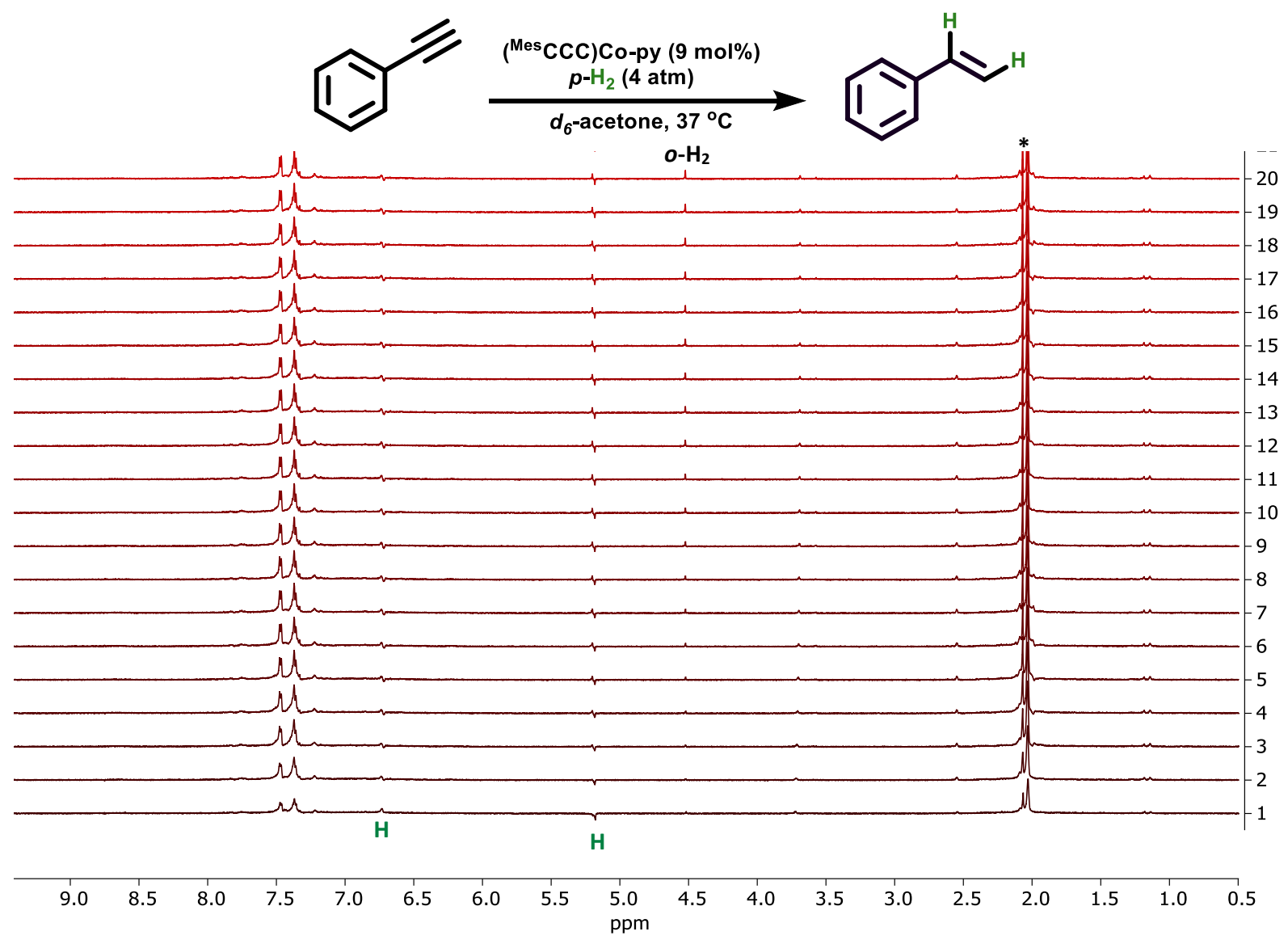

Figure S87. ${ }^{1} \mathrm{H}$ NMR spectra (acetone- $\left.d_{6}(*), 600 \mathrm{MHz}, 37^{\circ} \mathrm{C}\right)$ of the reaction of ethynylbenzene $(65 \mathrm{mM})$ using ( $\left.{ }^{\mathrm{Mes}} \mathrm{CCC}\right) \mathrm{Co}-\mathrm{py}(9 \mathrm{~mol} \%, 5.9 \mathrm{mM})$ and $p-\mathrm{H}_{2}(4 \mathrm{~atm})$ at the $50 \mathrm{G}$ fringe line of the magnet. No additional shaking occurred between transients. Bottom spectrum is the first collected transient, followed by an acquisition time of $4.096 \mathrm{~s}$ to collect the next transient above it with no additional delay between transients. Minimal polarization of the olefinic hydrogens are observed with no observable polarization of the ring. 
${ }^{2} \mathrm{H}$ NMR Spectrum, $600 \mathrm{MHz}$, acetone- $d_{6}\left(45^{\circ}\right.$ pulse $)$
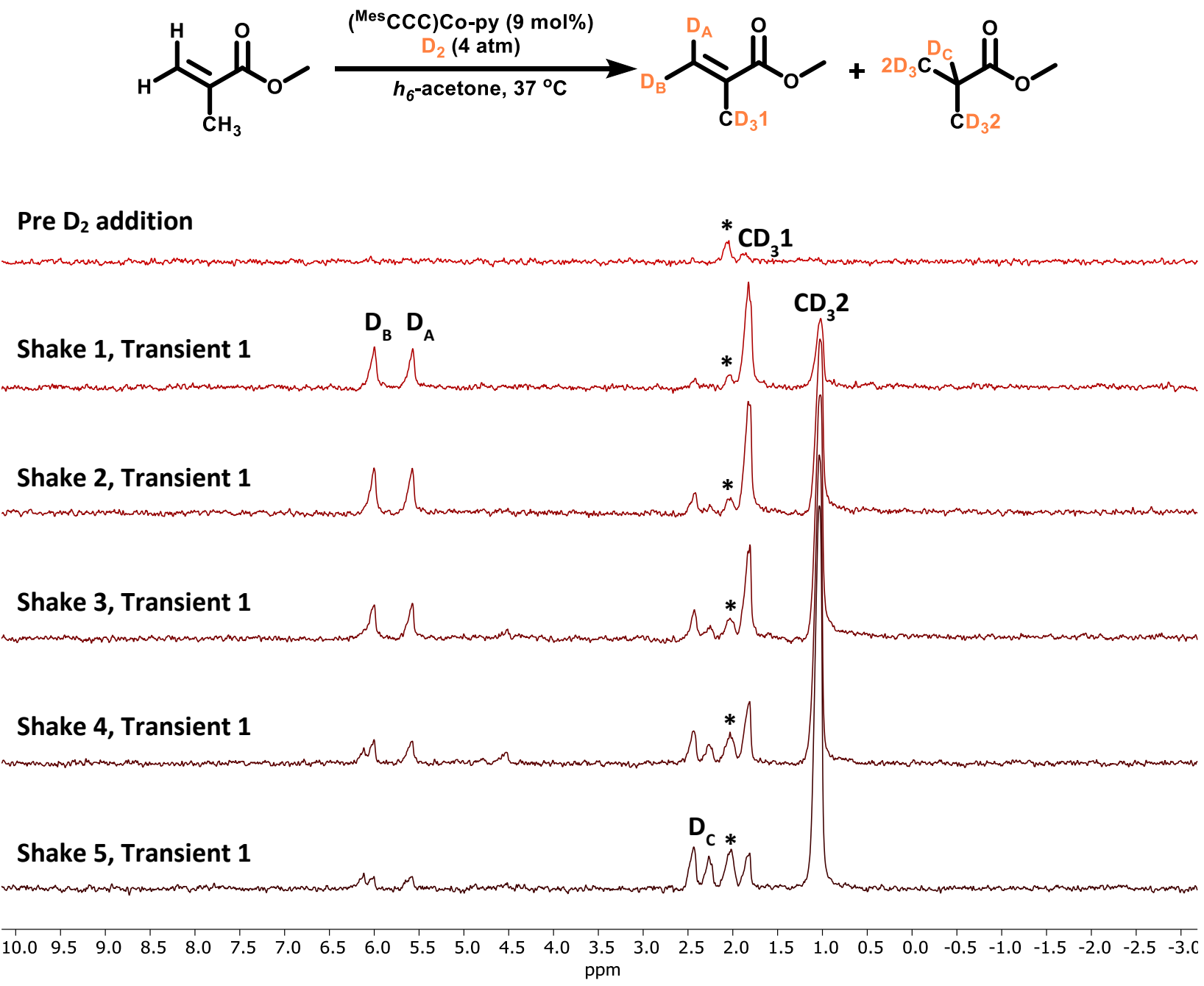

Figure S88. ${ }^{2} \mathrm{H}$ NMR spectra (acetone- $h_{6}(*), 600 \mathrm{MHz}, 37^{\circ} \mathrm{C}$ ) of the reaction of methyl methacrylate (65 $\mathrm{mM})$ using $\left({ }^{\mathrm{Mes}} \mathrm{CCC}\right) \mathrm{Co}-\mathrm{py}(9 \mathrm{~mol} \%, 5.9 \mathrm{mM})$ and $\mathrm{D}_{2}(4 \mathrm{~atm})$ at the $50 \mathrm{G}$ fringe line of the magnet. Shown spectra are the first transient of spectra after shaking to reintroduce $\mathrm{D}_{2}$ gas into the solution. In the first shake, the incorporation of deuterium in the intact product is rapid and the reduction with deuterium also occurs simultaneously. 
${ }^{2} \mathrm{H}$ NMR Spectrum, $600 \mathrm{MHz}$, acetone- $d_{6}\left(45^{\circ}\right.$ pulse $)$

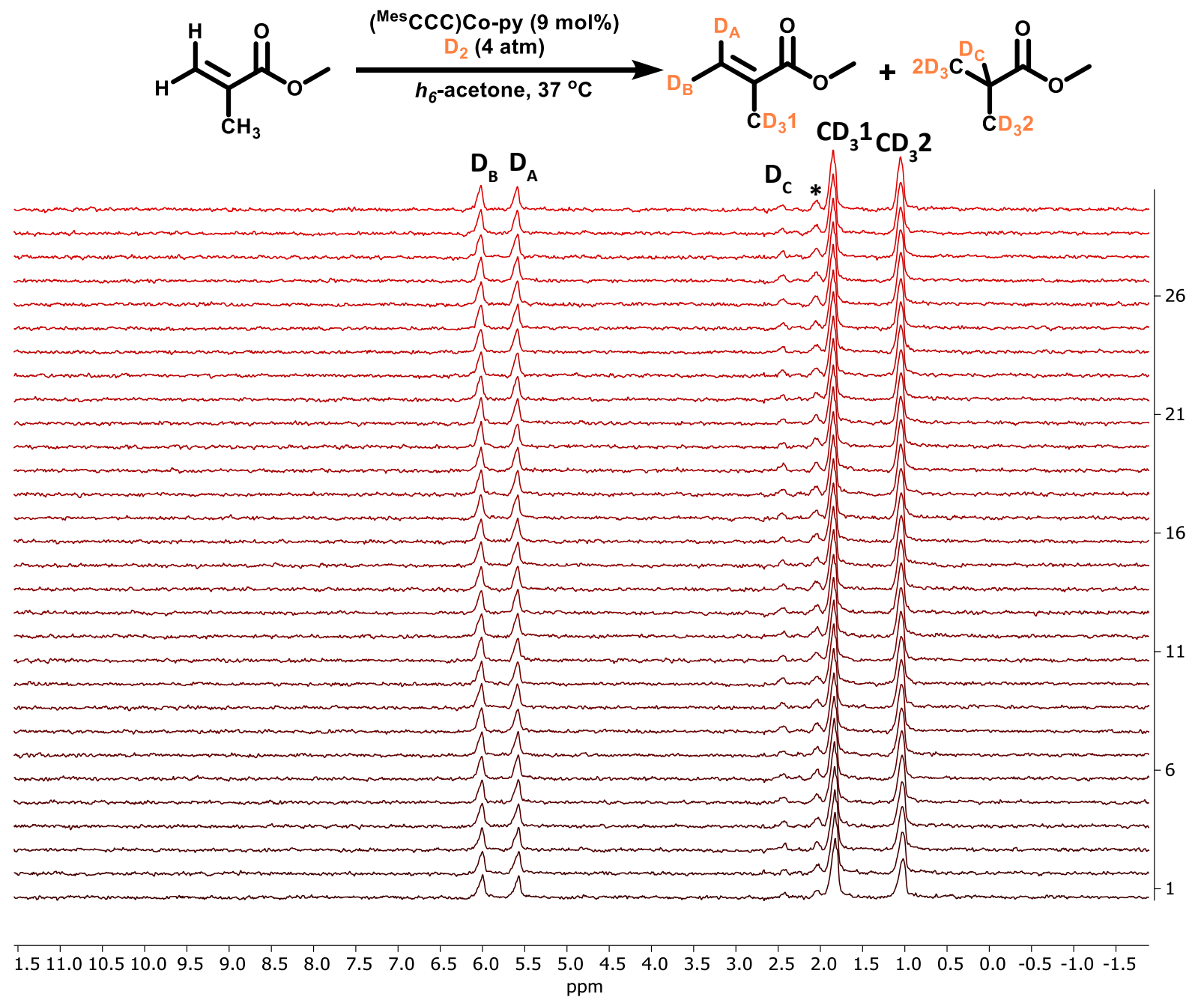

Figure S89. ${ }^{2} \mathrm{H}$ NMR spectra (acetone- $h_{6}(*), 600 \mathrm{MHz}, 37{ }^{\circ} \mathrm{C}$ ) of the reaction of methyl methacrylate $(65$ $\mathrm{mM})$ using $\left({ }^{\mathrm{Mes}} \mathrm{CCC}\right) \mathrm{Co}-$ py $(9 \mathrm{~mol} \%, 5.9 \mathrm{mM})$ and $\mathrm{D}_{2}(4 \mathrm{~atm})$ at the $50 \mathrm{G}$ fringe line of the magnet. Shown spectra are the subsequent transients taken after the first introduction of $\mathrm{D}_{2}$ gas into the solution, with no additional shaking between transients. Each spectrum was taken with an acquisition time between transients and no additional delay time between transients. 


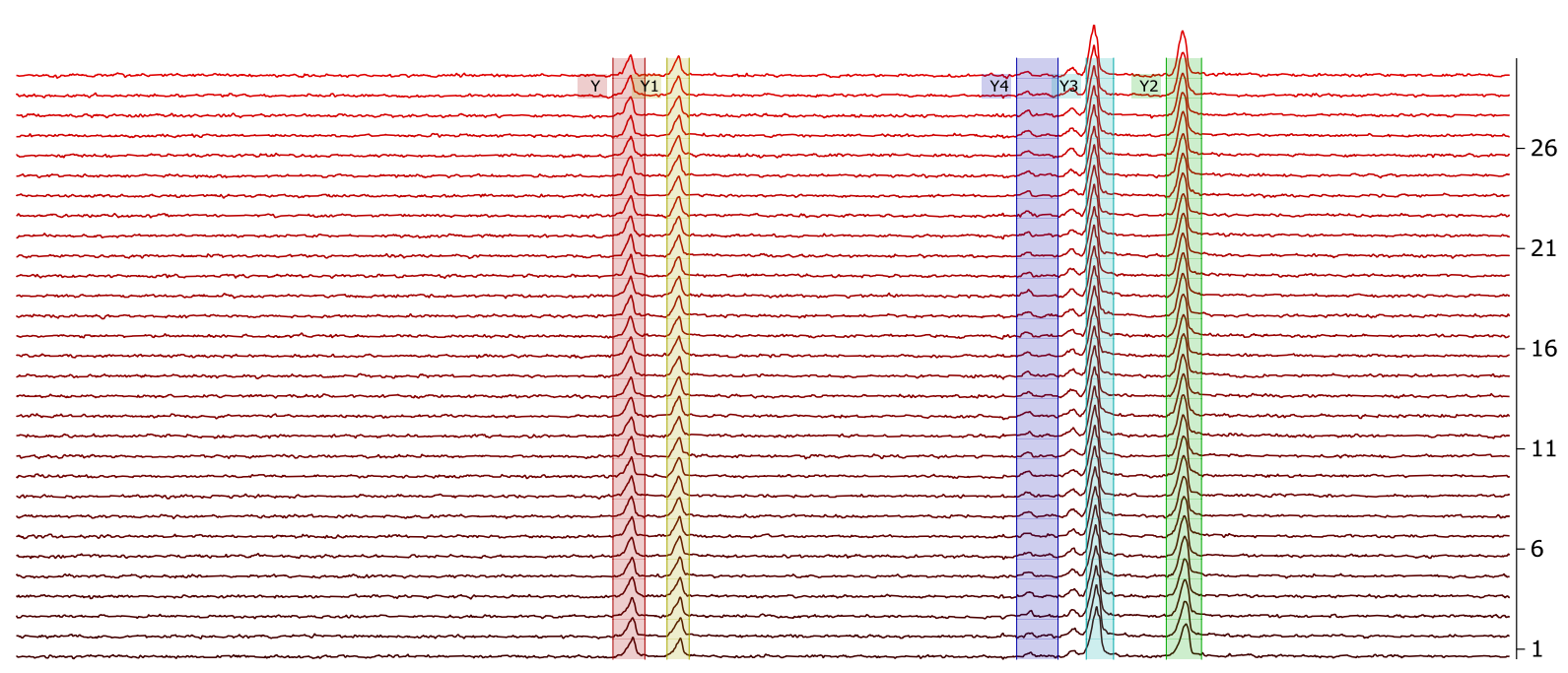

\begin{tabular}{lllllllllllllllllllllllllll}
\hline 1.5 & 11.0 & 10.5 & 10.0 & 9.5 & 9.0 & 8.5 & 8.0 & 7.5 & 7.0 & 6.5 & 6.0 & 5.5 & $\begin{array}{c}1 \\
5.0\end{array}$ & 4.5 & 4.0 & 3.5 & 3.0 & 2.5 & 2.0 & 1.5 & 1.0 & 0.5 & 0.0 & -0.5 & -1.0 & -1.5
\end{tabular}

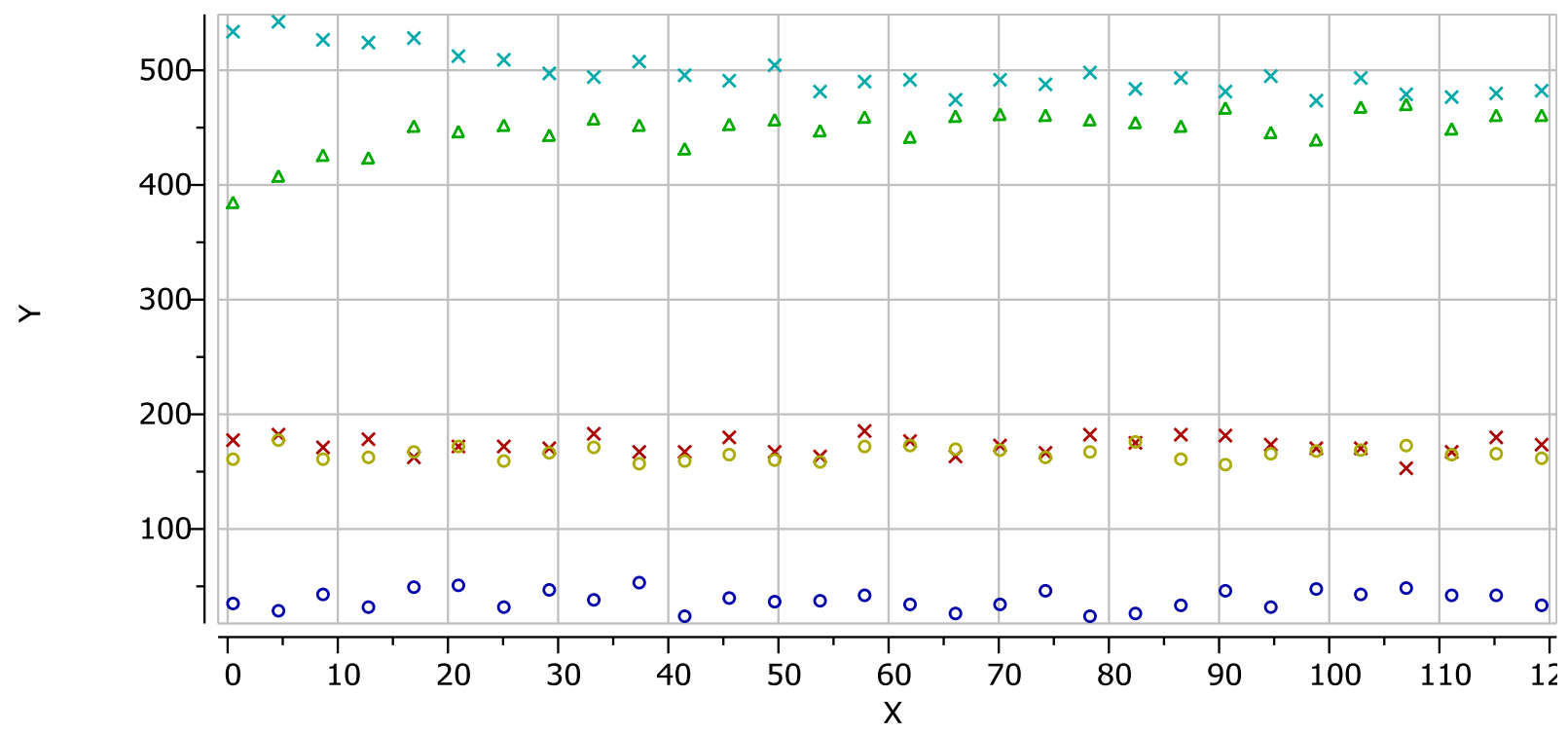

Graph S1. Integral graph of the ${ }^{2} \mathrm{H}$ NMR spectra of the first introduction (first shake) of $\mathrm{D}_{2}$ gas to a $65 \mathrm{mM}$ solution of methyl methacrylate with $\left({ }^{\mathrm{Mes}} \mathrm{CCC}\right) \mathrm{Co}$-py $(9 \mathrm{~mol} \%)$. Values show that very little net change in incorporation after introduction of gas occurs. This pattern is also observed in subsequent shakes. (Note: color of points correspond to colors in the spectra above; red $=\mathrm{D}_{\mathrm{B}}$, yellow $=\mathrm{D}_{\mathrm{A}}$, dark blue $=\mathrm{D}_{\mathrm{C}}$, teal $=$ $\mathrm{CD}_{3} 1$, green $=\mathrm{CD}_{3} 2$ ). 
${ }^{2} \mathrm{H}$ NMR Spectrum, $600 \mathrm{MHz}$, acetone- $d_{6}\left(45^{\circ}\right.$ pulse $)$
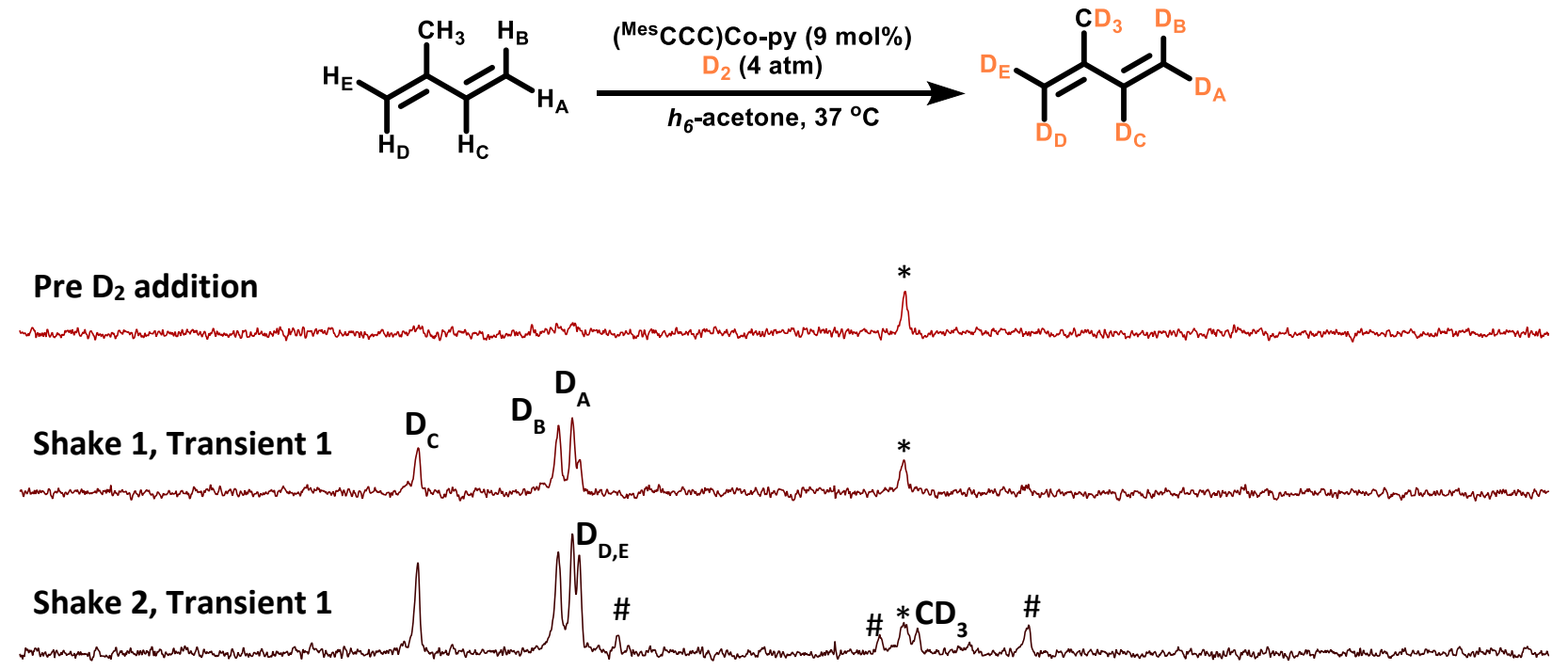

\begin{tabular}{lllllllllllllllllllllllllllllllllllllllllllll}
\hline 0.0 & 9.5 & 9.0 & 8.5 & 8.0 & 7.5 & 7.0 & 6.5 & 6.0 & 5.5 & 5.0 & 4.5 & 4.0 & 3.5 & 3.0 & 2.5 & 2.0 & 1.5 & 1.0 & 0.5 & 0.0 & -0.5 & -1.0 & -1.5 & -2.0 & -2.5 & -3.0 & -3.5
\end{tabular}

Figure S90. ${ }^{2} \mathrm{H}$ NMR spectra (acetone- $h_{6}(*), 600 \mathrm{MHz}, 37^{\circ} \mathrm{C}$ ) of the reaction of isoprene $(65 \mathrm{mM})$ using $\left({ }^{\mathrm{Mes}} \mathrm{CCC}\right) \mathrm{Co}-\mathrm{py}(9 \mathrm{~mol} \%, 5.9 \mathrm{mM})$ and $\mathrm{D}_{2}(4 \mathrm{~atm})$ at the $50 \mathrm{G}$ fringe line of the magnet. Shown spectra are the first transient of spectra after shaking to reintroduce $\mathrm{D}_{2}$ gas into the solution. In the first shake, the incorporation of deuterium in the intact product is rapid and the reduction with incorporation to sites $\mathrm{D}$ and E being slower than the monosubstituted A, B. and C sites. Hydrogenation occurs at a slower time scale. 
${ }^{2} \mathrm{H}$ NMR Spectrum, $600 \mathrm{MHz}$, acetone- $d_{6}\left(45^{\circ}\right.$ pulse $)$

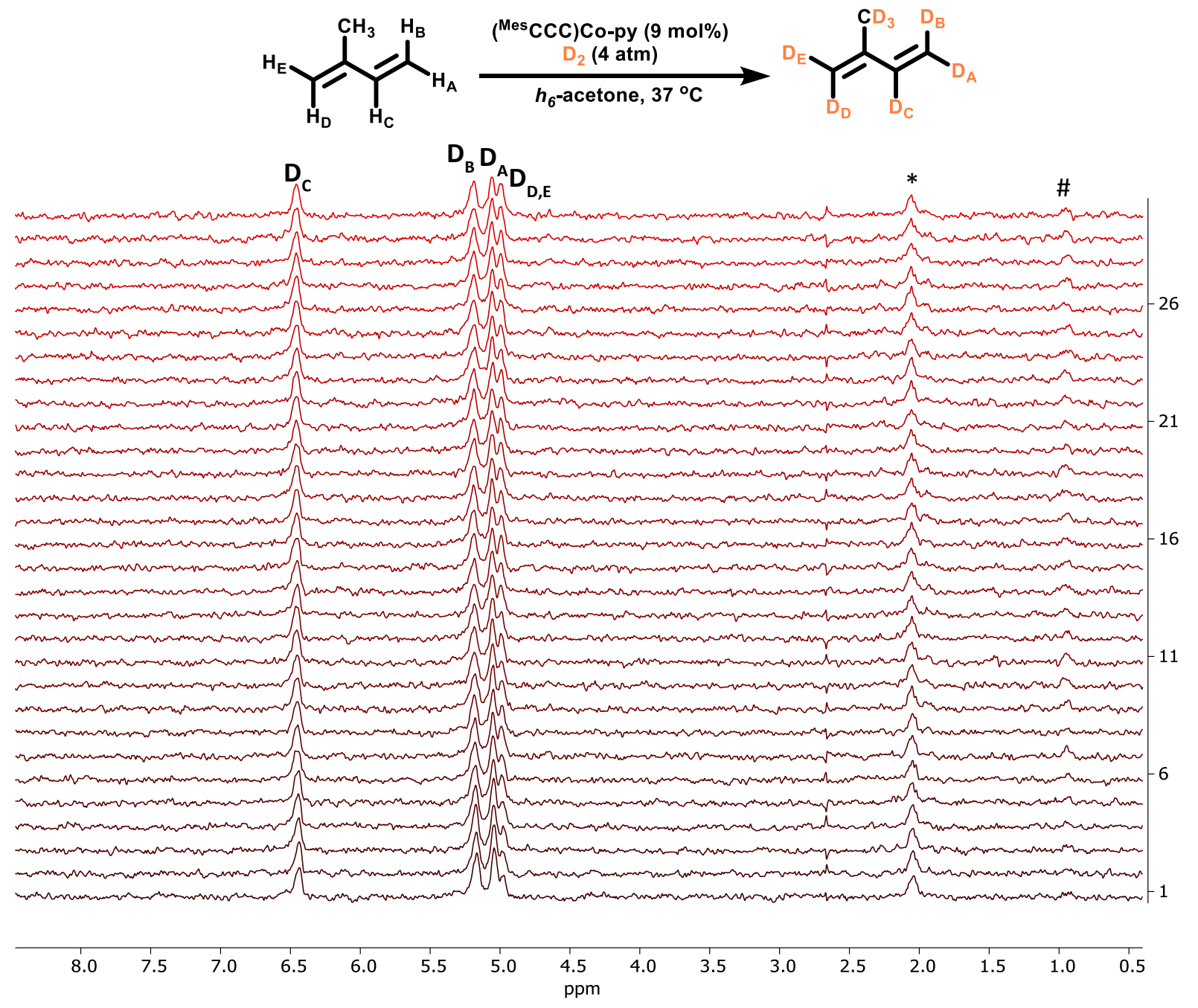

Figure S91. ${ }^{2} \mathrm{H}$ NMR spectra (acetone- $h_{6}(*), 600 \mathrm{MHz}, 37^{\circ} \mathrm{C}$ ) of the reaction of isoprene $(65 \mathrm{mM})$ using ( $\left.{ }^{\mathrm{Mes}} \mathrm{CCC}\right) \mathrm{Co}$-py $(9 \mathrm{~mol} \%, 5.9 \mathrm{mM})$ and $\mathrm{D}_{2}(4 \mathrm{~atm})$ at the $50 \mathrm{G}$ fringe line of the magnet. Shown spectra are the subsequent transients taken after the first introduction of $\mathrm{D}_{2}$ gas into the solution, with no additional shaking between transients. Each spectrum was taken with an acquisition time between transients and no additional delay time between transients. 

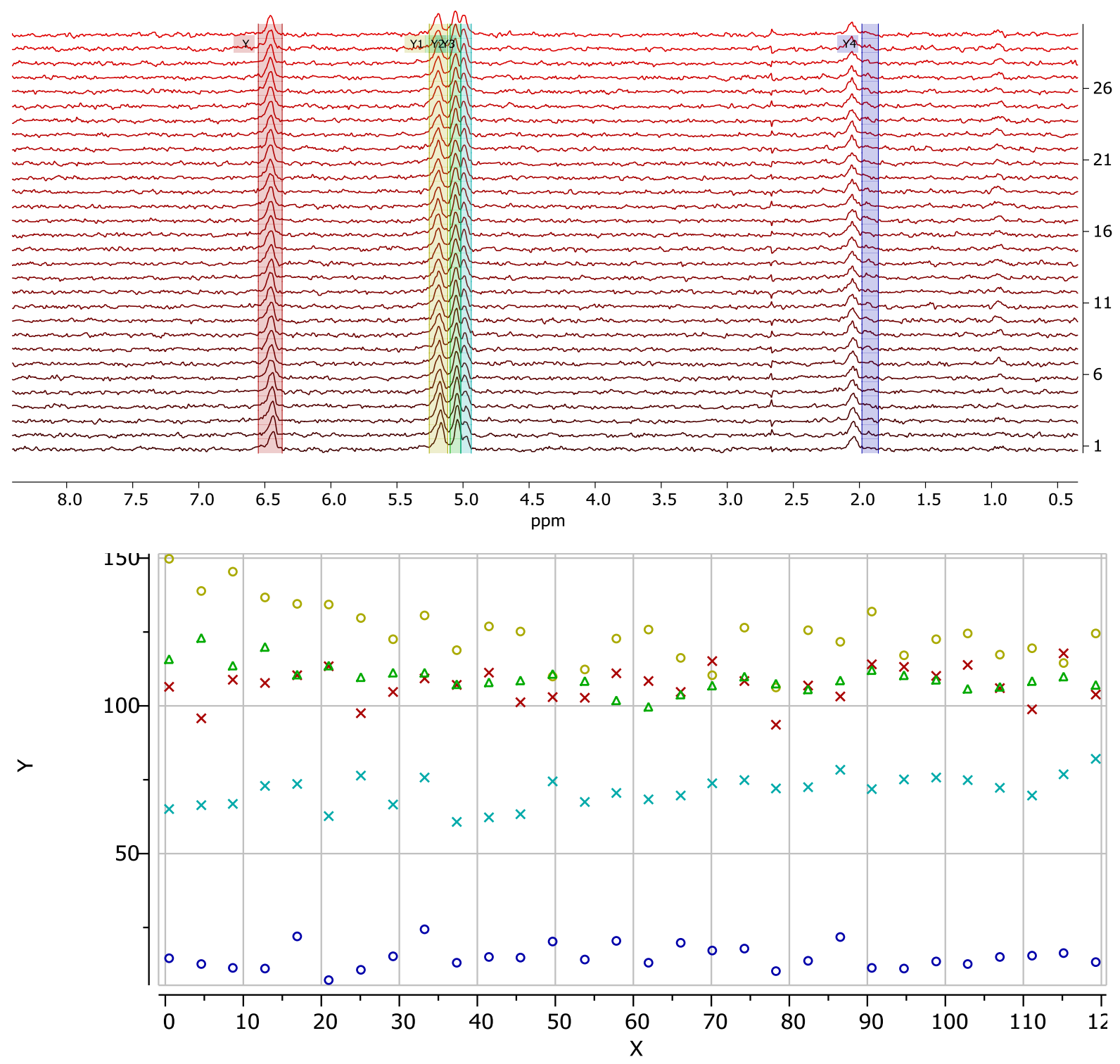

Graph S2. Integral graph of the ${ }^{2} \mathrm{H}$ NMR spectra of the first introduction (first shake) of $\mathrm{D}_{2}$ gas to a $65 \mathrm{mM}$ solution of isoprene with $\left({ }^{\mathrm{Mes}} \mathrm{CCC}\right) \mathrm{Co}-\mathrm{py}(9 \mathrm{~mol} \%)$. Values show that little net change in incorporation amounts after introduction of gas occurs. This pattern is also observed in subsequent shakes. (Note: color of points correspond to colors in the spectra above; red $=\mathrm{D}_{\mathrm{C}}$, yellow $=\mathrm{D}_{\mathrm{B}}$, green $=\mathrm{D}_{\mathrm{A}}$, teal $=\mathrm{D}_{\mathrm{D}, \mathrm{E}}$, dark blue $=\mathrm{CD}_{3}$,). 


\section{References:}

1. Pangborn, A. B; Giardello, M. A.; Grubbs, R. H.; Rosen, R. K.; Timmers, F. J. Organometallics, 1996, 15, 1518-1520.

2. Fulmer, G. R.; Miller, A. J. M.; Sherden, N. H.; Gottlieb, H. E.; Nudelman, A.; Stoltz, B. M.; Bercaw, J. E.; Goldberg, K. I. Organometallics 2010, 29, 2176-2179.

3. Tokmic, K.; Jackson, B. J.; Salazar, A.; Woods, T. J.; Fout, A. R. J. Am. Chem. Soc. 2017, 139, 13554-13561.

4. Tom, B. A.; Bhasker, S.; Miyamoto, Y.; Momose, T.; McCall, B. J. Rev. Sci. Instrum. 2009, 80, 016108 . 